\title{
MOVING BEYOND LOVE AND LUCK: \\ BUILDING RIGHT RELATIONSHIPS AND RESPECTING LIVED \\ EXPERIENCE IN NEW ZEALAND AUTISM POLICY
}

\author{
by \\ HILARY STACE
}

A thesis submitted to the Victoria University of Wellington

in fulfilment of the requirements for the degree of Doctor of Philosophy

Victoria University of Wellington

2011 


\section{Abstract}

Autism Spectrum Disorder (ASD) diagnoses have been rising rapidly in recent years and New Zealand is just one country grappling with the policy challenges this presents. Currently, love, such as a supportive family, and luck, that appropriate services are available, are required by people with autism and their families for good outcomes, a situation that is neither equitable nor sustainable. Autism was first named as a separate condition in 1943. The concept of autism has developed significantly since then in many ways, including as the cultural identity that many autistic adults now claim. Influenced by the international disability rights movement and local activism, New Zealand policy is now based on the social model of disability, whereby society as a whole has responsibility for removing disabling barriers.

In 1997, a New Zealand mother, unable to find appropriate support at a time of crisis, killed her autistic daughter. A decade of policy work followed, leading to the 2008 publication of the New Zealand Autism Spectrum Disorder Guideline (Ministries of Health and Education, 2008) which is the first whole-of-spectrum, whole-of-life, wholeof-government, best practice approach in the world to address the extensive issues surrounding ASD. Prioritisation and initial attempts at implementation revealed new problems. The complexity, lack of simple solutions and fragmentation of autism policy indicates that this is a 'wicked' policy problem. To move beyond this situation requires innovative and collaborative approaches. The 'transformative paradigm' is a research methodology which builds on recent developments in participatory and emancipatory research, and disciplines such as disability studies. It advocates approaches based on mixed methods, social justice, ethics and partnership, so is particularly suited to examining a problem such as autism, and indicating ways forward.

There is untapped expertise among those with lived experience of autism and their families to tackle the 'wicked' aspects of autism, but to harness this expertise requires relationship building which addresses power imbalances and past injustices. This thesis analyses New Zealand autism policy and suggests ways this lived experience could be better respected and incorporated into policy processes, in an attempt to move past the currently required variables of love and luck. 


\section{Acknowledgements}

I would like to thank my supervisors, Associate Professor Jackie Cumming, Director of the Health Services Research Centre in the School of Government at Victoria University of Wellington, and Dr Lesley Hall from Victoria University's Gender and Women's Studies programme for all their advice and encouragement. Also the late Rev Dr Christopher Newell, a supreme disability activist and academic, who acted as supervisor and mentor until his death in June 2008. I was lucky to win a three year Disability Placement Programme scholarship from the Health Research Council of New Zealand, and later $\mathrm{PhD}$ completion funding from the combined universities' Building Research Capability in the Social Sciences (BRCSS), who also kindly extended their thesis submission deadline.

Thanks are also due to so many people who have encouraged and supported me over the years of this project. To my son Oscar who set me on this path and permits me to talk about him, and his sister Serena, and Martin, who have supported and advised me all the way. To my advisors John and Matt, and to my friends Jen and Alan, and all the other people in the autism world for providing glimpses into lived experience. To all the parents including Wendy, Niki, Richard, Russell, Marion, Giovanni and Justine, and the numerous other experts, including public servants and other professionals, who have helped me and given me their time and wisdom over the years (and not forgetting those from the neurotypical world such as Jane and Marie who kept me focused). Also thank you to Donna Mertens and the other overseas academics, for inspiration; to all my colleagues at the Health Services Research Centre for ongoing academic discussions, and Amanda and Dawn of the School of Government. Finally, I hope that in some way this thesis will help to make a positive difference to people with autism and their families. 


\section{Glossary}

\begin{tabular}{|c|c|}
\hline $\mathrm{AA}$ & Altogether Autism \\
\hline $\mathrm{ABA}$ & Applied Behaviour Analysis \\
\hline ACC & Accident Compensation Corporation \\
\hline ADHD & Attention Deficit Hyperactivity Disorder \\
\hline AIT & Autism Intervention Trust \\
\hline ANZ & Autism New Zealand \\
\hline ASAN & Autistic Self Advocacy Network (US based) \\
\hline ASD & Autism Spectrum Disorder(s) \\
\hline ASK Trust & Autism Spectrum Kiwis Trust \\
\hline ASNZ & Asperger's Syndrome New Zealand \\
\hline Asperger(s) Syndrome & $\begin{array}{l}\text { Type of autism usually without intellectual } \\
\text { impairment or language delay, named after Hans } \\
\text { Asperger }\end{array}$ \\
\hline Aspie & $\begin{array}{l}\text { Optional self description for person with } \\
\text { Asperger's syndrome }\end{array}$ \\
\hline AspieHelp & Christchurch-based self advocacy group \\
\hline Autism Spectrum Disorder & $\begin{array}{l}\text { Diagnostic umbrella term for range of conditions } \\
\text { (DSM or ICD) characterised by 'deficits' in } \\
\text { communication, understanding and imagination }\end{array}$ \\
\hline Autism & $\begin{array}{l}\text { Encompassing term for the spectrum of autistic } \\
\text { conditions and experience }\end{array}$ \\
\hline Autistic disorder & Diagnostic term for ASD condition \\
\hline Biomedical & $\begin{array}{l}\text { Term used for chemical interventions for autism } \\
\text { that may not be evidence-based }\end{array}$ \\
\hline Blog & $\begin{array}{l}\text { Regular and usually brief commentary, on a } \\
\text { dedicated website }\end{array}$ \\
\hline BSS & Behaviour Support Service \\
\hline Bulk funding & A lump sum of money given to schools \\
\hline CAMS & Child and Adolescent Mental Health Service \\
\hline Carer relief & $\begin{array}{l}\text { Allocation of days by NASC for primary carer to } \\
\text { pay alternative carer }\end{array}$ \\
\hline $\mathrm{C} \& \mathrm{C}$ DHB & Capital and Coast District Health Board \\
\hline Chelation & $\begin{array}{l}\text { Biomedical (non-evidence-based) process of } \\
\text { removing heavy metals from autistic child }\end{array}$ \\
\hline Child Disability Allowance & $\begin{array}{l}\text { Sum of money paid weekly to parents of eligible } \\
\text { disabled children }\end{array}$ \\
\hline Co-morbid & $\begin{array}{l}\text { Condition which exists with another eg autism and } \\
\text { intellectual impairment }\end{array}$ \\
\hline Consumer & $\begin{array}{l}\text { Person (eg client, patient) who is the target/user of } \\
\text { policy or service }\end{array}$ \\
\hline CYF & Child Youth and Family \\
\hline Deaf & $\begin{array}{l}\text { Capital D indicates identification as a cultural } \\
\text { minority }\end{array}$ \\
\hline Decile & $\begin{array}{l}\text { Rating system for state funded schools based on the } \\
\text { socio-economic status of families of the area, with }\end{array}$ \\
\hline
\end{tabular}




\begin{tabular}{|c|c|}
\hline & 1 the most deprived and 10 the least \\
\hline Deinstitutionalisation & $\begin{array}{l}\text { The process of closing the big mental health and } \\
\text { psychopaedic institutions and rehousing the } \\
\text { residents }\end{array}$ \\
\hline Deprivation & $\begin{array}{l}\text { New Zealand Deprivation 1-10 health policy scale } \\
\text { with } 10 \text { the most deprived area and } 1 \text { the least } \\
\text { (opposite to the Education rating decile system) }\end{array}$ \\
\hline DHB & District Health Board \\
\hline DIAS & Disability Information and Advisory Service \\
\hline DSAC & $\begin{array}{l}\text { Disability Services Advisory Committee (of a } \\
\text { DHB) }\end{array}$ \\
\hline DSM & $\begin{array}{l}\text { Diagnostic and Statistical Manual of Mental } \\
\text { Disorders (American Psychiatric Association) }\end{array}$ \\
\hline DSS & Ministry of Health, Disability Support Services \\
\hline EarlyBird & $\begin{array}{l}\text { Parent education programme provided by Autism } \\
\text { NZ }\end{array}$ \\
\hline ERO & Education Review Office \\
\hline FC & Facilitated Communication; typing with assistance \\
\hline Fono & Samoan word for meeting \\
\hline Fundholder school & $\begin{array}{l}\text { A school with many special needs students which } \\
\text { gets their grant in a lump sum so they buy in their } \\
\text { own resources, rather than using the services of the } \\
\text { Ministry of Education's Special Education }\end{array}$ \\
\hline GP & General Practitioner (primary health doctor) \\
\hline GSE & $\begin{array}{l}\text { Ministry of Education, Group Special Education } \\
\text { (now just Special Education) }\end{array}$ \\
\hline HFA & Health Funding Authority (disestablished in 2001) \\
\hline HFA & High Functioning Autism \\
\hline Honorable/Hon & $\begin{array}{l}\text { Title for life for Members of Parliament who have } \\
\text { been cabinet ministers }\end{array}$ \\
\hline Hyperbaric chamber & $\begin{array}{l}\text { Pressurised capsule used by some parents to treat } \\
\text { their child's autism }\end{array}$ \\
\hline IACC & $\begin{array}{l}\text { US Department of Health and Human Services, } \\
\text { Interagency Autism Coordinating Committee }\end{array}$ \\
\hline IAG & $\begin{array}{l}\text { Implementation Advisory Group (New Zealand } \\
\text { Guidelines Group) }\end{array}$ \\
\hline ICD & $\begin{array}{l}\text { International Classification of Disability (World } \\
\text { Health Organisation) }\end{array}$ \\
\hline ID & $\begin{array}{l}\text { Intellectual disability; in New Zealand usually a } \\
\text { combination of significantly below average } \\
\text { intellectual and adaptive function }\end{array}$ \\
\hline IEP & Individual Education Programme or Plan \\
\hline IF & $\begin{array}{l}\text { Individualised Funding (disabled person controls } \\
\text { finances for their own support) }\end{array}$ \\
\hline Impairment & A specific condition \\
\hline Incidence & New cases of a condition in a population \\
\hline Invalids' Benefit & $\begin{array}{l}\text { Welfare payment that autistic people may be } \\
\text { eligible for from } 16 \text { years old }\end{array}$ \\
\hline LAC & Local Area Coordination \\
\hline
\end{tabular}




\begin{tabular}{|c|c|}
\hline LGG & $\begin{array}{l}\text { Living Guideline Group (New Zealand Guidelines } \\
\text { Group) }\end{array}$ \\
\hline Magnet school & $\begin{array}{l}\text { Mainstream school with a larger proportion than } \\
\text { normal of students with special educational needs, } \\
\text { usually because of more inclusive cultures }\end{array}$ \\
\hline Mainstream Programme & $\begin{array}{l}\text { Supported employment programme for disabled } \\
\text { people in government agencies }\end{array}$ \\
\hline Medical model & Individual, deficit based model of disability \\
\hline MMR & Measles, mumps and rubella immunisation \\
\hline MoE & Ministry of Education \\
\hline $\mathrm{MoH}$ & Ministry of Health \\
\hline $\mathrm{MoU}$ & Memorandum of Understanding \\
\hline MP & Member of Parliament (New Zealand's one house) \\
\hline MSD & Ministry of Social Development \\
\hline NASC & Needs Assessment and Service Coordination \\
\hline NASCA & NASC Association \\
\hline NCEA & $\begin{array}{l}\text { National Certificate of Educational Achievement } \\
\text { (NZ's main school based assessment system) }\end{array}$ \\
\hline Neurodiverse & Neurological difference such as autism \\
\hline Neurotypical & 'Normal' neurology \\
\hline New Model & $\begin{array}{l}\text { A pilot programme in the Bay of Plenty for an } \\
\text { alternative way of providing disability support }\end{array}$ \\
\hline NGO & Non government organisation \\
\hline No Child Left Behind & US school-based standards and testing programme \\
\hline NZDS & New Zealand Disability Strategy \\
\hline NZQA & New Zealand Qualifications Authority \\
\hline NZEI & $\begin{array}{l}\text { New Zealand Educational Institute (education } \\
\text { union, including teacher aides and support staff) }\end{array}$ \\
\hline NZGG & New Zealand Guidelines Group \\
\hline NZSL & New Zealand Sign Language \\
\hline ODI & $\begin{array}{l}\text { Office For Disability Issues (Ministry for Social } \\
\text { Development) }\end{array}$ \\
\hline ORRS/ORS & $\begin{array}{l}\text { Ongoing Reviewable Resourcing Scheme/Ongoing } \\
\text { Resourcing Scheme }\end{array}$ \\
\hline Pasifika & $\begin{array}{l}\text { People from Pacific Island communities living in } \\
\text { NZ }\end{array}$ \\
\hline Plunket nurse & $\begin{array}{l}\text { Well-child public nurse for babies and young } \\
\text { children employed by the NZ Plunket Society }\end{array}$ \\
\hline Playcentre & $\begin{array}{l}\text { Parent run pre-school model developed in New } \\
\text { Zealand }\end{array}$ \\
\hline PPTA & Post Primary Teachers' Association (teacher union) \\
\hline Prevalence & $\begin{array}{l}\text { Percentage of population with condition at any one } \\
\text { time }\end{array}$ \\
\hline Psychopaedic & $\begin{array}{l}\text { Medical facility for institutionalised disabled } \\
\text { children (psychopaedic nurse 1960s NZ invention) }\end{array}$ \\
\hline Refrigerator mother & $\begin{array}{l}\text { Blaming label for parents (usually mothers) of } \\
\text { autistic children suggested by Kanner, and } \\
\text { popularised by Bettelheim's } 1967 \text { book The Empty } \\
\text { Fortress }\end{array}$ \\
\hline
\end{tabular}




\begin{tabular}{|c|c|}
\hline RFA & Regional Funding Authority \\
\hline RFP & Request for proposal \\
\hline RFT & Request for tender \\
\hline RHA & Regional Health Authority (disestablished 2001) \\
\hline RIDCA & Regional Intellectual Disability Care Agency \\
\hline RIDSAS & $\begin{array}{l}\text { Regional Intellectual Disability Supported } \\
\text { Accommodation Service }\end{array}$ \\
\hline RTLB & Resource Teacher: Learning and Behaviour \\
\hline Savant & Rare exceptional skills in a particular area \\
\hline SCERTS & $\begin{array}{l}\text { Social Communication Emotional Regulation } \\
\text { Transactional Supports (pre-school ASD } \\
\text { intervention programme) }\end{array}$ \\
\hline SE2000 & Special Education 2000 (education policy 1996) \\
\hline SEG & $\begin{array}{l}\text { Special Education Grant (given to all state schools } \\
\text { regardless of numbers of students with special } \\
\text { needs) }\end{array}$ \\
\hline SES & Special Education Services (later GSE) \\
\hline Sickness Benefit & $\begin{array}{l}\text { Regularly reviewable welfare payment for person } \\
\text { too ill to work }\end{array}$ \\
\hline Social model of disability & $\begin{array}{l}\text { Sees disability as socially constructed by society } \\
\text { which creates barriers }\end{array}$ \\
\hline Strengthening families & $\begin{array}{l}\text { Holistic NZ model for support of family or young } \\
\text { person involving all agencies working together }\end{array}$ \\
\hline Supported employment & $\begin{array}{l}\text { Specialist agency support for transition to work and } \\
\text { sometimes ongoing support for disabled person }\end{array}$ \\
\hline Tips for autism & $\begin{array}{l}\text { School based programme run by the Ministry of } \\
\text { Education }\end{array}$ \\
\hline TIS & $\begin{array}{l}\text { Technical Implementation Service (New Zealand } \\
\text { Guidelines Group) }\end{array}$ \\
\hline Treaty of Waitangi & $\begin{array}{l}\text { NZ's } 1840 \text { founding constitutional document } \\
\text { between indigenous Maori and British Crown }\end{array}$ \\
\hline UNCRPWD & $\begin{array}{l}\text { United Nations Convention on the Rights of } \\
\text { Persons with Disabilities }\end{array}$ \\
\hline WINZ & $\begin{array}{l}\text { Work and Income New Zealand, part of the } \\
\text { Ministry of Social Development }\end{array}$ \\
\hline
\end{tabular}




\section{Glossary of Māori words}

\begin{tabular}{|c|c|}
\hline Aotearoa & New Zealand \\
\hline Aroha & Love \\
\hline Awhinatanga & Assistance, support \\
\hline Hapū & Sub-tribe, clan \\
\hline He Korowai Oranga & Māori Health Strategy \\
\hline Hui & Meeting \\
\hline Iwi & Tribal grouping \\
\hline Kai & Food \\
\hline Kaitiaki & Guardian, caretaker/s \\
\hline Kaiwhakahaere & Leader, manager \\
\hline karakia & Prayer, chant, religious or spiritual incantation \\
\hline kaumātua & Older male, elder/s \\
\hline Kaupapa & The way things are done, philosophy \\
\hline Kaupapa Māori & Māori philosophy, principles, language and culture \\
\hline Kawa & Protocol \\
\hline Koha & Gift, contribution \\
\hline Kōrero & Talk \\
\hline Kuia & Older woman \\
\hline Mahi & Work, occupation \\
\hline Mana & Integrity, prestige, status \\
\hline Manaakitanga & Care for, nurturing, according respect and dignity \\
\hline Manuhiri & Visitors \\
\hline Marae & Meeting area of whānau or iwi \\
\hline Mihi/mihimihi & Greetings, introductions, speeches \\
\hline Pākehā & Non indigenous person, usually of European origin \\
\hline Tāngata Whaiora & People with experience of mental illness \\
\hline Tāngata whenua & Indigeneous inhabitants, or hosts \\
\hline Te reo Māori & The Māori language \\
\hline Te taha hinengaro & The mental and emotional aspects of health \\
\hline Te taha tinana & The physical aspects of health \\
\hline Te taha wairua & The spiritual aspects of health \\
\hline Te taha whānau & The family and community aspects of health \\
\hline Te whare tapa whā & $\begin{array}{l}\text { Model of health that envisages a house with four walls of } \\
\text { spiritual, physical, family, psychological health }\end{array}$ \\
\hline Tikanga & Customs, protocol, obligations and conditions \\
\hline Whakapapa & Genealogy, cultural identity \\
\hline Whanaungatanga & To establish relationships \\
\hline Whānau & Extended family \\
\hline Whānau Ora & $\begin{array}{l}\text { Applying Māori principles and philosophy to enhance } \\
\text { wellbeing; also the name of a programme of holistic } \\
\text { support for family or person having difficulties }\end{array}$ \\
\hline Whāngai & The raising of a child by non-biological parents \\
\hline Whare & House/s \\
\hline
\end{tabular}




\section{Contents}

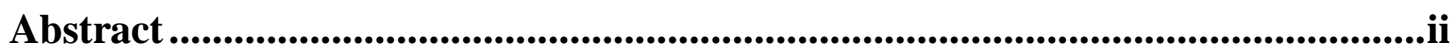

Acknowledgements ...............................................................................................................iii

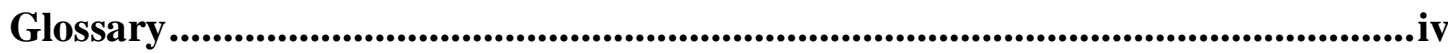

Glossary of Māori words ....................................................................................................viii

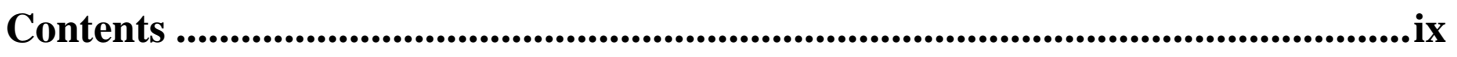

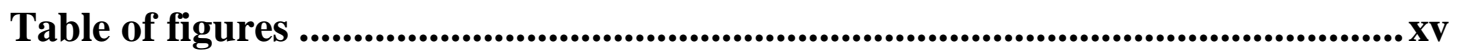

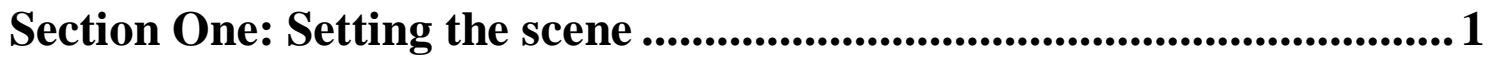

Chapter One: The policy challenge of autism ...........................................................2

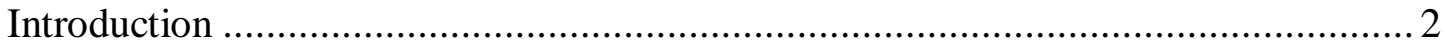

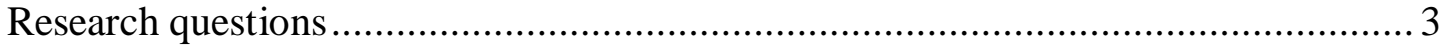

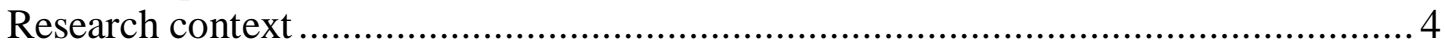

What is autism - definitions............................................................................. 4

Medical or individual model versus social model of disability ........................ 7

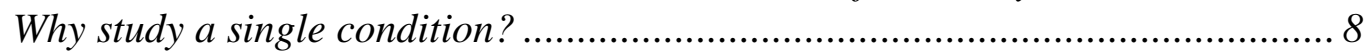

Supports required and the importance of public policy .................................... 8

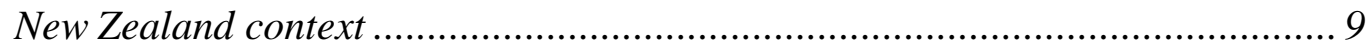

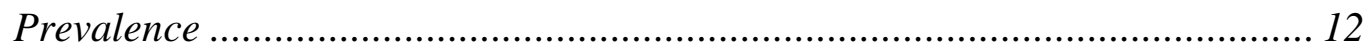

International policy context - the 'problem' of autism ................................... 14

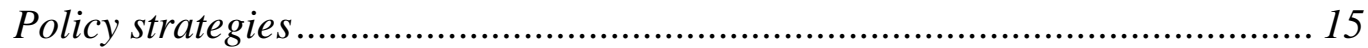

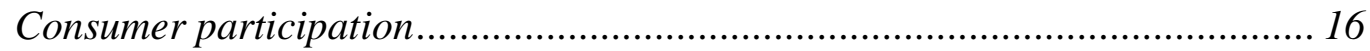

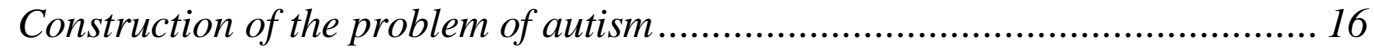

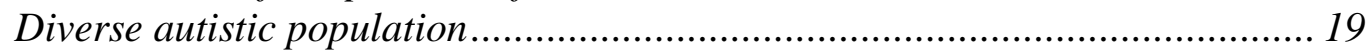

Love and luck required for good outcomes .................................................... 20

Right relationships and lived experience .................................................... 21

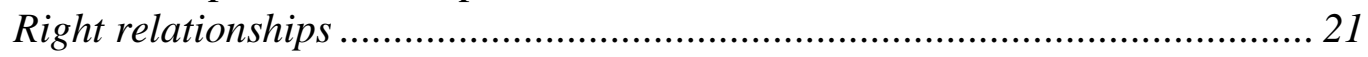

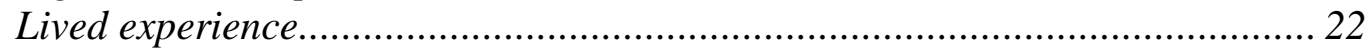

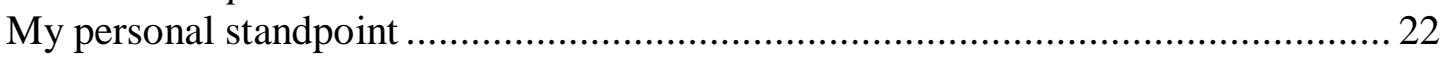

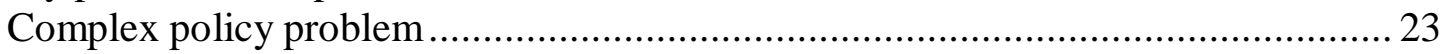

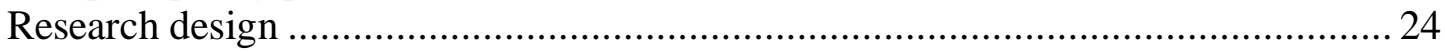

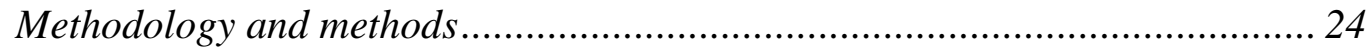

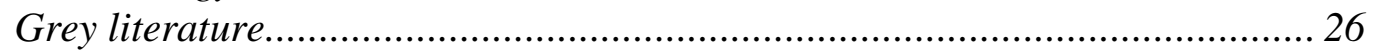

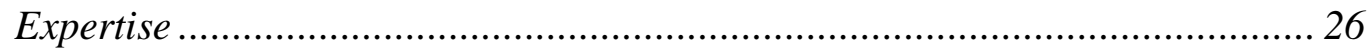

Framework for tackling research questions, and chapter outlines ......................... 27

Chapter Two: Methodology and methods..........................................................31

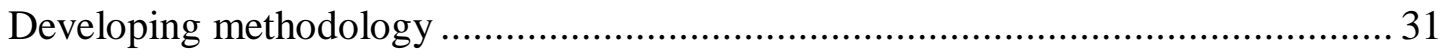




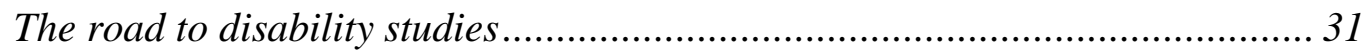

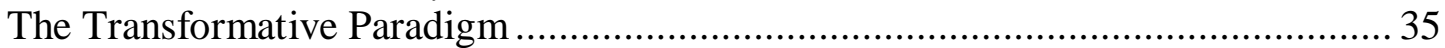

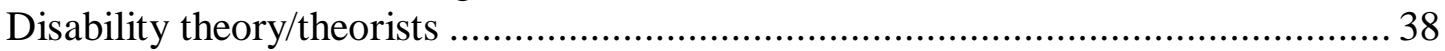

Emancipatory/transformative research methodology ...................................... 45

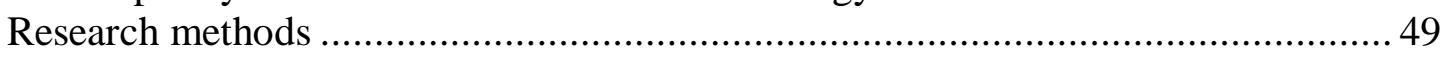

Strengths and limits of research methods................................................ 54

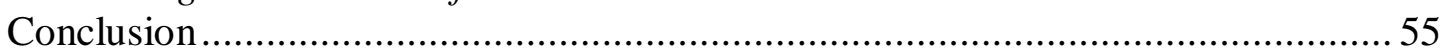

Chapter Three: Experts and expertise .............................................................556

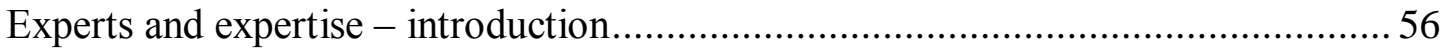

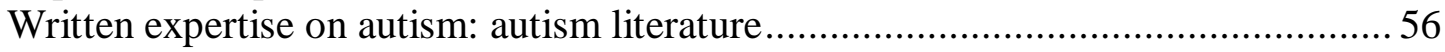

Experts on lived experience of autism: grey literature sources....................... 56

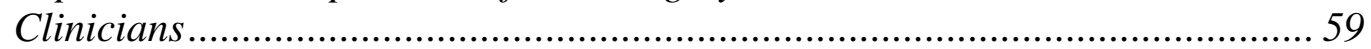

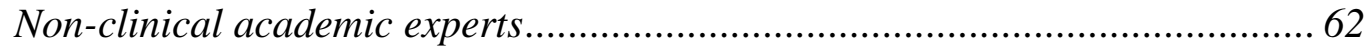

Academics from the field of disability studies, and disability activists ............ 63

People involved in the development and implementation of relevant New

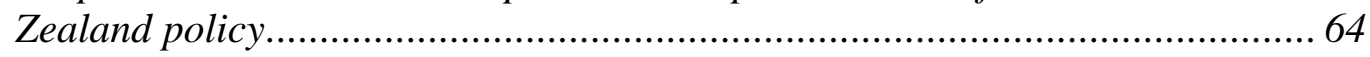

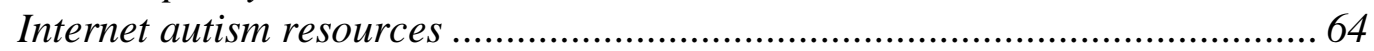

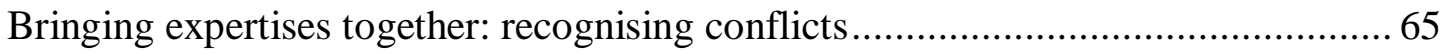

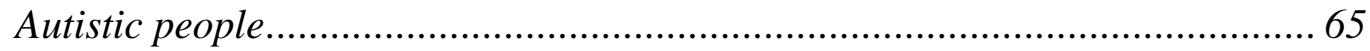

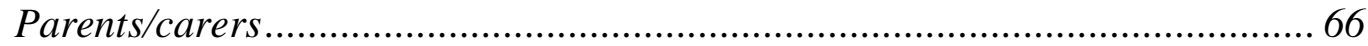

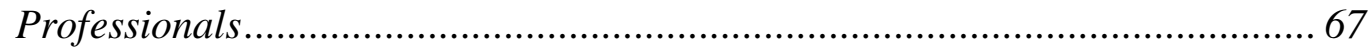

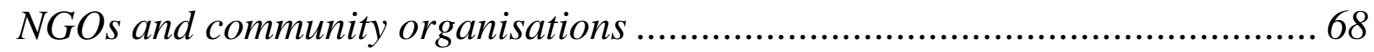

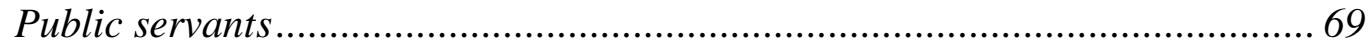

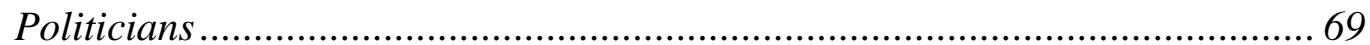

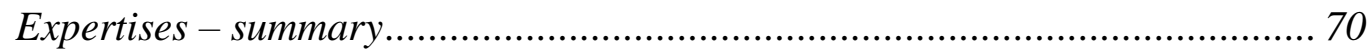

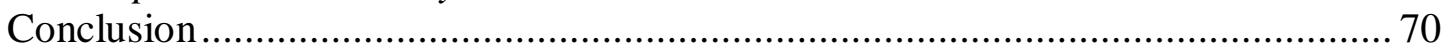

Section Two: Contextual Background....................................................... 72

Chapter Four: The history and construction of autism ......................................73

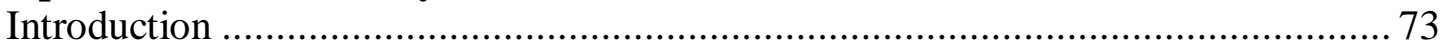

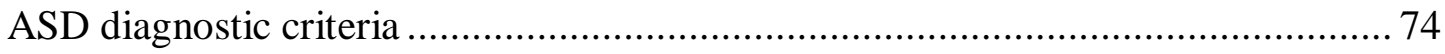

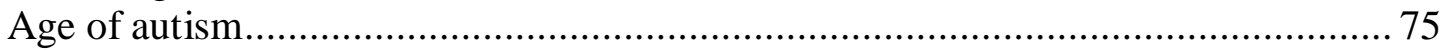

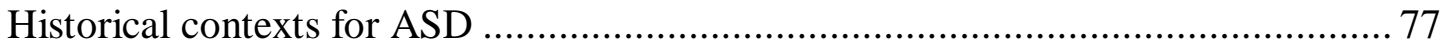

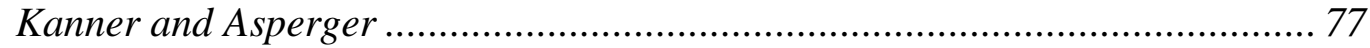

Historical context for the work of Kanner and Asperger ................................ 77

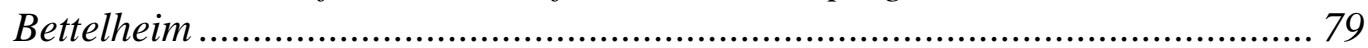

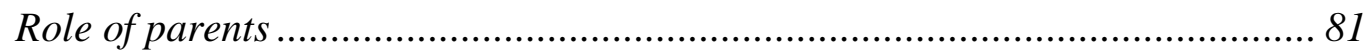

Historical examples ............................................................................. 83

Diagnostic and Statistical Manual of Mental Disorders ...................................... 84

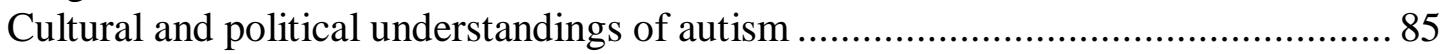

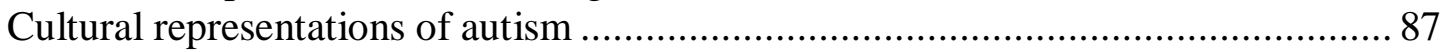

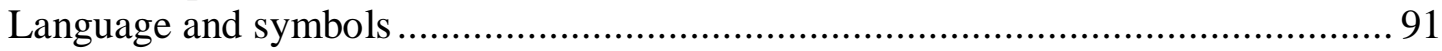

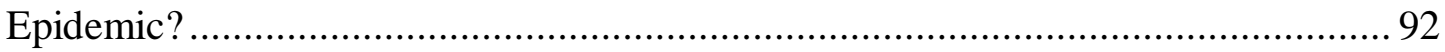

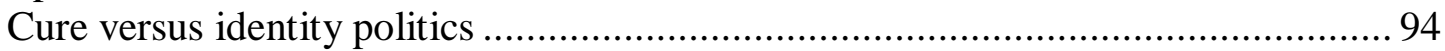

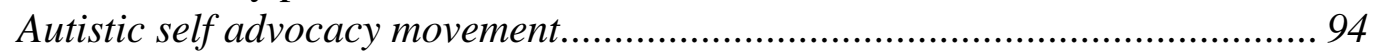




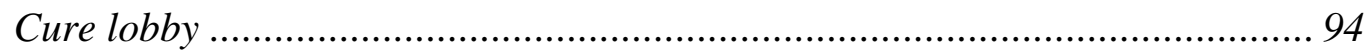

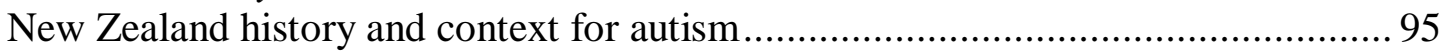

Autism NGOs: Autism New Zealand ........................................................... 97

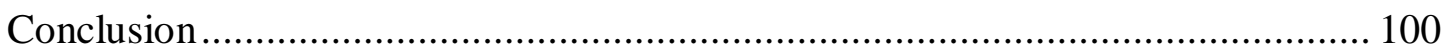

Chapter Five: New Zealand disability history, activism, policy and ethics.......101

United Nations Convention on the Rights of Persons with Disabilities ................. 101

New Zealand Disability Strategy .............................................................. 101

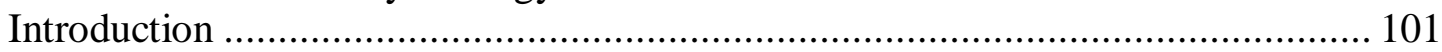

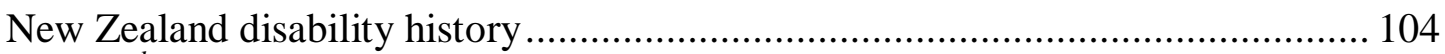

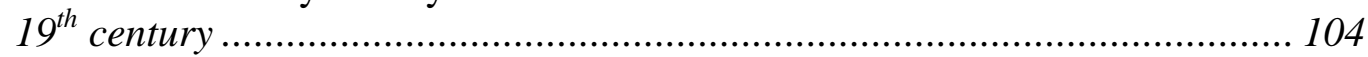

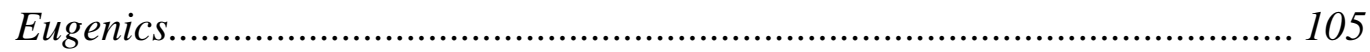

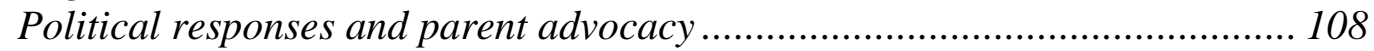

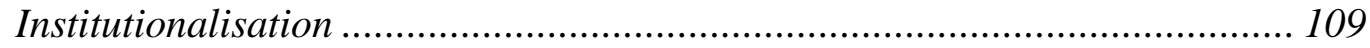

1975 Disabled Person's Community Welfare Act........................................ 111

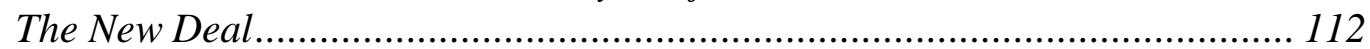

Rise of disability rights activism and the social model of disability .................... 112

Social model of disability ...................................................................... 112

New Zealand disability rights movement: achievements............................. 113

Partnership between disability activists and politicians: window of policy

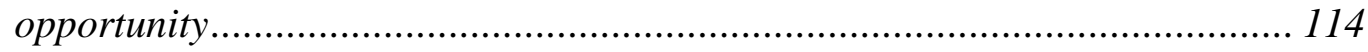

Activism, ethics and consumer participation in disability policy ......................... 116

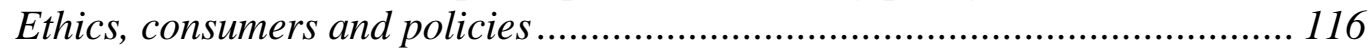

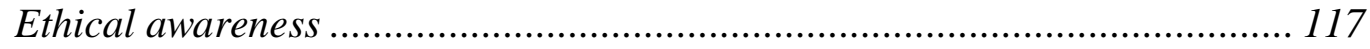

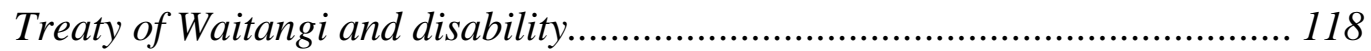

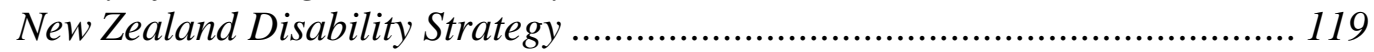

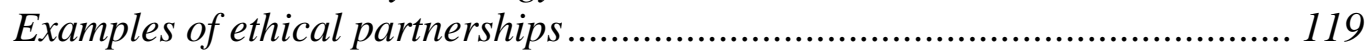

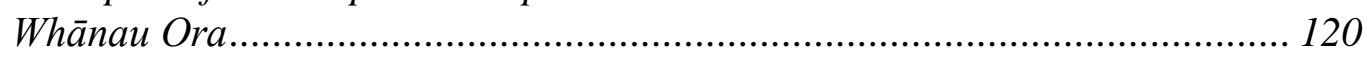

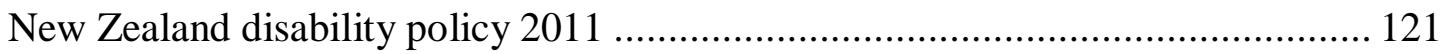

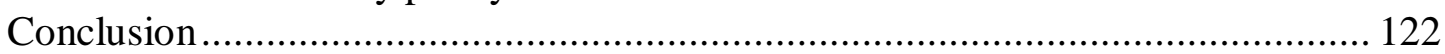

Chapter Six: Love and luck, right relationships and lived experience ............... 123

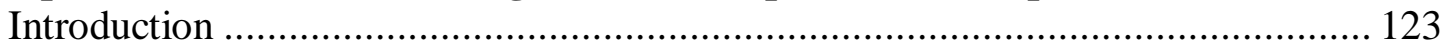

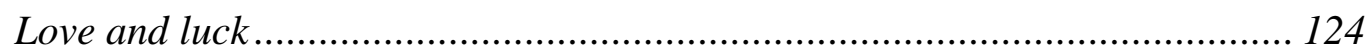

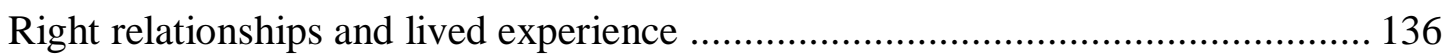

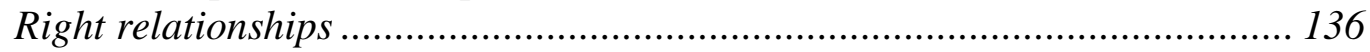

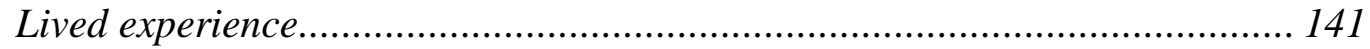

Examples of right relationships and respecting lived experience................... 143

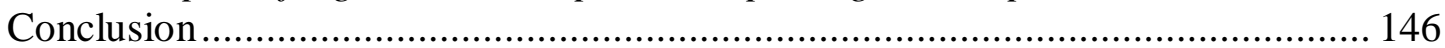

Section Three: Autism policy issues ..................................................... 147

Chapter Seven: Is autism a 'wicked' policy challenge? ........................................ 148

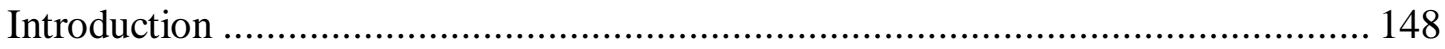

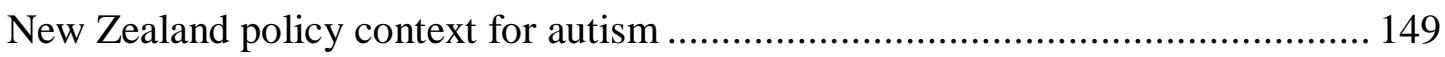

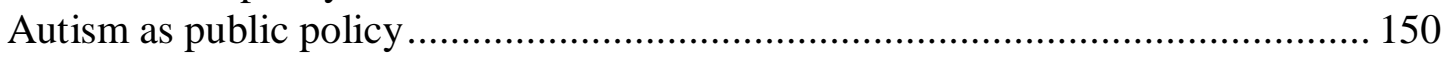

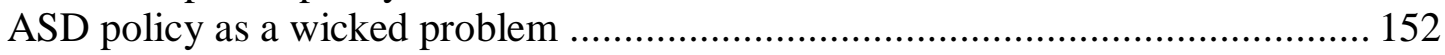


Wicked problems:

Are difficult to clearly define ........................................................................ 153

Have many interdependencies and are often multi-causal........................... 154

Attempts to address wicked problems often lead to unforeseen consequences 155

Are often not stable ................................................................................ 156

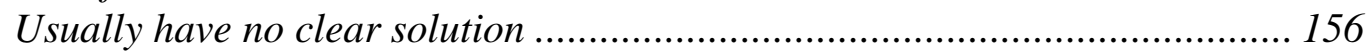

Are socially complex ........................................................................... 156

Rarely fit conveniently within the responsibility of any one organisation ....... 157

Involve changing behaviours ................................................................ 158

Some wicked problems are characterised by chronic policy failure .............. 159

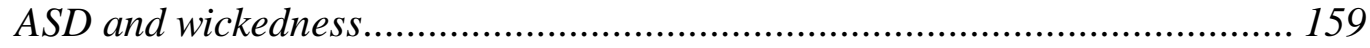

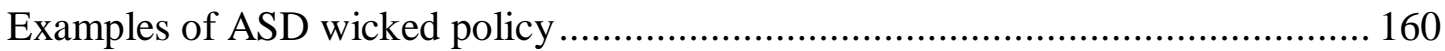

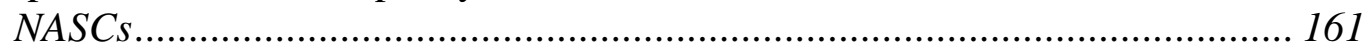

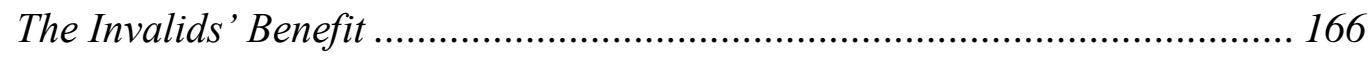

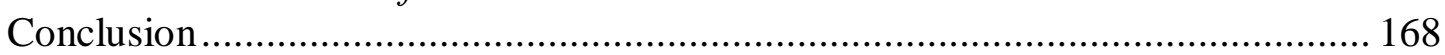

Chapter Eight: Education policy and ASD .....................................................170

Introduction: Special education in New Zealand, and implications for autism........ 171

Special educational policies: 1877 to 2010 Special Education Review........... 173

Teacher aides/educational support workers............................................. 179

Everyday education provision for students with autism................................ 180

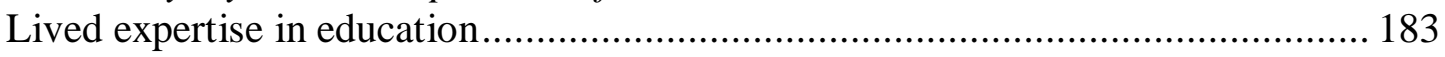

Examples from lived experience .......................................................... 184

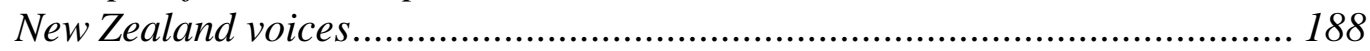

Studies with disabled children ............................................................... 191

Autistic children at school in New Zealand: two local examples.......................... 193

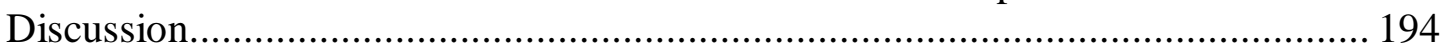

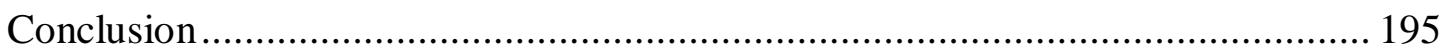

Chapter Nine: Case study, the NZ ASD Guideline .............................................197

Introduction: What is the Guideline and why was it written? ............................... 198

Part One: sowing the seeds for the ASD Guideline: Casey Albury and government

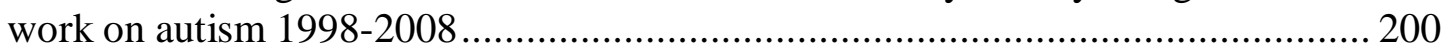

Policy initiatives ................................................................................. 202

NGO support-Autism New Zealand ................................................... 202

Parent courses - EarlyBird and SPELL ...................................................... 203

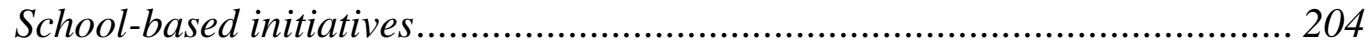

'Lets Talk' consultation process ................................................................... 204

Needs Assessment and Service Coordination initiatives ................................. 205

ASD pilot projects .................................................................................. 206

ASD Disability Information and Advisory Service (DIAS).......................... 208

Māori and Pasifika................................................................................ 208

Intellectual Disability (Compulsory Care and Rehabilitation) Act 2003........ 208

Part Two: ASD Guideline publication and progress .............................................. 209

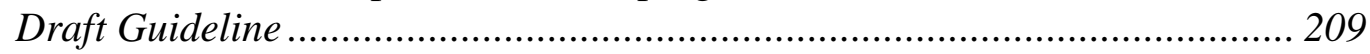

Publication and planning for implementation ............................................. 210

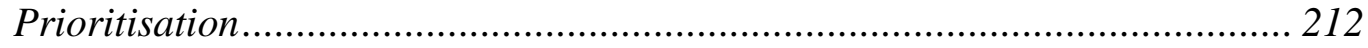

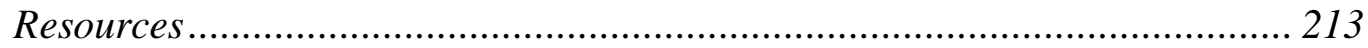

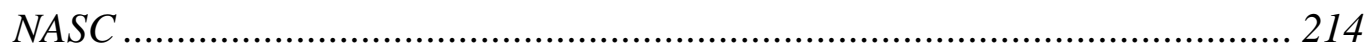

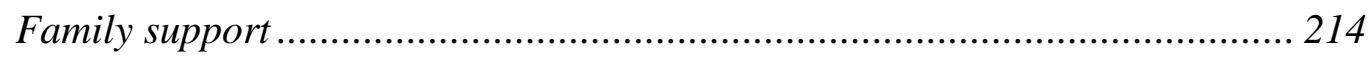




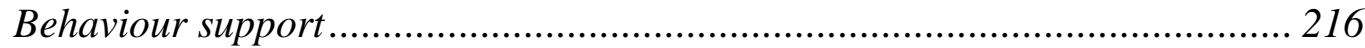

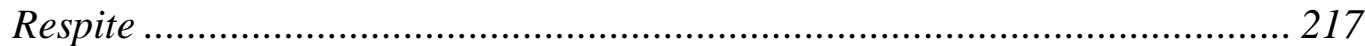

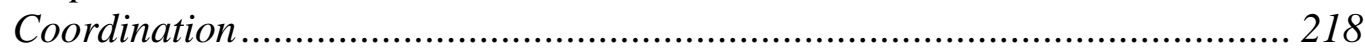

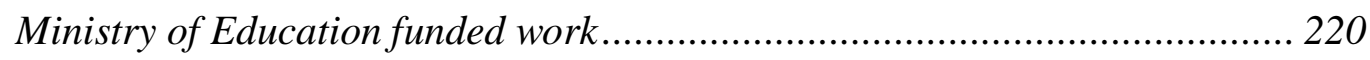

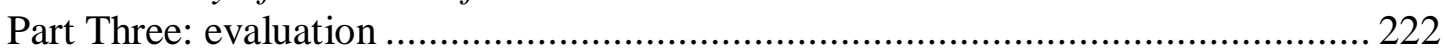

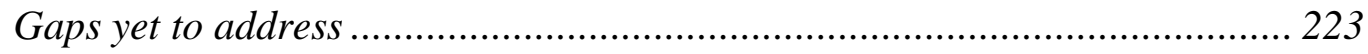

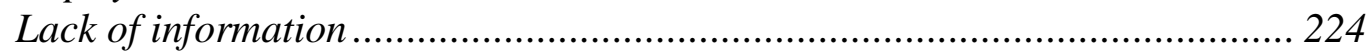

Assessment of Guideline by my informants ............................................... 226

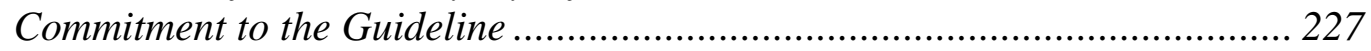

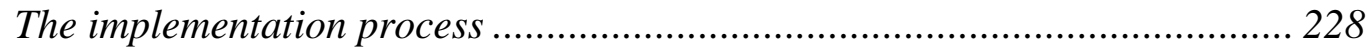

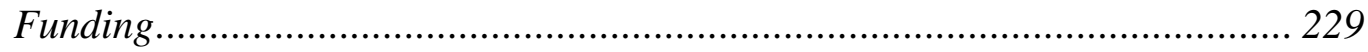

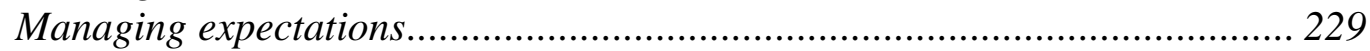

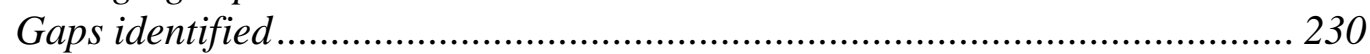

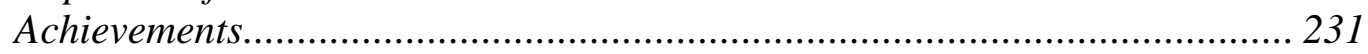

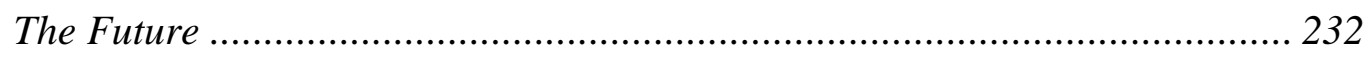

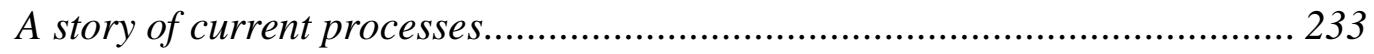

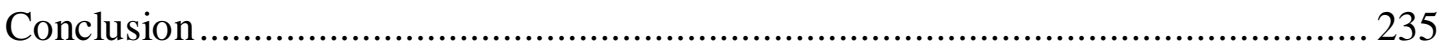

Section Four: Summary and conclusions ............................................. 238

Chapter Ten: Summary and conclusions.........................................................2239

Summary of the argument and scholarly framework ............................................2239

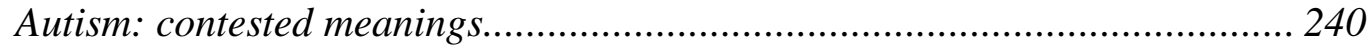

New Zealand and personal context ............................................................ 242

Love and luck, right relationships, lived experience .................................... 243

Policy issues: wicked policy, autism as public policy .................................. 243

Methodology: disability studies and the transformative paradigm ................ 244

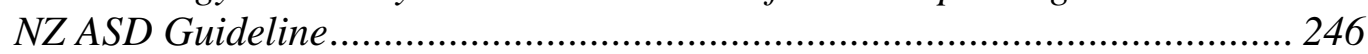

Main conclusion from Guideline: more coordination required ..................... 246

Conceptualised research model .............................................................. 247

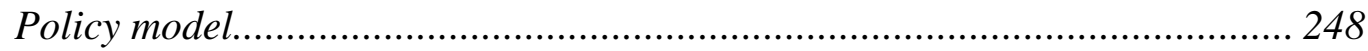

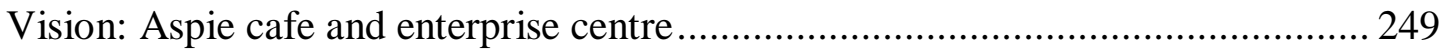

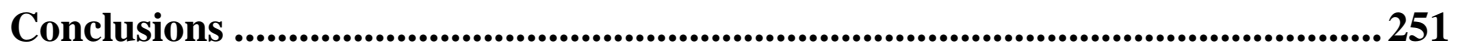

Consideration of research questions .............................................................. 252

How can right relationships and lived experience be better incorporated into

New Zealand ASD policy? ........................................................................... 252

What do the concepts of love and luck, right relationships and lived experience

mean in the context of the ASD policy process? ......................................... 252

Why is ASD a wicked policy problem?......................................................... 253

How might policy ensure that people with ASD and the families move beyond the uncertainties of love and luck to reliable and appropriate supports which give individuals and families more choice and control over their lives? ................ 253

To what extent does the NZ ASD Guideline meet the criteria of incorporating 'right relationships' and 'lived experience' and what can we learn from the development and implementation of the Guideline? ..................................... 254

Recommendations for improving autism policy............................................... 255 


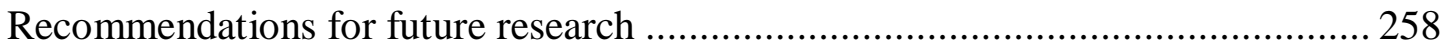

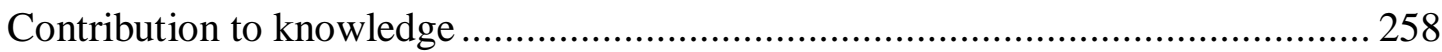

Final comment: autism policy leadership ............................................. 259

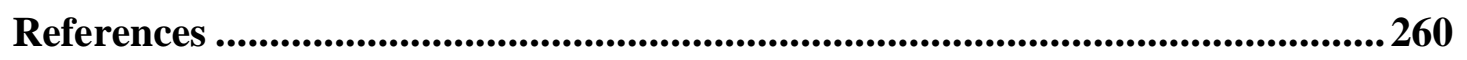

Appendix One: Diagnostic criteria for ASD (DSM-IV-TR and ICD-10)..........289

1. DSM-IV-TR (American Psychiatric Association, 2000) …................................ 289

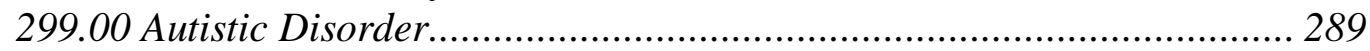

299.80 Asperger's Disorder ...................................................................... 290

299.80 Pervasive Developmental Disorder Not Otherwise Specified (Including

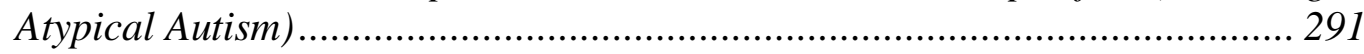

2. ICD-10 (World Health Organisation, 2007) ................................................... 292

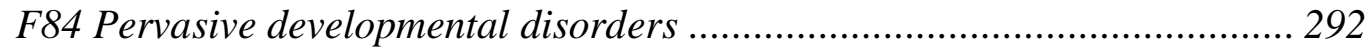

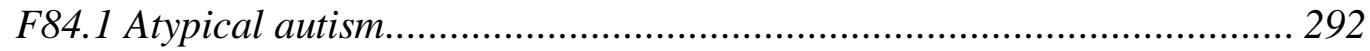

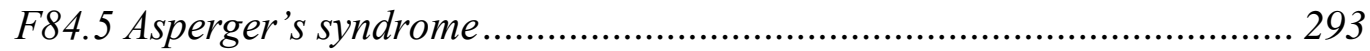

F84.8 Other pervasive developmental disorders ....................................... 293

F84.9 Pervasive developmental disorder, unspecified .................................. 293

Appendix Two: Key Informants................................................................294

Appendix Three: Ethics Approval ...............................................................2295 


\section{Table of figures $^{1}$}

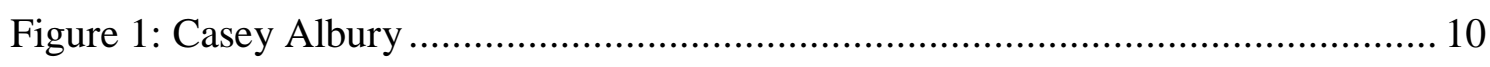

Figure 2: Basic beliefs of the Transformative Paradigm .......................................... 38

Figure 3: The Social and Scientific Formulations of Disability ................................ 44

Figure 4: Contrasting the Emancipatory and Transformative paradigms .................... 49

Figure 5: Autistic Self Advocacy Network protest at a university in the US ................ 73

Figure 6: Aspies for Freedom logo showing rainbow infinity symbol....................... 91

Figure 7: Treaty of Waitangi provisions in English and Māori................................ 118

Figure 8: Minister of Education Lockwood Smith 28 November 1995 by Tom Scott. 148

Figure 9: Government agencies supporting people with an intellectual disability ....... 150

Figure 10: Transformative paradigm relationship building model............................. 249

\footnotetext{
${ }^{1}$ Sources not publicly available are used with permission.
} 


\section{Section One: Setting the scene}

\section{Introduction, methodology and sources of expertise}

This first section of three chapters introduces the topic, relevant terms and contexts. Chapter One outlines the thesis as a whole, and explains why my underlying assumption is that lived experience needs to be included in New Zealand policy processes. The methodological approach is outlined in Chapter Two and explains what methods were chosen, why my experts' voices are often found in the 'grey literature' of autobiographies and the internet, why and how data were analysed, and the significance of Mertens' transformative paradigm. Chapter Three extends the methods chapter by explaining the concept of expertise and where that expertise can be found. 


\section{Chapter One: The policy challenge of autism}

\section{Introduction}

Autism Spectrum Disorder (ASD) diagnoses have been rising rapidly in recent years and New Zealand is just one country grappling with the consequent policy challenges. Currently, love, such as a supportive family, and luck, that appropriate services are available, are required by people with autism and their families for good outcomes. This situation is neither equitable nor sustainable, but to move beyond it requires innovative and collaborative approaches. One New Zealand response to the lack of coherent autism policy has been the development of the New Zealand Autism Spectrum Disorder Guideline (Ministries of Health and Education, 2008), hereafter referred to as the ASD guideline, which is the first whole-of-spectrum, whole-of-life, whole-of-government, best practice approach in the world to address the complexity of issues surrounding ASD. However, the Guideline remains a largely theoretical document and there is untapped expertise among those with lived experience of autism, and their families, to improve implementation and services. To incorporate this expertise into the policy process requires relationship building which addresses power imbalances and past injustices. This thesis will suggest ways lived experience could be better incorporated into policy.

This study will argue that effective and equitable autism policy, which enables people with autism and their families to move beyond the uncertainties of love and luck and to access appropriate and timely services and supports, requires getting the relationships right between the developers, implementers and target populations of the policy, and acknowledging the value of lived experience of autism in the process. But the policy environment can be problematic to an extent that it can be considered 'wicked', and a characteristic of wicked policy is that it can frustrate attempts at resolution (Australian Public Service Commission, 2007; Conklin, 2005). Therefore, a detailed examination of the 2008 ASD guideline, an important New Zealand milestone which is currently undergoing implementation, provides an appropriate case study (Ministries of Health and Education, 2008). Having examined the implications of right relationships and lived experience, the final chapter will provide examples of how theory may become practice. 
This first chapter outlines my approach to the thesis and provides definitions and context for the subsequent study. It lists my research questions, and reviews the current research and policy context around autism. The chapter includes definitions of autism and provides details of core concepts such as the social model versus the medical (or individual) model of disability, and provides some context for New Zealand policy in terms of international research, policies, strategies and prevalence data. Introductions are given to terms that will be explored in later chapters, such as love and luck, right relationships, and lived experience. I describe my methodological approach which will be developed further in Chapter Two, and indicate those whose expertise I consider in Chapter Three. The research questions are addressed throughout this dissertation in the search for a better autism policy process. Chapter One concludes with brief outlines of the following chapters.

\section{Research questions}

Given the complexity of autism and the need for policies to improve the lives of those with autism this thesis asks the following research questions. My main question is the first one which will largely be answered by examination of the other questions.

- How can right relationships and lived experience be better incorporated into New Zealand autism policy?

- What do the concepts of love and luck, right relationships and lived experience mean in the context of the autism policy process?

- Why is autism policy a wicked problem?

- How might policy ensure that people with autism and their families move beyond the uncertainty of love and luck to reliable and appropriate supports which give individuals and families more choice and control over their lives?

- To what extent does the NZ ASD guideline meet the criteria of incorporating right relationships and lived experience and what can we learn from its development and implementation? 


\section{Research context}

In this section, I highlight some definitions, concepts, and descriptions of autism and autism policy. Together, this material serves to narrow and justify the focus of the thesis on a problem definition and solution approach.

\section{What is autism - definitions}

Autism is a condition within the range of diagnoses known as Pervasive Developmental Disorders. The autism spectrum covers a large range of experiences, from the nonverbal child requiring significant care, to the highly articulate and intelligent person who may be an academic or an information technology expert with Asperger's syndrome or 'higher functioning' autism. Although they are commonly referred to as autism spectrum disorders or ASD, I use autism as an umbrella term, and use ASD and autism interchangeably. The 2008 ASD guideline has the following definition:

Those diagnosed with ASD all display:

- Impairment in the ability to understand and use verbal and non-verbal communication

- Impairment in the ability to understand social behaviour, which affects their ability to interact with other people

- Impairment in the ability to think and behave flexibly which may be shown in restricted, obsessional or repetitive activities. (2008, p. 17)

As indicated above, ASD is characterised by problems around communication and behaviour, an unsurprising assumption as this definition comes from the perspective of non-autistic (known to many autistic people as neurotypical) people, and we tend to see and describe problems or deficits, not abilities. In contrast, the website of the US-based Autistic Self Advocacy network has a strengths-based description on its website:

Autism is a neurological variation that occurs in about 1 in 150 people and is classified as a developmental disability. Although it may be more common than previously thought, it is not a new condition and exists in all parts of the world, in both children and adults of all ages. The terms 
"Autistic" and "autism spectrum" often are used to refer inclusively to people who have an official diagnosis on the autism spectrum ... or who self-identify with the Autistic community. While all Autistics are as unique as any other human beings, they share some characteristics typical of autism in common.

1. Different sensory experiences.

2. Non-standard ways of learning and approaching problem solving.

3. Deeply focused thinking and passionate interests in specific subjects.

4. Atypical, sometimes repetitive, movement.

5. Need for consistency, routine, and order.

6. Difficulties in understanding and expressing language as used in typical communication, both verbal and non-verbal.

7. Difficulties in understanding and expressing typical social interaction. (Autistic Self Advocacy Network, 2011)

To complicate matters further there are two main diagnostic descriptions used by most English speaking countries. They are found in the American Psychiatric Association's Diagnostic and Statistical Manual of Mental Disorders 4th edition Text Revision dated 2000 (DSM-IV-TR), and the World Health Organisation's International Clinical Description 10th revision 2007 (ICD-10). (See Appendix One for the full DSM IV and ICD-10 diagnostic descriptions.) Both describe a similar range of Pervasive Developmental Disorders (American Psychiatric Association, 2000; World Health Organisation, 2007) although the $D S M$ refers to autism as a mental health disorder while for the $I C D$ it is a disability.

According to the DSM-IV-TR:

Pervasive Development Disorders are characterised by severe and pervasive impairment in several areas of development: reciprocal social interaction skills, communication skills, or the presence of stereotyped behaviour, interests, and activities... [they include] Autistic Disorder, Rett's Disorder, Childhood Disintegrative Disorder, Asperger's Disorder, Pervasive 
Development Disorder Not Otherwise Specified. (American Psychiatric Association, 2000, p. 69)

Within Autistic Disorder, code 299.00, (a condition which varies with the age and development of the person) is Asperger's Disorder (299.80) which is diagnosed by a 'qualitative impairment in social interaction'...'restricted repetitive and stereotyped patterns of behaviour, interests and activities', which causes 'clinically significant impairment in social, occupational, or other important areas of functioning' (2000, p. 70). Asperger's differs from Autistic Disorder in that there is no significant language or cognitive delay. The DSM does not use the word spectrum; this term was first used for autism by British child psychiatrist Lorna Wing (1997) for the triad of impairments identified in the NZ ASD guideline's definition quoted above.

The $D S M-I V$ is particularly important in some states of the United States where DSMcoded diagnostic labels are essential for getting some health and education supports and insurance payments. So well-known is the DSM that some autistic people such as US writer Stephen Shore (2008), refer to themselves as members of Club 299 - the DSM number for autistic disorder. The DSM is currently undergoing revision for a new edition. This is proving controversial regarding autism, including divisions between clinicians and parents who see a problem to fix versus those who do not want it described as a psychiatric condition (Grinker, 2010; Spiegel, 2010; Svoboda, 2009; Swedo, 2008; Wolman, 2008). Homosexuality, which was included in the DSM until 1972, was earlier similarly contested and dropped after gay rights activism (Grinker, 2007).

The official criteria do not include the significant role of sensory sensitivities as described by two adults with autism:

Many autistic people process informational input from five external-directed senses (vision, hearing, smell, taste, touch) and two internal-directed senses (balance, muscular feedback) differently from how non-autistic people process sensory input. Autistic people's senses may be hypersensitive (highly increased in sensitivity) or hyposensitive (highly decreased in 
sensitivity). The level and nature of sensitivity will vary greatly under different circumstances and in different situations, depending on an autistic person's stress level, emotional state, and surroundings. (S. M. Robertson \& Ne'eman, 2008)

\section{Medical or individual model versus social model of disability}

The two contrasting definitions of autism mentioned above - from clinical sources and from the community itself - also illustrate the difference between what is known in disability studies as the medical (or individual) model of disability and the social model of disability. One is imposed by those who see physical, communication or functioning problems and deficits, with individuals or groups of individuals requiring fixing; the other comes from within the disability community itself describing identity, and the challenges a cultural minority has fitting in with a majority population that may not be welcoming. People with lived experience of disability have developed the social model of disability over the last few decades, whereby society itself creates the barriers and so has the solutions to counter the medical model that has traditionally seen the individual person as the problem.

As the DSM and ICD descriptions are based on deficits located in an individual, they are not helpful in the New Zealand disability public policy environment which is based on the social model of disability whereby people may have impairments but they are disabled by the structures, rules and attitudes of society. The 2001 New Zealand Disability Strategy describes the social model on its first page:

Disability is not something individuals have. What individuals have are impairments. They may be physical, sensory, neurological, psychiatric, intellectual or other impairments. Disability is the process which happens when one group of people create barriers by designing a world only for their way of living, taking no account of the impairments other people have. (Ministry of Health, 2001, p. 1)

The social model and discussions around its implementation are central to this thesis for their impact on New Zealand autism policy. Michael Oliver, a British disabled academic who first described the social model, argues that it is a tool for improving the lives of 
disabled people, not just a theory (2009). The contrasting definitions of autism given above and the contrasting perspectives on the medical versus social model are part of the reason why ASD might be considered as an intractable policy issue. One definition reflects an essentialist view that disability is something inherent to an individual, and the other a constructivist view that disability is constructed by a disabling society. The social model advocates, and those who prefer the medical model, sometimes battle each other to be heard in the autism policy debate, internationally and in New Zealand. As further detailed in Chapter Seven, the complex and contested nature of autism fits the characteristics of 'wicked' policy challenges. Urgent, innovative and collaborative approaches are therefore both needed and possible, as this thesis establishes.

\section{Why study a single condition?}

Autism is only one of a many impairments people may be diagnosed with, so why study it in isolation from other related conditions? A single diagnosis study may be interpreted as medical model thinking. However, there are several justifications for a study of autism. It is a condition that developed out of specific historical, sociological, disability and policy contexts. It is a concept and a diagnosis that is still evolving and is not clinically measurable in a biomedical sense. It is largely invisible, unlike most impairments. The growing numbers of people with this diagnosis provide a particular public policy challenge, as people have autism throughout their lives, requiring educational, social, employment, welfare, residential and recreational environments to respond appropriately to each individual. While similar in many ways to a variety of other impairments, there are many aspects of autism that make it a unique policy challenge.

\section{Supports required and the importance of public policy}

The sort of support and services that people with autism and their families need are varied, individually specific, and change over the course of the day, and over the lifetime of the person with autism - which all adds to the cross-agency policy challenge. Examples of services commonly required include respite (for example I have a friend whose autistic daughter only sleeps about three hours a night, and to cope with the day the mother needs someone else to look after the child sometimes so she can get some sleep herself) and behaviour support (such as regulating behaviours from sensory overload which could be manifested as hitting or self-harming and may involve 
medication). Autistic teenagers might need help with social skills to understand the nonautistic world, or a buddy to act as a social interpreter. Support that autistic adults need could be related to living independently such as help with household tasks. Employment support could involve help with transport, or understanding the requirements of the job including the non-verbal communication of workmates, and dealing with anxiety. Educational supports could include adapting the curriculum so it is easier for the autistic child to understand what is required, or changing the school environment so that it is less noisy or more predictable, and recognising that extra processing time may be required for tasks.

Getting the policy approach right in New Zealand nationally and locally is important because, as this thesis will illustrate, appropriate and timely services and supports can make a positive difference to individuals, families and communities. Unfortunately, responsibilities are spread over many government agencies and services delivered by many different providers. The issues are too complex for individuals and families to tackle on a case by case basis, although many try, and challenges include navigating a way through funding, access, information and services (if there are any). This thesis suggests that a way forward to a smoother more appropriate policy environment requires greater involvement of those with lived experience of autism, and the following chapters provide analysis and examples to support this assumption.

\section{New Zealand context}

Two separate incidents, fourteen years apart, illustrate the complex issues that surround social and political responses to autism.

On 14 July 1997, in a provincial New Zealand town, a mother killed her 17-year-old autistic daughter, Casey Albury (Werry, 1998). Suddenly the spotlight was on autism as a policy problem in New Zealand. The mother's trial, and eventual sentence, was a popular media story (NZPA, 2003). Autism was generally considered a rare and unusual condition, and if people had heard about it, it was possibly because of the 1988 Oscar award winning movie Rain man (Internet Movie Database, 1988). As the New Zealand story developed, a picture emerged of fragmented and inadequate services and of a tired and stressed parent unable to cope with the behaviour of her much-loved autistic daughter. 
Figure 1: Casey Albury ${ }^{2}$

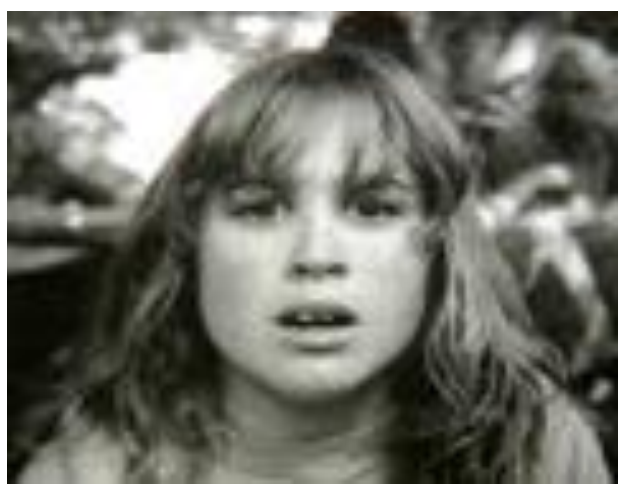

Source: http://www.teara.govt.nz/en/care-and-carers/1/4

New Zealand is not the only country where parents have killed their autistic children, as evidenced by a 2003 study examining the risk factor of autism for children in filicides, which mentions Casey's death (Palermo, 2003). But for autism in New Zealand, the incident was a defining moment as the publicity generated was a catalyst for policy action. It even inspired a British radio play (J. Park, 2000). It was such a significant event that ten years later, David Cohen, a New Zealand journalist and father of a young autistic boy, revisited the story as part of his international autobiographical search to understand autism, and his book included a rare interview with Janine AlburyThompson, who had by then completed her prison term for the manslaughter of her daughter (2007).

The public attention to the killing was matched by political attention to this new policy problem of ASD. The Minister of Health, the Honorable ${ }^{3}$ Bill English called for information and action, and was surprised by how extensive the problems appeared to be (2007). An interdepartmental report into ASD services was produced by the Ministry of Health's David Curry (1998) and an official investigation was undertaken by Professor John Werry (1998), an Auckland child psychiatrist. Early in his report Werry commented on the importance of parental lived expertise:

\footnotetext{
${ }^{2}$ Presenting this photograph of Casey Albury is intended to honour her memory and portray her as a real person, rather than as mere statistic.

${ }^{3}$ Life-long title for an MP who has been a cabinet minister.
} 
If 30 years in medicine and child and adolescent psychiatry has taught me anything, it is that when a parent tells you they think there is something wrong with their child, you had better listen to what they say because they are often right. (1998, p. 4)

At first it was not clear whether the death of Casey Albury was an isolated incident or indicative of a larger problem, but soon feedback from parents and professionals, surveys and research, confirmed extensive problems around supports for people with autism and their families, and many gaps in service provision (Autistic Association of New Zealand, 2001). A decade of work began which resulted in the launch at Parliament on World Autism Day, 2 April 2008, of the ASD guideline, a guideline based on international best practice in the delivery of services for autism (Cunliffe, 2008; Ministries of Health and Education, 2008). The Guideline acknowledges Casey's death as the start of the process of reforming ASD services in New Zealand (Ministries of Health and Education, 2008). This work towards the Guideline took place within a context of considerable political, policy and legislative attention to disability generally, flowing from the rights-based 2001 Disability Strategy (Ministry of Health, 2001), which was intended to be a government-wide guide for policy review and implementation.

However, in 2011 the 'case' of autistic man Arie Smith-Voorkamp ${ }^{4}$ again saw autism in the news for several months. Arie, a 25-year-old with Asperger's, was in the habit of collecting light fittings, with permission, from demolition sites. Soon after the lethal 22 February 2011 earthquake he took light fitting and bulbs from an abandoned building which had been wrecked in the earlier 2010 September earthquake and was awaiting demolition. His partner Michael tried to dissuade him. In the emergency circumstances of greatly increased police and army presence, they were both arrested for allegedly looting, and Arie's badly beaten face appeared in the paper under the heading 'the face of looting', in an article that included unsympathetic remarks from the Minister of Police (Autism New Zealand, 2011; Wade, 2011). What had changed in the years since Casey's death was that autism had become much better known and in the mainstream

\footnotetext{
${ }^{4}$ The case was followed and reported on in a widely read blog Hard News on the Public Address website http://publicaddress.net/hardnews/angry-and-thrilled-about-arie/
} 
media Arie was also frequently portrayed as a person with agency, thoughts and feelings. This time his cause was taken up by the autistic self advocacy community itself which lobbied politicians and the media on his behalf. After a long saga, all charges were dropped against him and his partner Michael in August (Clarkson, 2011).

New Zealand data on autism are minimal, with no information about numbers of people diagnosed, let alone any age, gender or ethnicity breakdown, nor numbers of people such as teacher aides employed to provide support to autistic children.

\section{Prevalence}

The number of people being diagnosed with ASD is rising rapidly, causing speculation about an epidemic (Nadesan, 2005). Werry (1998) reported a prevalence rate of $0.3 \%$ of the New Zealand population. Prevalence studies are now becoming common, although conclusions vary. A report commissioned by the Australian Advisory Board on Autism Spectrum Disorders (McDermott, Williams, Ridley, Glasson, \& Wray, 2007) estimated a prevalence rate of 62.5 per 10,000, or half a million people in Australia living in ASDaffected families, restated by the Australian Government in 2008 as between 4 and 100 per 10,000 (Australian Government Department of Health and Aging, 2008). 'Based on recent overseas data, ASD ... is thought to affect more than 40,000 New Zealanders' states the ASD guideline (2008, p. 17), which is in line with Autism New Zealand's prevalence estimate of 1:100 (Autism New Zealand, 2005). This has been reinforced by a study in South Thames, London, estimating the prevalence of all ASDs at 116 per 10,000 or $1 \%$ of the child population (Baird, Siminoff, Pickles, \& Chandler, 2006). A study of special education reporting in districts across Wisconsin from 2002-2008 showed an overall increase over time with the highest prevalence rate of about 12 in 1000 in some districts (Maenner \& Durkin, 2010). A recent English epidemiological study of adults found the prevalence of ASD in adults is similar to children at about 9.8 per 1000 (Traolach, et al., 2011). The picture is confusing but the general direction is of increasing prevalence.

But there are still questions around the accuracy of data as ASD is not yet something that can be tested for biomedically, and a variety of diagnostic tools are currently in use. As US autism specialists Catherine Lord and Somer Bishop (2010) summarised recently, American prevalence is about 1:110 children (1:70 boys and 1:315 girls) but 
data collection methods are highly variable and sometimes only reflect families who can afford to seek services. Autism theorists until at least the 1960s assumed it was a middle or upper class condition (Autistic Childrens' Association of South Australia Inc, 1967), perhaps because it was only these children who were presenting to clinicians with symptoms. Lord and Bishop (2010) also found that race/ethnicity appears to be a factor indicative of unmet need confirming another wide-ranging review of US data by Mandel and others (2009), which also has implications for Māori in New Zealand (Bevan-Brown, 2004). However, research such as that by Grinker (2007) has indicated that autism is present in most countries and cultures, although support and services may be hard to find. Recently, a high child autism prevalence rate has been found in Somali immigrant families living in Minnesota (McNeil, 2009, 2011). A review of prevalence studies from several countries by researchers from Macao (Zaroff \& Uhm, 2011) found reported rates from 1 to 157 per 10,000, and they conclude that the 'greatest influence is due to methodological variables'.

In California, Schecter and Grether (2008) looked at prevalence in association with another topical ASD issue, the theory that thimerosal in vaccines causes autism, in their study of a cohort attending California's Department of Developmental Services 1995 2007. They showed that removing thimerosal from vaccines from 1999 did not lead to a decrease in autism.

Whatever the prevalence, some studies have looked at the increasing incidence of autism and the policy implications, for example Baker's (2004) US study on educational services following de-institutionalisation of disabled people into the community. Lord and Bishops' (2010) recommendations (which echo the purpose of the Guideline) include the integration of autism healthcare and education research and policy to address disparities, equity of access and promote interventions based on best practice

There are several reasons why accurate New Zealand prevalence data are rare. First, special education support for children in the compulsory education sector is provided on assessed need, not on a diagnostic label, so the Ministry of Education is not collecting ASD diagnoses as such, only details of children's special learning needs. Second, clinicians are using a variety of diagnostic tools when assessing a child who has been 
referred to them and one may decide on a diagnosis of ASD while another gives a less specific, or different label. Third, data for those seeking services for ASD are not collected in any systematic way. Most Ministry of Health-funded disability services require a diagnosis of one of only three categories: physical, intellectual or sensory (vision or hearing) impairment (Gibson, 2010). There is no legislative or auditing requirement on agencies such as schools or primary health providers to collect data on ASD. Fourth, the national census has only in recent years started asking about disability, and specific questions about autism were asked for the first time in the 2006 census of a small sub-sample of those who had already identified as disabled in the main census (Statistics New Zealand, 2007). Autism and Asperger's are categorised as 'other', but depending on how the informant answered, could also be included in the statistics for those with intellectual disability, psychological disability, speaking disability or those requiring special education. Autism does not fit neatly into the generally used disability categories of physical, sensory, intellectual, neurological or mental health. The March 2011 New Zealand census would have used categories of function utilising the World Health Organisation's International Classification of Functioning, Disability and Health with 'difficulty of learning or understanding' possibly the most appropriate category for people with ASD (Statistics New Zealand, 2009), although whether people would have been happy to self-report remains untested. Unfortunately, this census was cancelled due to the February 2011 Christchurch earthquake which led to the dislocation of many people, and caused damage to the census processing centre.

For this thesis a prevalence rate in New Zealand of about 1:100 is accepted (although some may remained undiagnosed) or about 40,000 people. However, although there is disagreement over rates, there is a general consensus that diagnoses internationally are growing (Grinker, 2007; Nadesan, 2005).

\section{International policy context - the 'problem' of autism}

There has been considerable attention to ASD in the international literature in the past decade. Most of the literature addresses causes and treatments (which is not the focus of my research), but only a few studies consider policy issues. Almost all the literature frames autism as problematic and negative. For example, the 'problem of autism' such as direct costs or lost income has been exemplified by attempts to assess the economic 
impact of autism. Ganz (2007) estimated the lifetime cost of a US autistic child born in 2000 as \$US3.2 million or \$35 billion for their birth cohort, with most cost occurring in adulthood. This built on earlier British work by Jarbrink and Knapp (2001) which estimated the lifetime cost for a person with autism as over $£ 2.4$ million pounds and estimated ASD prevalence in the population at 5 in 10,000. Family costs were only a small proportion of the total expenditure which would mainly go on daily support and activities. Jarbrink, Fombonne and Knapp (2003) developed a pilot study using a research instrument which they tested on the families of seventeen autistic children and found that parents faced significant extra economic and social costs for their autistic children, arising from lost employment, and costs of therapies and medications. A Spanish study (Sanchez-Valle, et al., 2008) examined ASD in the context of DALYs (Disability Adjusted Life Years) and found such an approach could be useful as a health policy tool, including its ability to measure the effect of various interventions.

In their 2000 US study, Feinberg and Vacca (2000) delved into the policy implications of autism acknowledging increased prevalence, little consensus on aetiology or interventions, complex educational issues and the shift to family-centred services, as relevant issues. A study in Queensland, Australia, observed major issues for families of a person with autism over a ten year period (Gray, 2002).

\section{Policy strategies}

Many countries are producing autism strategies but so far without the coverage of the NZ ASD guideline. A 2003 review in Ontario, Canada, provided an evidence-based report on interventions for children and adolescents (Perry \& Condillac, 2003). England consulted on an adult strategy after community advocacy indicated substantial mental health issues in autistic adults (National Autistic Society, 2009). The Australian federal government in 2006 commissioned a review of research to find the best early intervention model (Roberts \& Prior, 2006), ahead of substantial increased government funding to the sector. State and federal governments are now working on autism plans (Victoria Australia Department of Human Services, 2009). The US's federal government advisory panel, the Interagency Autism Coordinating Committee (IACC), regularly updates its strategic plan for autism research, following the passage of the 2006 Combating Autism Act (US Congress, 2006; US Department of Health \& Human Services, 2009, 2010b). Prevention and interventions feature strongly, although a 
consumer focus is mentioned as it 'is important to consider the impact of research on the human rights, dignity, and quality of life of people with ASD from prenatal development forward' and '[s]trategies are needed to gain and use the first-hand experience of people with ASD, their families and caregivers' (US Department of Health \& Human Services, 2009). In January 2011 the IACC reviewed and approved the latest update of their strategic plan for ASD research, in a meeting that was open to the public in person and by video link (US Department of Health \& Human Services, 2011). The Scottish Parliament, in January 2011, voted down a bill that would have seen the development and enforcement of a Scottish autism strategy (Anonymous, 2011). This bill also tackled the problem that other strategies have not addressed, of enforcement, in this case by requiring legal compliance.

In the term of Obama's US presidency, some important appointments have been made. In 2010, Ari Ne'eman, the coordinator of the Autistic Self Advocacy Network, was appointed to the government's National Council on Disability (Baker, 2011; Silberman, 2010) as one of several disability advocates. Ari Ne'eman and Stephen Shore, who both have autism, are also members of the IACC (US Department of Health \& Human Services, 2010a).

\section{Consumer participation}

Despite these recent appointments, there are very few research reports from the consumer perspective of disability participation in policy. Silverman and Brosco (2007) researched the historical partnerships between families and clinicians in autism advocacy and awareness. Frawley (2007; Frawley \& Bigby, 2011) studied the input of people with intellectual impairment (which possibly included people with autism) on Australian boards and panels. Some research has looked at autistic lives and touched on policy implications such as English research which explored the life-stories of 25 young adults with Asperger's and their parents (Portway \& Johnson, 2005).

\section{Construction of the problem of autism}

Autism has been constructed in many ways over the decades since its initial 1940s naming, including being blamed on parents, particularly mothers (Bettelheim, 1967; Severson, Aune, \& Jodlowski, 2008) or considered a condition that only affected the middle classes (Autistic Childrens' Association of South Australia Inc, 1967). 
The 1988 movie Rain man starring Dustin Hoffman as autistic man, Raymond Babbit, and Tom Cruise, has been influential in creating an idea of autism in the public mind. Dustin Hoffman's character was partly based on autistic savant Kim Peek, who died in December 2009 (Peek, 1996; Weber, 2009), and has led to the idea that people with autism also have savant abilities or exceptional brilliance in areas such as maths, music or art. Savantism is very rare in the general population but estimates are that up to $30 \%$ of the autistic population could have it, depending on definitions used, and that $50 \%$ of savants are autistic (Biever, 2009). A novel by British author, Mark Haddon, The curious incident of the dog in the night-time (2003), has been internationally popular with its main character an autistic teenager with special mathematical abilities. However, the autistic spectrum is diverse and these are just two possible representations of autistic people. There are an increasing number of fictional portrayals, which will be considered further in Chapter Four.

Some academics have considered autism as a problem that has been constructed to aid large pharmaceutical or genetic research companies. Autism parent and academic, Majia Holder Nadesan $(2005,2008 \mathrm{a}, 2008 \mathrm{c})$ is a proponent of the Foucauldian analysis of autism in the context of biopolitics and bioeconomics. Michel Foucault argued that the most effective way to keep society in check was to get its members to do survelliance on each other (Foucault, 1980; Tremain, 2005). Nadesan claims modern parents are encouraged to become experts on 'normal' child development and seek treatment when their children appear to 'deviate' from some prescribed norm. Substantial resourcing goes into finding causes and treatments for these 'defective' children. She talks of the ascendancy of 'brain science' in autism which has:

increased parental surveillance of infant development, particularly in middle-class families... Parents, enjoined to be responsible for engineering their child's intellectual and emotional development, become increasingly sensitive to any "delays" in their children's cognitive and social development. (Nadesan, 2005, p. 111) 
This analysis echoes the influences of past policy approaches based on ideas of eugenics whereby people with what were considered genetic 'defects' faced discrimination, as they threatened 'racial fitness' (alluding to an assumption of 'purity' of a particular ethnic group such as Caucasians of European descent). Institutionalisation of people with impairments including autism can be traced to these attitudes (Evans, 2004; Kerr \& Shakespeare, 2002).

Another construction of autism is provided by the many parents and professionals who ignore or actively dismiss scientific evidence and best practice in favour of interventions without that evidence base. The measles, mumps and rubella (MMR) vaccination debate is a significant example, and even though the original study was proved fraudulent and inaccurate (Deer, 2011a, 2011b, 2011c; General Medical Council, 2010), this evidence has been ignored by some parents around the world who continue to link immunisations with autism and comment on websites such as www.ageofautism.com (Offit, 2008). Some parents continue to seek interventions and government support to 'recover' or 'cure' their child. A number of these interventions - such as chelation, testosterone or hyperbaric oxygen therapy - are not only scientifically disproven but could be considered dangerous and abusive (Green, et al., 2006; Osteen, 2008; Shute, 2010; US Food and Drug Administration, 2010). Many of these parents belong to organisations which are powerful, well-resourced and politically influential. Such lobbying leads to two problems from a policy perspective: parents demanding interventions which are not scientifically proven, or policy and funding attention going to genetic and clinical research for cure rather than support for autistic people.

An alternative attitude which incorporates a more positive example of social construction is a wellness model. This has been pioneered in New Zealand through the work of Māori academics such as Mason Durie (1998) and his te whare tapa whā model of a house held together by four complementary walls of physical, psychological, spiritual and family health. Such ideas have been developed by those working in mental health who have added terms such as tangata whaiora (people with lived experience of mental illness) (Boulton, 2005), and underpin the current Whānau Ora approach to policy development (Ministry of Health, 2008; Taskforce on Whānau-Centred 
Initiatives, 2010). In later chapters, this thesis looks at the possibilities of utilising such approaches for autism.

\section{Diverse autistic population}

Another policy aspect to be considered arises from the earlier discussion on definitions, in this case autism versus autism spectrum disorder (ASD). ASD is a clinical diagnosis through the DSM IV while autism is a more encompassing and larger concept. The committee reviewing my research ethics application asked me to replace autism with ASD. There is a problem with this. Many adults in the autism community, who have a diagnosis on the spectrum, identify as part of a cultural minority (Boundy, 2008; S. M. Robertson, 2010; S. M. Robertson \& Ne'eman, 2008). They do not see themselves as having a disorder or deficit and they do not identify with the term ASD; New Zealander Jen Birch (2003) is one who has adapted this term into autism spectrum difference. As mentioned above, some have formed themselves into a global on-line autism self advocacy network (Silberman, 2010). So, although, there are some common autistic characteristics, there is great diversity in the presentation of autism, and the language to describe the condition is itself contested. Those working in autism policy have to incorporate this diversity. This thesis mainly uses the terms ASD, autism and autistic.

New Zealand is just one of many countries grappling with how to respond to the growing numbers of autism diagnoses, and some of the challenges are outlined above. The main implications of these challenges for this thesis can be summarised as lack of understanding or knowledge about ASD, non-existent, inappropriate or inequitable services and other supports, or a variety of other barriers to the participation of autistic people in the community. In trying to make sense of this situation this thesis asserts that there are four main concepts central to the matters considered in the thesis and they are reflected in the title: love and luck; right relationships; and lived experience. Although largely unmeasurable in intangible, good outcomes depend on them. 


\section{Love and luck required for good outcomes}

For this thesis these terms have specific autism-related meanings, and include having a loving family to support and advocate for the autistic family member ${ }^{5}$, the luck in having such a family, as well as finding the appropriate supports and supportive people at the right time. Love and luck frequently go together in these circumstances which is why I consider them together. Reports from people with autism and family members in published accounts, websites, or media interviews frequently mention the importance of love and luck in accessing timely and appropriate services and supports. The importance of loving support is reflected in an anonymous comment which leads the section on 'Support for Individuals, Families and Carers' in the ASD guideline:

Many adults with autism believe that positive family involvement and support help individuals with autism develop the skills necessary to be as successful as possible as adults. I think it was the work of many people who loved me that got me where I am now. (Ministries of Health and Education, 2008, p. 61)

Among the submissions on the draft Guideline was one submitted by advocacy group and service provider CCS (formerly the Crippled Children's Society and now CCS DisabilityAction) written by Matt Frost, in his capacity as Policy and Information Researcher at their National Office:

the life chances of people shouldn't come down to 'luck'...If they have a satisfactory multidisciplinary assessment, they may be 'lucky' and get services. This Guideline does not tell me how this 'luck' factor will be reduced.... (CCS, 2007)

Later that year Frost (2007a) gave a presentation to the New Zealand Historical Association conference on his autistic autobiography emphasising his luck to have had

\footnotetext{
${ }^{5}$ Occasionally, well intentioned and loving family members may also inadvertently harm autistic family members such as through the administration of certain 'therapies'.
} 
the love of a supportive family. Along with love and luck, which for the purposes of this thesis may be considered together, the other central concepts are right relationships and lived experience which also have autism-specific meanings.

\section{Right relationships and lived experience}

\section{Right relationships}

The concept of right relationship(s) which seeks to build relationships on a basis of ethics, respect and equity, is originally a Buddhist term adopted by some working in disability studies or human services (Kendrick, 2000, 2008b, 2009). They use the term to critique the history of disabled people as defective beings who were institutionalised for who they were, not what they had done; objects of pity and care; or cases to be managed by service providers. Critical disability studies is a growing discipline which has developed from disability and other human rights causes and emphasises issues around power, human rights, language and ethics. These attitudes are reflected by several contributors to the 2005 New Zealand edited book Allies in emancipation; moving from providing service to being of support (O'Brien \& Sullivan, 2005).

Researchers, policy advisors or service providers who do not respect right relationships use the lives of disabled people for their own professional gain without giving anything back, and have been labelled 'parasite people' or 'tarmac professors' by disability activists and academics such as Paul Hunt (1981) and Michael Oliver (2002). Seeking right relationships between disabled people and others was a central theme of the Trusting Partnerships conference in Rotorua in November 2008 which featured a keynote address on "The principle of "right relationship" as a guide to ethical partnering' (Kendrick, 2008b). Building right relationships with the autism sector, especially those with autism, involves respecting historical abuses such as institutionalisation, and includes aspects of citizenship, Treaty of Waitangi principles, ${ }^{6}$ whanaungatanga (establishing relationships), and Disability Strategy principles (Ministry of Health, 2001). It is the attitudinal, self-reflective, power sharing work you

\footnotetext{
${ }^{6}$ The Treaty of Waitangi is New Zealand's founding constitutional document signed in 1840 between the indigenous Māori and agents of the British Crown. Its three principles are usually expressed as partnership, participation and protection.
} 
have to do to before you get to trust and the other aspects of relationships, and it can be highly symbolic.

\section{Lived experience}

The expertise of disabled people and their families has not historically been respected in policy development (Beatson, 2004; Institute of Policy Studies, 2008; Thompson, 2007). For this thesis, the most important experts in autism are those who live with the condition, as they are the experts on their own lives. Although there is a diversity of lived experience by autistic people, there are broadly agreed themes about identity and rights which are reflected in autism advocacy websites such as ASAN's www.autisticadvocacy.org and www.neurodiversityinternational.org.uk. However, in the broadest sense, autism experts also include a variety of other groups, such as parents and carers, professionals, community organisations and advocacy groups, public servants and academics, and even the politicians who need to have expertise about what to prioritise and fund. Collaboration based on right relationships could see all these expertises gathered together and shared. However, the reality is that power remains hierarchical with the politicians at the top and people with autism at the bottom. These ideas and their implications for policy are central to my thesis and explored in later chapters.

\section{My personal standpoint}

My interest in autism has developed from parenting my autistic son who is now an adult, and who once featured in a newspaper article about his work (Managh, 2005). He has given me permission to discuss aspects of his life. He did not get a diagnosis of autism until he was twelve. Before then his special educational needs had been generally well met by his Wellington primary school which had an inclusive attitude and particular expertise in speech language therapy. From my conversations with other parents I realised that we were lucky and that good educational supports for autistic children were scarce and fragile. I became involved in the local branch of Autism New Zealand and spent six years on its national board. I had a small role in the development of the ASD guideline as a temporary member of its Guideline Steering Group. I am a board member of the New Zealand Guidelines Group which won the initial contract for the implementation of the Guideline. 
So although I do not have lived experience of autism my expertise is gained from parenting and advocacy, and that is the position I write from. I do not see autism per se as a problem. I acknowledge that autism can be associated with considerable strengths and abilities, often untapped, although the autistic population is as diverse as any other group of humans. It is when the appropriate supports and services are not in place when required that problems arise.

\section{Complex policy problem}

Autism research tends to concentrate on the problem individual with autism rather than on how the citizenship rights of people with autism can be improved via the social and economic policy environment. Little peer-reviewed research incorporating the perspectives and expertise of those with lived experience of autism, or suggesting how relationships between autistic people and policy makers could be improved to incorporate their lived experience, is available. If we had the opportunity to hear the voices of those with autism we may hear about positive aspects of autism and the benefits people with autism can bring, not only to the policy process but also to wider society.

Anecdotal evidence from advocacy groups and families of people with ASD, backed by the literature (Ministries of Health and Education, 2008), indicate that timely and appropriate support services can make a positive difference to the ability of people with ASD to participate in education, employment and recreation, as well as make everyday life choices in the community. If support is not provided when needed, then people with ASD risk social exclusion and serious adverse outcomes, as indicated by Casey Albury's death (Werry, 1998). But currently access to appropriate services and supports is largely dependent on the autistic person having a loving, supportive family/whānau to advocate for them, and luck that there are indeed appropriate and accessible services and supports available in their region. Thus, fourteen years after Casey's death, it is apparent from the frequent media reports, parental surveys, and the numbers of people contacting Autism NZ and other disability support agencies, that the system is not working equitably and appropriately for people with ASD. Indicators include the case of a Nelson teenage autistic girl in early 2009 who was locked in a police cell as there was 
no other respite facility for her after her mother could no longer cope with her autismrelated behaviour (NZPA, 2009), and a 2008 survey which found significant levels of unmet need for autism services and support in Hawkes Bay (Woodcock \& Robertshaw, 2008).

As indicated above there are significant policy problems around ASD, but little examination as to why these problems arise. Unfortunately, texts on New Zealand's social policy, such as Duncan (2004) and even those on diversity such as Boston, Callister and Wolf (2006), do not go into detail on disability issues, let alone autism. The evidence-based $A S D$ guideline with its almost 300 recommendations is one attempt to address the complexity of autism support and service delivery issues (Ministries of Health and Education, 2008). But Chapter Nine reveals that progress on implementation is slow.

Dana Lee Baker is a US-based academic who theorises autism as a complex policy problem (Baker, 2006a, 2011). She writes about the significance of neurodiversity/neurotypical perspectives, and has also adapted some significant policy ideas of John Kingdon (1995), such as his concept of 'policy entrepreneurs', (Baker, 2011; Baker \& Steuernagel, 2009) into the autism context. Figure 9 in that chapter indicates the tangled web of New Zealand disability policy responsibilities.

\section{Research design}

\section{Methodology and methods}

The 'transformative paradigm' as developed by Donna Mertens (2009) provides the framework both for this research and for how to address the problems of ASD policy. The transformative paradigm allows for a social justice approach through a disability rights perspective. It encourages the inclusion of those most affected by the issues and values their lived expertise. Chapter Two relates the paradigm to concepts such as participatory and emancipatory research, as well as to the social model of disability. The transformative paradigm also provides a useful lens to evaluate the 'wicked' policy challenge of autism in Chapter Seven, and the ASD guideline as a case study of autism policy in Chapter Nine. 
The transformative paradigm provides an umbrella underneath which the research design and methodology can be built. It 'reframes the researcher's world view in terms of establishing the focus of the research, development of research questions, and decisions about data collection, analysis, interpretation, and use' (Mertens, Bledsloe, Sullivan, \& Wilson, 2010, p. 199) and 'methodological decisions are made with a conscious awareness of contextual and historical factors' (Mertens, 2009, p. 59). It is particularly suitable for marginalised minorities such as autistic people as it combines research and evaluation, social justice, the input of the people who have most to benefit from good outcomes, and a desire to make a positive difference. This paradigm is examined in Chapter Two.

The historical, political and policy context of autism is examined through the methodology of critical theory such as that developed by disability rights activists and utilises and incorporates material that is by and of the autistic community. This helps to develop a model of policy process that can be used in the New Zealand policy context. I have two research advisors who identify as autistic.

In understanding the current policy problem of autism and the road which has led to the $A S D$ guideline there are three main threads to consider:

- The history of the idea of autism as a separate diagnosable condition within the bigger context of the history of disability and the idea of disabled people as defective, marginalised and institutionalised as being particularly relevant for those with autism.

- The development of disability rights activism since the late 1960 s which challenged these assumptions and which has since grown in numbers and influence. The autism self advocacy movement which claims autism as a cultural identity has developed from this context aided by the rise of global internet use. This movement has challenged the idea that expertise resides in the clinicians or that autistic and other disabled people are defective or require fixing. Instead, they have insisted that the expertise for their lives resides with them. Therefore partnerships with autistic people (and their friends and supporters) are required for successful policy development. 
- The current New Zealand policy framework which, since the 2001 Disability Strategy has been based on the social model of disability, whereby people have impairments but it is society which causes disability (Ministry of Health, 2001).

In developing an appropriate research design, Creswell's (2003) guidance has been helpful, as have various chapters on research and ethics in both Denzin and Lincoln's Handbook of Qualitative Research (Denzin \& Lincoln, 2005) and the Handbook of Social Research Ethics which includes chapters specifically on disability research (Ginsberg \& Mertens, 2008).

\section{Grey literature}

The transformative paradigm requires qualitative research although it can incorporate mixed methods, and my methods have included interviews and textual analysis. It allows for and encourages the use of grey literature which suits my purposes for this research. This thesis utilises some of the usual academic literature to explore the topic, but the lived experience perspective of people with autism is rarely captured in such sources. Neither are the minutiae of the workings of government agencies. So, in order to access material by, from and about people in the sector, I have utilised the grey literature sources outside the academy such as blogs, auto/biographies, social media, newspaper and magazine articles, government reports, submissions and meeting minutes. Additionally, the media provides valuable resources, in stories and press releases, to examine the construction of concepts of autism. This has entailed a significant amount of original research and detective work to tease out relevant material which provides insight into the personal, family and policy experiences of autism. The US National Library of Medicine (2006) studied the use of grey literature and found it was the preferred source for groups such as policymakers as it was often more up to date and accessible than academic literature.

\section{Expertise}

In choosing sources I have also interrogated the concept of expertise. The expertise I draw on comes from a variety of perspectives: clinical and academic experts on autistic disorder as well as academic experts on the construction of autism; experts on the lived experience of autism from the perspective of being a person with autism or a family member; experts on policy and politics, including disability policy in general and autism 
policy in particular. My experts provide a variety of texts for analysis for themes which have public policy implications. These themes include stories of lived experience and families, relationships and power, citizenship, inclusion and exclusion, and specific areas of autism services such as education, health and employment. According to Ryan and Barnard (2003), such thematic analysis uses careful reading of data sources to interpret the words of the informants in a disciplined way.

There is also literature relating to the international and New Zealand disability sector, and an international body of academic work on critical disability studies, and on research ethics. It is also important to look for gaps in information. For example, although reducing disparities between Māori and Pacific populations and pakeha are government priorities there is little information on the Māori or Pasifika experience of autism (Bevan-Brown, 2004). Indigenous people and autism seems to be an internationally neglected area of research.

\section{Framework for tackling research questions, and chapter outlines}

To answer my main research question 'how can right relationships and lived experience be better incorporated into New Zealand autism policy?' the research is grouped into four sections.

The first section of three chapters provides the standard research framework: introduction, methodology and reviews sources of expertise. This first chapter has introduced the topic, my research questions and theoretical and personal approaches. Some contrasting definitions of autism are provided, as are the social and medical models of disability. The concepts that will be explored further in the following chapters are introduced and their significance for autism policy explained: love and luck, right relationships, and lived experience. The topics of wicked policy, and the ASD guideline which provides a case study, are introduced.

The second chapter establishes my methodological framework through considerations of the emancipatory approaches developed by British disability activists, and the wider transformative paradigm developed by Donna Mertens. The latter incorporates 
understandings from theoretical approaches, including emancipatory, which have attempted to bring marginalised communities into the mainstream. The transformative paradigm is based on values, ethics and social justice and ideas such as the links between the personal and the political. Using its lens provides insight into the nature of experts and evidence around ASD, and challenges some assumptions around expertise. What disability researchers can learn from those who have been using Māori worldviews is also considered. The chapter describes my research methods and analysis; what worked and why.

Chapter Three explains my interpretations of the concepts of experts and expertise and why this thesis emphasises grey literature as the main source for autistic voices. Although many of my sources are mainstream autism clinicians, such as Tony Attwood, others are autistic autobiographers and bloggers. It also looks at the current political debates between self-advocates - those who claim autistic identity - and those who seek interventions and cures.

The second section of three chapters provides the contextual background and concept analysis for this thesis, and gives a re-presentation of autism suitable for this investigation. It is impossible to understand the present without knowing where we have come from so Chapter Four looks at the history of autism as a diagnosis and the cultural creation of the idea of autism. It brings in the 1940s clinical originators of the condition - Kanner and Asperger - and places them in their historical contexts. It considers issues of cultural representation, language and identity, and finally autism history and policy issues in New Zealand, including the role of Autism New Zealand.

Chapter Five places autism into a disability policy context and as a beneficiary of the disability rights movement, internationally and in New Zealand, for without this activism, autistic people could still be institutionalised and denied education, employment and independent living. Disability rights activism also challenged the medical model of disability as individual defect and replaced it with the social model of disability. 
Chapter Six specifically addresses the research question "what do the concepts of love and luck, right relationships and lived experience mean in the context of the autism policy process?' and examines how the latter two concepts could help move us past the current situation which appears heavily dependent for good outcomes on the former two. Voices of those with lived experience provide context and examples of good and poor practices.

The third section concentrates on autism as a policy problem. Chapter Seven directly addresses the research question 'why is autism policy a wicked problem?' and provides a framework for assessing ASD policy development in New Zealand and the current policy context. It examines the concept of 'wicked' problems and whether this approach is relevant and useful in analysing autism policy. It considers what might be learnt from those advocating policy approaches recognising Treaty of Waitangi issues, such as Mason Durie (1998) and the Whānau Ora tool for Māori-led policy development, implementation and evaluation. It looks at processes in New Zealand that are not working well for people with autism, such as the Needs Assessment and Service Coordination system.

Because issues around education loom large for parents and people with autism, as all autistic children are required to attend school, Chapter Eight considers the vital topic of education. The 1989 Education Act and the 1996 policy of Special Education 2000 are explained and contextualised. Comments from autistic students are provided, and some educational innovations noted.

Chapter Nine addresses the research question 'to what extent does the NZ ASD guideline meet the criteria of incorporating right relationships and lived experience and what can we learn from its development and implementation?' It is the longest and most detailed chapter as it describes and attempts to evaluate the history, development and implementation so far of the ASD guideline. The Guideline provides a convenient case study for autism policy: what has worked, what has been problematic, and what gaps remain. There has also been an extensive amount of policy, research and service development work preceding its 2008 publication which has not been well publicised. This chapter draws on interviews with several key informants, and asks what can be 
learned from this process to improve policy. It also considers whether the Guideline project illuminates the thesis questions of wicked policy and lived experience.

The final section and chapter summarises the arguments behind the thesis research question 'how might policy ensure that people with autism and their families move beyond the uncertainty of love and luck to reliable and appropriate supports which give individuals and families more choice and control over their lives? It considers answers provided throughout the thesis to the main research question 'how can right relationships and lived experience be better incorporated into New Zealand autism policy? Chapter Ten brings all the historical, contextual and policy threads together in considering how we could move beyond the inequitable system of requiring love and luck for good autism services and supports. It outlines a research model that I have developed during the course of this research which provides a conceptual model of the changes required, a diagram of how the policy process could be improved and a vision for the future. The research questions posed in Chapter One are considered and answered, gaps and recommendations for further research are identified, and the contribution to knowledge that this thesis has provided is assessed. 


\section{Chapter Two: Methodology and methods}

\section{Developing methodology}

\section{The road to disability studies}

The previous chapter outlined the framework of this dissertation and the context and arguments for my thesis including my research questions. This chapter describes the methodology for undertaking this research. It examines the choice of appropriate methods, the suitability of Mertens' (2009) transformative paradigm to frame the structure and methods, and the development of theories and research methodologies in the discipline of disability studies relevant to this study of autism.

It took a long time to decide on an appropriate methodology for this research. It has become a personal hybrid shaped by the academic disciplines I have studied over several decades, combined with recent reading and other influences. My academic disciplines, history (particularly New Zealand history), and women's studies, formed the basis of my methodology, followed by more recent work in fields such as health services research and policy studies, plus my lived experience in the community and voluntary sector as an autism parent and advocate. Participatory research was the initial intention. However, involvement in the disability sector led me further on to emancipatory research, which was developed by disability studies activists, and to the transformative paradigm which took some of those ideas further. Disability activists in the United Kingdom developed the social model of disability which was named as such by disabled academic Michael Oliver (1990) about 30 years ago. He has recently reminded us (2009) that the social model is a tool for achieving social justice for disabled people, not just a theory. My approach incorporates the policy assumptions behind the women's rights slogan, 'the personal is political', and 'nothing about us without us' (Charlton, 1998) from disability rights.

My research privileges lived experience. For my purposes, lived experience is mainly revealed through texts, so learning about textual interpretive theories such as hermeneutics, phenomenology, and discourse analysis (Corker \& French, 1999) has been useful. The mixed research methods I intended to use included textual analysis, 
interviews, a quantitative questionnaire of all the participants in one project, and a snowball survey using social networking media. However, although I received ethical approval for the last two, various problems saw them abandoned, which I discuss later in this chapter.

Research and evaluation expert Donna Mertens (2009) from Gallaudet University, recently developed the transformative paradigm from earlier work including that by Guba and Lincoln (1994). It suits my approach as it allows for and encourages a multiplicity of research and evaluation methods, underpinned by the principle of social justice, and includes participatory and emancipatory approaches. But I have not been as participatory, emancipatory or transformative as I intended. Emancipatory research would see those who are the subjects of the research - in my case autistic people become the researchers who set the questions and run the research process (with my assistance) and to be transformative the research outcome would be improved lives for autistic people. My consultation with autistic people (and their families) has instead mainly been informal, although some also became my key informant interviewees. My two autistic advisors have offered commentary and feedback but the questions were mine, not theirs. Autism research cannot be judged transformative until the research translates into ongoing and reviewable improvements to practice benefiting autistic people, and this has not yet happened, and may not happen at all. However, Chapter Ten has a vision of how things could be.

To understand motivation and standpoint when attempting transformative research requires personal reflection and disclosure. Influences on my youth included the Vietnam War and second-wave feminism. My first discipline was history and as a consequence of the 1960s global upheavals the 'great white man theory of history' was challenged by historians who wanted acknowledgement of the contribution of women, indigenous people, workers and ordinary people. Māori and feminist activists led this debate in New Zealand. In the UK, 'people's history' or 'history from below' - how the history of ordinary people could be built up by fragments - was also being advocated by English historians such as Raphael Samuel (1994) and his leftwing History Workshop, and feminist academics such as Liz Stanley (1992) who theorised auto/biography as a multi-faceted kaleidoscope. 
Returning to university as an older student in the 1990s, I learned about New Zealand's eugenic policy past which was supported by powerful people across the political spectrum from liberal women to conservative men, united by a fear that 'deviance' or 'defect' (otherness) was degrading the quality of the 'race' (Stace, 1998a). I was shocked to learn that its most well-known policy expression - the Nazi holocaust - also resulted in the deaths of hundreds of thousands of disabled people (Evans, 2004; Kerr \& Shakespeare, 2002; Sullivan, 2007). As a consequence of personal experience parenting a child who was different, later diagnosed with autism, and working in a university environment, I stumbled across disability studies. It provided a counter-critique for dehumanising attitudes to otherness, ideas which continue to surface in subtle ways through genetic engineering technologies, and politicians who question the right of certain groups to 'breed' (Stace, 1998a; Sullivan, 2007).

Feminist methodology challenged the objectivity and neutrality of positivist research theory and instead assumed it was valid and ethical for the researcher to admit and reflect on their role in the research process. Feminist disciplinary approaches found common ground with citizenship theorists such as Ruth Lister (1997) considering the role of women, including disabled women in her work, and disability activist Carol Thomas (1999) critiquing the role of feminism in disability studies. Disability is not a new label as US historian Catherine Kudlick suggests:

More than another "Other" to add to a growing list of oppressed groups..., disability lies at the root of gender and race inequities... People against women's suffrage often cited women's physical and mental incapacities. (Kudlick, 2006, p. 163)

I found in disability studies a rich and diverse academic discipline, borne out of lived experience of discrimination. Those fighting against able-ism had much the same concerns as those fighting sexism, racism or homophobia. The personal was indeed political. There seemed to be two main pathways to modern disability studies. The most influential one in New Zealand was heavily influenced by British sociologists and materialists (themselves disabled) who wanted to challenge the power and oppression of the able-ist world and so created the social model of disability whereby disability is 
caused by society and does not reside in the individual person. Meanwhile US disability activists had tapped into their historical tradition of individual rights. Their major success was the 1990 Americans with Disabilities Act, which ensured individual access to activities non-disabled Americans enjoyed.

New Zealand and Australian disability rights academics and activists have been developing local interpretations since the early 1980s when the first disabled people-led organisation was founded and a telethon marked the United Nation's 1981 disability awareness year (Ballard, 1994; Beatson, 2004; Goggin \& Newell, 2005; Meekosha \& Shuttleworth, 2009; Sullivan, 2008). New Zealand's first post graduate disability studies course, Disability Studies, was offered at Massey University in 1993. It differed markedly from rehabilitation studies - which focuses on strategies of recovery from individual impairment - insofar as disability studies focuses on the negative social response to impairment and characterises disability as social oppression. In 2001 another disability focused paper was offered and the programme upgraded to a Post Graduate Diploma in Arts (Disability Studies). In 2009 the endorsement in Disability Studies was removed when Massey undertook a review of all its degree programmes. The disability papers are now offered as part of the PGDipArts and options in the MA (Social Policy) and Master of Social Work programmes; Massey remains the only university in NZ offering papers in disability studies (taught, incidentally, by a disabled person) at postgraduate level.

As in any healthy discipline, internal debates also rage in disability studies. Debates concern issues such as whether groups such as women, indigenous people or those with more severe impairments are marginalised by the more able white men with status who dominate the discourse, and what terminology is most appropriate to describe disabled people's lives. Definitions are contested. Discussions over the use of 'people with a disability', 'people with disability', 'persons with disabilities' or 'disabled people' (which is the locally preferred term used in the sense of being disabled by society) (Sullivan, 2000) are ongoing including on internet discussion sites. Many Deaf people see themselves as a distinct culture not a disability group (Lane, Hoffmeister, \& Bahan, 1996), hence the capital $D$, as do many autistics who define themselves against a neurotypical society (Boundy, 2008; S. M. Robertson, 2010; S. M. Robertson \& 
Ne'eman, 2008). There is much diversity and flexibility within disability studies, and although numbers of disability studies practitioners are small, the networks are global and extensive.

So, all these paths have influenced my choice of methodology and my methods. The dominant discipline of this thesis is disability studies in a university government policy school with supervisors from health services and gender and women's studies, and with disabled people from outside the university as advisors. For this autism policy research I have incorporated approaches from across disciplines (for example, the first person perspective of women's studies) that seek social justice-based policy change for an oppressed, marginalised but diverse group which also has untapped expertise to help itself, and which encourages the researcher to be an active participant in the research. Mertens' transformative paradigm (2009) is a helpful umbrella approach for such crossdisciplinary research.

\section{The Transformative Paradigm}

The transformative paradigm as developed by Donna Mertens (2009; Mertens, et al., 2010) seeks to make a difference to people by involving them and their communities in research processes that are ethical and respectful of their lived expertise. A paradigm is more than a research theory. In a chapter by Mertens and others on utilising mixed methods for transformative purposes in a recent book on mixed methods, qualitative research theorist Yvonna Lincoln describes a paradigm as:

a metaphysics, an integrated philosophical statement which encompasses positions on ontology (what we believe the nature of reality to be), epistemology (what we believe can be known about that reality, how the reality "works", and the best ways for coming-to-know), axiology (the roles of values, aesthetics within any inquiry), and teleology (what we believe the ends of inquiries might provide to us by way of knowledge, and what forms the ends might take). Paradigms are overarching cosmological statements to which we subscribe when we engage in research, although there might be other paradigms which we employ or deploy in other realms of our lives, such as faith (a theological paradigm), the law (a judicial paradigm), or 
simple social description (a demographic paradigm, for instance). (Mertens, et al., 2010, pp. 194-195)

Lincoln asserts that theories 'are nested within and under paradigms', and 'are related, as "parent" and "child"; that is, paradigms and theories belong in ontological and epistemological and axiological "families"” (2010, p. 195).

The transformative paradigm aligns with my research approach and values. For example, it has a basis of social justice and assumptions that research should benefit marginalised populations. Lived experience is valued. Agency of those most affected is encouraged, in that they are active participants and decision-makers, not passive recipients of the decisions of others. It allows the researcher to be a participant in the research and builds on earlier theories of participatory research. I am an advocate for autism through my own personal experience and participation in autism advocacy. With other methodologies, being a participant in your own research can be problematic, but with the transformative paradigm this engagement is encouraged (Bell, 2009; Mertens, 2009). The values, assumptions and cultural baggage one brings to research must also be acknowledged and critiqued as part of the research process. As a participant insider this suits me. The paradigm guides the researcher in, for example, encouraging selfreflection throughout the research process, of knowing yourself in relationship to the community studied and building strategies for trusting, ethical relationships and partnerships (Mertens, 2009).

Three common themes of transformative research that I incorporate into my research design are:

- Underlying assumptions that rely on ethical stances of inclusion and challenging oppressive social structures.

- An entry process into the community that is designed to build trust and make goals and strategies transparent.

- Dissemination of findings in ways that encourage use of the results to enhance social justice and human rights. $(2009$, p. 5) 
Examples of these themes are that I try to act ethically at all times (heeding the international ethical principles of autonomy, beneficence, respect and justice) and as a researcher I do not regard myself as in any way superior to those in the autism community. I can also use my skills to support participation of autistic people and families in areas such as government or political processes through, for example, submissions to parliamentary select committees. As researcher and parent I work alongside members of the autism community in a variety of contexts such as in committees, events, and social media. Dissemination of findings is an important ethical consideration for any research. I intend to report findings in a variety of conference presentations, talks and papers including via the internet. I also hope that this research provides a building block for further research which builds capacity of those with autism.

The paradigm builds on work developed over the last few decades by marginalised groups to address their discrimination. The decades since the 1960s have seen the rise of academic disciplines critiquing the experience of those marginalised or discriminated against because of their, for example, race, disability, gender or sexual orientation. Significant for scholars in all these disciplines is the participatory aspect that they are in their research and care about the outcomes, and this has led to challenges to positivist assumptions about objectivity and some neutral discoverable truth.

Mertens' transformative approach requires that research alone is not sufficient to achieve emancipation. Ongoing evaluation is also required, so her paradigm is the meshing of the best of emancipatory and participatory research with evaluation theories and practices. Evaluation involves examining the objectives and planning of policies to assess progress and whether the objectives are being met. For my specific evaluation of the ASD guideline implementation (Chapter Nine) my informants are also stakeholders in the process. So part of my evaluation is participatory as some of my informants are also potential beneficiaries of improved policies - insiders who can enhance evaluation with their insider knowledge. Their participation and feedback has the potential to improve the project in that they come to the issues from many years of problem solving these issues. The basic beliefs of the transformative paradigm are illustrated in Figure 2 below. 
Figure 2: Basic beliefs of the Transformative Paradigm

\begin{tabular}{|c|c|}
\hline Axiology: assumptions about ethics & $\begin{array}{l}\text { Respect for cultural norms of } \\
\text { interaction; promotion of human rights } \\
\text { and increase in social justice }\end{array}$ \\
\hline $\begin{array}{l}\text { Ontology: assumptions about the nature } \\
\text { of what exists; what is reality }\end{array}$ & $\begin{array}{l}\text { Recognises influence of privilege in } \\
\text { determining what is real and the } \\
\text { consequences of accepting one version } \\
\text { over another; multiple realities are } \\
\text { shaped by social, political, cultural, } \\
\text { economic, ethnic, gender, disability and } \\
\text { other values }\end{array}$ \\
\hline $\begin{array}{l}\text { Epistemology: assumptions about the } \\
\text { nature of knowledge and the relationship } \\
\text { between researcher/evaluator and } \\
\text { stakeholders needed to achieve accurate } \\
\text { knowledge }\end{array}$ & $\begin{array}{l}\text { Interactive link between researcher and } \\
\text { participants; knowledge socially and } \\
\text { historically situated; issues of power and } \\
\text { privilege addressed; development of } \\
\text { trusting relationships crucial }\end{array}$ \\
\hline $\begin{array}{l}\text { Methodology: assumptions about } \\
\text { appropriate methods of inquiry }\end{array}$ & $\begin{array}{l}\text { Qualitative methods crucial but mixed } \\
\text { methods can be used; methods are } \\
\text { adjusted to accommodate cultural } \\
\text { complexity; contextual and historical } \\
\text { factors acknowledged, especially as they } \\
\text { relate to discrimination and oppression }\end{array}$ \\
\hline
\end{tabular}

Source: Mertens, 2009, p. 49 abridged

\section{Disability theory/theorists}

Although Mertens works at Gallaudet, the Deaf university in Washington, she does not identify as a disabled person, nor as a disability studies academic; she is a research methodology and evaluation theorist and practitioner who has developed and works within the transformative paradigm. So to understand the development of disability studies I have examined the theories of some of those who have contributed to the discipline. Associate Professor Christopher Newell, who taught bioethics at the University of Hobart medical school, was my research mentor and supervisor until his 
death in June 2008. Over several conversations and supervision sessions he helped shape my methodological approach. He hated the standard able-ist question, 'What's wrong with you?' People who asked that of him were answered with an equally invasive personal question (Newell, 2007b). Counteracting the otherness of disability was very important to him:

For me, one of the enduring challenges in the trans-disciplinary endeavour that is disability studies is the importance of assisting society to move people with disability from 'other' to be part of the nice, normal 'us' - our moral community. (Newell, 2005, p. ix)

He sometimes lectured to his medical students from his hospital bed, an experience which was probably very powerful for them. He wanted his students to understand and see the essential humanity of every disabled person they might meet in their future work. He required a power wheelchair and oxygen to get through his day and valued the times he needed the professional skills of the paramedics he had taught, when he was at his most vulnerable.

Now retired, British sociologist Michael Oliver is the 'father' of British disability studies. He recently revisited his earlier writings and controversies in disability studies. For my purposes, his assertion that 'the social model of disability is a practical tool like a hammer or a screwdriver, not a theory, an idea or a concept' $(2009$, p. 57), is very apt. I wanted to compile a body of research that can be used to change policy and attitudes.

Seeing the social model as a tool rather than a theory is a way of answering critics who claim it is a flawed theory because it assumes disabled people are all the same and does not incorporate differences due to gender, ethnicity or ageing, or the realities of impairment, and may privilege the 'able disabled' (Shakespeare, 2006). However, such an approach can also be used by non-disabled people against disabled people. This is illustrated by the 2010 impasse whereby some parents of autistic children tried to stop autistic self-advocate Ari Ne'eman's appointment to President Obama's National Council on Disability on the grounds that he was not autistic enough (Silberman, 2010). 
Individual experience of disabling environments and attitudes is at the heart of the social model as a political tool. The next step is 'the transformation ... of disability from personal trouble to political issue' (Oliver, 2009, p. 20). Some policy is based on the individual model of disability - currently the basis for approaches like rehabilitation - but such support will only benefit one person while barrier-free environments will help lots of groups (2009, pp. 45-46). In areas like employment:

much greater resources are currently spent on employment rehabilitation, training and so on (individual model) rather than removing the barriers to work or attempting to prevent the labour market from operating in a discriminatory manner. (2009, p. 46)

Oliver reflects the views of French philosopher Foucault (Foucault 1980; Tremain, 2005) as to how one group manages to exercise power over another and how people are encouraged to provide surveillance over their peers:

Like power, ideology is at its most influential when it is invisible and the ideology of normality permeates the whole of society. (Oliver, 2009, p. 38)

There are two dimensions to the operation of power that are relevant to questions of control: power to control the individual body and power to control the social body. (2009, p. 37)

Oliver promotes a citizenship approach whereby disabled people are 'equal citizens with full rights and responsibilities' (2009, p. 54), as opposed to humanitarian or compliance approaches, and which is:

(a) Economic: disabled people ... seen as contributing members of society as both workers and valued customers or users.

(b) Political: disabled people ... recognized as empowered individuals, voters and a powerful interest group.

(c) Moral: disabled people ... seen as active citizens with all that implies in terms of rights and responsibilities. (2009, p. 54) 
He suggests we are in a time of paradigm change. Referencing the earlier work of Thomas Kuhn (1970) who wrote about scientific revolutions and changing paradigms:

Most social theorists agree that we are entering a period of profound change for the societies in which we live, although different theorists use different terminology to refer to these changes. (Oliver, 2009, p. 72)

These shifts happen when problems in exiting paradigms 'become so great that they force a shift to an entirely new paradigm through ... a complete revolution in our thinking' (2009, p. 73). Oliver elaborates using the example of special education and autistic children whereby a new paradigm of education is now required to accommodate the learning needs of autistic children. Education is examined further in Chapter Eight. Mertens (2009) also references Kuhn's work in the development of her transformative paradigm.

Robyn Munford and Martin Sullivan, two founders of disability studies in New Zealand, have also been influenced by Oliver's work. They applied social model thinking to New Zealand social policy and their paper 'The articulation of theory and practice: critique and resistance in Aotearoa New Zealand' was published in 1998 soon after major changes in the delivery of disability services had been implemented (Sullivan \& Munford, 1998).

Foucault did not write about disability specifically, but his ideas have been widely picked up within disability studies, including by Sullivan and Munford. One influential idea is of the suppression of 'subjugated knowledges' which are 'knowledges located low down on the hierarchy, beneath the required level of ... scientificity' (Foucault, 1980; Sullivan \& Munford, 1998, p. 183). However, these voices of lived experience of disability have now started being heard (Ballard, 1994; Busch \& Johnsen, 2008; People First New Zealand Inc, 2010; Spectrum Care Trust Board, 2010). Foucault also considered the exercise of power by a variety of technologies including the medical discourse: 
A central technology of power that operates to create disabled people is the medical discourse on impairment. Discourse functions to regulate the way individuals think about the world and live their lives. (Sullivan \& Munford, 1998, p. 187)

In this discourse disability is created as abnormality, unruly, damaged and inadequate, and the anomalous body must be regulated. This leads to the 'creation of special services in order to ensure that these unruly bodies are cared for in disciplined and regulated environments such as special schools, sheltered workshops etc' (1998, p. 188).

However, where there is power there is also resistance, exemplified in the rise of the disability rights movement. A particular discourse can influence how a policy problem is framed. Munford and Sullivan illustrate this with the New Deal policy of the New Zealand National Government in the 1990s (Shipley \& Upton, 1992a). Deinstitutionalisation was then underway but the government also sought to limit welfare benefits. The problem was where to put disability support services (DSS), whether to keep it under the Department of Social Welfare (DSW) or transfer into the Department of Health. 'Under the DSW scenario their bodies would be inscribed as dependent objects worthy of charity and welfare while under health their bodies would be remedicalised, and inscribed as pathological and lacking' (Sullivan \& Munford, 1998, p. 189). Disabled people were consulted as part of the New Deal process and reported that instead of those options they would like a separate disability agency (Shipley \& Upton, 1992; Sullivan \& Munford, 1998). Their opinions were dismissed and DSS went into Health.

The 1990s in New Zealand saw the dominance of the market model which assumed that if services are required the market will provide them and that the consumer/customer has choice about what services to purchase (World Health Organisation, 2004). In this model clients make active choices between providers and that choice will not result in any negative effects for the consumer such as being left without any provider. Discourse analysis is useful for examining the loaded word 'choice' in disability policy and Sullivan and Munford (1998, p. 187) note that choice was one of the principles 
articulated in the National Government's New Deal (Shipley \& Upton, 1992) and would be provided by the market. But in disability services, choice only exists when options are resourced and promoted so everyone knows about them and can afford to access them. The pure market model was also limited by the mechanisms of government agency purchasing (in effect the government was monopsonistic) and complicated by systems of insurance/compensation (for example the Accident Compensation Corporation provided cover by public levy of disability caused by accident, but not by illness) and the individual's ability to pay. However, the downside of the market model as it was practiced in New Zealand at the time was the service gaps that led to a chain of events resulting in Casey Albury's 1997 death (Werry, 1998). The market did not provide the services required at the time by her mother nor for many other disabled people. Yet the market discourse can still be manipulated against disabled people with Sullivan and Munford noting that 'disabled children and their families are targeted by the state as excessive consumers of scarce resources' (Sullivan \& Munford, 1998, p. 187).

This blaming the victim discourse can be seen with the establishment of a government working party on welfare reform in 2010 (with an agenda of budgetary restraint) that included no disabled people nor anyone representing beneficiaries (Office of the Minister for Social Development and Employment, 2010).

Canadian Marcia Rioux is a disability theorist who has visited New Zealand to assist disabled people with their monitoring of the United Nations Convention on the Rights of Persons with Disabilities (UNCRPWD) (Convention Coalition, 2010). She and Fraser Valentine (Rioux \& Valentine, 2006) have developed a conceptual model which incorporates both the medical and social models, which they label individual pathology' and 'social pathology' (see Figure 3), which may help when trying to understand different approaches and subtle but significant differences in treatment, prevention and social responsibility. 
Figure 3: The Social and Scientific Formulations of Disability

\begin{tabular}{|c|c|}
\hline \multicolumn{2}{|c|}{ INDIVIDUAL PATHOLOGY } \\
\hline $\begin{array}{c}\text { Biomedical approach } \\
\text { (consequence of biological } \\
\text { characteristics) }\end{array}$ & $\begin{array}{l}\text { Functional approach } \\
\text { (consequence of functional } \\
\text { abilities and capacities) }\end{array}$ \\
\hline $\begin{array}{l}\text { - Treatment: through medicine and } \\
\text { biotechnology } \\
\text { - Prevention: through biological or } \\
\text { genetic intervention or screening } \\
\text { - Social responsibility: to eliminate } \\
\text { or cure }\end{array}$ & $\begin{array}{l}\text { - Treatment: through rehabilitation } \\
\text { services } \\
\text { - Prevention: through early } \\
\text { diagnosis and treatment } \\
\text { - Social responsibility: to ameliorate } \\
\text { and provide comfort }\end{array}$ \\
\hline \multicolumn{2}{|c|}{ SOCIAL PATHOLOGY } \\
\hline $\begin{array}{l}\text { Environmental approach } \\
\text { (consequence of environmental } \\
\text { factors and service arrangements) }\end{array}$ & $\begin{array}{l}\text { Human rights approach } \\
\text { (consequence of social organization } \\
\text { and relationship of individual to society) }\end{array}$ \\
\hline $\begin{array}{l}\text { - Treatment: through increased } \\
\text { individual control of services and } \\
\text { supports } \\
\text { - Prevention: through elimination of } \\
\text { social, economic, and physical } \\
\text { barriers } \\
\text { - Social responsibility: to eliminate } \\
\text { systemic barriers }\end{array}$ & $\begin{array}{l}\text { Treatment: through reformulation } \\
\text { of economic, social, and political } \\
\text { policy } \\
\text { - Prevention: through recognition of } \\
\text { conditions of disability as inherent } \\
\text { in society } \\
\text { - Social responsibility: to provide } \\
\text { political and social entitlements }\end{array}$ \\
\hline
\end{tabular}

(Source: Rioux \& Valentine, 2006, p. 49)

There are also many parallels between the experiences of disabled people and Māori, and the knowledge of those involved in research on Māori issues also has value for my research. In an address to the post-graduate students' conference at Victoria University in November 2009, Linda Smith (2009) related how her own research on Māori education could not be separated from the reality of everyday life into something other. She gave an example of the daily road she drove which connected and wove between many topics and sites of her research, such as the school, government departments and services. Such interconnectedness is similar for disability policy and disabled people.

Research questions about Māori and disabled people are often framed around the target population being a problem, and she provided as an example the question, 'What is the problem with Māori that they are not achieving?' Instead, it could be asked 'Why are 
some achieving and some not, or more importantly, why is this group not achieving in this first world country?' (2009). There are similarities with reframing individual/medical model questions about disability to social model ones, such as rephrasing, 'What problems does autism cause in the workplace?' To, 'How could workplaces and employment processes better recognise the talents of a diverse workforce including people with autism and other impairments?'

Linda Smith also noted that certain areas of research have more status than others and the champions of such research are also powerful, and to get funding, attention and resources you need to use these networks. Disabled person, activist and academic Gerry Zarb (1992) refers to this aspect as the 'material relations of research'. There is less funding and therefore less status internationally for social model disability and autism research than for such areas as genetics, brain science, and pharmaceuticals. The funding system also needs to be more democratic. For example Health Research Council funding forms could be made more accessible to vision impaired or intellectually impaired people. The work of academics like Mason Durie, Linda Smith and others over recent decades has started to bring Māori-led research and policy in from the margins, providing examples that disability researchers could borrow and adapt.

\section{Emancipatory/transformative research methodology}

One of the triggers for the establishment of the discipline of disability studies was an incident in the 1960s when residents of an English Cheshire Home (one of a network of residential group homes for disabled people), asked the Tavistock Institute to investigate their conditions as part of a dispute between residents and management (Mercer, 2002, p. 230). However, the able-bodied researchers used research methodology which located the problems within an individual/medical model of disability rather than condemning the institutional conditions the residents had to live with. The researchers later admitted feeling trapped by the positivist methodology available to them (E. J. Miller \& Gwynne, 1972). Disappointed, Paul Hunt (1981), one of the residents, labelled them the 'parasite people' for 'siding with the oppressors, looking after their own professional and academic interests, and leaving the residents feeling exploited and betrayed' (Mercer, 2002, p. 230). Hunt became one of the 
founders of UPIAS (the Union of Physically Impaired Against Segregation) in the early 1970s. UPIAS published a statement of rights, The fundamental principles of disability, which can be seen as marking the start of disability rights movement, the social model and directly to the new discipline of disability studies (UPIAS, 1976).

Research methodology, including social research, up until then had been dominated by positivism, which values neutrality and objectivity; at its 'ontological core is the assumption that the social and natural worlds contain a single reality' and quantitative methods can 'establish cause-and-effect relationships between social phenomena' (Mercer, 2002, p. 231). Positivism and the softer post-positivism research methodology for social research have since been challenged by phenomenology, which British disability studies academic Geof Mercer describes as part of:

the interpretive paradigm (including hermeneutics and phenomenology) [which] stresses clear-cut differences between the natural and social sciences. Its unifying belief centres on the social construction of reality and the existence of multiple versions (ontological pluralism). (Mercer, 2002, p. 231)

Hermeneutics refers to the interpretation and understanding of texts or events by analysing their meanings and context, which is also relevant to my work. Referencing Lincoln and Guba (2000), Mercer suggests that:

the accent is on interpretative (qualitative) data, with an inductive build up of concepts, research questions and theories, rather than testing hypotheses; information expressed in feelings, attitudes, and actions; and engaging researcher and researched as fellow participants in producing, generating and validating meanings about these phenomena. (Mercer, 2002, p. 231)

This describes much of my research approach, and although much about phenomenological research suited my purpose, I sought more than just understanding phenomena; I wanted methodology that could have practical application. 
Paulo Freire's work developing critical social theory is often cited in disability studies (Freire, 1972). He promoted education using participatory methods among disadvantaged people in South America in the early 1970s (and even visited New Zealand) and suggested that through critical reflection people could both analyse their problems politically and empower themselves to take action. 'It accentuated interactive or "dialogic" methods, which went well beyond interpretive empathy for the subject and stressed the researcher's partisan involvement in emancipatory struggles' (Mercer, 2002, p. 231).

Mercer also acknowledges the enormous methodological contribution of Michael Oliver, who by the early 1990s was working as an academic sociologist. Oliver (1997) took account of the above developments in social research, added learnings from those involved in feminist and anti-racism work and created the praxis-oriented emancipatory paradigm. He linked the different methodologies to policy making 'engineering/prediction (positivist), enlightenment (interpretive), and struggle (emancipatory)' (Mercer, 2002, p. 233). Emancipatory research included:

- rejection of the individual model of disability and its replacement by a social model approach;

- concentration on a partisan research approach (so denying researcher objectivity and neutrality) in order to facilitate the political struggles of disabled people;

- reversal of the traditional researcher-researched hierarcy/social relations of research production, while also challenging the material relations of research production;

- pluralism in choice of methodologies and methods. (Mercer, 2002, p. 233)

Oliver himself (2009) also has much to say about the process of doing research that I find helpful:

The goal of objectivity has broken down in the face of criticisms from a variety of disempowered and disenfranchised groups ... to the point where personal experience has sometimes become a standpoint epistemology' 
(2009, p. 72) ... The solution ..., according to Carol Thomas (1999), is to combine structural analysis with writing oneself into the picture. (2009, p. 72)

He is also optimistic:

Increasingly, as oppressed groups such as disabled people continue the political process collectively empowering themselves, research practice based upon the investigatory discourse and utilizing 'tourist' approaches by 'tarmac' professors and researchers will find it increasingly difficult to find sites and experiences ripe for colonization. Disabled people and other oppressed groups will no longer be prepared to tolerate exploitative investigatory research based upon exclusionary social relations of research production. (2009, p. 117)

Oliver summarises his life's work. 'For me, all social theory must be judged on three interrelated elements: its adequacy in describing experience; its ability to explain experience; and, finally, its potential to transform experience' (2009, p. 89).

What then is the step from emancipatory to transformative research? Additional factors seem to be a more collaborative approach with various 'allies' with shared values and commitment to diversity, pragmatic choices of methods, and a continuous cycle of review, evaluation and improvement which help make an emancipatory piece of research transformative (Mertens, 2009). The following table has been developed (Mertens, Sullivan, \& Stace, 2011) to explain the differences. 
Figure 4: Contrasting the Emancipatory and Transformative paradigms

\begin{tabular}{|c|c|c|}
\hline & Emancipatory & Transformative \\
\hline Focus & $\begin{array}{l}\text { Focuses exclusively on disability as } \\
\text { the central focus }\end{array}$ & $\begin{array}{l}\text { Focuses on dimensions of diversity } \\
\text { associated with differential access to power } \\
\text { and privilege, including disability, gender, } \\
\text { race/ethnicity, social class, sexual } \\
\text { orientation, and other contextually important } \\
\text { dimensions of diversity }\end{array}$ \\
\hline $\begin{array}{l}\text { Role of } \\
\text { researcher/ } \\
\text { participants }\end{array}$ & $\begin{array}{l}\text { Assumes participants are } \\
\text { "conscious of their situation and } \\
\text { ready to take leadership" (Sullivan, } \\
2009, \text { p. } 77 \text { ) }\end{array}$ & $\begin{array}{l}\text { Team approach; partnerships are formed; } \\
\text { capacity building undertaken as necessary }\end{array}$ \\
\hline $\begin{array}{l}\text { Model of } \\
\text { research }\end{array}$ & $\begin{array}{l}\text { Participatory action research; } \\
\text { interpretive approaches }\end{array}$ & $\begin{array}{l}\text { Multiple and mixed methods; culturally } \\
\text { respectful; supportive of diverse needs }\end{array}$ \\
\hline Tone & Sets up an "us" against "them" tone & $\begin{array}{l}\text { Acknowledges the need to work together to } \\
\text { challenge oppressive structures }\end{array}$ \\
\hline
\end{tabular}

Source: Mertens, et al., 2011, p.231

\section{Research methods}

As shown in Figure 4, mixed methods suit the transformative paradigm, but the paradigm requires qualitative methods. It also encourages the researcher to provide and respect historical and cultural contexts, to focus on the dimensions of diversity, and to act ethically and address power issues by working in partnership with participants. This reflects Mercer's (2002) earlier warning that you may intend your research to be emancipatory and then choose research methods that reinforce the researcher's power and knowledge over the research participant. 
To collect data I started with a thorough search of the academic databases through the Victoria University Library. This method produced some significant papers on aspects of ASD such as prevalence, aetiology, neuroscience and clinical interventions, but produced minimal references to the voices of autistic people. Where I did locate significant primary and secondary texts describing lived experience of autism was on the internet: on websites, blogs and through social media such as Facebook and Twitter. Many governments are working on autism strategies and these can be followed through reports, submissions or minutes of meetings (or in one case through many hours of live webcam from the United States' Interagency Autism Committee). I attended in person conference presentations, public meetings and select committee hearings. The mainstream media is also a major resource for autism information, particularly views of autism, and for occasional interviews with autistic people.

So, much of my research comprised textual analysis of this 'grey' literature as it provides a rich picture of the dynamics of lived experience, and access to a large variety of perspectives and debates, much of which is relevant for policy. These texts, most of which are available in the public domain, are non-invasive, non-exploitative and convenient. People with lived experience of autism or other relevant expertise have written material in public places such as published books, articles, letters, reports or websites. No more of their precious time is required by the researcher for the researcher's work. There is also a written record that readers can refer back to. There is a growing industry of autism publishing including auto/biography. Through my Facebook page and email groups I get several alerts every day about autism news, website references, media articles, Youtube clips and research alerts. As countries increasingly tackle policy issues around autism and other disability issues, not only are the official policy documents and research available on-line, but accompanied by intensive blog-based discussion; much of it by and from people with autism. Over the many years I have been involved with autism advocacy and research I have also built up a large collection of many of these types of 'grey' (not traditionally academic) literature mentioned above. Through a colleague I was lucky to have access to a collection of international books on disability studies, which also proved very useful. 
I also conducted interviews with ten key informants and these were based on the ASD guideline as I wanted to explore issues in depth around its development and implementation. My interviews confirmed that interviewees' knowledge covered a much wider range than the Guideline so I have also included their reflections in other chapters. Nine of the interviews were face to face for one to two hours each and one was completed by email. I have a background in oral history methodology which requires extensive research and preparation before undertaking interviews. Interviewing requires reflection on ethical issues such as power, knowledge and safety and questions about the knowledge the researcher brings and what knowledge is being produced (Hall, 2004). In my purposive sample, I knew all my interviewees and had discussed autism issues and worked with several of them over many years. I chose them as interviewees, as not only had they all had expertise on aspects of the ASD guideline, but they also had extensive knowledge of personal and policy issues around autism. I approached them to participate several months before I actually undertook the interviews. With this background knowledge I could undertake in-depth semi-structured interviews which were an efficient use of their time as they could discuss the issues they wanted to, but I could also ask more probing questions about areas I knew they had particular expertise in, such as in diagnosis, education, parenting or advocacy. I felt my insider knowledge and relationship with the interviewee led to particularly rich interview data (Costley, Elliott \& Gibbs, 2010). There is a potential that an insider approach risks lack of critical appraisal but I felt my insider knowledge enhanced my questioning and enabled me to challenge the data on occasions. I also had email feedback from two informants.

So this was a purposive sample of people with particular perspectives and skill sets to help fill in the knowledge gaps. Oral history methodology generally uses a general thematic approach to the interview as a whole piece of primary material. This means I took notes as they talked about particular aspects, and repeated listening to the tapes helped me to capture nuances. Colour coding of written transcriptions supplemented this approach. I had to be very careful to protect their identities as the autism sector in New Zealand is relatively small and interconnected. The interviewees are identified by pseudonyms, apart from one who has given specific permission for that disclosure, and Appendix Two provides brief biographical notes. My informants have consented to the use of their quotes in the text and I am grateful that they have also consented to 
archiving the audio tapes in the Oral History Archive at the Alexander Turnbull Library as part of our evolving autism cultural voice.

Thematic analysis, whereby themes are identified in the data, was a fundamental part of my qualitative research analysis (Braun \& Clarke, 2006; Creswell, 2003; Ryan \& Barnard, 2003). Specifically, I used the approach of Braun and Clarke who suggest the processes of familiarising yourself with the data, generating initial codes, searching for themes, reviewing themes, defining and naming themes, and producing the report. Texts and interviews were analysed for words and concepts which provided the initial coding such as: love, luck, lucky, relationships, relationship building, lived experience, family, policy, strategy, services, respect, advocacy, self advocacy, culture, identity, neurodiverse and neurotypical (those last five words often indicate the author is writing from the perspective of autism as identity). The following words may indicate the source of data is from the lobby seeking cure: biomedical, recovery, MMR, chelation, vaccine, mercury, therapies. These key words in texts were colour coded. For the ASD guideline case study themes developed from those issues which came up regularly in the reports, newsletters and interviews such as coordination, respite, behaviour, education, and adults. Iterative analysis of the data, particularly interviews, also revealed significant policy gaps yet to be addressed, and these are described near the end of Chapter Nine. Through these processes I uncovered contradictions and convergence as well as fresh ideas such as the phenomena of wicked aspects of policy that I explore in Chapter Seven, and ways to incorporate lived experience into policy.

There were two more parts to my original research plans for which I received ethics approval, but did not end up using. I prepared a short anonymous paper survey of all those involved in the Guideline's Implementation Advisory Group (IAG) from 20082010. A snowball survey through my email and social networking sites asking 'What is autism?' completed my intended research methods. I was curious to see what understanding there is in the virtual world, and how such a technique works as a research method. There was considerable disquiet among a few IAG members to the survey as they thought individual members would be identifiable, or that the information could reflect poorly on the funding ministries. (This reflected the sensitivity of the work, the small ASD sector and a new political environment of cost-cutting). 
Other members disagreed, but I decided it was not worth pursuing as I was getting sufficient data from my in-depth interviews, social media and grey literature. Although I have extensive social media networks I only got very few replies to my electronic question 'what is autism'. Responses included: that it was too difficult to define; people assumed I knew enough already; or they just preferred to discuss their more immediate concerns online. I could have tried a different interviewing method but that would have required new ethics approval. For this case study, the key informant interviews were supplemented by my extensive collection of Guideline-related grey literature, such as newsletters, research reports, minutes, pilot projects and evaluations.

With two decades of experience in autism as a parent, researcher, participant and advocate I was already familiar with many of the key events, debates, developments and this perspective helped me to apply a critical analysis to data, as a triangulation method.

The research received approval from the Multi-region Ethics Committee administered by the Ministry of Health (see Appendix Three). I attended the meeting in person to discuss any concerns the committee had about my application. I had been careful about issues of confidentiality. Their main concerns were the representativeness of my purposive interviewing sample and the matter of bias in recruitment. From my own experience on ethics committees I know this is a common concern for researchers who are not familiar with qualitative methods. I explained that as an insider from the sector I wanted to fill knowledge gaps and this required rich data from people with a variety of 'autism expertises', rather than a random anonymous sample. Qualitative research does not aim for objectivity but for in-depth understanding of issues. For my interviews I sought key informants to cover a selection of perspectives such as: people with autism, parents, public servants, people from advocacy groups or NGOs, and politicians. This provided a selection of views to get a picture of the relevant issues. They also preferred I use the term Autism Spectrum Disorder or ASD rather than just autism. This reflects different ways of understanding a condition. For the committee it is merely a clinical diagnosis, whereas for me it is more than that, even an identity in which the word 'disorder' offends. 
For Oliver, accessibility of research is important, 'if such work is going to be part of an emancipatory project it cannot just be accessible to academics' (2009, p. 179). I hope that my writing will be accessible to people interested in the topic, not just those used to academic writing.

\section{Strengths and limits of research methods}

The main benefit of depending so heavily on grey literature is a wealth of valuable material about the debates in the community itself, from insider and outsider perspectives, including the construction of autism in the media, and glimpses into the workings of government on a significant policy issue. The strengths of seeking out grey literature, including social media, are that there is a kaleidoscope of material available and using this research data meant that I heard from many of those involved in current debates and with insider information that is rarely captured in peer-reviewed academic publications. Much of it was in real time: a blog post can alert readers to events that have just happened or are about to happen with an insider's knowledge, whereas an academic publication might rely on data collected months or years earlier. An autobiographical account relates what is really important for that person, and can indicate readily what is or is not working from a policy perspective. Similarly, my interviews gave information of much wider policy significance than just the Guideline development or implementation.

There are also limitations on this research. Many more interviews (and I originally intended to do many more, but those I completed gave sufficient in-depth data and diversity for my purposes) may have given a wider understanding of the Guideline process. For example, I did not interview any of the NZ Guideline Group staff. More interviews with autistic people would probably have provided more diversity. I could have used the interviews more extensively (and used NVivo rather than manual thematic analysis), and provided less contextual information, but historical, political and policy context is essential to make sense of the present and future. I anticipated but did not complete a quantitative survey, so lost one potentially valuable method.

I initially intended to rely on interviewees for basic information about their lives and what policy changes would or would not help their personal circumstances. However, as 
I progressed through the research I found that there was already a good range of such data such as the research by Bevan-Brown (2004).

The drawbacks or risks of using grey literature are many. Due to the extent of the material and the constantly changing nature of grey literature, a definitive search to uncover every blog, website, article or forum that exists is impossible, and I have had to pick and choose among those that I have found. There is of course no peer review of the quality or authenticity of data or information, and the source may or may not be representative. I have judged quality through a filter of my personal experience and perspective, tried to ascertain authenticity through such methods as responses and comments on blogs, and tested my assumptions on my advisors. Ideally, I would have liked to set up a reference group of people on the spectrum to help with research questions and ongoing advice. Instead, I asked two autistic adults who were also friends to review various aspects of the research including reading drafts. I was seeking, above all, authenticity, in order to understand and improve autism policy process, and I consider my methods and methodology have provided adequate insight for my purposes. Some suggestions for further research are given in the concluding chapter.

\section{Conclusion}

This chapter has explained the process I used for deciding on appropriate research methods and methodology and why I found Merten's transformative paradigm appropriate. It provides a sheltering umbrella for methodological approaches advocated and developed by disability and feminist theorists and others concerned to bring the marginalised into the mainstream and to address issues of social justice, rights and reciprocity. Her emphasis on evaluation ties in well with Oliver's promotion of the social model of disability as a political tool and implementation action. Finding the appropriate methods and materials of inquiry included going to the growing number of autism communities connected by the internet. Additional perspectives were provided by in-depth interviews with key informants who provided a wide-range of New Zealand specific autism policy information. The following chapter looks at sources of expertise from within the autism community itself, and from allies and others in the autism sector. 


\section{Chapter Three: Experts and expertise}

\section{Experts and expertise - introduction}

The last chapter outlined my methodological approach. This chapter looks at various types of expertise relevant to answering my research questions and asks who are the experts and what references and sources are there to understand the policy issues around autism? These sources include autistic people, parents and advocates, clinicians and non-clinical academics (those who study autism in the context of culture, disability studies or history) and people working in policy.

The transformative paradigm, outlined in the previous chapter, highly values the lived expertise of those who are also subjects of the research, and they are my most valued informants. Tapping into this lived experience is also one of the central aspects of getting beyond love and luck as it provides insight into what works and what does not. However, also valued are those with clinical, professional and academic expertise who use the lens of their own disciplines to examine the experience of autism. Also critical to this study are the academic and policy experts on the wider experience of autism and disability, historically and currently. This study draws on them all. Chapter Seven will show that one way to challenge the complex 'wicked' policy aspects of autism is to utilise and combine a variety of expertises.

\section{Written expertise on autism: autism literature}

\section{Experts on lived experience of autism: grey literature sources}

The work of clinical and research experts provides context for this thesis, but my real experts are those who live with autism, many of whom proudly claim the label. This material is seldom found in conventional academic texts or contexts - apart from those such as Wendy Lawson $(2000,2008)$ an autistic academic from Deakin University - but constitutes a rich and valid data collection of grey literature. As mentioned in the previous chapter Mertens (2009) encourages the use of this grey material for transformative research as it is often the only way to incorporate the voices of the researched. These voices are more likely to be found in the growing number of autobiographies, or on websites and Facebook pages of those espousing autistic and 
disability rights. Examples are Ari Ne'eman (Kalb, 2009; Silberman, 2010), Paula Durbin-Westby and others involved with the Autistic Self Advocacy Network (ASAN) who are responsible for its prolific output of news and articles about autism from a lived experience and self advocacy perspective, and Colin Revell and Larry Arnold who are frequent contributors to a British-based international disability electronic listserv run from Leeds University. A British-based hub site for autism news and websites, www leftbrainrightbrain.co.uk, provided frequent reports on the investigation by the British General Medical Council case against Andrew Wakefield who falsely linked MMR vaccine and autism in a 1998 Lancet article (Deer, 2011a, 2011b, 2011c; General Medical Council, 2010; Wakefield, 1998). Increasing numbers of autistic adults and autism groups, including in New Zealand, have their own web-based and social networking sites.

The international autistic self advocacy movement has emerged from the convergence of disability activism and the rise of the global internet movement. Many members of the autism rights movement see themselves as a cultural minority, subject to discrimination for their difference in a similar way to other minorities (Trevedi, 2005). This identity movement challenges many parent or clinician-led groups. Many of those with autism such as Alyson Bradley and her correspondents on the busy New Zealand Asplanet site often mention that digital communication is an easier form of social interaction than in person. The irony of this is reflected in a 2010 international fundraising initiative by autism parent groups for a 'Communications Shutdown' on 1 November 2010 (www.communicationsshutdown.org), when people were meant to forgo social media for a day and instead buy a charity electronic application that would put an appropriate message on their site, in the belief that would raise awareness about the communication difficulties people with autism experience. However, in a backlash to the idea some autistic adults set up 'Autistic Speaking Day' and their Facebook page (as viewed on 27 October 2010) stated that:

- Autistic people are not silent, online or offline.

- Non-autistic people will have no more clue what autistic people's lives are like simply by staying off of Facebook for a day, because while they are avoiding their computer, they are still not autistic. 
- The invention of the Internet has prevented autistic people from feeling so isolated. Autistic people use social networking sites, forums, and blogs to talk to other autistic people, and even nonverbal autistics or autistics who have difficulty effectively communicating have an opportunity to socialize online.

Autobiographies by autistic people and biographies of autistic lives are vital sources for research on autism policy as they usually have useful suggestions, even if indirectly, about improving policies for good outcomes. Examples include New Zealander Jen Birch (2003), British writer Daniel Tammet's two autobiographical volumes (2006, 2009) and John E. Robison (2007) from the United States. Donna Williams' autobiographies $(1992,1994)$ show that even misunderstood autistic children can grow into resilient autistic adults. Temple Grandin (2006, 2008, 2009), an animal scientist and engineer, has been writing about her life and aspects of autism for many years. She and her autism intrigued neurologist Oliver Sacks who used her self-description that the rules of human behaviour were as much a mystery to her as if she were 'an anthropologist on Mars' for the title of his 1995 book. Grandin is also a commentator on many policy issues such as the negative effects on autistic children of the 'No Child Left Behind' policy of the Bush administration (2008). She had many complaints from parents and teachers that the rigid testing requirements alienated the child from classroom education and left no room for individualised teaching or incorporating their special interests (2008, pp. 45-46). She has visited New Zealand several times, speaking to large audiences. Her story has been made into an eponymous award winning movie for television (Internet Movie Data Base, 2010).

Other examples of autistic auto/biography include Kamram Nazeer (2006) who attended a special school with a group of autistic children in late 1970s New York. A British civil servant, he returned to the United States to see what had become of his former schoolmates, and in doing so provides great insight into the effectiveness of autism educational and employment policies. Articulate non-verbal US woman Amanda Baggs (ww.Ballastexistenz.autistics.org) whose behaviour appears to the 'neurotypical' eye to be very autistic, has helped provide insight into the lived experience of autism (Wolman, 2008). An on-line US journal called The voices and choices of autism, edited 
by a non-verbal woman, Sharisa Joy Kochmeister, contains contributions from autistic people around the world, including New Zealand. She is also a prolific on-line social networker. Her writing is controversial because she is a supporter of an intervention which helped her learn to type and therefore communicate with words called facilitated communication (Kochmeister, 2009). Facilitated communication is challenged by many behavioural psychologists and other sceptics (Offit, 2008), as they suggest that the support person is actually producing the words, a claim strenuously denied by US educationalist Doug Biklen (2005) and many autistics. Jessica Kingsley Publishers has published several quality books on the autistic experience such as the Voices from the spectrum: parents, grandparents, siblings, people with autism, and professionals share their wisdom (Ariel \& Naseef, 2006). In New Zealand the http://humans.org.nz and www.asplanet.info website post stories from autistic people and family members. Much of the content is relevant to policy and service improvement.

Parental autobiographies are a growth industry internationally. One of the earliest was the late Clara Claiborne Park's 1967 biography The Siege about her autistic daughter Jessy, revised for a second edition in 1982, and updated in 2001 as Exiting nirvana. Fran Peek (1996) has written about his son Kim who was an inspiration for Dustin Hoffman's Rain man. Two local fathers who have written on their experiences of parenting autistic children are Wellington journalist David Cohen (2007), and Bill Murray (2006) who runs the Cloud Nine Children's Foundation for children and young people with Asperger's Syndrome in Wellington. Although people with autism and parents have different perspectives, they may share common concerns. Sometimes they may conflict, as in issues around independence. Parents are experts on caring for and advocacy for their autistic family member, not the lived experience of autism as an autistic person.

All the above are examples of grey literature relevant to this thesis.

\section{Clinicians}

There is a great deal of academic writing on autism that has also been useful. Peer reviewed international academic literature on autism research is extensive and growing. But it tends to concentrate on clinical, genetic aspects or behavioural interventions, and rarely on the public policy implications, apart from calls for more funding and research. 
Brisbane-based Tony Attwood is an English-trained psychologist who briefly worked at Kimberley psychopaedic hospital in Levin in the 1980s. His speciality is Asperger's syndrome or higher functioning autism, but his easy communication style resonates with a wide audience. Such is his popularity with parents that Autism NZ bases its conference every second year around his availability. The first book I read after my son's diagnosis was Attwood's Asperger's syndrome: a guide for parents and professionals (1998) which has now been superseded by his Complete guide to Asperger's syndrome (2007). He is sometimes challenged by autistic self-advocates, for example when they condemned his association with a group that apparently warns against friendship with autistic adults (Autistic Self Advocacy Network, 19 April 2009). But he knows many self advocates personally after working in the field for decades. He is constantly updating knowledge for a wide audience.

Another whose work is well known internationally is Simon Baron-Cohen of Cambridge University who has written on the 'theory of mind', that people with autism cannot understand that other people think differently from them, which he calls 'mindblindness', and as autism currently affects males much more than females he has labelled this logical, linear way of thinking as the 'male brain theory' which is related to biological sex differences (1997, 2004; Baron-Cohen, Leslie, \& Frith, 1985). The media thirst for stories about autism, particularly from the 'cause and cure' lobby (Baker, 2009), resulted in his complaint about being the victim of media misrepresentation over his research on prenatal testosterone; some made the deduction from his work that autism may be caused by high levels of prenatal testosterone and therefore screened for, when he had made no such claim (Allen, 2009; Baron-Cohen, 2009).

Pat Howlin, Francesca Happé, Eric Fombonne (APAC09, 2009) are other academics on the international conference circuit, who must balance their day jobs of teaching and research with the public's desire to learn about autism, while also being flag-bearers for legitimate, evidence-based and peer-reviewed research. They have developed understanding of the strengths and weaknesses of the autistic brain and their fields include evidence-based interventions. Happé (2003; Happé \& Frith, 2009), for example, has developed the idea of 'central coherence theory', that people with autism are very good with details, including visual detail, but often fail to notice the bigger picture. 
Amongst their other autism work, Howlin (2005) and Fombonne (2003) critique popular autism theories and treatments which do not stand up to scrutiny such as the MMR vaccine/thimerosal/autism link, and invasive treatments such as chelation. Other academics have become international experts and speakers on appropriate educational interventions and support for children with autism. These include Rita Jordan from Britain who frequently visits New Zealand and Jeff Sigafoos, a US educational psychologist currently based at Victoria University.

Michael Fitzgerald is a Professor of Child and Adolescent Psychiatry at Trinity College Dublin known for applying diagnostic criteria to famous people from the past to see if they would have been labelled autistic today (Fitzgerald, 2005; Fitzgerald \& O'Brien, 2007; O'Connell \& Fitzgerald, 2003). His latest book (2010) changes direction in looking at the role of 'autistic psychopathy' in criminal offending, particularly serial murders.

There are also those who use the 'rhetoric of science' (Severson, et al., 2008), but whose work is not evidence-based (such as the refrigerator mother theories of Bruno Bettelheim which I examine in Chapter Four). Although I do not regard them as experts, many parents do, and so I have included them here. Current examples include sites such as www.ageofautism.com, which remains a vocal supporter of Wakefield even after his research was condemned by the British General Medical Council (GMC) as mentioned earlier. The GMC found his conclusions were not only flawed but his severely unethical methods included taking blood samples from children attending his son's $5^{\text {th }}$ birthday party without parental consent or knowledge, and unnecessary colonoscopies in which one child had their bowel perforated. However, so widespread is the belief in immunisation-caused ASD that many parents worldwide refuse to immunise their children and epidemics of measles have started to appear in parts of the United States and Europe (Allen, 2009; Deer, 2009), and now in New Zealand. Other clinicians such as the Gaier father and son team promote untested treatments such as Lupron (testosterone injections) and chelation chemicals to cure autism (Offit, 2008; Roylance, 2011). 


\section{Non-clinical academic experts}

Other academic ASD work has come from those who study autism as cultural construction and representation. This group includes writers such as Majia Holmer Nadesan (Nadesan, 2005, 2008b) who teaches communication studies at Arizona State University, Stuart Murray (2008a, 2008b) from the English Department at the University of Leeds and anthropologist Roy Richard Grinker (2007) from George Washington University. Interestingly, they are all parents of autistic children who have used the lens of their own discipline to research autism. Murray, a father of two autistic sons, examines the power of media and film representation of autism. Ethnographer Grinker travelled to several countries such as South Korea, South Africa and India to compare attitudes and interventions to autism with his own experience as a father of an autistic girl in the United States.

Douglas Biklen (2005) is an educationalist whose work challenges many other academic autism experts. His work is controversial with some behavioural psychologists for his promotion of facilitated or augmentative communication, whereby many severely impaired, non-verbal autistic people have learned to communicate by typing, involving physical support from an assistant although many have gone on to become independent typists. His critics, such as Offit (2008), suggest that the assistant, not the autistic person, does the writing. This has been refuted by many of those Biklen has supported such as autistic Australian woman Lucy Blackman in her autobiography Lucy's story (2001). He also promotes the idea of autism as not something absolute but as a social construction (in which he has several allies, as mentioned earlier), and critiques the main current theories of autism such as theory of mind, central coherence, and that autistic people have an 'aloneness' and lack empathy. His 2005 book Autism and the myth of the person alone includes firsthand accounts by several severely autistic people who were unable to communicate with words until they learned his techniques. His work is significant in the ongoing debate of who speaks for autistic people.

Papers from a US conference on the social construction of autism have been edited into a volume called Autism and representation (Osteen, 2008). It includes papers from Murray (2008a) and Nadesan (2008b), as well as contributions from several autistic people. Dana Lee Baker (Baker, 2006a, 2006b, 2007, 2011; Baker \& Steuernagel, 2009) 
from Washington State University writes about autism policy from a political studies perspective. Australian sociologist David Gray (1994, 2001, 2002) has long studied families and autism. His longitudinal study and other research on parental coping strategies and resilience have policy implications.

There are also a growing number of reports and papers on various aspects of autism such as education, recreation and outsider perceptions that have also been useful (Burke, 2009; Huws \& Jones, 2010; Moloney, 2010; Myers \& Plauche Johnson, 2007; Rocque, 2010).

\section{Academics from the field of disability studies, and disability activists}

The field of critical disability studies has developed since the late 1960s and is relevant to my research on autism. There are significant milestones such as the 1975 statement from British disability rights group UPIAS (1976) which provided a structural analysis and redefinition of disability, and led to the founding of international organisations such as Rehabilitation International. There are significant works by British disabled academics developing and critiquing the social model (Oliver, 1990, 1997, 2002; Shakespeare, 2006; Sheldon, Traustadottir, Beresford, Boxall, \& Oliver, 2006). Much of the British-based work has developed out of sociological concepts of collectivism and class. Theorists such as Brazilian Marxist educator Freire (1972) have provided useful frameworks. In contrast the US disability rights movement has largely developed out of the human rights discourse (Sullivan, 2008). Disability academics from Australia and New Zealand have also contributed to the debate including Australians Christopher Newell and Gerard Goggin, and New Zealanders Martin Sullivan and the late Anne Bray (Bray \& Mirfin-Veitch, 2003; Goggin \& Newell, 2005; Newell, 2006; O'Brien \& Sullivan, 2005). Peter Beatson (2004) and Margaret Tennant (1996) have published in this area, and the New Zealand Journal of Disability Studies has many relevant articles. Several disability theorists internationally have found Foucault's views of the power/knowledge discourse, biopower and biopolitics, the body, punishment and mental health useful in their own critiques (Nadesan, 2008c; Sullivan, 1995; Tremain, 2005). Critiquing the role and power of the researcher has also reinforced the importance of getting relationships right in research (P. Hunt, 1981; Oliver, 1990, 1997, 2002). 
The development and monitoring of the 2006 UN Convention on the Rights of Persons With Disabilities has united and linked disability activists from many countries. New Zealand played a significant part in its drafting (Convention Coalition, 2010; Frost, 2007b; Moriarty, 2009; Moriarty \& Dew, 2011). Canadian Marcia Rioux (Rioux \& Valentine, 2006) has devised a disability-led global monitoring response.

\section{People involved in the development and implementation of relevant New Zealand policy}

Joanna Curzon, research team leader at the Ministry of Education, has been responsible for championing the Guideline development over many years and commissioning much of the educational research involved. In 2008 a special issue of the Ministry's Kairaranga (Ministry of Education, 2008) was devoted to evaluation of several ASD projects. A Senior Officials cross-departmental group oversees autism policy in their various ministries. The area of disability policy has been active for many years, with disabled people taking a growing role such as in the development of the Disability Strategy (Ministry of Health, 2001). Matt Frost (2007b) and Martin Sullivan (2005, 2009) are two disability activists who have written and presented on New Zealand's disability policy. Public servants Lynda Little (2003) researched the ASD guideline development up until 2003 as part of her Masters of Public Policy (MPP) degree and for her MPP Tessa Thompson (2007) examined why New Zealand disability policy and implementation is not as effective as it could be. The Institute of Policy Studies at Victoria University (2008), commissioned a study for public sector managers and front line staff on 'joining up the horizontal and the vertical' which included examples from autism. History of health policy is also relevant as are the implications of our contracting model for health and social services (Cumming \& Stace, 2006; Tennant, 2007; World Health Organisation, 2004).

The New Zealand Guidelines Group held the contract for the first two years of implementation of the ASD guideline and its work included consulting with the sector, developing materials, and developing service specifications for autism services.

\section{Internet autism resources}

For this research I read widely on work in the autism field and set up electronic alerts from a variety of sources including clearing houses and websites. There is a vast amount 
published in the academic literature about aetiology and treatments, but surprisingly little about policy. I was particularly interested in any policy-related debates.

\section{Bringing expertises together: recognising conflicts}

Traditionally in the area of autism, the experts have been the professionals and clinicians. Consumers and lived experience were largely ignored. But we need a new way to acknowledge expertise and get different voices into the decision making process at all levels. For my purposes an expert is someone who has experience of the issues, preferably first hand. So, who are the experts when you look at an issue like autism?

\section{Autistic people}

Those who live with it every day - autistic people themselves - are the obvious experts, and there is diversity in their lived experience. The growth of the disability rights movement since the 1960s has brought new expectations for inclusion for disabled people. This current generation of autistic people is the first with expectations of rights to education, employment, independence, and self advocacy.

There is a strategy employed by those who seek to divide the autistic community, which implies colonisation of the self advocacy movement by those who are more articulate or high-functioning, and examples can be seen on the comments sections of websites such as the www.ageofautism.com. Some of the parents there claim that the self advocacy movement is pushing the rights of the more articulate at the expense of those whose parents want their child's autism treated. However, to me this only indicates a need to encourage a stronger self advocacy movement among people with greater support needs. There are challenges in involving non-verbal or more severely impaired people in decision making and research processes. But just because it is hard does not mean we cannot or should not. Interestingly, a draft for the new edition of the $D S M-V$ suggests there will only be one general category for autism as the divisions between such terms as high functioning and low functioning are unclear and unhelpful, and Asperger's syndrome is likely to disappear (Grinker, 2010). Discussion on autism websites such as Asplanet has been lively with an occasional 'high functioning' adult unhappy about the prospect of being grouped with those with more classic autism. 


\section{Parents/carers}

Another group of experts, also historically sidelined, are those who care for autistic people, such as parents and other family members. They are also experts, because they have faced and found solutions to some of the caring and advocacy issues. But their expertise is of a different kind from those who have disability. It is a caring and problem-solving expertise. Like me they become experts thanks to their disabled family member. Autism New Zealand grew out of parents seeking support and understanding for their autistic children in the 1960s, when this was still a new and rare diagnosis (Bruce, 2010). Two influential websites started by parents of autistic children to counter the misleading information that MMR and Thimerosal were implicated in autism are www.neurodiversity.com and www.autismdiva.com.

Unfortunately, while parents may be experts on their disabled children, they are not always the best advocates for their disabled children. I know that there are times when my expectations for my son are much lower than he deserves and I have had to be pushed by others to give him more independence - to allow him the dignity of risk. There are also parents of autistic children whose actions are harmful or potentially dangerous for their children, usually unintentionally. Parents have, of course, allowed their children to be institutionalised (although often for complex reasons, and not always of their choosing). Parents occasionally kill their autistic children. Some have killed out of desperation and others have killed in seeking to cure the autism through suffocation, exorcism or injection (Offit, 2008). Others, in their attempt to cure or treat the autism subject their children to untested chemicals or medications, or prevent them from getting immunisations which could prevent illness. Many parents subject their autistic children to chelation therapy with the aim of removing the heavy and toxic metals such as mercury that they consider caused the autism. Lupron is a form of testosterone that many parents inject their children with, apparently to prevent 'autistic' behaviour. Others seal their children in hyperbaric oxygen chambers, or severely limit the food their children are allowed to eat, or force them to do repetitive and boring intensive therapy. A parent quoted on the www.ageofautism.com website on 28 April 2009, reports that she happily sprinkles an industrial chemical, not approved for human consumption, on her autistic child's gluten-free breakfast. So it cannot be assumed that 
parents are the best advocates for their children, even when they have the best of intentions.

Some parents talk of their autistic children having no souls or of being stolen by autism, such as a recent campaign by powerful parent lobby group Autism Speaks (Wallis, 2009). Offit's (2008) book on bad autism science contains photos of parents at rallies with their children holding banners with negative comments about their children. Antivaccine campaigner David Kirby recently called autistic children 'toxic' (Kirby, 2011; Sullivan (blogger), 2011).

New Zealand now has a carers' peak body comprised of several advocacy groups, including Autism NZ, called the Carers' Alliance, which succeeded in negotiating a Carers' Strategy and five-year action plan with the former Labour-led government (Ministry of Social Development, 2008). Recently there was a report from the National Health Committee on support for carers (National Health Committee, 2010). There has been a long-running court case between the Crown and the Human Rights Commission about payment for parent carers of adult disabled people. Since the early 1990s parents and family members have not been able to claim payment at the same rate as non-family carers as they are considered 'natural' support. Opponents cite the ethical question of families profiting from a family member's disability. The parents won their case in January 2010 (Human Rights Commission, 2010), but it has since been appealed by the Ministry of Health.

\section{Professionals}

Then there is the expertise of those who work with disabled people using their professional knowledge as teachers, psychologists, speech therapists, advocates, clinicians and paid carers. They are the ones who can go home and leave the disability behind. The pay packet is not a measure of expertise. I have found my best support in some exceptional teacher aides, carers and volunteers - the lowest paid in the hierarchy. There are hundreds of professionals in New Zealand who belong to professional associations with codes of ethics doing their best for children and adults with autism and with the best of available knowledge. 
However, as indicated above there are divisions among clinicians and professionals who have an interest in autism. While Kanner and Asperger were fascinated by and tried to help a group of children, Bettelheim - in retrospect - did not appear to be so principled (Severson, et al., 2008). But he was only one of many academics and clinicians who believe they have the best intervention for autism. Lovaas (1987) was a Skinnerian behaviourist psychologist who pioneered an intervention based on operant conditioning called Applied Behaviour Analysis (ABA) in the 1970s. This one-on-one therapy required autistic children to do repetitive tasks as taught by the therapist, sometimes for hours on end. Compliant behaviour was rewarded with lollies/candy and non compliance brought punishment. The 1967 Adelaide autism conference proceedings describe an early version of the therapy whereby punishment was a smack on the hand (Autistic Childrens' Association of South Australia Inc, 1967). These days ABA is extremely popular although corporal punishment is no longer recommended. Many parents spent thousands of dollars a year on ABA - even mortgaging their houses. Training for therapists varies from those who have done a two or three day course, to degree studies. Many parents on websites (Goldberg \& Putrino, 2009) or known personally to me credit ABA with developmental progress of their autistic children. The Living Guideline Group, which is part of the ongoing ASD guideline work, assessed meta-analytical evaluations of $\mathrm{ABA}$ and concluded that the published Guideline recommendations for generic evidence-based intensive early intervention were valid (New Zealand Guidelines Group, 2009). Meanwhile some autistic adults have criticised interventions as abusive when autistic children are forced to participate in repetitive, boring and unhelpful therapy (Baker, 2006b; Boundy, 2008; S. M. Robertson, 2010; Trevedi, 2005).

\section{NGOs and community organisations}

Then there is the expertise of the non-governmental agencies which get government money through contracts and raise money from the community. They are often run by parents or professionals. Their challenge is to increase the representation of disabled members in their organisations in both governance and management. Some are genuine support groups for people with autism which seek autistic expertise in their governance and operations, while others contain lobbyists for particular interventions, are primarily service providers, or corporate charities. 
Age of Autism and Generation Rescue are US examples of parental groups lobbying for interventions to 'recover' their children from autism. Autism NZ and the UK's National Autistic Society are respected nationwide organisations that started as parent groups but now have professional and autistic members.

Altogether Autism is a New Zealand organisation which started when a collaboration between NGOs Parent to Parent and Life Unlimited won a contract in 2006 over the other applicant, which was Autism NZ, to provide information about autism. However, Altogether Autism and Autism NZ now often collaborate, with a Memorandum of Understanding. There are also various regional ABA trusts. Some members of Autism NZ's Auckland branch split from the national organisation to become Autism House and they now provide therapies and information about non evidenced-based interventions such as chelation.

\section{Public servants}

Then there are the public servants - policy makers, advisors, educators and researchers, whose job it is to bid for public money from politicians, and to use it wisely to improve the lives of disabled people and their families. Joanna Curzon, mentioned earlier, from the Ministry of Education, is an example of a public servant who has been supportive of parents and one of the main movers behind the ASD guideline. Such people could be considered autism 'policy entrepreneurs' (Baker \& Steuernagel, 2009) as described in Chapter Seven.

\section{Politicians}

The controllers of the purse - politicians - must also be considered. From my own experience I know that the Hon Ruth Dyson, the Minister for Disability Issues in the previous Labour-led government, encouraged policy progress around autism. The current minister, the Hon Tariana Turia, has secured funding for disability-led (although not autism-specific) research to monitor the UN convention. Anecdotally, several current members of parliament are known to have family connections with autism, and some mention this experience openly such as in public hearings of select committees. Most New Zealand electorate politicians would be aware of problems around access to education and support for autistic young people through their constituency work. 


\section{Expertises - summary}

So there is a wealth of expertise in the community about autism. People can belong to more than one of these groups. Some who work as professionals also have autistic family members, and some may suspect that they themselves are on the spectrum. We desperately need all these people to work together to get good outcomes for autistic people and their families, while at the same time guarding against those who seek to harm or put autistic people at risk with dangerous therapies and interventions.

In the past these expertises have been ranked, with professionals and policy people near the top. We have ignored the expertise of disabled people totally until recently, to the extent of abusive institutionalisation. But how do you turn that power hierarchy around? Whole-of-government approaches have the potential to harness all the various expertises. One good example from New Zealand to incorporate a variety of expertises was the development of the ASD guideline which is examined further in Chapter Nine. This was the product of a decade of cross-government work led by the Ministries of Health and Education. Workstreams incorporating public servants, professionals, researchers, parents and people on the spectrum evaluated autism best practice from around the world. The initial implementation advisory process was chaired by a young man with autism, later replaced by a new cross-sector advisory group which included five members with autism.

\section{Conclusion}

This chapter has described the types of experts and expertise I consider important for my inquiry and provided examples of the types of literature sources I use to answer my research questions. A smaller proportion than usual for a $\mathrm{PhD}$ thesis is sourced from the academic literature, and a larger proportion from articles in the media, auto/biographical accounts, websites and social media. Other material comprises policy documents and reports as governments in various countries develop autism strategies. The reliance on grey literature is necessary as the firsthand accounts of lived experience of autism that I require for my study are rarely found in the academic literature.

This section has set the scene for my research and has outlined the issues, the methodology and reviewed the literature sources for the literature. The following 
section provides specific context and definitions for this thesis: how autism fits into the bigger context of disability studies, activism and policy; and the importance of the terms used in the research questions. 


\title{
Section Two: Contextual Background
}

\author{
History and construction of autism; disability policy \\ and the role of the disability rights movement; love and \\ luck, right relationships and lived experience
}

None of the events on the path to today's autism policy challenges happened in a vacuum, and the next three chapters examine some vital and specific contexts and concepts relevant to this thesis.

When Kanner named autism in 1943, it had not magically appeared out of nowhere. It took place against a context of specific historical, clinical, political and social developments. Not surprisingly, it is a diagnosis that has evolved as society's roles and expectations change. Activism by autistic people and parents has played a significant role. Chapter Four covers these aspects of autism and autism policy.

Autism activism has to be seen against the wider context of changing views of disability and the rise of disability rights activism, which is the topic of Chapter Five. Without the disability rights movement, its theorists and the activists, people with autism could still be living in institutions with few human rights, and certainly not participating in the policy process. The concept of disability has also been challenged and changed over the decades from something located in the individual to something created by society.

'Love', 'luck', 'right relationship(s)' and 'lived experience' are concepts vital to the argument of this thesis. Chapter Six explains why these are key and relevant terms. 


\section{Chapter Four: The history and construction of autism}

Figure 5: Autistic Self Advocacy Network protest at a university in the US

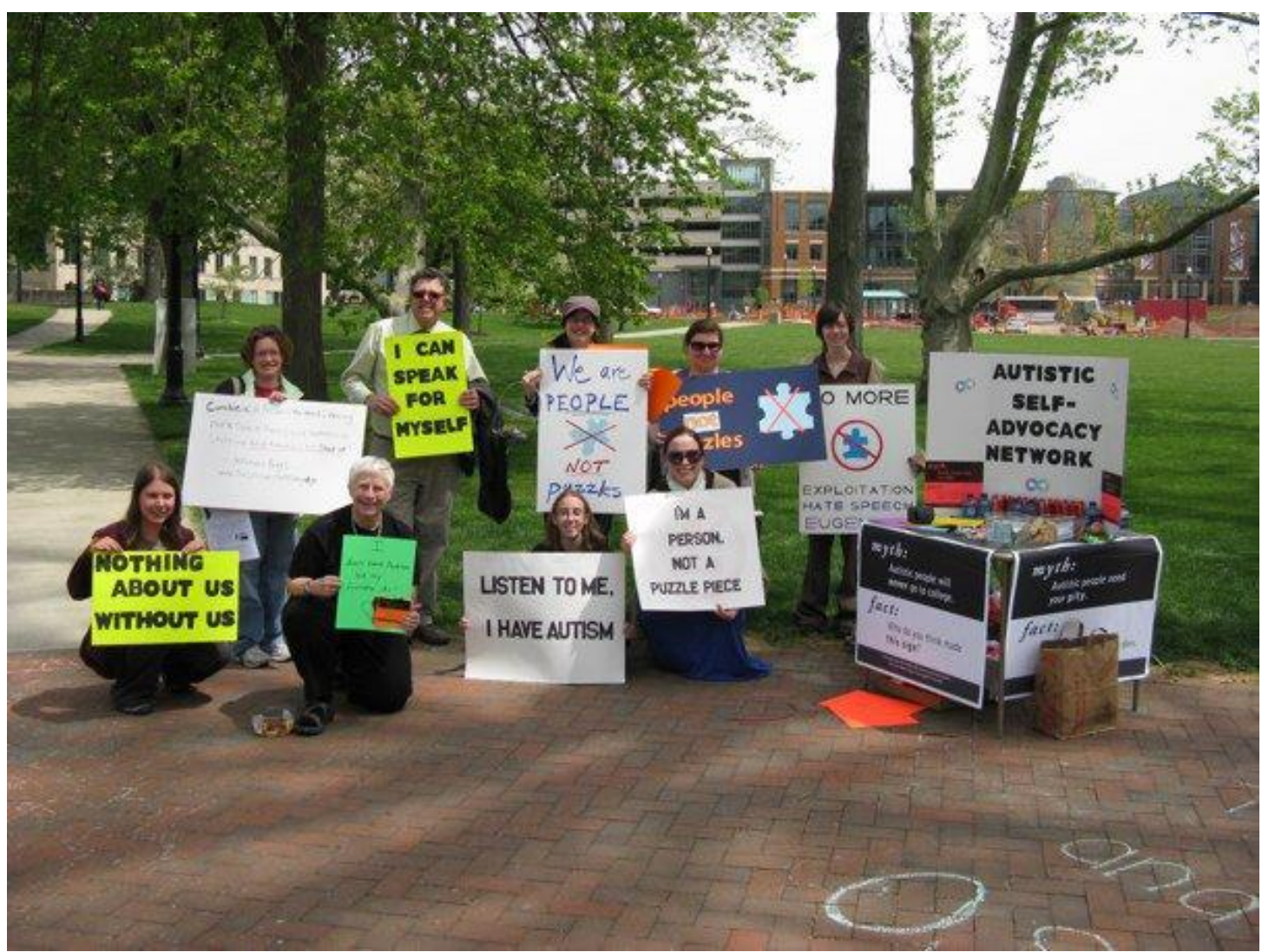

Source: Facebook January 2011

\section{Introduction}

While the previous chapter outlined some of the sources used to answer my research questions, this chapter examines the concept of autism itself: the historical context, the naming of the diagnosis including the role of the Diagnostic and Statistical Manual of Mental Disorders (DSM), the role of significant players such as Kanner, Asperger and Bettelheim, and ongoing discourse such as around the meme of the refrigerator mother. Although it is a clinical diagnosis, the idea of autism is also a cultural construction. It has been constructed through media, film and language, in arguments about whether it constitutes an epidemic and as a contested concept from those who claim it as a positive 
part of their identity to those who consider it a tragedy requiring elimination. I will conclude the chapter with a short history of autism in New Zealand.

Autism was first named as a separate condition in 1943 by Dr Leo Kanner (1943). But why there were apparently no people with autism 100 years ago and why are there so many now (Stace, 2008)? This chapter looks at the development of the diagnosis of autism internationally and locally, in the context of the development of attitudes to disability and mental health, psychology and psychiatry, and evolving views about normal childhood. It looks at how the diagnostic and clinical understandings and concept of autism have developed over the last century, how these have been represented in popular culture, and considers whether there is an autism epidemic.

As knowledge about ASD is constantly developing and evolving, many details and ideas about autism are contested; consequently this moving, kaleidoscopic picture makes it difficult to address from a policy perspective. To help understand why autism is such a difficult policy problem requires examination of the idea of autism as a combination of such aspects as diagnostic criteria, historical context, the social construction of a problem and identity-versus-cure politics. New Zealand's autism policy challenge is linked with all of these strands.

\section{ASD diagnostic criteria}

Australian Judy Singer who has a mother and daughter with autism notes: 'As befits a disability emerging for the first time in the postmodern era, the autistic spectrum has fuzzy boundaries. Not even its name has been agreed on' (1999, p. 63).

ASD is becoming an ever-wider spectrum and autism an increasingly contested concept. As mentioned in Chapter One, the diagnostic criteria for Autistic Disorder 299.00, Asperger's Disorder 299.80, and other related conditions collectively known as Pervasive Developmental Disorders, covers several pages in the DSM (American Psychiatric Association, 2000). The World Health Organisation's (2007) latest ICD-10 criteria are similar (see Appendix One for more detail). The criteria can be summarised in three main areas: impairment in social interaction; impairment in communication such as delays in use of language or unusual use of language; and repetitive or 
restrictive behaviour. There are a variety of interpretive options so it is not surprising that ASD has spawned an array of diagnostic tools.

However, as mentioned earlier, official descriptions only give a partial picture as they diagnose impairment in terms of deficit from the perspective of a neurotypical person (a non-autistic outsider), and neglect the autistic person's perspective. For example, neither the $D S M$ or $I C D$ list includes sensory sensitivities (which may cause behavioural reactions), although various hyper- and hypo-sensory sensitivities are commonly reported by autistic people (Abrahamson, Enticott, \& Tonge, 2010; S. M. Robertson \& Ne'eman, 2008), and feature prominently in the definitions of autism by those on the spectrum such as the ASAN website www.autisticadvocacy.org. Another common problem for autistic people living in a neurotypical world seems to be with executive functioning such as personal organisation, time management, and ability to predict outcomes even from activities that are done regularly (such as the duration of the school day). Such problems for autistic people stem from having to cope with a population of neurotypical people in a world which they sometimes find unpredictable and difficult to understand. The issues are similar to the experiences of a cultural minority in a majority culture, and some autistic people now identify as a cultural minority - using commonly used collective terms such as 'Aspies' or 'Aspergians' (Robison, 2007; Silberman, 2010; Trevedi, 2005).

\section{Age of autism}

Majia Nadesan, Professor of Communication Studies at Arizona State University suggests:

that autism is a disorder of the early twentieth century, whereas high functioning variants such as Asperger's Syndrome... and Pervasive Developmental Disorder ... are disorders of the late twentieth- and early 20first centuries ... Childhood psychosis was not widely recognized professionally until the closing decades of the nineteenth century, and the idea of the developmental disorder was a twentieth-century psychiatric innovation. ... Identification of individuals with "mild" autism spectrum conditions awaited a host of conditions: the invention of intensive 
mothering, the standardization of (narrowly delineated) benchmarks of developmental normality, and widespread pediatric surveillance of very young children (Nadesan, 2008b, p. 84).

As stated earlier, latest prevalence estimates (US Department of Health and Human Services, 2010b) are that about 1:100 people are on the autism spectrum, a huge increase in the last twenty years. Psychologist Tony Attwood (2009), who has studied autism for almost 40 years, half-jested in a Wellington talk that all humans are on a continuum, with those with autism clustered more towards one end.

Professor Fitzgerald (2005; Fitzgerald \& O'Brien, 2007), Professor of Child and Adolescent Psychiatry at Trinity College Dublin, is credited with coining the term 'age of autism' (Arnold, 2009). He also uses his psychiatric expertise to diagnose Asperger's or autism in influential historical figures including writers, philosophers and mathematicians, which fascinates some, and infuriates others, who see autism as a tragedy requiring a cure and who have called their group the Age of Autism (www.ageofautism.com) to fight against the normalisation of autism. Fitzgerald reflects this dichotomy in his co-authored book asking whether Asperger Syndrome is a gift or a curse (Lyons \& Fitzgerald, 2005). There is a continuum of responses to autism from parents and people with autism, but these two strong viewpoints are represented strongly enough in the grey literature to be considered as almost a cultural war.

This division between those who see autism as fascinating, positive, and even part of cultural identity, versus those who see it as personal tragedy and seek intervention and cure, also occurs in New Zealand, and is a complicating factor in formulating policy approaches to autism. If we are indeed in the age of autism, how did it happen? The above examples illustrate that our understanding of autism is constantly evolving and it is difficult to predict where we will be in twenty years time. 


\section{Historical contexts for ASD}

Understanding the present warrants a brief overview of autism history.

\section{Kanner and Asperger}

Interest in the study of childhood and child development grew in the early decades of the $20^{\text {th }}$ century. Into this context came Leo Kanner, an Austrian-born German-educated pioneer child psychiatrist, who by the 1930s was working in the United States. He first named autism as a separate condition in 1943 in a seminal article called 'Autistic disturbances of affective contact' about a group of children he was working with (Kanner, 1943). Meanwhile in Vienna, Austrian paediatrician Hans Asperger was working with a group of similar children. He described a more strengths-based condition than Kanner - possibly because disabled children were being sent to concentration camps at the time, and he wanted to avoid a label that could be considered dangerous. It took until 1981 for his work to be translated into English by British autism researcher Lorna Wing (Frith, 1991) and until 1994 for Asperger's syndrome to become an official diagnosis in the DSM IV (Grinker, 2007). However, a recent study claims that the historical journeys of the papers from the two different diagnosticians are responsible for the distinction and Asperger's and autism 'are different quantitative manifestations of the same disorder' (Sanders, 2009).

Kanner studied an elite group of children of well-educated middle-class parents, and although he realised there was something genetic in their condition, he initially blamed parents, particularly mothers. He said parents kept their children 'neatly in a refrigerator that did not defrost', as quoted in Grinker (2007, p. 72). Apparently he later regretted saying this as the idea was taken up with enthusiasm by Bruno Bettelheim (1967) of the 'refrigerator mother' theory in his 1967 book The Empty Fortress. This mother-blaming persisted for many decades, and remains problematic (Stace, 2010b).

\section{Historical context for the work of Kanner and Asperger}

The $19^{\text {th }}$ century, particularly in Britain and Europe, could be considered the era of the 'great confinement' (Foucault, 1977). Poor people, people with infectious diseases or mental health issues were readily locked away in big institutions. This captive population provided a great opportunity for the medical profession to observe and 
theorise, and some offered public viewing. There were probably people in those institutions who would today be diagnosed with autism. One indication is that the term 'idiot savant' was coined in 1887 by John Langdon Down (who identified what is now known as Down Syndrome) (Grinker, 2007, pp. 54-55). But generally they were just part of the great other - the 'idiots', the 'feeble minded', the 'mentally defective', to use contemporary terms. These labels were probably as well known as today's ASD and Asperger's syndrome.

Throughout the $19^{\text {th }}$ century scientific knowledge made major advances. The publication of Darwin's (1859) On the origin of species in 1859 was tremendously influential as it showed humans were genetically linked rather than being here randomly or created by a divine power. Over the decades others developed his ideas about genetic heritability. The medical model developed whereby people were seen as body parts which could be diseased and cured. There was a growing desire to classify and define.

As Nadesan notes above, Kanner's work took place in the contemporary contexts of developments in understanding mental illness, and in the study of childhood. The decades leading up to Kanner's work naming autism had seen many developments, particularly in the area of child psychology. From the early $20^{\text {th }}$ century the new fields of psychiatry and psychology developed in Europe and Britain as mental illness moved from something located in the body like a disease to something in the mind which could be treated by counselling or psychoanalysis (Grinker, 2007). Probably best known in this field, with an influence lasting a century, was Sigmund Freud. Eugen Bleuler, a Swiss colleague of Sigmund Freud, treated young people with mental illness and named the diagnosis of schizophrenia in 1908, and in describing its symptoms he used the word autismus or autism in a 1910 paper (R. Kuhn \& Cahn, 2004). So autism as a diagnostic description is 100 years old, although Bleuler didn't use it in the modern sense. Interest in the study of childhood continued into the 1920s with Swiss psychologist Piaget defining normal developmental progress as he observed and reported on the development of his own children (L. Smith, 1993). So mothers started anxiously observing their own children. 
Into this context came Austrian-born Kanner who by the 1930s was working in Baltimore, as the first-ever specialist child psychiatrist. As mentioned above, he observed children who also had an 'aloneness' and borrowed the word 'autism' from Bleuler for his 1943 paper. Meanwhile in Vienna, and possibly unaware of Kanner's study, Austrian paediatrician Hans Asperger was working with his group of children, and seeing something similar for his 1944 paper that would not become known to the English-speaking world for several decades.

Nadesan has summed up the influences behind the development of the diagnosis of autism:

[T]he convergence of new ideas about childhood, new systems of surveillance, new expert authorities, and new institutional arrangements provided the conditions of possibility for autism to be identified, named and interpreted. We must place Hans Asperger's pediatric practice and Leo Kanner's child psychiatry within these historical contexts. .... both Kanner and Asperger appropriated Bleuler's description of the schizophrenic's "autistic" style of thinking, which Bleuler had appropriated from Freud. This intellectual heritage engendered the assumption that autism was characterized by aloneness, solipsism, and a turning away from the social world, resulting in a failure to develop a "normal" ego. However, whereas Kanner viewed autistic thinking in relation to psychosis, as an underdeveloped or disintegrating ego ..., Asperger was more inclined to regard the children under his care as afflicted with a particular type of (nonpsychotic but disordered) ego that afforded unique insight into the natural world even while it created social discord. Both Kanner and Asperger felt that autistic thinking resulted from inborn, biological forces; however, Kanner also noted behavioral and personality similarities in the parents of his autistic children ..., thereby implying the possibility for some level of social influence in creating autistic symptoms. (2008b, p. 87)

\section{Bettelheim}

Another whose work would have an internationally long-lasting influence was Bruno Bettelheim (1967). His theories have since been shown to be false and after his death by 
suicide in 1990, aged 89, some of his former child patients reported emotional and physical abuse (Grinker, 2007). But he is important in the construction of autism in that his work represents 'a little-studied phenomenon in the rhetoric of science: the persistence of false beliefs in an ostensibly scientific community' (Severson, et al., 2008, p. 66).

Bettelheim was a holocaust survivor (he was freed from a concentration camp on Hitler's birthday in 1939 and then migrated to America) who was not qualified in psychoanalysis, but managed to find employment as the Director of the Orthogenic School for 'emotionally disturbed children' at the University of Chicago. He suggested autistic children suffered from 'extreme situations' similar to being in the holocaust but caused by maternal deprivation. He advocated what he called 'milieu therapy', a psychoanalytic approach to reaching the inner child, which unfortunately 'will always, to some degree, mean a descent to one's own hell' (2008, p. 71). But rather than being regarded as an eccentric unqualified therapist, Bettelheim developed a following among a mainstream American audience as a popular writer for publications such as the Ladies Home Journal, Scientific American and Playboy. His:

career benefited from his ability to construct an ethos that appealed to an audience beyond the scientific community. His status as a European intellectual propelled him to fame with an American mass audience. Furthermore, his desire to produce readable texts secured his position as an expert on child behaviour. (2008, p. 76)

So when his book The empty fortress: infantile autism and the birth of the self was published in 1967 it was to a ready-made audience. The empty fortress expanded the refrigerator mother motif that Kanner had earlier suggested, and others had echoed, and which was a useful tool in that by blaming parents, particularly mothers, it challenged the authority and expertise of mothers. They were the villains and the therapist was the healer. Some call this the 'autism conversion narrative' involving 'visionary therapists who rescued children from toxic parents and the hostile culture threatening sensitive young people in post-war America' (Fisher, 2008, p. 53). 


\section{Role of parents}

In August 1967 the first autism conference in the southern hemisphere was held in Adelaide, South Australia, entitled 'Autism: Cure tomorrow, Care today' (Autistic Childrens' Association of South Australia Inc, 1967). Marion Bruce, who was then the mother of a young boy with autism and the wife of a GP from the Wellington region, attended (Bruce, 2010). She had a significant role in the development of autism awareness and parent support in New Zealand. The published papers of the 1967 conference provide a unique snapshot of autism best practice from the era. Bettleheim's work was already well known, and challenged by several speakers who saw organic, not parental, causes of autism. Mrs Bruce suggests (and has given me permission to quote her) that one of the most significant changes in autism over the decades has been the discovery that autism may have genetic causes, and that parents are no longer blamed for causing autism, as per the 'cruel' refrigerator mother theory which was widely accepted in the community when her child was young. This prejudice, plus the common assumption (begun by Kanner) that autism only affected well-off middle- or upper-class families made seeking support and fundraising difficult (Bruce, 2010). She was grateful for a musical couple who fundraised for autism:

One thing they did for us, every year they gave a concert and every year Myra would sort out some beautiful home that belonged to some high class social person among the psychologists and professional people. And what it did to help us was legitimise us because those people would not have raised money for oddballs. And [being part of $\mathrm{IHC}^{7}$ gave us a sort of leg up.

Consequently, she would now:

encourage any parent to get into the genetic stuff if they have the opportunity, because they will have something to blame. (Bruce, 2010)

Many of the 1967 conference presenters were Australian clinicians working with autistic children to encourage speech, improve behaviour and educational outcomes.

\footnotetext{
${ }^{7}$ Intellectually Handicapped Children's Association now called IHC.
} 
International best practice is frequently referred to in the papers, including an assumption that a large proportion of the autistic children have normal intelligence and should have access to therapies to improve their lives and more significantly access to education (albeit in special classrooms), which was an innovative idea at the time. However, as the interventions are long-term, requiring input several times a week over sometimes many years, there are references to the target population, children as young as four years old, being in residential institutions, either long or short term (such as school holidays). One presenter referred to the counselling required for parents concerned at this enforced separation from their children, and several presenters referred to behaviours such as bed wetting (which could be a result of separation from family and familiar surroundings). But they do not question the ethics of such separation.

Conference papers present the caring face of institutional care, but recent reports from those who have been institutionalised tell us this was not a happy or supportive time for many children (Department of Internal Affairs, 2007). For example, Bettelheim's research on supposedly autistic children (and there are claims that they were misdiagnosed) was based on a few children who were residents of his Orthogenic School, some who subsequently spoke out about abuse (Grinker, 2007).

The Kanner/Bettelheim influence in blaming mothers for their child's autism is significant because, as indicated above, mothers have been fighting it ever since. One of the ways many middle-class mothers have fought back against such views and the other mother-blaming male child-rearing experts is by becoming experts on child development - as my mother told me that she and her mother had done under the influence of the experts of their eras. In the 1940s when Kanner and Asperger were studying their child populations the 'scientific mothering' rules of those such as New Zealand's Truby King, the founder of the Plunket ${ }^{8}$ movement, and the child development theories of those such as Swiss psychologist Piaget were popular (Grinker, 2007; Nadesan, 2005; Stace, 1998a). The 'Plunket' book that every mother was issued with and in which the Plunket nurse detailed her child's growth and development,

\footnotetext{
8 The Royal New Zealand Plunket Society was founded in 1907 (and still survives nationwide as a major 'well child' provider) to encourage 'scientific mothering' and promoted strict rules for child rearing, feeding and sleeping. Plunket nurses saw and still visit a large proportion of New Zealand babies.
} 
plotted against a normal graph, is a superb example of the technology of surveillance (Sullivan, 1995).

Mothers learn what is normal and from surveillance of their children's development, are alert to any supposed 'deviance'. So in the extreme case of an autism diagnosis - a tragedy in this scenario - they become experts on autism and may pursue various treatments in an attempt to return their child to normality (Nadesan, 2005). The autistic child has been constructed in the public mind over the decade as locked inside, a nonfitting jigsaw piece, the child poisoned by immunisation, a suffering child in need of rescuing or curing, both heroic and tragic. Some parents have been encouraged to medicate, with new drugs developed to treat autistic symptoms, and thus medicalise something that in other contexts is not seen as problematic (the medicalisation of pregnancy, and drug interventions for menopause are other examples of the pathologising of normal human conditions).

This inevitably leads to conflicts such as in Britain in 2007 when former actress Jane Asher launched the National Autism Society's campaign 'Thinking differently about autism' which encouraged acceptance of autism as just another way of being. She was immediately attacked by a parents' lobby group which did not want autism to be seen as normal but instead wanted to have access to the latest treatments (S. Murray, 2008b).

A 2009 article in the New Scientist (Anonymous, 2009) suggested schizophrenia and autism could be opposites, with schizophrenia implicated by undeveloped regions of the brain while autism is an overdevelopment of the same regions, or they could be linked to deletions or duplications of particular stretches of DNA. However, the previously common diagnosis of childhood schizophrenia is rarely used today, while childhood autism diagnoses have become increasingly common. Additionally recent reports are of record levels of antipsychotics given to children (US Food and Drug Administration, 2009).

\section{Historical examples}

It is likely that there have always been people with autism, well before the condition was named - for example the traditional village 'idiot', court jesters, feral children, people in travelling circuses, and that eccentric great uncle many families report, could 
all have been on the spectrum. The 'ship of fools' was one policy reaction to intellectually and mentally disabled people from previous centuries- when people, some of whom may have had autism, were put on ships and cast adrift (Foucault, 1977). Others were incarcerated in asylums, or workhouses. There are also innovative and creative people from the past who may have been autistic but found appropriate support and acceptance. Fitzgerald (2005), mentioned earlier, has diagnosed several high achievers posthumously including Beethoven and Hans Christian Andersen. Another example is Viktor, the famous $18^{\text {th }}$ century feral child of Aveyron in France, who has been posthumously diagnosed as autistic by long-time autism specialist Professor Uta Frith (2003).

\section{Diagnostic and Statistical Manual of Mental Disorders}

A major contributor to the rise in diagnoses is the American Psychiatric Association's $D S M$ (see Appendix One). In the U.S. services are dependent on where you live, what insurance cover you have and what diagnostic coding has been used (Grinker, 2007). No insurance, or a poor education district, and access to services minimal. In this context the DSM tick has become a powerful tool in getting a diagnosis and therefore support. A coding change in the US's education system to allow an autism label a few years ago resulted in a huge rise in numbers of students with autism (2007).

The DSM influence on the 'epidemic' of autism is fascinating. According to Grinker (2007), the 1918 forerunner was a short Manual for the use of institutions for the insane. The DSM 1952 and DSM-II in 1968 gave outlines of about 100 psychiatric conditions, and did not mention autism although it was hinted at under 'Schizophrenia, childhood type'. But DSM-III in 1980 removed autism from schizophrenia and called it a pervasive developmental disorder (PDD). The DSM-IV had more explicit explanations for autistic disorder and the first mention of Asperger's Disorder. A proofing mistake in the PDD-NOS (not otherwise specified) section, which is the largest group of ASDs, left 'or' instead of 'and' inserted between symptoms, which meant only one symptom was required to confirm a diagnosis. This opened the diagnostic floodgates until the mistake was corrected, and the criteria tightened in the 2000 Text Revision (American Psychiatric Association, 2000). The next DSM is due out in 2013 and, as mentioned previously, not only is the triad of impairments likely to be revised, but Asperger's is 
likely to be removed as many no longer consider it a psychiatric condition (Grinker, 2010). The DSM is only one source, and other tools such as the World Health Organisation's ICF-10 are used in other countries, and there are also a large range of diagnostic questionnaires and tests, but the DSM with its power and status, has played a significant role in the construction of the idea of autism.

\section{Cultural and political understandings of autism}

Medical, psychological and social understanding of autism is constantly evolving. Numerous clinical papers are published in peer-reviewed journals every year. But this thesis is more concerned with the idea of autism as something culturally located, and although the large majority of research on ASD is clinical or genetic, the numbers of those considering the cultural constructions and representation of autism are increasing. Proponents include three authors whose work has already been referred to: Nadesan, Murray and Grinker. They are all parents of autistic children who have used the lens of their own discipline to research autism. All agree that study into autism is in its infancy, and Murray speculates that the autism spectrum may be as wide as the non-autism spectrum (2008b). Ethnographer Grinker (2007) travelled to several countries such as South Korea, South Africa and India to compare attitudes and interventions to autism with his own experience as a father of an autistic girl in the United States.

In 2006 the US Government passed the Combating Autism Act (US Congress, 2006). However, rather than destroying autism as its name suggests, its aim was to coordinate autism knowledge and best practice through centres of research excellence. It also created an Interagency Autism Coordinating Committee. Since then, the Committee has been going through a process similar to the New Zealand Guideline development, in that they are attempting to define the issues and to recommend best practice.

As mentioned earlier there are concerns about equity of access (Bishop \& Lord, 2010) with the middle-classes being the most likely to benefit (which may explain why it has been considered a middle-class condition). A recent media report on autism in California echoes the middle-class assumption (Phend, 2010), and another the role of social networks in autism diagnosis (Liu, King, \& Bearman, 2010). Poorer or socially marginalised families are less likely to have the networks, time or money. 
Consequently, disability is generally under-reported in these groups (Ministry of Health, 2004a). This is backed up by new English research on autism in adults which concludes that autistic 'adults living in the community are socially disadvantaged and tend to be unrecognized' (Traolach, et al., 2011, p. 459).

Reports of high autism prevalence rates for Somali immigrant children in Minnesota have triggered research investigation (McNeil, 2009, 2011). This could be a genetic predisposition, a result of exposure to stress, toxins, or lack of food in refugee camps, or is possibly related to the increased surveillance from health and education authorities of an identified refugee immigrant population. It will be interesting to hear what conclusions they come to.

Questions also have to be asked about who benefits from this attention on autism. As mentioned earlier, the Harvard Medical School has estimated that the cost of autism is US \$3.2 million over a person's lifetime (Ganz, 2007). Autism is therefore lucrative bio-capital as Nadesan (2008c) has noted. Just as some therapists benefit from autism as a result of the 'conversion narrative' mentioned above whereby therapists can 'rescue' the child, there is also big money in patenting autism genes. Internationally, while genetic research is popular, there seems to be little funding going into research into environmental toxins, which might implicate and cost big business (Nadesan, 2005), and money for improving services for poor children seems to be in short supply.

Ironically, in their efforts to 'combat' autism the US authorities have legitimated the huge industry that has grown up recently around autism. Clinical 'experts' are unlikely to seek their own extinction. This is part of the fascination of autism - the more attention it receives the more it grows, the more people know about it and the more diagnoses there are.

Many understandings of autism are based on fear. A 2007 newspaper article about an autistic child in provincial New Zealand used language more appropriate to animals, such as his being a destructive force 'out of control', rather than a young teenage boy (Anonymous, 2007). This reflects back to fear and fascination with feral children of the past (Frith, 2003) and the $19^{\text {th }}$ century public visits to the 'madhouses' or 'freakshow' 
circuses which all reinforced the other, the unknown and threatening (Foucault, 1977). Eugenics and institutionalisation were policy responses to control the other. But the idea of autism as something to fear was even reflected in discussion with the ethics committee during my application for this research, when one member of the committee asked me how I was going to protect myself from the autistic people I might come across.

So the idea of autism can be culturally formed. It also depends on wider cultural notions of what it means to be human, and prevailing political and ideological views on rights and equity. Much of our history has been influenced by ideas that people are not inherently equal. Discussion on autism blogs (e.g. Www.aspiesforfreedom.com) show that some in the autism rights community see genetic testing as having the potential to cause a new genocide against disabled people, including those with autism.

\section{Cultural representations of autism}

The idea that autism is culturally formed can be illustrated by sources or constructions people refer to when asked about autism. Murray (2008b) cites the power of media representation of autism - notably Rain man which influenced a generation about autism (Internet Movie Database, 1988) and the novel The curious incident of the dog in the night-time (Haddon, 2003). Bettelheim's refrigerator mother meme is also still powerful. Ironically, two of the above are works of fiction, while Bettelheim's was a questionable study based on only three children who may not have been autistic (Severson, et al., 2008). Others mention the discredited theory that it is caused by vaccines. They might quote cases of people who have committed crimes such as school shootings or hacking (even though the perpetrators might not have been officially diagnosed with autism) (Fitzgerald, 2010). These all underpin cultural understandings of autism.

Rain man starred actor Dustin Hoffman as Raymond Babbit, an autistic savant living in a caring institution discovered by his younger brother Charlie (played by Tom Cruise) after his father's death. Twenty years later Rain man still features in references to autism. In the 2006 movie Snow cake (Internet Movie Database, 2006) featuring Sigourney Weaver as a high functioning autistic woman in Canada, an unhelpful 
neighbour character comments, 'I know about autism, I've seen Rain man'. Snow cake is a good portrayal of high functioning autism, showing such aspects as the need for personal space, difficulty coping with change, and family stresses. The main character is a parent of a non-autistic child, similar to the movie I am Sam (Internet Movie Database, 2001).

Autistic characters - although usually unlabelled - have featured in many movies. Before Rain man, in 1979 Peter Sellers played a very convincing autistic man (although autism is never mentioned), Chauncey Gardner in Being There (Internet Movie Database, 1979). This adult autistic man named (significantly for my thesis), Chance, has no biographical history apart from being the live-in gardener for a wealthy man. When his benefactor dies he goes wandering into the unfamiliar city, and ends up renamed and living with a wealthy businessman and his wife who are friends of the president. The autism-logical observations Chance makes are taken as unusual wisdom. Peter Sellers plays the role so well he could have had an insider's knowledge. Even earlier, the cult 1971 movie Harold and Maude (Internet Movie Database, 1971), features the young Aspergic Harold, a loner, obsessed with funerals, who meets fellow funeral follower, free-spirited 79-year-old Maude.

Rain man has been followed by other autistic brother movies. What's eating Gilbert Grape? (Internet Movie Database, 1993) featured a young Leonardo DiCaprio and Johnny Depp as brothers. DiCaprio made his name as an actor in this movie, in which he plays an autistic/intellectually impaired teenage boy (no diagnosis is mentioned) in a dysfunctional rural American family, while the Johnny Depp older character tries to sort out the family. Lars and the real girl (Internet Movie Database, 2007b) is another movie where the autism/Asperger's of the main character is not mentioned but his difference, and the community's toleration of it, is integral to the story which is set in a US mid-western winter. Lars, who has been hassled about not having a girlfriend, orders a blow up doll which he treats as a real person, and everyone else in the town does too, including his brother and sister-in-law. The black balloon (Internet Movie Database, 2008) is an Australian movie about autism which owes much to Rain man in that it is the story of the relationship between two brothers. Toni Collette plays the mother of two teenage boys whose family has recently moved to a new town. The older 
son is classically autistic (which is mentioned frequently as part of the story line) and the story centres on the younger brother coping with his autistic brother while trying to fit into the new place as a normal teenager. Unfortunately, this realistic and powerful movie did not have a cinema release in New Zealand, although in 2011 it screened on television. The two main actors apparently went in character to shopping malls to investigate public reactions to autism.

Other films which portray main characters who could be autistic without mentioning it include Forest Gump (Internet Movie Database, 1994) and Shine (Internet Movie Database, 1996). The novel About a boy by Nick Hornby (1998) features a young British teenage boy who is bullied, socially awkward, logical and quite Aspergic. Hornby, who has an autistic son, creates a convincing portrayal, although once again autism is not mentioned. However, the movie of the book (Internet Movie Database, 2002) plays down these aspects of the boy, and the self-centred Hugh Grant character is more of a focus.

More recent movies have labelled their main characters with autism. Mozart and the whale (Internet Movie Database, 2005) refers to a fancy dress date by the two main characters who meet at an Asperger's social group. It was based on the autobiography of an autistic married couple, and the screenplay was by Ronald Bass who also worked on Rain man. NZ director Taika Waititi's Eagle vs shark (Internet Movie Database, 2007a) has a similar theme of geeky, loner characters.

Adam (Internet Movie Database, 2009) is a didactic movie set in a New York winter which sets out to explain that people with Asperger's are real people with hopes and dreams. At one point a school teacher takes off her shelf Aspergic writer Liane Holliday Wiley's (1999) autobiography Pretending to be normal which she recommends as a good book about Asperger's. The main character explains his Asperger's while getting to know his new neighbour who becomes a love interest. The movie begins with his father's funeral and a focus on his life alone in the apartment they shared, with stocks of his favourite food becoming depleted. He loses his a job in an electronics toy company. This film has a very instructional feel to it, and as such is useful for families and friends of people with Asperger's as it shows significant aspects of autism such as literal 
interpretations, honesty (and a subtext of the problems lying brings), and uses words such as aspie and neurotypical. Practical support is provided by a down-to-earth character called Harlen, a friend of Adam's late father, who coaches on appropriate behaviour as well as provides support for visiting lawyers and employment advice. The movie has a theme of honesty and shows being 'normal' isn't always so great. The movie is gently humorous, not laughing at the 'aspie' so much as the misreading of the familiar. I attended a showing which was also a fundraiser for the local branch of Autism New Zealand and afterwards asked an adult with Asperger's what he thought of it. He found it totally confusing and thought it was definitely not for people with autism. It was unrealistic that Adam got a new job so easily, he said. But he conceded it might be useful for non-autistic people, in particular how Harlen acted as the supportive older friend.

Asperger's is also becoming marketable as television and a successful comedy series is the Big bang theory (Internet Movie Database, 2007-), a boys' own story about a group of nerdy young scientists, and the attractive normal-but-not-very-bright girl next door. One character, Sheldon, is portrayed as geeky, with significant mind-blindness, poor social skills, literality, dislike of change and love of ritual, including the same routines and even the same place on the sofa. However, he is a brilliant physicist, so a character of some status. Temple Grandin has herself now been portrayed in an eponymous movie for television (Internet Movie Database, 2010). Co-incidentally, the actress who plays her recently married the actor who played Adam in Adam.

Murray (2008a, p. 246) claims cultural representations of autism have three aspects in common: 'fascination with the condition' 'the attraction of witnessing the condition', and 'ontological difference' that the autistic character provides.

Typically, this involves placing the autistic individual in relation to supposedly typical neurological behaviour, and then mediating an idea of the human by a refractive comparison between the two. (2008a, p. 246) 
This applies to all the above examples except perhaps Mozart and the whale in which there are two main characters with autism. Perhaps this is why their autobiography (Newport, Newport, \& Dodd, 2007) works better as a book than a movie.

\section{Language and symbols}

Language is very important to our cultural understandings of autism. Autism as a separate condition didn't exist until it was named. Once named it became treatable and people developed careers and money-making opportunities around it. Language will keep evolving. The usage of DSM label 'Autistic disorder' now seems less generally used than ASD, which is sometimes referred to as autistic spectrum conditions, or difference, or simply 'autism'.

By using negative language and words like suffer, victims, abnormal and tragedy, the media commonly portrays disabled people as somehow deficient - with flawed minds and bodies. Sometimes, however, they are portrayed as heroes when doing ordinary things like sport or education. Both approaches are patronising. Autistic people are often portrayed as somehow trapped or introverted or not fitting, therefore, something to be studied or viewed from the outside. The jigsaw symbol much beloved of international autism parents groups is disliked by many in the autism rights movement who do not see themselves as a puzzle, or trapped inside a shell. For example, Neurodiversity International has an 'Aspies for Freedom' website which features their preferred rainbow 'infinity' symbol (see below). I suggest that parents need to be careful about talking negatively about their children with autism as children can pick it up and adopt these attitudes as part of their identity. Autism is already linked with high rates of depression and anxiety (Attwood, 2007). There has also recently been the development of hate speech in the US such as a 'hating autism' website.

Figure 6: Aspies for Freedom logo showing rainbow infinity symbol

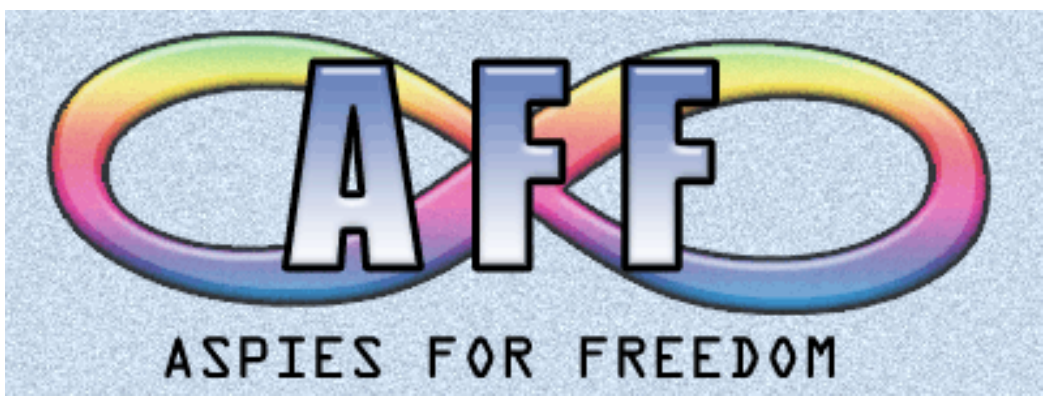

Source: www.aspiesforfreedom.org 
So autism is not something you can touch or see. Parents, professionals, people with autism, and societies, create, and continue to create, the idea of 'autism' which changes according to circumstances. At diagnosis we might be initially be devastated or relieved - personally I was relieved to have a label and a framework to explain my son's unusual behaviours, mannerisms and speech. For babysitters, family members and peers we probably play down the differences and emphasise the similarity with other children (Nadesan, 2005). The education system can be fraught for all parties. For school inclusion parents tread a fine line, playing down differences enough to be included but also hoping for extra support. For individual Ongoing Resourcing Scheme (ORS) ${ }^{9}$ funding applications the most negative picture is required, although education is otherwise all about achievement and progress. I suggest that these subtleties and nuances of language need to be considered in the policy processes, and those with lived experience are best placed to explain them.

\section{Epidemic?}

As mentioned previously many claim an 'epidemic' has caused the increase in autism diagnoses. However, there are various reasons for the rapid growth in diagnoses and prevalence data over recent decades, mainly due to the increased understanding, community knowledge and improved diagnostic tools, while the idea of an epidemic has been constructed to serve various vested interests, such as those who profit from interventions and treatments (Grinker, 2007; Liu, et al., 2010; Nadesan, 2005, 2008a). Other diagnoses such as schizophrenia seem to be going out of fashion in favour of one of autism, and the autism-immunisation link has been soundly discredited. A study of English adults shows similar prevalence of autism in adults as in children, although with fewer diagnoses, which discredits the epidemic theory (Troalach, et al, 2001). One of my key informants summed up what seems to be a commonly held view in the autism community:

Well my belief about that is that in our family we have multitudes of allergies and we respond to all sorts of medications and things quite

\footnotetext{
9 In January 2011 this has become Ongoing Resourcing Scheme, and lasts for the child's entire school life, although hours can be reviewed.
} 
differently and I actually wonder if it's more in the individual ... response to ... the vaccination rather than the actual vaccination being faulty. (Sam, 2010)

Whether there is an epidemic or not, some suggest that environmental toxins or lifestyle could be implicated in autism diagnoses (Nadesan, 2005). Personally, I would prefer that less was spent on genetic testing, with its eugenic potential, and more on promoting safe physical and social environments and addressing barriers to support and services.

We are at a point of time in history when several strands have come together to make autism visible regardless of any epidemic. This is the first generation of autistic people which has not been institutionalised on a large scale and the first generation with expectation of rights to education, employment and independence. The medical model where individuals are 'broken' has been replaced by the social model which instead promotes support for that person's participation (Oliver, 2009). There are also social influences with an autism diagnosis more likely if there are others diagnosed nearby (Liu, et al., 2010). Some proudly claim it as identity, or a distinctive culture (Silberman, 2010). We live in a era of 'self-actualisation' (Nadesan, 2005) which sees people as individuals with economic choices and responsibilities striving to be 'the best we can be' and to fulfil our 'hopes and dreams' (and for many this means disabled people as well). There are well-known ideas about normality, and an expectation that deviation from this normal development will be picked up early in a child's life and treated in an effort to restore or catch up to normal. An autism diagnosis fulfils this need to label and treat difference.

Since Kanner first named autism as a separate condition, clinicians have developed expertise and parents concerned about the development of their children have sought them out. In this internet age there is a multiplicity of global experts. Some publishers specialise in books on autism. So knowledge about, and diagnoses of, autism have steadily increased in New Zealand and internationally. There are now numerous academic journals, autobiographies and websites providing a global network for those interested in autism. Even so, outcomes for many autistic people internationally and locally, as reported anecdotally and on websites and social media, appear to be poor. 
The variables of love and luck (examined in Chapter Seven) seem to be required for the autistic person to have any chance of an ordinary life and participation in citizenship. From a practical policy perspective, the challenge comes in meeting the support and service needs of those diagnosed with autism and those still undiagnosed. Whether this increase is due to an epidemic is less important than doing the best for those with autism.

\section{Cure versus identity politics}

Our predominantly negative view of autism as something deficient is challenged by members of the autism community such as non-verbal autistic woman Amanda Baggs on her Ballastexistenz website (Wolman, 2008). Her video including explanations of her apparently autistic behaviours has had over a million views. She portrays a model of lived experience that challenges our assumptions of what is normal. Some autistic advocates look forward to a time when there is no treatment for autism as it will be seen as a minority culture in its own right and not something abnormal (Boundy, 2008; S. M. Robertson, 2010; Trevedi, 2005). While some understanding and support would be nice, they don't want treatment or interventions. These views challenge us from the dominant culture.

\section{Autistic self advocacy movement}

The autistic self advocacy movement has emerged from the convergence of disability self advocacy and the rise of global internet movement. For many of those with autism, digital communication is an easier form of social interaction than in person. As mentioned earlier, members of the autism rights movement see themselves as a cultural minority, subject to discrimination for their difference in a similar way to other minorities and this identity movement challenges many parent or clinician-led groups, The Autistic Self Advocacy Network (ASAN) in the United States and the Englandbased Neurodiversity International are two of many autism groups and websites challenging the view of autism as deficit, and instead claiming autism as a minority culture, for which interventions are not required, and may even be abusive (Kalb, 2009).

\section{Cure lobby}

Well-known people or celebrities also influence the autism debate. For example, United States celebrity Jenny McCarthy (www.generationrescue.org) is one of the most vocal 
advocates for the 'autism denial' lobby, those who advocate that autism is not caused by genes or parenting but by immunisations and toxins, hence it can also be cured, or 'sufferers' 'recovered' by biomedical interventions. Such spokespeople are often sought out by the media to comment on topics such as academic scientific reports which they may not have the expertise to critique, but which gives them credibility (Offit, 2008). Other groups such as the powerful United States-based lobby group, Autism Speaks, instead seek scientific and genetic research for new treatments. In 2009 Autism Speaks had a campaign that showed autism as an enemy that stole children, but after criticism from ASAN and others, the campaign was dropped (Wallis, 2009).

These contrasting approaches are part of the continuum of modern disability agendas that Baker (2011, p ix) has identified as 'cause, care, cure and celebration'. Autism is complex and diverse so it is no surprise that public policy has not kept up in terms of recognising the diversity of issues around autism and providing appropriate services and supports.

\section{New Zealand history and context for autism}

In New Zealand government disability policies are currently based on ideals of inclusion, diversity, rights and responsibilities (Ministry of Health, 2001). But this paradigm of rights and inclusion has only developed in the last few decades and remains fragile. A fuller history of NZ disability history follows in Chapter Five, but here I describe the autism-specific context. By the 1940s in New Zealand some parents of intellectually impaired children were frustrated by the lack of education and support so they started the Intellectually Handicapped Children's Parents' Association, the forerunner of today's IHC (Millen, 1999). These dedicated parents poured their energy into advocacy for their children, often falling out with their colleagues in the process. This was the era of large institutions and 'chemical strait-jacket' sedation.

One of my valued key informants is Marion Bruce, who I have already mentioned. In the 1960s she had a young son who was 'different'. He was eventually diagnosed with the rare condition of autism. So unusual was it that only a tentative assessment could be made by the Wellington multi-disciplinary child health team, until an overseas expert from London, Dr Mildred Creak, visited to confirm the diagnosis for the few children 
with this label in New Zealand (Bruce, 2010). Dr Creak was a retired clinician who had been working on diagnostic criteria for autism (Graham, 1993), and was a Quaker with family links to Whanganui, hence her visit to New Zealand. She met children and families in several centres and confirmed their tentative diagnoses.

She encouraged Mrs Bruce to attend the upcoming autism conference in Adelaide (Autistic Childrens' Association of South Australia Inc, 1967), and contact other families in New Zealand to set up a parent network. Their first meeting took place in 1969 under the Intellectually Handicapped Children's Association umbrella, and with the support of the President, Dr Donald Beasley. Over the years, the group ran seminars, workshops and holiday programmes and lobbied for understanding and resources for autistic children. This group became the Autistic Association and eventually Autism New Zealand.

But as recently as the 1970s, parents were urged by professionals and family members to put their autistic children into institutions and forget about them. So the closure of our last institution, Kimberley, in 2006 was a great landmark (Milner, 2008). Many parents had always resisted and fought for the educational and citizenship rights of their autistic children (Millen, 1999). But getting support for diagnosis, education and independent living was an ongoing struggle. Mrs Bruce became a member and eventually chair of the Wellington Hospital Board and managed to persuade the board to set up the Puketiro Centre at Kenepuru, as part of the Wellington Hospital Board, and where the regional child development team is still based. She was also instrumental in getting a special school at Kenepuru established for autistic and intellectually impaired children. Parents today have good reason to thank these earlier parents for their hard work.

By the late 1980s, New Zealand children were starting to be diagnosed with Asperger's Syndrome, by child development teams keeping up with latest international autism developments. That was not long after Asperger's work was translated into English and before it was an official diagnosis in the DSM IV. In those days autism itself was a rare condition thought to affect about three people in 10,000 and this new condition of Asperger's even rarer. Many of these lucky children are now adults living 
independently, and have families who are very familiar with autism/Asperger's and its characteristics (Bierens, 2009). However, some autistic people continued to suffer in mental institutions (Department of Internal Affairs, 2007). Jen Birch (2003) gives a horrifying account of bullying and degrading treatment while an adult patient at Kingseat, an Auckland psychiatric institution, in the 1980s. Her luck came with a lifechanging autism diagnosis much later when she was in her 40s.

The 1997 death of Casey Albury led to media and policy interest, two major reports (Curry, 1998; Werry, 1998) and a decade of work leading to the 2008 ASD guideline, and $\$ 17.5$ million towards its implementation over three years. The death and the subsequent court case were heavily featured in the media (NZPA, 2003), and readily recalled twelve years later by my various informants.

Autism stories now frequently feature in our media. In April 2007, a story hit the headlines of an autistic teenager with out-of-control behaviour and no respite options for the family (Anonymous, 2007). A similar story appeared in 2009 (NZPA, 2009). Autistic people are presented as problems or objects of pity, or in stark contrast, inspirational or heroic as the 2008 story of the teenage hacker from Coromandel who escaped jail and was subsequently employed for his expertise by a telecommunications company (Field, 2009). Rarely do the media feature stories about autistic children or adults doing normal things, and rarely is the autism an add-on to the story, rather than the point of the article. After the Christchurch earthquake in February 2011, a young man with Asperger's was arrested and allegedly beaten and jailed for looting as a result of a misunderstanding about his special interest in light fittings which he had taken from an abandoned building (Autism New Zealand, 2011a; Wade, 2011). Not only do these stories illustrate that there is clearly a policy problem with autism, but there are also barriers to the inclusion of people with autism.

\section{Autism NGOs: Autism New Zealand}

In the last few years, several autism advocacy groups have appeared in New Zealand, some as trusts to facilitate the provision of particular therapies such as Applied Behaviour Analysis; some for specific populations, such as the Cloud Nine Children's Foundation (for those with Asperger's Syndrome); and more recently as support and advocacy groups for people on the spectrum, such as Aspiehelp in Christchurch and 
Asperger's Syndrome New Zealand (www.asnz.exofire.net) based in Wellington. Altogether Autism was created to deliver the Autism Disability Information Advisory Service (DIAS) in 2007, and remains a significant provider of web-based information. However, the oldest and biggest autism group is Autism New Zealand which has its origin in the late 1960s when parents of autistic children formed their own subcommittee of IHC and eventually became the independent Autistic Association.

Its strength and weakness was that it remained a parent-led organisation, and at the time of the Werry and Curry reports following Casey Albury's death, was still basically a one person Christchurch-based operation, with a board and regional committees of committed parents, and an occasional paid staff member. Building up its capacity to support parents was seen as vital and one of my key informants, who at that time working in health policy, told me that Government support was therefore provided. This included developing internal policies to improve the professionalism of the organisation, preparing information packs for parents, and scoping provision of parent education courses such as the National Autism Society's 'EarlyBird'. The organisation was assisted to develop capacity to bid for and deliver government contracts, of which 'EarlyBird' has been one of their longest and most successful. A large survey of parents of autistic children was undertaken which highlighted many of the gaps and issues that were later addressed in the Guideline work (Autistic Association of New Zealand, 2001) and is referred to in Chapter Nine.

In the last ten years, Autism New Zealand has grown to become an established and professional Wellington-based non-government organisation, charity and advocacy group, with a multi-million dollar annual turnover, located close to Parliament and the head offices of the Ministries of Education and Health, paid staff around the country and contracts including for parent education programmes, and with ambitions to become a service provider in respite and residential care, which are two of the most problematic areas for families (Autism New Zealand, 2011b). They also host regular local and international speakers and seminars, and a well-attended conference every two years. Significantly, it is still parent-led but now the chief executive and several staff do not have family members with autism. The last decade of growth and redirection has been painful at times, and very time consuming particularly for the voluntary 
chairperson, but the organisation is now rebuilding relationships with former challengers such as Altogether Autism. It is firmly positioned as the premier New Zealand autism organisation, with a growing number of government contracts. The website (www.autismnz.org.nz) features the mission statement: 'to improve the quality of life for people with autism, Asperger syndrome, those with associated conditions, their family/whanau and those who support them'. However, the role of autistic adults in the structure of the organisation is subject to ongoing debates as the organisation transitions from its previous role as mainly a parent organisation into something bigger.

Michael Kendrick, whose theories on 'right relationships' are covered in Chapter Six, warns there are risks for groups like Autism New Zealand that have grown out their communities, in that their corporate success may alienate them from the community they have developed from, thus reflecting the wicked problem (see Chapter Seven) of unintended consequences:

It is notable that even the bureaucracies of non-governmental and voluntary organisations, which have historically arisen from within the community and commonly see themselves as champions of community, have rather quickly adopted the same technocratic ethos as their funders. It is also notable that the face of government for ordinary citizens is no longer just the government's own bureaucracies. It is also the rented or purchased bureaucracies of the non-governmental organisations who now do the government's bidding through a vast and complex web of contracts, programs, and mechanisms, many of which are incomprehensible to most ordinary citizens. (Kendrick, 2003)

To prevent this happening, he urges such organisations to remain small and close to people (Kendrick, 2000, 2009) which keeps them authentic, and focused on the people they are there to represent. This is a problem for an organisation like Autism New Zealand which has ambitions to be the main New Zealand autism organisation, and to have both a powerful voice when it comes to advocacy but also be a contractual partner with government and a service provider. However, to facilitate the collaboration required to counter the 'wicked' problems of autism policy (which will be explained in 
Chapter Seven), government needs to work with NGOs, and Autism New Zealand which is large, visible and professional is ideally placed for this role, if it can still remain 'authentic' in Kendrick's terms.

\section{Conclusion}

It was a 65-year journey from Kanner's 1943 article to the 2008 publication of the ASD guideline. But autism's journey started much earlier than that. It has to be seen in the context of developments over many decades in fields such medicine, mental health, and attitudes to childrearing. Since Kanner, it has been constructed in many ways in film, language and identity politics. New Zealand's autism story includes parent activism, a public death, much research and many reports. The Guideline itself is examined in Chapter Nine, but to answer my research question about how to improve policy and the significance of lived experience, autism needs to be seen in the context of wider disability rights activism, disability policy achievements and the academic discipline of disability studies, which are the subjects of the following chapter. 


\section{Chapter Five: New Zealand disability history, activism, policy and ethics}

\section{United Nations Convention on the Rights of Persons with Disabilities}

Article 1 - Purpose

The purpose of the present Convention is to promote, protect and ensure the full and equal enjoyment of all human rights and fundamental freedoms by all persons with disabilities, and to promote respect for their inherent dignity.

Persons with disabilities include those who have long-term physical, mental, intellectual or sensory impairments which in interaction with various barriers may hinder their full and effective participation in society on an equal basis with others. (United Nations, 2006)

\section{New Zealand Disability Strategy}

Underpinning the New Zealand Disability Strategy is a vision of a fully inclusive society. New Zealand will be inclusive when people with impairments can say they live in:

A society that highly values our lives and continually enhances our full participation. (2001, p. 1)

\section{Introduction}

The previous chapter examined the history of the diagnosis and cultural construction of autism. However, it is only one impairment type in a population of disabled people. Over the last forty years in particular, disabled people have organised and agitated for 
recognition and rights, culminating in the 2007 UNCRPWD. Autistic people need to be considered in the context of this bigger social history, although some of them might not identify as part of a bigger group. For example, people with autism would probably still be institutionalised, and the $A S D$ guideline would not have included people with autism in its workstreams, without the influence of the wider disability rights movement. The overlap is illustrated by the photograph of the autism rights protest which heads the previous chapter in which one person holds a sign with the international disability slogan: 'nothing about us, without us'.

This chapter contextualises New Zealand's disability history, and the gradual rise of disability activism along with public awareness of ethical responsibilities and consumer rights. The chapter concludes with an assessment of the current state of New Zealand disability policy as it impacts on autism policy.

In 2010 , the estimated $20 \%$ of the New Zealand population who identify as disabled ${ }^{10}$ (Ministry of Health, 2004a), are still largely invisible in the official record. As a group they have never been treated as active citizens with input into nation building. The latest edition of the Oxford history of New Zealand (Byrnes, 2009) does not have any index references to disability. Neither are there any index references for disability, disability rights, or disability activism in volumes by prominent historian James Belich (1996, 2001), or Michael King's influential Penguin history of New Zealand (2003). Museum exhibitions consistently ignore this aspect of NZ's history. Yet largely because of activism by disabled people and their supporters, this current generation of young people is the first generation of autistic and other disabled people which has not been institutionalised or legally denied citizenship rights, due to public policy decisions in New Zealand.

Over the last two hundred years, disability history has named and constructed people with impairments or mental health issues as problem populations which need to be managed. As mentioned earlier, New Zealand has a shameful history of public policy in disability and mental health, particularly in the early decades of the $20^{\text {th }}$ century when a

\footnotetext{
${ }^{10}$ For example, 'One in Five' is a long-running programme about disability issues on Radio New Zealand.
} 
desire to grade, label and lock away predominated public policy decisions. A 1925 Committee of Inquiry report emphasised the spurious link between disability and moral degeneracy (Fleming, 1981; Stace, 1998a; Triggs, et al., 1925). The voices and expertise of the subjects of this inquiry were of course not heard.

However, from the late 1960s, disability rights activism here and in other countries has challenged these attitudes, and the processes of deinstitutionalisation have slowly given way to community residential care and supported independent living and rights-based government policies. Current New Zealand disability policy and approaches as expressed in the Disability Strategy (Ministry of Health, 2001) reflect the social model of disability whereby people have impairments, but it is society's laws, regulations and attitudes which disable people. The 'Ordinary Life' report (National Advisory Committee on Health and Disability, 2003) locates the person with impairment (specifically people with intellectual disability and including many with autism) at the centre of a circle of social and other supports which enable them access to and to participate in an 'ordinary life'. The development and monitoring of the 2006 UNCRPWD has united and linked disability activists from many countries. New Zealand played a significant part in its drafting (Frost, 2007b; Moriarty, 2009; Moriarty \& Dew, 2011; United Nations, 2006).

New Zealand's disability history is a largely under-researched field. In her assessment, Tennant (1996) outlines themes in our disability history: expectations of health, developing medical knowledge, changing New Zealand demographics (which was largely young and male in the $19^{\text {th }}$ century and is now ageing), effect of war and epidemics, emergence of organised advocacy groups, influence of overseas models, and changing language. Although disability rights activism is still invisible in our national identity history, a few activists are starting to write their own history, including those with autism, such as Frost (2007a) and Birch (2003). Australian disability activists have also written about their experience, comparing the battle for disability rights with 'cultural apartheid' (Goggin \& Newell, 2005).

This chapter puts disability activism in the context of New Zealand disability policy history, contemporary views on disability and international activism. It also covers 
tentative recent steps towards an awareness of ethical policy process which respects the lived experiences of policy consumers (disabled people and their families and supporters) and encourages right relationships. All impact on autism policy.

\section{New Zealand disability history}

\section{$19^{\text {th }}$ century}

Even though we are geographically isolated, since the early days of Pākehā ${ }^{11}$ settlement New Zealand has kept up with the latest trends and theories of Britain, Europe and North America, and has sometimes even led the field, from votes for women, to the creation of the pyschopaedic nurse (specialists in institutionalised care for children with intellectual impairment and other disabilities including autism) (Gates, 2008), and to the ASD guideline.

Nineteenth-century New Zealand was settled mainly by people from Britain and Europe who were prepared to endure a risky and lengthy sea trip for a chance of a better life. So strong was this urge that New Zealand came to be seen as an ideal society (Fairburn, 1990) (although inclusion of the indigenous inhabitants was still not generally part of this vision). Although infectious illness and accidents were common, disability was unwelcome, both because it did not fit in with this ideal society and because it could be a burden on others in a time when most of the population survived on hard physical work (Beatson, 2004; Tennant, 1996). So support was left to the benevolence of families or groups providing charitable aid. The immigration acts that restricted the entry of Chinese in the late $19^{\text {th }}$ century also banned 'cripples, idiots, lunatics, infirm, blind, deaf and dumb' (these categories included people who today would have autism). The 1882 Imbecile Passengers Act required a bond from the person in charge of the ship before one of these 'undesirables' was discharged from the ship, and the 1899 Immigration Restriction Act went further banning the 'idiot', the insane and the contagious (Beatson, 2004, p. 448).

Mental illness, then as now, was generally feared and misunderstood. A 1946 Lunatics Ordinance provided for public provision for incarceration of the mentally ill, at first in

\footnotetext{
${ }^{11}$ Indigenous Māori name for white settlers, now used to describe non-Māori population.
} 
gaols (Beastson, 2004). The first public 'lunatic' asylum was opened in Karori in 1854 and one in Porirua opened in 1887; by 1896 its site covered 100 acres. Typically for the time, the Porirua asylum mixed several categories of 'undesirables': those with mental health issues, intellectual impairment, alcoholics, elderly and homeless people (2004; Hill, 2005). For decades, these 'inmates' provided large captive communities for doctors and specialists to practice theories and interventions. Physically disabled people were more likely to be housed with old people in the 'chronics wards' established in the early $20^{\text {th }}$ century in ordinary hospitals (Sullivan, 1991, 1995). Asylums from then until very recently are remembered more for the incarceration of their 'inmates' than for humane treatment. Firsthand accounts are provided by New Zealand writer Janet Frame's autobiography (1989) and other writings which relate her experiences as a patient during the 1940s and 1950s including numerous unanaesthetised electroconvulsive therapy sessions, and repeatedly threatened lobotomy.

As New Zealand society developed, two important themes emerged here as elsewhere. Children began to be seen as more than just little adults or economic units (Nadesan, 2010). Their education became important and the 1877 Education Act provided free secular primary school education (MacMorran, 1900; Mitchell, 1985). Its purposes were for a better educated workforce but also government surveillance of children and their development. Rules and inspections were rigid.

As the $19^{\text {th }}$ century progressed, so did medical and social policy, and some groups such as those with vision and hearing impairments, were seen as 'habilitable', meaning they had potential as worker citizens (Sullivan, 1991, 1995). Hence, the establishment of the residential schools which inadvertently provided the sites for deaf and blind people to develop cultures in opposition to oral and sighted cultures, and thus activism among these impairment groups (Beatson, 2004; Sullivan, 1995).

\section{Eugenics}

By the turn of the $20^{\text {th }}$ century the white birth rate was dropping. The new century coincided with an increasing interest in the science of genetics and heredity raised by Darwin (1859) and developed by others, now known as Social Darwinism. In New Zealand these ideas were taken up by both liberals and conservatives who were concerned about the decreasing white middle class birth rate and consequent fears of 
losing their racial (and moral) supremacy. New Zealand born W A Chapple (1903) published The fertility of the unfit which preached sterilisation for people with mental, moral and physical defects. The Eugenics Education society was founded in Dunedin in 1910 with an influential membership, one of whom was Truby King, the Medical Superintendent of Otago's Seacliff Asylum (Fleming, 1981; Sullivan, 1995). Theories and language linked intellectual impairment and some physical impairments like epilepsy to inferiority and moral degeneracy. Negative eugenists sought to limit fertility by public policy while positive eugenists supported intervenist policies to increase population 'fitness'.

In this context, Plunket was started in 1907 to train mothers to grow healthy little citizens and soldiers for the empire (Stace, 1998a). Founder Truby King, Seacliffe Superintendent, who had a physical impairment, later became Inspector General of Health (Brookes, 1993; Olssen, 1981). He, his wife and supporters were positive eugenists who believed that teaching mothers the strict rules of scientific mothering would increase the fitness of the race. Committees of wealthy middle class women then took the ideology to the breeding populace. King was our local manifestation of the scientific mothering trend, and part of the international tradition of male experts telling women how to parent and then blaming them if anything went wrong. The mothers themselves of course were never consulted. French-born nun Suzanne Aubert had personal experience of disability and was one of the few to speak out against eugenics (Munro, 1996). She founded her Home for Incurables in Whanganui in 1899 and, in 1907, opened her first Home of Compassion for all 'needy' or disabled adults or children (which likely included those with autism) in Wellington.

But certain types of intellectual impairment continued to be linked with 'immorality'. So girls' and boys' homes and farm schools were founded mainly to keep the sexes apart and prevent criminality, deviant behaviour or reproduction. In 1908, Otekaike (Campbell Park School) near Oamaru was opened as a residential school for 'feebleminded' boys and a few years later a similar residential school for 'feeble-minded' girls, Salisbury, was opened in Richmond, near Nelson (Mitchell, 1985). These special schools were run by the Education Department, while Levin Farm, opened on the site that later became the Kimberley psychopaedic hospital, and Templeton near 
Christchurch, came under the Mental Hospitals Department. Differing classifications of 'defect' determined which government department was responsible for each individual.

The 1911 Mental Defectives Act classified groups of 'other' into idiots, imbeciles and feeble-minded. Special schools and special classes started. Education helped reinforce social and economic roles. The school medical service was founded to identify 'defective' children so they could be sent to the appropriate institutions and the 1914 Education Act made it obligatory for parents, teachers and police to report 'mentally defective' children to the Department of Education. The census of 1916 was the last time until 1996 that specific questions about disability were asked, possibly due to the lack of enthusiasm for self-identification (Beatson, 2004).

As mentioned above, in 1925 a Committee of Inquiry into Mental Defectives and Sexual Offenders linked intellectual impairment with moral degeneracy and potential sexual offending, and sought to separate suspect parents and children (S Robertson, 1989; Triggs, et al., 1925). At-risk children could be taken off families and the shortlived Eugenics board kept lists of 'defectives'. A rare voice of protest was expressed by a mother about the proposed travelling clinics which would examine intellectually impaired children (Dr Gray was the Acting Inspector General of Health).

"Oh Mother, save me from Dr. Gray

'Cause teacher says he's coming to-day

And if I'm stupid he'll take me away.

Oh, Mummie, save me from Dr.Gray!"

"I cannot save you, my little child."

His Mummie said and her eyes were wild.

"You belong to the State, you're no more my child!

But Oh, my darling don't stupid be

Or he'll say we've tainted heredity.

And must be eradicated - you and me!" (S Robertson, 1989, pp. 123-124) 
The revelation of the extent of eugenic policies in Nazi Germany (including the death of many thousands of disabled people) dampened overt policy enthusiasm. However, it has never gone away and ongoing manifestations include occasional politicians urging limits on 'breeding' of undesirable groups such as beneficiaries. More significant for disability activists are the potential of genetic technologies such as pre-implantation genetic diagnosis, amniocentesis and other pre-natal testing to prevent births of 'undesirable', meaning disabled, children (Kerr \& Shakespeare, 2002). Fortunately, in spite of extensive and potentially lucrative research efforts, there is no genetic test yet for autism.

\section{Political responses and parent advocacy}

The first Labour government (1935-1949) brought in various measures including free hospital treatment. In 1936 an invalids' pension was introduced, and in 1938 the Social Security Act which is regarded as the foundation of the welfare state, provided disability support and pensions. This principle of taxing according to means in order to receive support according to need when required was thus established in New Zealand (Sutch, 1966). In 1939, the Director General of Education Dr Beeby and Minister of Education Peter Fraser made their visionary statement about the rights to education for every child including the words 'to the best of their abilities and the fullest extent of their powers' (Mitchell, 1985, p.29), a goal which still remains elusive to many autistic families.

The rise of parental advocacy (including by parents of autistic children) is exemplified by the start of the IHC. The Intellectually Handicapped Children's Parents Association [IHC] was founded in 1949 by Hal and Margaret Anyon, parents of a child with Down Syndrome, who wanted him to have an education and to live at home (Millen, 1999). At that time children with intellectual impairment were among those least likely to access education, and were often sent to institutional care. (Autism as a separate diagnosis was virtually unknown and children with autism were also assumed to be 'mentally handicapped'). As mentioned in the previous chapter, the parent-led group Autism NZ developed as a sub-group of the IHC in the late 1960s. There is now the parent and NGO-led Carers' Alliance which has succeeded in forging a Carers' Strategy with Government (Ministry of Social Development, 2008). In 2011 the Carers' Alliance is leading the charge against the Ministry of Health-led challenge to a recent Human 
Rights Commission Review Tribunal decision (mentioned earlier) that family carers of high needs adult disabled children should be paid (Human Rights Commission, 2010).

\section{Institutionalisation}

The mid- $20^{\text {th }}$ century was the era of the large institutions, strong experimental drugs, unanaesthetised electro convulsive therapies and sedation. In many countries (and probably also in New Zealand) lobotomies were routinely used for children displaying symptoms we would probably today describe as autistic (Ogren, Sjöström S., \& O, 2000).

In spite of best practice evidence and parental advocacy turning against these big institutions, the 1953 report of the National Government's Consultative Committee, which became known as the Aitken report after the doctor who was chair of the committee, recommended that disabled and mentally ill people be housed in large 'mental deficiency colonies' containing several hundred people, and extending current institutions such as those at Levin and Templeton (Millen, 1999). Parents would be encouraged to leave their disabled children in these institutions from about the age of five. (Millen, 1999; Consultative Committee on Intellectually Handicapped Children, 1953). The report was greeted with disappointment by the parents of intellectually impaired children who had lobbied politicians for the review, hoping it would recommend community support for their children. The committee which included no 'consumer' or parent representatives and only one woman (who was appointed after complaints), not only rejected their pleas but also reinforced the use of words and concepts such as 'idiots' 'imbeciles' and 'feeble-minded' that the parents had objected to (Millen, 1999). Some parents here and overseas put their children (including autistic ones) in such institutions and kept their existence secret, often for many decades. One elderly man - whose brother was sent to one of these places - told me this was because the parents thought the siblings would not be able to find partners if the prospective partners knew about their 'handicapped' sibling.

The Aitken report rejected best practice for the era. The Intellectually Handicapped Children's Parents' Association (the forerunner of the IHC) and others had campaigned for improved educational support, and community residential opportunities for their children as then recommended by the World Health Organisation (Millen, 1999). But 
the report became government policy. Had consumers been involved it is possible the consequences might not have been so negative.

Only six years after the Aitken report, in 1959, following a change of government, another report headed by Sir Charles Burns of the New Zealand Branch of the British Medical Association (Burns, 1959), and an ally of the IHC parents, recommended small residential homes in the community and criticised the Aitken policies as 'based on outworn and outmoded ideas' (Millen, 1999). But the momentum generated by the Aitken report took another two decades to start turning around; indeed, the 1970s saw the largest number of people entering institutions before numbers started to drop.

As a gesture to those who supported the Burns report, funds were provided for services such as day programmes for intellectually disabled people. The 1960 Disabled Persons Employment Promotion Act was passed so organisations could employ disabled people in 'sheltered workshops' without any requirement to pay, or give them employment rights. Contemporary thinking was that giving people something to do, and thus keeping them out of institutions, was more important than having the working conditions nondisabled people protected. Of course, disabled people had no say in the formulation of this policy. That expectations change over time is illustrated by the battle by disability activists and their political allies versus the big providers, some parents and politicians, which finally saw this Act repealed in 2007 (National Equal Opportunities Network, 2007). The phrase 'sheltered workshop' today carries the same baggage as 'institutions'. Two significant things happened in the intervening decades: increased ethical awareness and the rise of the disability rights movement.

Concerns about institutionalisation had been growing since about the 1940s and in 1972 a Royal Commission on Psychopaedic Hospitals recommended transference from large institutions to community care, and led to three decades of deinstitutionalisation, during which the Government had to pay for both community care and upkeep for the large institutions (although both suffered from poor resourcing). At its height, an estimated $2 \%$ of the population was institutionalised (Beatson, 2004) with over 800 people at Kimberley. By 1978, the occupancy rate was 0.24\%, the lowest since 1881 (Department of Statistics, 1980, p. 144). 
Fifty years later another Government set up a Confidential Forum to hear the stories of abuse that resulted from policy such as the Aitken report recommended. Its findings were published in June 2007 as Te Aiotanga the Report of the Confidential Forum for Former In-patients of Psychiatric Hospitals (Department of Internal Affairs, 2007). It contains testimony from residents and others in state care before 1992, as well as some family members and staff. Their lived experience went back to the 1940s. Many were children - the youngest four years old - when they went into residential care. Many of these people would have had autism although without that diagnosis at the time. Although there were occasional references to kind and helpful staff, the report is grim reading. In 2009, a Listening Service was established to continue to hear stories from those in state care and from those denied human rights and personal identity (Confidential Listening and Assistance Service, 2009). This restorative justice approach is not about financial compensation, but to acknowledge the oppression and denial of humanity of one group by another in the name of policy and politics (White, 2007). The last such institution, the Kimberley Centre, only closed in 2006 (Milner, 2008). The Frozen Funds charitable trust has been set up from unclaimed welfare payments from this era (Frozen Funds Charitable Trust, 2009). Many in the sector would like an official government apology but this is unlikely (Cullen, 2007).

\section{Disabled Person's Community Welfare Act}

The Woodhouse report commissioned by the National Government (Royal Commission to Inquire into and Report Upon Workers' Compensation, 1967) led to the 1972 Accident Compensation Commission Act. MPs and policy makers who had served in recent wars and seen terrible injuries supported this no-fault compensation scheme to ensure others would not have to struggle as they or their injured colleagues had. But ACC favoured one group: workers injured by accident. After advocacy by MP J. B. Munro, long time IHC member and polio survivor, the 1972-5 Labour Government responded by extending these ACC benefits, albeit in a less generous and means-tested form, to all disabled people in the 1975 Disabled Persons Community Welfare Act. This Act legislated compliance for the recently-developed New Zealand Standard building code 4121 including guidelines for accessibility (Beatson, 2004). This marks the first time society had had to change for disabled people, not the other way around. However, tensions remain because ACC provisions for people injured by accident are generally 
far more generous and holistic than those whose similar impairment is not accidentrelated (Armstrong \& Laurs, 2008).

\section{The New Deal}

By the late 1980s, neo-liberal politicians were in ascendancy. In spite of the Royal Commission on Social Policy advocating more support for disabled people (R. Hunt, 1988), Minister of Finance Ruth Richardson's 1991 'Mother of all budgets' cut welfare provisions and had a major effect on disabled people, many of whom were already at the bottom of the socioeconomic ladder. As mentioned in Chapter Two, in 1992, Minister of Social Welfare, Jenny Shipley and Minister of Health, Simon Upton, promised a New Deal to 'improve the quality of life for people with disabilities' but within 'the financial realities facing the country today' (Shipley \& Upton, 1992, p. 25). Their answer was to bring the market into service provision, and previously free services would now have to be purchased by 'clients' from the state through Regional Health Authorities and service providers. The service provider tendered for the service via a contestable contracting process. From 1994, most disability support services went from Social Welfare into new Regional Health Authorities (Sullivan \& Munford, 1998). Support was no longer a statutory right but accessed within the context of a ring-fenced and capped budget. Access would be through a new Needs Assessment and Service Coordination process, which has proved so problematic that it is currently undergoing major revision (Office of the Associate Minister of Health, 2010) (see Chapter Seven).

But by 1995 the model was already under stress as the capped budget was not enough to provide required services, particularly at a time of high unemployment, market rents for state housing, and compulsory work testing for all beneficiaries. The killing of autistic girl Casey Albury in 1997 occurred in this context.

\section{Rise of disability rights activism and the social model of disability}

\section{Social model of disability}

From the 1970s the growing international disability rights movement developed what became known as the social model of disability whereby people have impairments but it is society's attitudes that disable. For example, when a person who uses a wheelchair 
requires access to a public building the problem lies not with the person's paralysis the impairment - but poor building design that excludes the entry of some citizens (Oliver, 2009; Sullivan, 1991).

It is very difficult for people marginalised by society to organise themselves in a strong advocacy force, particularly those institutionalised and whose markers of identity such as personal clothing, possessions, and even names, were removed. But as mentioned in previous chapters, a manifesto of the movement published by the London Union of the Physically Impaired Against Segregation (UPIAS) called for a change of attitude to disability policy. Disability activism took slightly different paths in the US and the UK. While British theorists generally adapted theories from Marxism and concepts such as oppression and disability studies developed within sociology departments, US disability activists tended to prefer an individualised human rights model reflecting disciplines of psychology or law (Sullivan, 2008).

\section{New Zealand disability rights movement: achievements}

Disabled lobbyists were also busy in New Zealand. Many of their achievements would also benefit those with autism. Significant outcomes of the activism include (Beatson, 2004; Office for Disability Issues, 2010):

- An International Year of Disabled People in 1981 (marked here by a Telethon) and the formation of the peak disability organisation in NZ the Disabled Persons Assembly which was of and controlled by disabled people;

- Growing calls for policy change through the Royal Commission on Social Policy (RCSP) which contained a chapter on disability written by disability activist and later Human Rights Commissioner Robyn Hunt (R. Hunt, 1988);

- The right for all disabled children to attend their local school in the 1989 Education Act;

- The inclusion of disability in the 1993 Human Rights Act;

- The disability sector-led 2001 Disability Strategy and the 2006 UNCRPWD, in which many disabled New Zealanders and their allies had significant input ; (Frost, 2007b; Moriarty, 2009; Moriarty \& Dew, 2011); 
- Closure of our last institution, Kimberley, in 2006 after a long saga to placate anxious parents (Milner, 2008);

- The end of sheltered workshops, and new employment rights for disabled workers (National Equal Opportunities Network, 2007);

- NZ Sign Language made an official language along with English and Te Reo Māori (Office for Disability Issues, 2010);

- ACC provisions extended (Armstrong \& Laurs, 2008); and

- New Zealand won the international FD Roosevelt Disability award in 2007 for leadership in disability policy (Dyson, 2007; Frost, 2007b).

\section{Partnership between disability activists and politicians: window of policy opportunity}

As mentioned above, during the 1990s New Zealand disability activists, disenchanted with the inability of 'the market' to provide appropriate or adequate support or services, targetted sympathetic politicians and educated them about the social model and disability rights. The election in November 1999 of the new Labour-Alliance coalition government provided that window of policy opportunity that policy theorist Kingdon (1995) mentions as significant for policy change.

In 1999, Prime Minister Helen Clark appointed the first-ever Minister for Disability Issues, Ruth Dyson, who set up the Office for Disability Issues, in the Ministry of Social Development. Significantly, the Office had a governance group of consumers disabled people and advocates. In 2001, the Disability Strategy (Ministry of Health, 2001) was published after a long consultation led by disabled people. The Office for

Disability Issues (www.odi.govt.nz) was charged with monitoring progress. Following the Disability Strategy, related reports were published such as the 2003 To Have an 'Ordinary' Life report (National Committee on Health and Disability, 2003) that explained how the social model should work for adults with an intellectual impairment. Other reports targeted disability support in the education sector and employment.

During these years, New Zealand was actively involved in the drafting of the UNCRPWD (Frost, 2007b). The committee chair was a New Zealander, several disabled people were part of the official delegation, and the Office for Disability issues 
provided the research and secretariat. Robert Martin, a New Zealander who had grown up in an institution, was the first person with intellectual impairment ever to address the United Nations, which he did in his role of chair of Inclusion International (2007b). The 2008 Disability Act which ensured all New Zealand law was compliant with the UNCRPWD, and New Zealand's ratification of the Convention in September 2008, were two of the last actions of the Labour-led government.

Following concerns raised by consumers, parliament's Social Services Select Committee consulted with the sector for an Inquiry into the quality of care and service provision for people with disabilities. The inquiry, which began in 2006, was sparked by ongoing complaints from the public and stories about poor services for disabled people which made regular newspaper headlines over many years. It illustrates problems that Tessa Thompson (2007) identifies in her research on disability policy: that Ministers often do not get the information they require to make appropriate decisions, for reasons such as too many levels of bureaucracy between those on the front line and the minister; the right people not being around the table when decisions are made; and ministerial advisors second guessing or not giving the minister the appropriate information. It could be that the policy area is complex and possibly of the 'wicked' nature, which is examined in Chapter Seven. The report with cross party support came out weeks before the 2008 general election (Parliament. Social Services Committee, 2008). The new government's response was a ministerial committee and a cabinet paper on a 'new model' of disability support was released in mid-2010 (Office of the Associate Minister of Health, 2010). This has led to several new projects, including a pilot for an alternative to NASCs, reviews of residential care and training of carers, and extensions to individualised funding. Although that select committee process started in 2006 resultant policy that will affect the lives of disabled people including those with autism, only appeared in 2010. The new model is currently being piloted in the Bay of Plenty (Ministry of Health, 2010) for two years before any decisions on roll out are made. 


\section{Activism, ethics and consumer participation in disability policy}

Ethical awareness and consumer engagement are two important requirements for building those right relationships that this thesis seeks and that transformative research requires.

\section{Ethics, consumers and policies}

Ethical assumptions mean recognising the inherent humanity in every person, whereby, as the late Dr Christopher Newell - an Australian bio-ethicist and disability activist expressed it, 'every person is fully and equally human' (Newell, 2007a). Ethics in public policy are based in traditions of social justice and democracy, and also reflect the fundamental principle of human morality and of treating other people as you yourself would like to be treated. For several decades the international disability rights movement has demanded of policy makers that there be 'nothing about us without us' (Charlton, 1998). In New Zealand, the Disability Strategy (Ministry of Health, 2001), calls for an inclusive New Zealand.

Consumer in this context is a person who is affected by the policy under consideration, usually a disabled person but sometimes a family member or advocate. Client or service user are terms sometimes used but have commercial connotations which might not be appropriate in the circumstances. Other terms include disabled person (preferred New Zealand usage), person with disability or, as some bureaucrats and service providers put it, PWD (Sullivan, 2000). Not every disabled person will be affected by a particular disability policy, whereas a consumer of it will be.

Policies are decisions made by people in governance positions and implemented by people in operational positions. This context concerns policies discussed and made by central government and implemented by and through government departments, local government, and the third sector (NGOs, not for profit and voluntary organisations); it can also include regulation of the private sector, such as through accessible building requirements. 


\section{Ethical awareness}

Large scale institutionalisation of mentally ill and disabled people, including children, is just one example of unethical public policy, formulated and implemented without any consideration of what outcomes the target population might want from the policy. Indeed, the prevailing paternalism denied the possibility of these people or their families having views worth considering, let alone any role in the policy process. Ethics is about morality and what makes us human; this is why ethics and public policy always need to go together. Those making public policy today also need to consider the impact their policy decisions may have into the future.

New Zealand's current ethical framework for research involving humans is a result of public outrage at past ethical injustices. Many countries have had significant events that put the spotlight on ethics. In the USA in 1979, the Belmont Report considered revelations around the Tuskegee Syphilis Trials, whereby some patients had been denied available treatment (Tolich \& Flanagan, 2009). As a result research in the USA is now expected to be underpinned by ethical principles of beneficence, respect and justice. New Zealand's touchstone event was the 1988 Cartwright inquiry into the 'unfortunate experiment' by a professor at National Women's hospital who had been experimenting on his cervical cancer patients about the progression of their cancer, including non-treatment, unknown to them (Committee of Inquiry into Allegations Concerning the Treatment of Cervical Cancer at National Women's Hospital and into Other Related Matters, 1988). As a result the Health and Disability Commissioner was established and the Ministry of Health now administers ministerially-appointed research ethics committees comprised of professionals and lay people which are underpinned by ethical principles including respect for persons, informed and voluntary consent, social and cultural sensitivity to participants, and distributive justice (Ministry of Health, 2006b). The first Disability Commissioner has been appointed in the Human Rights Commission following government adaptation of a Green Party Member of Parliament's private members' bill (Delahunty, 2010).

Tertiary institutions also have ethics committees. But ethics approval is only required for a small proportion of research undertaken. Researchers in the Ministry of Education 
working on a series of participatory action projects with autistic children in educational settings had to develop their own ethical framework (L Smith, 2007).

Overseas examples of unethical behaviour specifically about ASD is provided by the inquiry by the British Medical Council into the 1997 research by Andrew Wakefield which falsely linked immunisation with autism, mentioned earlier, and the recent Maryland Board of Physicians case against the unqualified Gaier father and son team who promote testosterone suppressor Lupron for autistic children (Roylance, 2011).

\section{Treaty of Waitangi and disability}

A discussion about ethical public policy in Aotearoa New Zealand requires consideration of our founding document, the Treaty of Waitangi which was signed on 6 Feb 1840 between Māori and representatives of the British Crown. The British settlers and the local tribal chiefs had differing expectations of the purpose of the Treaty (Orange, 1996). It is a short document, in two languages, consisting of three articles.

Figure 7: Treaty of Waitangi provisions in English and Māori

\begin{tabular}{|l|l|l|l|}
\hline & Article One & Article Two & Article Three \\
\hline English Text & $\begin{array}{l}\text { Crown Sovereignty } \\
\text { (Mana) }\end{array}$ & $\begin{array}{l}\text { Tribal Property } \\
\text { rights. Pre-emption } \\
\text { by Crown only }\end{array}$ & $\begin{array}{l}\text { Royal protection } \\
\text { and citizenship } \\
\text { rights }\end{array}$ \\
\hline Maori Text & $\begin{array}{l}\text { Crown authority to } \\
\text { govern } \\
\text { (kawanatanga) }\end{array}$ & $\begin{array}{l}\text { Tribal authority } \\
\text { over cultural, social } \\
\text { and economic } \\
\text { resources }\end{array}$ & $\begin{array}{l}\text { Royal protection } \\
\text { and citizen rights }\end{array}$ \\
\hline implications & $\begin{array}{l}\text { Parliament's right } \\
\text { and authority to } \\
\text { govern }\end{array}$ & $\begin{array}{l}\text { Tribal right to } \\
\text { exercise tino } \\
\text { rangatiranga (self- } \\
\text { determination) }\end{array}$ & $\begin{array}{l}\text { Maori individuals' } \\
\text { right to expect a } \\
\text { society's benefits }\end{array}$ \\
\hline
\end{tabular}

Source: Durie, 1998, p. 84

It was largely ignored by governments until a Māori renaissance of the 1970s (parallel with the growth of the disability rights movement, gay rights and second wave 
feminism). Action and lobbying by Māori themselves ensured biculturalism became the basis, first for Māori policy, and then the goal for all government departments.

A series of Treaty principles - partnership, participation and protection - emerged in a number of forums including the 1988 Royal Commission on Social Policy (RCSP), the courts and the Crown/government (Stace \& Sullivan, 2011; Sullivan, 2009). The disability rights movement can also benefit from those principals which the RCSP formulated, to guide the development and implementation of social policy generally. Anecdotally, many within the New Zealand disability rights movement see themselves as occupying a similar position to Māori as being marginalised in a dominant mainstream society (Sullivan, 2009).

\section{New Zealand Disability Strategy}

Many disabled people in Aotearoa/New Zealand came to the conclusion that they needed their own treaty: to establish a genuine partnership with government; to guarantee equal participation in society; and to affirmed the active protection of our citizenship rights by the state (Sullivan, 2009). Thus the Disability Strategy was adopted in 2001 (Ministry of Health, 2001). Fifteen objectives are set out for the Government to achieve. Ministries, departments and state agencies are required to report on progress in their annual reports to parliament.

Taken together, 'nothing about us without us' and the building of an inclusive society, can be seen as the bedrock of not only ethical disability policy, but ethical public policy generally. Partnership was highly visible during negotiations around the UNCRPWD; from the beginning the NZ delegation was the only one to consist of state officials and disabled people including one with intellectual disability (Frost, 2007b). The Disability Strategy has its limitations. For example, it only applies to the state and those contracted by the state to provide services, and while its philosophy is right, the objectives and implementation need work. It is now ten years old and progress is slow.

\section{Examples of ethical partnerships}

Small fragile steps are happening in various ways towards partnership between some government agencies and their consumers. They are usually initiated by those who seek to build respectful relationships. One good example is the Ministry of Health's 
Disability Services Consumer Consortium, which includes representation from people with autism and family members. This group meets twice a year, and members are also invited to participate on ministry panels and workgroups on projects such as workforce development or the evaluation of tenders and the letting of contracts. Disability Support Advisory Committees are a requirement of the 2000 Public Health and Disability Act for each of the District Health Boards, whereby disabled consumers have a role in governance. The ASD guideline is an example of an ethical policy process. Developed as a collaboration between people on the autism spectrum, parents, public servants, professionals, it is examined in Chapter Nine. These examples provide models of how to bring the expertise of autistic and other disabled people and their families into policy processes.

\section{Whānau Ora}

As mentioned above there are similarities in the struggle between Māori and disability activists, and anecdotal talk is that if you get it right for one marginalised group it will likely help others. Therefore it is worth considering the Whānau Ora tool (Ministry of Health, 2008) in this discussion. This 2008 tool was developed as a practical guide to implementing Treaty principles and tikanga Māori in the health and disability sector, specifically the Māori Health Strategy, He Korowai Oranga and is a government/sector/organisational partnership responsibility for the wellbeing of people, families and communities (which is the meaning of the term). It can therefore provide a guide for improving disability (and autism policy) as this also affects these communities. Whānau Ora is very focused on collaborative pathways and has several principles:

- Reducing inequalities

- Māori participation from design to evaluation

- Māori providers and staff nurtured

- Māori models supported

- Non-Māori staff capacity developed

- Foster community development and assets and access to services generally

- Accurate data utilised (Ministry of Health, 2008) 
Commitments at an organisational, programme implementation and evaluation level are reflective of Mertens' transformative paradigm (2009) and include such questions as 'How are Māori empowered to participate at all levels of the organisation?' 'Demonstrate how you will build and maintain good community relationships?' 'How are Māori staff involved and supported in the implementation activities?' It forms the basis for the Whānau Ora model of service delivery for Māori currently being rolled out throughout the country. This tool provides a possible model for an implementation and evaluation guide for the New Zealand Disability Strategy, and more specifically, for autism policy.

\section{New Zealand disability policy 2011}

Although there has been progress in the last decade on disability policy there is still much inequity. The nature of these things is that the more that becomes possible the higher the expectations become. Disabled people, including adults with autism, in New Zealand are still overwhelmingly living in poverty and without work or many life choices (Convention Coalition, 2010; Statistics New Zealand, 2007). Since the 2008 general election, disabled people appear once again to be excluded from policy development. An example is the 'Horn Report' on the health and disability sector (Ministerial Review Group, 2009). The report's title claims it aims to 'enhance ... the patient and consumer experience' yet still did not appear to have any consumer or disability representation on it. As a result of the Horn report the Ministry of Health's Disability Services Directorate, a group which oversees millions of dollars of disability support, was transferred into a new National Health Board. Neither have disabled people been represented on recent government working parties on tax, ACC and welfare reform. This raises questions about the ethics of the policy process and serious concerns about possible long term negative consequences, as the historical examples provided earlier indicate.

In 2011, in spite of decades of activists calling for 'nothing about us without us', disabled people, including those with autism, are still excluded from major policy decisions that affect them. They are still largely excluded from the public record although the government funded on-line encyclopedia Te Ara (www.terara.govt.nz) now has an article on disability organisations. Social model-based Disability Studies (as 
opposed to medical model 'rehabilitation') is only offered in one New Zealand university.

The UNCRPWD and Disability Strategy cited at the beginning of this chapter expect nothing less than 'the full and equal enjoyment of all human rights and fundamental freedoms' and a 'fully inclusive society'. These are strong statements, yet the recent report by the disabled peoples' coalition which researched and reported on New Zealand's implementation of the Convention (Convention Coalition, 2010) shows we have a long way to go. Ethically and legally, we as a society of humans cannot rest until the aims are achieved. Research such as mine, underpinned by the social justice principles of the transformative paradigm, has a valid role in highlighting injustice for disabled people, and seeking collaborative ways forward.

Our disability history shows quite clearly that the main factor for change is sustained and collective activism from within the community whether those activists are disabled people, parents, advocates or politicians. The activism that has gone before is also nurturing new activism from within the autism community.

\section{Conclusion}

Autism policy cannot be fully understood without the wider disability focus this chapter has provided: the historical contexts, the policies that shaped lives, and the rise of the disability activists and the disability studies theorists. Out of these contexts there are already some models emerging which could be developed further to enable the input of autistic lived experience into policy. In conclusion, it is clear from the examples above, that ethical disability policy is more likely to happen when there are good relationships between consumers and politicians. Right relationships require ethical awareness and consumer engagement and will be further examined in the next chapter, along with the other necessary aspects for improving autism policy such as respecting lived experience. I will also attempt to clarify what I mean by love and luck, why this seems to be an important requirement for good autism outcomes. 


\section{Chapter Six: Love and luck, right relationships and lived experience}

She has enriched our lives more than anything

(Father of an autistic child about his daughter) (Bevan-Brown, 2004, p. 79)

\section{Introduction}

In the first chapter I explained the significance of the concepts love and luck, right relationships and lived experience, for the framework of my thesis, and for understanding some of the complex issues underlying autism policy. This chapter examines the concepts in depth and their relevance for autism and autism policy.

Reports from people with autism and family members in research reports, articles, auto/biographical accounts, websites, blogs, or media interviews, frequently mention the importance of love and luck as significant factors for accessing timely and appropriate services and supports. However, these are problematic concepts from a policy point of view as they are subjective and hard to define. I have used them, and thus defined them as those with autism and carers, including my key informants, have used them in quotes throughout this chapter.

In anything to do with policy or human interaction, relationships are very important. Almost any problem can be solved if the parties involved put some effort into building relationships. But there is a particular ethical concept of right relationship advocated by Michael Kendrick (2000, 2008b, 2009), an American theorising a better way to do the human services of disability support, which encompasses values of respect, equality and of treating disabled service users as fully human rather than as other. This describes the particular nature of the relationship I hope to advocate for those working in autism policy or services. 
From the data analysed, and my own experience, there appears to be something missing in whose voices are heard in policy processes generally. Traditionally the highly paid medical and educational professionals hold the highest status as experts, but I noticed that the closer the professional was to the child, the lower paid and lower status they had. Yet some of the most valuable experts I encountered with my son were humble teacher aides. I know parents of children with autism who have developed a great deal of expertise by necessity. But who listens to us? And I realised from the growing numbers of autobiographical accounts of adults with autism, such as Temple Grandin (2006, 2008; Grandin \& Johnson, 2009) and Jen Birch (2003) that their insider perspective was virtually ignored. The expertise hierarchy needed turning on its head and respect accorded to those with lived experience. I sought a model that would privilege the lived experience of people with autism, but also respect the expertises that everyone else brought. So my thesis evolved: by building right relationships with those with lived experience and incorporating all the other expertises, we could we move policy beyond the current situation whereby autistic people need love and luck to get services and supports. What do I mean by these concepts? The quotes in the following sections illustrate how they are used in autism-specific contexts.

\section{Love and luck}

Among the submissions on the draft ASD guideline (Ministries of Health and Education, 2006, p. 24) was one submitted by advocacy group and service provider CCS (formerly the Crippled Children's Society and now CCSDisabilityAction) written by a young autistic man, Matt Frost, in his capacity as Policy and Information Researcher at their National Office, which considers this dilemma and which I quoted in Chapter One. Later that same year (2007a) he gave a presentation to the New Zealand Historical Association conference on his autistic autobiography emphasising his luck as an autistic child to have had the love of a supportive family. ${ }^{12}$ He elaborated on the theme as it related to education in a 2010 interview on Radio New Zealand:

In my own experience of education I use a phrase called 'love and luck', and I think for a lot of disabled students, or those disabled students who are

\footnotetext{
${ }^{12}$ Matt Frost was the chair of the Implementation Advisory Group for the Guideline 2008-10 and is acting chair of its Living Guideline Group.
} 
successful in negotiating ... the educational system, it does come down a lot to the love and support of whānau and family so if you have a parent who is a strong advocate for their child then that is really helpful... but also it comes down a bit to luck in that you will get a teacher who says you know I'm not that worried about the fact that Matt might have autism and I don't see that as a barrier in classroom learning ... I see it as an opportunity to encourage other students in the class to acknowledge that actually there is a diversity of experience in life. (Frost \& Gourley, 2010)

The importance of loving support is also reflected in an anonymous comment which leads the section on 'Support for Individuals, Families and Carers' in the ASD guideline: 'it was the work of many people who loved me that got me where I am now' (Ministries of Health and Education, 2008, p. 61).

When I first envisaged this research project my intention was to interview people with autism and their families about their lives at least twice over a period of time and from that analyse themes about what support and services would be required to improve their lives. Unbeknown to me, Francesca Bierens (2009) had already interviewed people from seven unnamed New Zealand families in 1994, revisited them fourteen years later, and published extracts from these interviews as A spectrum of light: inspirational interviews with families affected with autism. The word 'inspirational' indicates that this book is framing those with autism and by extension those raising them- as 'heroic'. To have autism implies something beyond normal, and thus caring for someone with autism requires extra dedication and strength. An alternative meme seen on some websites promoting cure of autism is of autism as 'tragedy', and they are the flip sides of the same attitude to autism as something threatening and challenging. This same dichotomy is often seen in general media stories about disabled people's lives as either tragic or heroic. Newell (2005) promotes instead that disability is part of the diversity of normality 'from other to us'.

Regardless of agenda, there is much useful information in Bierens' book. The chapters are arranged thematically to persuade the reader that autism is a family learning experience that, with support and understanding, does get easier over time. It promotes 
a view that autistic children have rights to inclusion in the family and society, have many valuable attributes, and can achieve independence and a lot more than the families anticipated fourteen years earlier. The author has possibly selected extracts from her interviews to fit the inspirational meme (this is my conjecture as of course full transcripts are not provided) that it can be tough at times, but it gets better and the parents are proud of their children. The final section contains updates, and interviews with two of the autistic subjects who are now adults. Many of the autistic adults have jobs, live independently, some drive, and one is training to become an audiologist. Some are non-verbal and live in residential care but still have full lives. This is probably all very useful to read if you are a parent of a newly diagnosed autistic child grieving about the diagnosis and worried about the future. A spectrum of light will probably, and justifiably, have a wide audience.

However, of most interest to me is the unstated theme of love and its importance for good outcomes. It may also be significant that all the children had two-parent families and fourteen years later only one couple has separated, although the child still has strong relationships with both parents. Parents quoted in A spectrum of light reflect love for their autistic offspring in various ways:

People don't seem to understand that I could love Peter. I'm sure they don't. He was born the same way as any other child is born so why would you treat him any different? (Bierens, 2009, pp. 32-33)

As a 21-year-old Joseph lives between two families, his own and a long-term respite family:

Joseph is part of the community as much as he can be. The fact that he lives with two families is really nice. He has a very normal life really. He goes to specialist services in his day but he's very much part of two families so he does have a lot of people in his life who love him. (2009, p. 164)

Her mother talks of Eleanor's life at 22: 
She's profoundly intellectually disabled and has no communicative language that we know of. She understands plenty of spoken language but she doesn't initiate any at all and yet she's as bright as a button. She's clever. She remembers where everything is. They love her at the Centre. (Bierens, 2009, p. 167)

The people at the Centre love Eleanor so they give her a really good time. She goes line dancing and she goes and feeds the ducks in the pond. She's on every outing going. She's still adored by her dad. He adores the ground she walks on. Totally compatible. She's delicious. (2009, p. 167)

Loving a child often means taking on an advocacy role for their rights:

We're the generation that said, 'Our child has the right to take part in the community that they were born into and that they live in'. So we are not going to hide our children away. (2009, p. 36)

Education advocacy played a major part in the lives of many parents, for their own child and for others:

He's mainstreamed. I had to fight for it because the children they've had at school previous to Joseph haven't had as severe a disability as Joseph and they thought he was a bit too hard. (2009, p. 38)

Their rationale was that Joseph was less important than the normal children and was better off staying at home. Probably while there's still special schools around it'll be like that. $(2009$, p. 40)

Joseph's classmates are going to grow up to be adults that don't have a problem with handicapped people basically. They haven't got the fear that all of us have got because we didn't have handicapped people in schools. (2009, p. 52) 
On the diagnosis of autism, loving parents take on a new responsibility:

It's the parents who are diagnosed, not the child. When the child is diagnosed with autism, nothing changes for the child. They just go on their merry way being what they were in the first place. It's the parents who are diagnosed. You are now the parents of an autistic child. It's your diagnosis, not the child's. There must be a more sane, kind way to break this life sentence to the parents. (2009, p. 115)

Loving parents try hard to adapt to the needs of the child:

I've adopted very much a 'go with the flow' approach and I find it creates a calm, happy environment where little things don't matter. I think parents of any child with a disability develop an odd sense of perspective and sense of humour that keeps their nerves firmly rooted in the nerve sockets. (2009, p. 86)

The biggest problem when we first found out about Richard's disability was ourselves. We adapted over the years and have just accepted him as a person at whatever stage he was at, regardless of whether he was half there or whatever the stage. We don't compare him with others. We compare him with himself, how he was before, mentally we note that he's improved. (2009, p. 89)

Loving parents see the child's potential:

I have enormous expectations for Alex. I don't dare to dream too far into the future. We don't set goals too far into the distant future and we tend to follow where Alex leads. And it's taken us on some interesting paths. (2009, p. 94).

However, a common parental desire, particularly in the early years after diagnosis, is to seek 'amelioration' of the autism, often later regretted: 
Poor John, I put him through all sorts of diets. You really get hopeful because you think it was simply a reaction to certain foods that makes him angry then it would be simple: You just wouldn't give it to him. Unfortunately nothing has shown up that clearly. (2009, p. 81)

Conflicting feelings over therapies were reinforced by my own interviewees. For, example, one of the parents I interviewed about the Guideline also mentioned her unease over the number of therapies she put her autistic child through. She wanted to do whatever she could to enable the best outcomes, but in retrospect feels her loving desire to do her best was quite tough for her child at times.

Love and luck are amorphous concepts, but for my purposes they could mean that the autistic child is brought up in a functioning household with sufficient food, shelter and safety, with at least one adult consistently caring, and seeking the best opportunities, supports and services for him or her. The children featured in Bierens' book are lucky to be born into such families. Some parents in A spectrum of light mention the concept of 'luck' specifically:

We were lucky. We had quite a smooth diagnosis. I just went to the right place at the right time pretty much, so I didn't really have a problem with that. They didn't say he was autistic. They told me he was 'developmentally delayed' and they waited till I said he was autistic and they after that they said he was autistic. I think it's a bit of a heavy duty label to put on a two and a half year old, so they said 'developmentally delayed' until he's a bit older probably, which is sensible. I suppose, but it's also a little bit hard because it gave you false hope. (Bierens, 2009, p. 116)

We've been very lucky with all the people we've had dealings with, excellent teachers aides, good speech therapists and itinerant teachers as well as a very positive principal. (2009, p. 71)

The question arises as to whether this might have been a different book if the author had interviewed mothers struggling to bring up an autistic child on a welfare benefit with no 
extended family or school support, or in a situation where domestic violence was common, or the family was part of a cultural minority.

It could be also be argued that some children are unlucky that their loving and well-off parents persist with sometimes dangerous and painful therapies that they would not subject their non-autistic children to, such as repeated injections, restricted diets or forced feeding with dietary supplements, sealing in hyperbaric chambers, and long hours of repetitive exercises, all of which are examples of commonly used interventions for autistic children (Baker, 2006b; Green, et al., 2006; Shute, 2010).

A 2000 study which interviewed parents of children with behaviour issues, many of whom were on the autistic spectrum, is reported in the Ministry of Health's Just surviving: talking with parents of children with very high support needs (Carpinter, Irwin, \& Rogers, 2000). The picture presented is grimmer - perhaps as the intended audience is government advisors, not newly diagnosed middle-class parents. However, love for their children by the mothers is no less evident, although many mentioned how difficult loving the child engaged in destructive and violent behaviour can be. Some parents also reported negative effects on relationships with siblings or other family members; 'love', but little 'luck' is evident in the family experiences reported.

An in-depth and unique study of Māori families and their experience of autism was undertaken by Massey University educationalist Jill Bevan-Brown (2004) as part of the Ministry of Education's participatory action research projects on ASD, begun in 2002. In her report Māori perspectives of autistic spectrum disorder she emphasised that 'a single Māori viewpoint on ASD cannot exist...[but their stories] can enrich our understanding of what life is like for a number of Māori children with ASD, their parents and their whanau' $(2004$, p. 3). Apart from a desire for culturally appropriate schooling and services by many families, they have similar things to say as Bierens' parents. They all loved their children although they admit to occasionally threatening or violent behaviour towards them at moments of extreme stress and tiredness. Casey Albury's death was referred to by one stressed mother desperate for support and suffering from lack of sleep. She got a quick referral to a service provider from her helpful GP (primary health doctor), but the provider concerned had a long waiting list: 
'So I said to him [the GP], Have we learnt nothing from Aubrey Thompson [sic]? Has anything changed?' (2004, p. 75).

Some were lucky to have supportive whānau (extended family) and some were not:

My whānau, they love Sophie...my mother had 21 kids - she had 13, but she raised 21 - whāngai, ... so there is always kids around. None of my family have an autistic child, or have any experience with autism, but none of them have a problem with it. (2004, p. 24)

In contrast:

My family are very very ignorant, they don't take Cory. ... They are very old book where there's something wrong with the child, it should have been locked away and out of sight, out of mind. Whereas my in-laws don't care, he's part of the family. (2004, p. 24)

Many were lucky to find supportive people somewhere in the system. A former teacher offered respite care:

She offered respite care because she said, "I love having him around and learning from him." So her whole attitude was, "You guys in his class are privileged to have him in your class, and you can learn so much from $\operatorname{him} . . . ”(2004$, p. 34)

As soon as I walked into that place and looked around you could see the peace. There's a lot of aroha and a lot of dedicated teachers. (2004, p. 34)

For another informant, a paediatrician gave his personal contact details and service out of office hours to ensure appointments went smoothly and crises were averted (2004, p. 33). However, many had to cope with racism and prejudice. A single mother whose child's school would not have him for the whole day reported the social worker's reaction: 
“Typical Māori, why isn't that kid at school?" I said, "Go and find me a school that will have him from nine till three and then you can say it". I had an answer for everything. (2004, p. 30)

As a Maori, as Pacific Islander, the expectation is that they are less likely to achieve - they are more likely to be in a bloody jail cell. $(2004$, p. 30)

Several families had or planned to move location to give their autistic child better opportunities (2004, p. 61).

Many of the themes in Bierens and Bevan-Brown's research are also borne out by the contributors from many countries, comprising family members, professionals and autistic people, to US compilation Voices from the spectrum (Ariel \& Naseef, 2006). The late Clara Claiborne Park's story of her daughter Jessy $(1982,2001)$ portrays a much-loved member of the family. Similarly, Kim Peek's father Fran (1996) who wrote their joint auto/biography draws a picture of Kim as a loved and honoured family member who used his luck with the Rain man movie connection to become a public speaker at schools and other groups on the importance of acceptance of difference. Other loving-parent biographies include those presented by Grinker (2007), whose daughter Isobel's autism was initially a shock. However, he reported in a recent piece in the New York Times (2010) that Isobel introduced herself to her new teacher with the assertion that 'my strength is that I have autism'.

I am not saying that without significant love and luck that there will necessarily be poor outcomes for autistic people. Australian writer, public speaker, musician and autism activist Donna Williams wrote about her miserable and sometimes abusive childhood in the first volume of her autobiography with the sad title Nobody nowhere (1992). However, after a diagnosis of autism as an adult and addressing some complex medical conditions, her life improved, and her lively blog reports her considerable ongoing achievements as a speaker, writer and musician and family member (http://blog.donnawilliams.net). UK-born Australian Wendy Lawson (2000, 2008) also writes of a lonely puzzled childhood and young adulthood. Now a grandmother, she has a $\mathrm{PhD}$ and is in demand as a speaker and mentor on autism. Lucy Blackman (2001), Jen 
Birch (2003) and Daniel Tammet $(2006,2009)$ are other adults who have written their autistic autobiographies. Although they were considerably misunderstood at times, and had some challenging experiences, they all had the constant love and advocacy of at least one parent, and have been lucky to have significant people enter and transform their lives at various times.

Aspergian (as he refers to himself) John Elder Robison (Burroughs, 2006; Robison, 2007) grew up in a dysfunctional and violent family and he narrowly avoided some dangerous situations. His author brother Augusten Burroughs (2006) has written about their abusive childhood in his books, including Running with scissors. Although Robison's early life was tough, he later had some luck such as meeting key people who understood and supported him (including his partner, and a clinician who gave him the diagnosis) and is now a successful businessman, speaker and the first autistic advisor to the influential parental lobby group Autism Speaks.

Love, without luck may not be enough. I personally know of several examples of families with loving parents of autistic adults and young people, but the parents have been unable to find support for their children who have ended up incarcerated, or suicidal. A public example is an autistic man wrongly imprisoned for rape, who was finally released and compensated only after continual lobbying by his parents (G. Brown \& Vance, 2011).

To counter these examples of love, luck or resilience there are many more real examples of adults disengaged from families, living in poverty, unemployed and without good quality of life that sometimes come to the attention of support agencies such as mental health providers and Autism New Zealand. As mentioned earlier, previous generations were sent to live in institutions, where they were subjected to strong medication and unpleasant interventions (Frame, 1989). Anecdotally, many of these (predominantly male) patients came out of the 'back rooms' of the institutions and ended up in substitute ones such as the residential care facilities for those with intellectual impairment and criminal behaviour provided under the 2003 Intellectual Disability (Compulsory Care) Act. I heard a sad recent local story of an autistic child who went 
into hospital for a minor condition, but the single mother could not be located when it was discharge time. Perhaps both love and luck were scarce in their lives?

Statistics show that disabled people (of which those with autism are an under-reported subset) are over-represented in the poverty, unemployment, poor educational attainment and inadequate housing statistics (Statistics New Zealand, 2007). The 1991 benefit cuts severely affected disabled people and their families (Sullivan \&Munford, 1998) and the current welfare reforms - without significant additional investment in employment, education and other support - are unlikely to improve the lives of autistic people who do not also have strong links to loving and resilient families, according to the data gathered by the network of groups who combined to form the Alternative Welfare Working Group in response to the Government's 2010 official Welfare Working Group (Welfare Justice - the Alternative Welfare Working Group, 2010a, 2010b; Welfare Working Group, 2010).

Attachment-theory adherents and psychologists would probably have more theories about definitions and implications of 'love', but that is not the focus for this study. However, parenting is complex and tied up with societal expectations. Many first-hand accounts of parenting a child with autism in autobiographies or websites, particularly from the United States, touch on issues around grief for a child who is not 'normal', meaning the parents are grieving for the 'normal' child with the 'normal' developmental trajectory they were expecting and on a diagnosis of autism have to re-examine their expectations. US websites also talk of autism mothers becoming either 'Warrior moms' or 'martyrs'. However these voices are part of the parental diversity, just as there is diversity in the autistic experience.

Some of the New Zealand parents Bevan-Brown talked to became politically active, others were strong advocates for their children while others felt uncomfortable speaking out. But many parents of autistic children will relate to the parental humiliation of the following scene:

Everybody is staring and your child is big and you're going like that... it's like, “What's wrong? Can't you control your child? What kind of parent are 
you?" It's not what they say but it's in their eyes, it's a judgement you feel. (Bevan-Brown, 2004, p. 77)

The topic of autism and luck sometimes can even be seen in the mainstream media. A columnist in the New Zealand Listener writing about a US medical student with Asperger's syndrome who made a fortune trading on the collapse of the US housing market, notes:

it was a stroke of luck that his special interest was financial markets ... only someone who has Asperger's would read a subprime-mortgage-bond prospectus. (Cone, 2010)

A summary of the roles of love and luck are presented by Russell Brown, Auckland father of two teenage boys with Asperger's in this recent post on his 'Public Address' site 'Hard News'. The thread discussion is about a well-known teenager, who does not have ASD but has several criminal convictions, who had once again become the news:

As the parent of ASD children, I can't help but wonder how [the young man concerned] might have turned out had he enjoyed a loving, supportive family life and good opportunities. Would he still have been a bad bastard? ... I've been surprised how many people have been prepared to dismiss him as the undeserving bad seed - and mindful that ASD people are overrepresented in the ranks of the apparently mad and bad in our prisons. (I'm not suggesting he is ASD, at all, but I do think about the way our younger boy could have developed in less fortunate circumstances.). (R. Brown, 2010)

The above examples show that love and luck are currently important in getting good outcomes for autistic children. But I would like a future whereby all ASD children are loved and cherished, and good services, appropriate support and opportunities are accessible to all, not just the lucky few, and parents are supported to do their best for their children. Public policy has a role in moving towards that goal, in partnership with the wealth of expertise such as portrayed in this chapter. 
Bevan-Brown summarises what parents told her that would help them. They needed 'on-going support to help them meet the growing and changing needs of their child'. (Bevan-Brown, 2004, p. 95):

Parents should not have to "fight" for services, nor should children have to go without the professional assistance that could improve their ability to communicate, to learn and to interact with others. (Bevan-Brown, 2004, p. 96)

But:

they did not want to be given a number to ring or a multitude of information to wade through... [instead] someone to sit down with them to explain exactly what ASD meant; how they could assist their child; what were future implications; what services, equipment and entitlements existed; and not only to explain how these could be obtained but also to assist them in the process. (Bevan-Brown, 2004, p. 95)

Her summary is a good description of what policy coordination based on 'right relationships' could look like in an autism support context. The importance of this 'pathway' role is raised again in Chapter Nine.

\section{Right relationships and lived experience}

\section{Right relationships}

Right relationship is originally a Buddhist concept based on ethics, respect and treating others as equals. The idea of right relationships has been adopted by many in disability studies as part of a critique of the history of disabled people as defective beings who were institutionalised for who they were - not what they had done - or objects of pity and care, or cases to be managed by service providers. Researchers who use the lives of disabled people for their own gain without giving anything back have been labelled 'parasite people' by disability activists mentioned in earlier chapters. 
Critical disability studies is a growing discipline which has developed from lived experience of disability and other human rights causes and emphasises issues around power, human rights, language and ethics. These attitudes are reflected by several contributors to the 2005 New Zealand edited book Allies in emancipation; moving from providing service to being of support (O'Brien \& Sullivan, 2005). The subtitle implies the era of providing a service 'to' a disabled person is over, and we are now in an era where the disabled person is central and they decide what support they require for participation in the community. This new relationship is based on partnership and equality and will liberate both carer and disabled people. Each chapter finishes with self-reflective exercises. In the book's forward, 'Moving disability from other to us', the late disability activist and bioethicist Christopher Newell advocates for:

the importance of a significant shift in mindset and associated power relations, so that the onus is placed on services to provide support for those who live with disability in ways that are determined by people with disability. (Newell, 2005, p. iv)

Key to this transformation is the power of relationships which 'can either transform our everyday lives and/or socialise us very effectively in narrow, passive recipient ways of being disabled. (Newell, 2005, p. x)

Seeking right relationships was a central theme of the 'Trusting Partnerships conference' in Rotorua in 2008. Keynote speaker, Michael Kendrick (2008) has been writing and speaking on the significance of right relationships in the human services sector for many years. He has taken this concept based on respect and treating others as equals and developed it into an ethical approach for those working with disabled people individually and through organisations: keeping things small and local, valuing those you work with, and being prepared to speak up for issues of social justice, and against those whose behaviours are abusive, is part of the self-reflective philosophy (2009). The conference organisers have a slogan and website 'Imagine Better' and a reputation for challenging disablist policies and practices. The conference organiser, Lorna Sullivan, is also part of Manawanui-in-Charge, an organisation which supports disabled people to access and manage their Individualised Funding (IF) packages. IF is a practical example 
of implementing a policy based on right relationships as theoretically the disabled person controls the funds and makes their own support decisions; however, the funding must be sufficient for an 'ordinary' life.

Examples of relationship building (the precursor to right relationships) were appreciated by parents in Jill Bevan-Brown's research. Some parents were involved by the school in appointment of their children's teacher aide (Bevan-Brown, 2004, p. 47). Parents mentioned schools that welcomed them and gave them the opportunity to talk to the students and staff about autism and how it presents. In one case a parent talked to the autistic child's sibling's class and commented. 'In the early days when the kids didn't know and even we didn't know, it was a lot harder' (2004, p. 47).

Right relationships are hard to define but people know when they experience 'bad relationships'. One of my key informants, Sam, had a long history of poor relationships with people who appeared to know best:

They kind of like control ... they seem to be in the sector because they have got a degree of control over people's lives and they are kind of like little dictators and authoritarians. And then you get this other group of people who really do value people like [her child] and have some respect and they work really well. Unfortunately, I still think we're outnumbered by the arrogant control freak.

There was just an assumption that [my having an autistic child] therefore gave them the right to have this great discussion like you were some kind of needy welfare person that needed them to make all the decisions.

Some professionals have attitudes or motivations that are not helpful, what Sam described as a patronising attitude by some who saw caring for her autistic child as a moral duty do be done for their own personal good: "the "brownie points to heaven" ... so all Morgan needed was good kind people and to be looked after for the rest of her life'. The abilities and attitude of the carers are very important to this parent: 'My 
biggest anxiety isn't about letting Morgan go, as some in the system might think... it would be about who I am letting her go to'.

It makes a difference to relationships if the professional values the people they are working with. As Sam says, 'If they don't value the people [they work with] then they are a kind of waste of time in your life', but if they do respect the child stresses ease, 'because she valued Morgan, everything that I wanted for Morgan she just took on board, so I didn't have to fight any more'. Sam appreciated the good people in the system who made a difference to the quality of the relationship: 'I've met some really nice people like those CYFs people ... she gave me a big hug'. But she noted that many professionals do not have good relationships with each other and suggested that they needed to work on their relationships with each other: 'I think there has to be [something] like strengthening families [for] strengthening the professionals'.

Reciprocity can improve a relationship if it happens that the professional's child also has a disability issue, and roles may be reversed. Sam is one of several of my informants who has experienced this: 'It's been kind of nice to be able to have a professional relationship, but still help them through or listen to some ... of what they are going through as a parent'.

Although, having a disabled child can feel very disempowering Sam changed her attitude when she realised working with her child was helping the economy: 'I remember thinking that [children such as hers] have $\mathrm{X}$ amount of people employed you know as in carers and teacher aides and ... they are all spending their money in the community'. This encouraged her to 'say to all service providers look you don't have to like me and I don't have to like you but you are paid to do a job, now do your job'.

Sam also considers she is lucky because her child has a diagnosis of autism with intellectual impairment. This might seem strange but in the New Zealand policy context it means the difference between getting services and being ineligible for any support: 'We've been lucky...you know they split autism and Asperger's and so you know it's forever changing....You have no guarantee with the Ministry of Health... it's always up for negotiation'. 
Building right relationships with the autism sector, especially those with autism, involves respecting historical abuses such as institutionalisation, and includes aspects of citizenship, Treaty of Waitangi principles, whanaungatanga (relationships), and Disability Strategy principles (Ministry of Health, 2001). It's the attitudinal, selfreflective, power-sharing work you have to do to before you get to trust and the other aspects of relationships, and it can be highly symbolic.

A particularly New Zealand expression of the holistic links between love and right relationships is provided by New Zealand author Witi Ihimaera in his 2009 novel The Trowenna Sea. The character speaking is a Scottish doctor living in $19^{\text {th }}$ century Tasmania, recalling the words of his dead Maori friend Hohepa:

I tried to remember Hohepa's works about the nature of love - or aroha. "It does not have one meaning," he had said, "but many. It cannot be considered by itself in isolation. It has to be associated with other works like awhinatanga, to support, and manaakitanga, to offer hospitality, and whanaungatanga, to honour kinship. When all its qualities are observed, they ensure that we are in the right relationship with each other and with our world. (Ihimaera, 2009, p. 464)

A contributor to Bevan-Brown reflects these values when describing what made the kura kaupapa (Māori language school) so welcoming for her autistic child:

It was the philosophy, it was absolutely the tikanga thing, the whanaungatanga, manaakitanga absolutely, and it made a hell of a difference, and the teachers' attitudes too. (Bevan-Brown, 2004, p. 83)

Kendrick (2000) suggests that the current system, which is reflected in many of the comments above, gives unwarranted power to managers and professionals:

This classically paternalistic pattern may have its origins in clinical presumptions about the service user's inherent dysfunctionality or incompetence. 
He has developed right relationship principles for the disability or human services:

1. Resolve to act ethically - how you would like to be treated

2. Resolve not to devalue people, do not endorse degrading practices

3. Decide to be loyal to people served

4. Uphold only what is truthful, not buy into manipulations or 'deceptive manipulations' of organisation

5. Recognise own shortcomings

6. Support 'others who are attempting to be good and ethical people'

7. Persevere with attempts at ethical behaviour

8. Encourage your organisation to be 'more faithful to people' 'a drawing of attention to the good that is possible if the organization were to do the right thing'

9. 'Seek to continually strengthen and prepare oneself to be conscientiously and consistently principled'

10. 'Lastly, one can make the decision to stand alongside the people that the organization serves such that they act as advocates, protectors and champions of people where this is welcomed by them and is needed'. (Kendrick, 2003)

\section{Lived experience}

In his submission on the draft ASD guideline mentioned earlier, Frost reflects the importance of 'right' relationships by the trust shown in him by his employer to write the submission, and he explains the significance of putting the autistic person and their lived experience at the centre of the policy relationship:

I am also personally offended by the continuing focus on my 'special field of interest' being an 'abnormality.' To me this is an awful way of categorising an important, special and useful part of my life...I think this Guideline would have been very different and indeed more useful if people with ASD had written it. I hope the fact my employer has trusted me enough to lead our response on this piece of work provides an example to the Ministries of Health and Education on how these activities can and indeed should be done. (CCS, 2007) 
As mentioned in previous chapters, the expertise of disabled people and their families has not historically been respected in policy development. Chapter Three provided examples of experts who live with the condition, and who deserve a bigger role. Parents too have lived expertise of parenting autistic children. In his 1998 report on the killing of Casey Albury Thomson, Professor Werry praised the expertise of parents. Some professionals do follow his advice as reflected in the following more recent comment:

My GP really amazed me because he turned around and said, "You know, you were right Mabel", He said, "I wouldn't have picked that [ASD]". (BevanBrown, 2004, p. 33)

A symbolic political battle raged on the internet in 2010 over getting autism lived expertise into policy processes. Ari Ne'eman of ASAN, is a young man who was nominated to President Obama's National Council on Disabilities. He was one of seven nominations from the President and the rest were approved by the Senate in March 2010. However, lobbying against Ne'eman by the 'cure' lobby saw his nomination blocked. Newspaper and web columnists in many countries, including New Zealand, took up his cause and a Facebook page to support the confirmation of his nomination was set up which soon had several thousand members globally posting supportive comments (Silberman, 2010). Contrasting comments from parents on websites which opposed his nomination included suggestions that he does not speak for parents, nor for lower-functioning autistic people. Many of them are outraged by his suggestion that being autistic is not a disaster and that he prefers research money to be spent on improved services than on interventions and cures.

Autism Speaks (AS) is a large parental lobby group and fundraiser for genetic and biomedical research. ASAN and AS have long been in opposing camps, mainly because AS advocates cure research and had no autistic people in its organisational structure. They recently appointed their first ever autistic advisor, the author John Elder Robison who has posted a blog on Autism Speaks' research project to identify autism in babies. However, even he is conflicted: 
I am really excited about the prospects for detecting and remediating autism in infants. Such detection will present us a unique opportunity. You see, the infant brain is at its most plastic and formable. If we could accurately identify those kids who were turning down an autistic path at age one, I think we'd have a good chance of steering many of them back to a typically developing course ... But what about some of the more powerful experimental therapies being studied today? ... In our quest to cure profound disability, we must always recognize the gifts that may be concealed within otherwise crippling conditions, and work to remediate the disability without extinguishing that creative fire. (Robison, 2010)

For the purpose of my research lived experience is primarily about respecting the expertise of people on the spectrum, whether verbal or not (speaking being only one form of communication). Parental expertise is important but different to the insider expertise that autistic people have. However, as there is huge diversity among autistic people and their families, no one lived experience will be the same as another, although they may be similar, share themes and concerns. That the current policy and services discourse does not see things from this lived experience perspective is illustrated by this optimistic plea on Stephen Shore's Facebook page (23 September 2010), from an autistic adult on his frequent dealings with the police:

I can begin to look forward to the day that police don't call my eyes "evasive", my body language "guilty", my weird mumblings "lies", my self defence "assault", my late night wanderings "suspicious", my helpfulnesses "crimes", my quiet demeanour "uncooperative", my hesitations "proof".

\section{Examples of right relationships and respecting lived experience}

There are a few examples of how right relationships and respect for lived experience has been incorporated into policy. The Labour-Alliance coalition Government elected in 1999 promised that the government would work in good faith with the voluntary and community sector and try and get the relationships right through its Statement of Government Intentions for an Improved Community-Government Relationship (SOGI) (New Zealand Government, 2001). This was a short document signed in 2001 by Helen 
Clark as Prime Minister and Steve Maharey the Minister for the Community and Voluntary Sector. It stated that:

Government is committed to creating a genuine partnership with community, voluntary and Iwi/Māori organisations. Building strong and respectful relationships with the community sector will take time and will require hard work, reflection and active engagement. (2001, p. [3])

Although the principles were strong, it was neither specific nor binding and it was reviewed in 2008 by the community and voluntary sector, and the report published in 2009 as Good Intentions (Association of Non-Governmental Organisations of Aotearoa, 2009). The resultant work by the Office of the Community and Voluntary Sector became a new ongoing consultation called 'Kia Tutahi: Standing Together', but with few obvious outcomes so far.

Another example of right relationships is the Consumer Consortium, mentioned above, set up in 2005 to advise the Ministry of Health's Disability Support Services (DSS) on issues relevant to its role as a major funder of disability services, and comprising representatives of disability advocacy groups and disabled people. The group of about 25 people (including support people such as those who assist the People First members, and New Zealand Sign Language interpreters for Deaf members), meets two or three times a year for two to three full days and a variety of DSS managers visit to discuss and seek feedback on policies and plans. I was a member of this group representing autism family members for Autism NZ from 2006 to 2009 (Jen Birch represented autistic people). Highlights for me were the two meetings chaired by People First representatives in 2008. However, this initiative appears to be a rare example of linking lived experience and policy, and its effectiveness has not yet been evaluated.

'Strengthening families' is a model for families requiring support whereby friends, family members, professionals and those from relevant agencies such as Work and Income or schools meet, share expertise and together plan a person-centred way forward. I attended a Strengthening Families meeting for a friend who has no family support and who has a high-needs autistic daughter. There were about twenty people in 
the room from a variety of government agencies, NGOs, the school, health professionals and even a secretary from the local MP's office. They asked my friend what she would like to see happen to enable an easier life for herself and her daughter and then worked out who could contribute and how. The host agency, in this case the Ministry of Education, provided facilitation and notes of the meeting and set up ongoing support. It was a great system as for many families, support is hard to find and keep, is fragmented, and information provided is contradictory. With everyone in the same room it is easy to sort out who will provide what support and how. But someone needs to ensure the decisions are implemented.

The first contracts for the new Whānau Ora policy have been let but the policy is light on details about how it will actually work (Ministry of Health, 2008; Taskforce on Whanau-Centred Initiatives, 2010; Te Puni Kokiri, 2010). It seems to be strongly related to the Strengthening Families holistic family support model, but in a more ongoing and pro-active way. However, in this time of Government budgetary restraint it is possible that money may be withdrawn from existing projects to fund it, so just how helpful it is for non-Māori autistic families remains to be seen.

Other examples of right relationships and respect for lived experience can be found in research projects. Dunedin's Donald Beasley ${ }^{13}$ Institute and affiliated researchers sought to find the opinions of 'special needs' students aged from 10-14 in schools around Dunedin (MacArthur, Sharp, Kelly, \& Gaffney, 2007). Several of the participants had autism and provided valuable insights into what they liked and disliked about teaching and learning (see Chapter Eight for more details). Melbourne had a large institution for intellectually impaired people, including those with autism, called Kew Cottages. Researchers from La Trobe University were contracted to research aspects of deinstitutionalisation and they enlisted the help of one-time resident Alan Robertson as lead researcher to assess the 'homeliness' of the new residential group housing' (A. Robertson, Frawley, \& Bigby, 2008).

\footnotetext{
${ }^{13}$ The Donald Beasley Institute is New Zealand's major research centre for research on intellectual disability; Paediatrician, Dr Donald Beasley, was head of the IHC at the time the ASD parents formed their committee within IHC.
} 
Guerin's masters research (2008) examined the 'quality learning circle' that a South Island school developed with a parent of an autistic student as a more equitable improvement on the school-as-expert model of the Individual Education Plan. The new model included shared facilitation and respect for all the expertises the circle members brought, including the mother, and encouraged a situation which supported the student and his learning. In the process all members became active learners.

Those behind the development and implementation of the ASD guideline have also tried to respect relationships and expertise, and this will be examined in detail in Chapter Nine.

\section{Conclusion}

Analysing the elements to successful policy processes is problematic. Those involved often know that something has or has not worked well but cannot pinpoint why. This chapter has tried to explain the importance for successful autism policy of some concepts that I consider vital but are hard to define. They are fluid and highly contextual and include love, 'luck', 'right relationships' and 'lived experience'. Through the quotes and examples I have tried to show that people involved in disability issues, and autism particularly, do know what these concepts mean for their own lives and those with autism, and feel devalued and disrespected when they are lacking. Therefore, it is worth giving them serious consideration in policy development and implementation.

A condition for which good outcomes depends on such ephemeral circumstances and unquantifiable variables such as 'love' and 'luck', indicates a policy problem so complex it could be called 'wicked policy', meaning solutions not obvious and that improving one aspect risks negative unintended consequences elsewhere. How to deal with the wickedness of autism policy is examined in the following chapter. 


\section{Section Three: Autism policy issues}

\section{ASD policy as 'wicked'; education and autism; NZ ASD Guideline as a case study}

This section examines several aspects of policy relevant to autism. Chapter Seven suggests autism policy can be seen as 'wicked' and tests aspects of wickedness with autism policy. It then looks at the current state of autism policy in New Zealand, using examples from Needs Assessment and Service Coordination and welfare, and how the wickedness could be addressed. Chapter Eight looks in more detail at policy issues around autism and education, including what autistic students say about their own educational experiences. Chapter Nine is a case study of a major attempt to address the wickedness of autism and improve collaboration, the NZ ASD guideline. 


\section{Chapter Seven: Is autism a 'wicked' policy challenge?}

Figure 8: Minister of Education Lockwood Smith 28 November 1995 by Tom Scott.

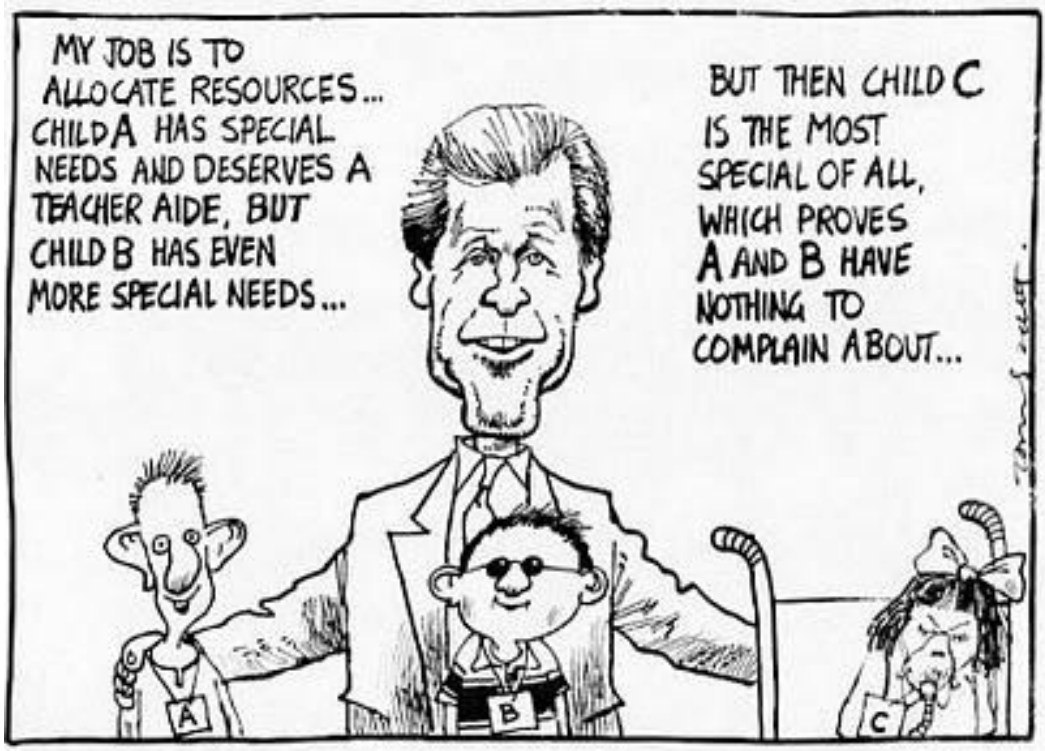

Source: Timeframes National Library of New Zealand ID: H-242-020. Used with permission.

\section{Introduction}

Without mentioning autism, the 1995 cartoon above illustrates several of the policy problems associated with ASD including: the education and health of vulnerable children; insufficient funding; poor assessment and prioritisation; lack of knowledge and understanding; and policy challenges across government agencies. These are sufficient challenges to indicate that autism could be a 'wicked' policy problem.

To examine this possibility more fully, this chapter starts with the current wider policy context for autism policy such as the Disability Strategy, the UNCRPWD and the ASD guideline followed by a note on the work of others who have written in the rare area of autism as a policy issue. It then borrows from recent work on wicked policy with specific ASD examples. An examination of two policies with significant ASDrelevance: Needs Assessment and Service Coordination, and the Invalids' Benefit follows and this chapter finishes with a discussion of a framework for assessing ASD policy development in New Zealand. 


\section{New Zealand policy context for autism}

New Zealand in 2011 has a Disability Strategy with fifteen principles covering all government agencies; the UNCRPWD is signed and ratified, and following the passage of the 2008 Disability Act, all laws are supposedly compliant with the Convention. The ASD guideline outlining best practice has begun to be implemented; the 1989 Education Act ensures the right of all children, including those with autism, to attend their local school from age five to nineteen, and support for disabled children (apart from their educational support) is provided through a nationwide Needs Assessment and Service Coordination (NASC) system, funded by the Ministry of Health. Children with autism up to the age of eighteen can get a free diagnosis through any one of the twenty District Health Boards. From sixteen years old (even if still at school) autistic people can access the Invalids' Benefit from Work and Income in the Ministry of Social Development with employment support provided by a network of agencies. Parliament's Social Services Select Committee investigated the quality of care and services for people with disabilities and reported in late 2008, and as a result a Cabinet paper promoting a 'new model' of disability supports was issued in June 2010; piloting of new programmes is underway. Considering all these factors one could assume there should be no problem in New Zealand for autistic people and those who support them - families, professionals and advocates - accessing all the support they need.

Unfortunately, the reality is quite different and there are still many problems. Autism support is limited and fragmented; it is spread over regionally based NASCs (left over from the old Regional Health Authority structure), District Health Boards and Ministry of Education special education districts (which have different boundaries), which contract local and regional services from dozens of service providers within a ringfenced, capped budget. In addition to Health, Education and Social Development, several government ministries or agencies have some responsibilities for autistic people, including Internal Affairs (which has various community funding mechanisms), Housing (such as state rental housing and modifications), ACC (which covers those for whom autism was caused by accident, such as birth trauma), Transport, and Statistics. Justice, Corrections and Police may also become involved at times, particularly as a result of misunderstandings such as those quoted by an autistic man in the previous chapter. Individuals and families have to navigate through a maze of agencies, 
providers, conflicting and overlapping policies and eligibility requirements in order to seek services and supports, which may or may not be appropriate or satisfactory. The illustration below illustrates the complexity of government agencies supporting adults with intellectual impairment (including ASD) in 2003. Although some agencies and names have changed, the situation remains complex.

Figure 9: Government agencies supporting people with an intellectual disability

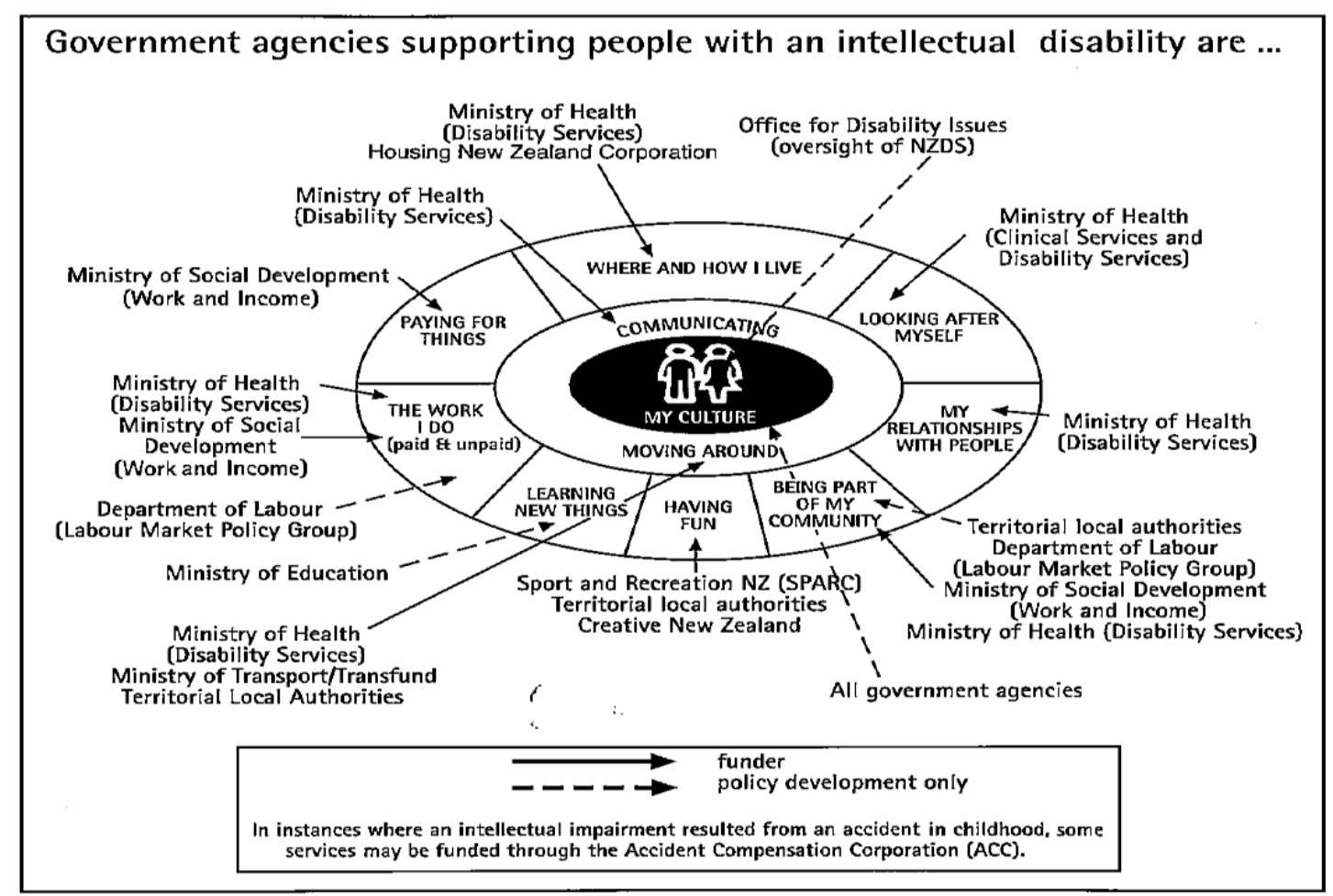

Source: National Advisory Committee on Health and Disability, 2003, p. 16

\section{Autism as public policy}

Few people have written about autism as public policy. Respected autism academic clinicians Lord and Bishop (2010) are two urging collaborative policy changes to address problems their research has revealed such as fragmentation, inconsistencies in data, and inequity of access (and which is also reflected in New Zealand). One who theorised the autism public policy link is Dana Lee Baker from Washington State University (Baker, 2006a, 2011; Baker \& Steuernagel, 2009). She has built on several of Kingdon's (1995) policy theories and adapted them into an autism policy context. He writes about such concepts as primaeval policy soup, and windows of policy opportunities when problems, politics and policies converge, sometimes as a result of 
crises, real or manufactured (Baker, 2006a, p. 178). Baker refers to Kingdon's proposal that:

public policy formulation takes place at a confluence of three streams: problems, politics and policy. Issues gain access to public agendas as a result of either a crisis or the invention of a crisis around a transcendent condition or compelling anecdote. (Baker, 2006a, p. 178)

Baker cites as a manufactured crisis the 1990s autism baby boom, whereby the incidence of autism has apparently risen rapidly. In New Zealand autism was also seen as a rare condition which affected just two or three children per 10,000 until recent years (Werry, 1998). Since the appearance of Asperger's syndrome in the DSM IV in 1994 (American Psychiatric Association, 2000), and increased understanding and awareness, autism now affects an estimated $1 \%$ of the New Zealand population or over 40,000 people (Ministries of Health and Education, 2008).

The New Zealand window of autism policy opportunity in Kingdon's terms was the 1997 death of Casey Albury, against the background of a growing rise in autism diagnoses. Over a decade later the policy focus remains. Baker believes that North America is in a policy paradigm transition but 'implementation lags ... behind intent' (2006a, p. 192). Earlier policy approaches of elimination of 'handicap' (such as through institutionalisation, or clinical interventions) are no longer the answer and neither is a patronising 'charity' model of government or agencies bestowing services. She notes the dilemma that although 'modern disability policy is close to the constructivist end of the continuum, current policy tends to retain limited essentialist elements' (2006a, p. 177). This means that disability policy is about the social construction of disability (social model) but operations are based on fixing individual deficit (medical model). This explains why, in New Zealand, we have a rights-based Disability Strategy but service delivery, particularly in Health-funded services, depends on narrow impairment labels. However, education has tried to be more 'needs-based' eschewing labelling children. This has led to two delivery systems, parallel diagnostic processes for children with autism, and creates problems for collaboration. 
Kingdon's 'dominant generic policy solutions of civic education, rights-based and services policies' (Baker, 2006a, p. 192) are common to both the United States and Canada, and I would add New Zealand and Australia:

as the autism case demonstrates, the balance being struck between individual and society responsibilities is potentially quite revolutionary, [allowing for] a negotiation between two loci of power, rights, and responsibilities. This new balance eliminates charitable action of government or society as a preferred and stagnant response to disability and instead involves all stakeholders in the governance of disability policy. (Baker, 2006a, p. 192)

This is another way of saying that we need to build relationships and get all expertises around the policy table, including those with lived experience of autism. The US government is making advances in this direction with the appointment of autistic people to the Government's IAAC, and the live and interactive broadcasting of that committee's proceedings.

We also need to encourage autism 'policy entrepreneurs', another of Kingdon's (1995) policy ideas, to develop from within the sector. Baker and Steuernagel (2009) note that 'autism policy entrepreneurs' are notable in the North American context as lobbyists for particular viewpoints, and (Baker, 2011) mentions Michelle Dawson as a policy entrepreneur promoting neurodiversity in Canada. We have the opportunity to support similar entrepreneurs here. Among my key informants (particularly in Chapter Nine) are some who could be seen as autism policy entrepreneurs.

\section{ASD policy as a wicked problem}

A condition which depends on love and luck indicates a policy problem so complex it could be called 'wicked policy', meaning a way forward is not obvious, it is socially complex, and that improving one aspect risks negative unintended consequences elsewhere (Australian Public Service Commission, 2007; Conklin, 2006). 'Wicked problems', according to the Australian Public Service Commission: 
- Are difficult to clearly define;

- Have many interdependencies and are often multi-causal;

- Can result in unforeseen consequences when tackled;

- Are often not stable;

- Usually have no clear solution;

- Are socially complex;

- Rarely fit conveniently within the responsibility of any one organisation;

- Involve changing behaviours;

- Can be characterised by chronic policy failure. (Australian Public Service Commission, 2007)

Conklin, a theorist on wicked problems, suggests that the 'forces of fragmentation' (such as differing perspectives and intentions) doom wicked projects with 'shared understanding and shared commitment' the antidote' (2006, p. 2). From Conklin's description of wickedness it is obvious that autism qualifies as a wicked policy problem. In the following section, I use the specific features of wicked problems, listed above, to examine aspects of autism policy.

\section{Wicked problems:}

\section{Are difficult to clearly define}

different stakeholders have different versions of what the problem is. Often, each version of the policy problem has an element of truth. (Australian Public Service Commission, 2007, p. 3 )

Baker notes 'a taxonomy of agendas shaping modern disability policy: cause, care, cure and celebration' (Baker, 2011, p. ix). It is not surprising therefore that these differing agendas clash over autism policy and priorities. In trying to address them all the ASD guideline developed over 300 recommendations, which represented 300 aspects of the problem and 300 ways to address it. Additionally, ASDs, of which there are several, are unable to be confirmed by biomedical testing, as there is nothing physical to see or measure (apart from genetic causes in a small minority of cases such as Fragile X) (Taylor, 2011). Diagnostic tools and procedures vary. The spectrum is growing wider as more conditions are added and diagnostic descriptions such as those provided by the 
$D S M$ and $I C D$ evolve, and the new $D S M-V$ 's draft indicates a simplified diagnosis into two areas only: social/communication and behaviours (Grinker, 2010). The definitions of autism provided in Chapter One illustrate that positive or negative interpretations can be given to a diagnosis. Additionally, some people consider there is an epidemic caused by environmental or biochemical factors; others suggest increased knowledge alone is leading to the increasing numbers diagnosed; a third group suggests a combination of factors, or different explanations.

\section{Have many interdependencies and are often multi-causal}

There are also often internally conflicting goals or objectives within the broader wicked problem. (Australian Public Service Commission, 2007, p. 3)

This is another way of saying they are very complex, and it is difficult to find a linear path from a single cause of a problem to one logical solution. In acknowledging the complexity of the issues and where to start tackling the problems, the Guideline features an anonymous quote:

It's like attacking a seven-headed monster; you don't know which head to attack first. (Ministries of Health and Education, 2008, p. 241)

Again, the Guideline process (Chapter Nine) illustrates the tension between attempting better provision for children, while neglecting the needs of adults. With ASD we also have the combined problems of insufficient data and diagnostic capacity, as well as an apparent increase in numbers of people with the condition, a fragmented system of policy development and implementation around service provision and supports, and a disability policy which is supposed to be centred on the needs of the individual and their family but a service delivery system that is conflicted between treating people as holistic beings, and tightly capped budgets. No two autistic people are the same and problems vary between individuals and over time. 


\section{Attempts to address wicked problems often lead to unforeseen consequences}

An example of both 'chronic policy failure' and an attempt to address wicked problems leading to 'unforeseen consequences', can be illustrated by the 1996 educational policy of Special Education 2000 [SE2000] (Wylie, 2000). This policy was intended to encourage the mainstreaming - integration of children with special educational needs including ASD - into regular schools and out of the units, special schools and classrooms in which many were receiving their education. SE2000 was in the spirit of Section Eight of the 1989 Education Act which anticipated that every local school would accommodate all the local children in all their diversity, rather than Section Nine of the Act which provided for segregated 'special' environments, and was also intended to address regional inequities. However, the decision to provide targeted funding for only $1 \%$ of students proved highly inadequate; additionally, in implementing the policy, insufficient classroom support was provided for many mainstreamed children and their teachers (Wylie, 2000). A specialist teacher scheme to replace the itinerant teacher specialists was begun, called the Resource Teacher, Learning and Behaviour [RTLB] which would support the classroom teachers across both primary and secondary schools, and would form clusters with a home base at one school in the cluster. However, there was little guidance provided to this new group of teachers and each cluster was left to 'invent the wheel' for themselves, leading to uneven support for schools. Two reports from the Education Review Office have revealed the resulting wide variations in RTLB practices and effectiveness (Education Review Office, 2004, 2009). New Zealand's 'self-managing schools' (each school is governed by its own board of trustees) had to purchase any specialist help from a separate agency - Special Education Services.

SE 2000 was eventually challenged by political and legal action (see Chapter Eight). Ironically, this was all as a result of a policy that was intended to be more equitable, transparent and fair across the country. The attempt by the government of the day to mainstream children with special needs, including autism, through the SE 2000 policy (and illustrated at the beginning of this chapter by a cartoon of the Education Minister of the time), led to many new problems including new inequities in funding and lack of suitably qualified staff. The feedback summary from the latest review of special 
education, which was ambitiously called 'Success for All', cites similar concerns to those expressed in earlier reviews (Ministry of Education, 2010b).

\section{Are often not stable}

Policy makers have to focus on a moving target. (Australian Public Service Commission, 2007, p. 4)

Autism knowledge, and the political and economic backdrop, are constantly changing so the policy solutions suggested in one context may be too expensive or outdated when the time comes for implementation. Developed in an era of economic growth and strong public services, implementation of the ASD guideline coincided with a global recession and cuts to the public services. Additionally, as children with autism grow into autistic adults the way autism manifests can change, as do support needs. Some children who appear highly autistic as pre-schoolers may appear to have only minor impairment as adults. However, mental health issues may have developed for them. For people who generally do not like change, transitions such as between schools and living situations can be particularly fraught. As mentioned above, even the official definition of autism is about to change with the new edition of the DSM.

\section{Usually have no clear solution}

There was little guidance about where to start with the Guideline's 300 recommendations. There is no agreement in the autism sector on what an endpoint would look like and ideas in the literature range from the elimination of autism to a society lead by autistic people. Conklin (2006, p. 7) suggests that there is a "no stopping rule' and instead that 'good enough' may be the best you can achieve with the resources you have.

\section{Are socially complex}

It is a key conclusion of the literature around wicked problems that the social complexity of wicked problems, rather than their technical complexity, overwhelms most problem-solving and project management approaches. (Australian Public Service Commission, 2007, p. 4) 
Problems are not easy to break down into simple cause and effect, but may involve changing and improving a variety of relationships, environments, attitudes and behaviours. The New Zealand response to autism has reflected this problem with a decade-long history of particular public servants - 'vision-holders' as one of my key informants with a background in health policy put it - trying to engage a variety of stakeholders in autism policy advisory groups. The Australian paper (2007, p. 4) recommends including government agencies at all levels, non-profit organisations, businesses as well as individuals. In New Zealand autism policy the private sector has not been greatly engaged but many families and advocacy groups have been, although communication processes have rarely spread the word to the wider community. Conklin talks about 'collective intelligence' which is a 'natural enabler of collaboration' but is challenged by the 'forces of fragmentation' which doom projects (2006, p.3). Fragmentation can happen when groups have to compete against each other for funding, or when communication is poor, both features of the New Zealand autism community.

\section{Rarely fit conveniently within the responsibility of any one organisation}

As shown above in Figure Nine, several government departments and ministries have autism and disability responsibilities. For example, although a person has ASD for 24 hours a day, seven days a week, the support they are eligible for, and the agency responsible for provision, varies according to the time of day and age of the person. If the person has special educational needs the Ministry of Education has responsibility for assessment and support between the hours of nine am and three pm on weekdays and until the person leaves school at eighteen, or 21 if they qualify for Ongoing Resourcing Funding (http://www.minedu.govt.nz). This may be delivered directly through one of the regional Special Education district offices, but some schools with large numbers of children with special educational needs choose 'bulk funding' for this support and these fundholder schools become responsible for all support provisions. However, all schools are answerable to each school's elected board. Schools have formed clusters for provision of another type of support frequently required by children with autism (the ones without targeted ORS funding), Resource Teachers of Learning and Behaviour (RTLB]. However, these RTLBs are funded to support the autistic student's classroom teacher not individual students, and only for a limited time. 
On leaving school, the responsibility for the autistic person's daytime support transfers to the Ministry of Social Development for welfare assistance and assorted vocational and employment support, or Ministry of Health-funded day services provided by a variety of agencies or non-governmental organisations (NGOs). These NGOs are likely to rely on various contestable funds administered by the Department of Internal Affairs.

Support needs for the non-school time are assessed and coordinated through sixteen different regional Needs Assessment and Service Coordination Agencies funded through the Ministry of Health (Ministry of Health, 2009b). If assessed as requiring support (and NASCs require not just an ASD diagnosis but a diagnosis of intellectual, physical or hearing/vision impairment as well), the NASC or the family subcontracts other providers (but not family members living at the same address) to provide that care. If the person with ASD is over 65, or has mental health needs, then the support is delivered through one of twenty DHBs. (People with autism often have mental health issues as a result of their daily stress, and are also aging). Through their child development teams DHBs also have responsibility for diagnosis of children and young people, but not adults (for whom there is no diagnostic pathway in the publicly funded system). In addition each organisation has its own definitions of what constitutes eligibility criteria, for example the age when a child becomes an adult varies between agencies. This simplified picture illustrates some of the confusing coordination and service delivery responsibilities that exist in New Zealand.

In New Zealand there also seems to be constant political change in the public sector with government departments and agencies regularly changing their structures, transferring responsibilities, merging or separating, cutting funding for projects and staff numbers (risking losing those with the 'institutional knowledge'), and changing eligibility criteria.

\section{Involve changing behaviours}

Innovative personalised approaches are likely to be necessary to motivate individuals to actively cooperate in achieving sustained behavioural change. (Australian Public Service Commission, 2007, p. 4) 
Autism is a hidden disability so a child's autistic behaviours can often be mistaken for naughtiness, and an individual child's abilities can range high and low across IQ scales and educational assessment. To address the needs of students with autism, some teachers have to learn new teaching techniques, schools need to adapt, even altering their physical environment to provide less sensory stimulation such as light or noise. Agencies providing support to the child need to work across boundaries to better coordinate services. Michael Kendrick's (2000, 2008a, 2008b, 2009) right relationship theories are relevant here as people working in autism support may need to review their own attitudes and behaviours around both collaboration and respecting the expertise the person they are supporting brings to the issue at hand (see also Chapter Six).

\section{Some wicked problems are characterised by chronic policy failure}

Disability has had decades of policy attention in New Zealand, as Chapter Five highlighted, yet disabled people still feature highly in the disadvantage statistics such as health, employment and income (Statistics New Zealand, 2007). For example, people with autism and other disabled people are no longer routinely institutionalised, but they are overrepresented among those living in poverty, and are highly dependent on welfare benefits, even in times of high employment (Welfare Justice - the Alternative Welfare Working Group, 2010). Feedback to disability forums run by the Ministry of Health's Disability Support Services Group around the country in 2006 and 2009 revealed that unmet need around autism, including education, was still significant (Ministry of Health, 2009a). Examples raised included access to education and support, and lack of support across the board including for pathways, timely diagnosis, interventions, respite, behaviour support, employment, independent living and services for autistic adults.

\section{ASD and wickedness}

From the examples above it is clear that ASD can be seen as a wicked policy problem. The assessment of ASD as a wicked problem pleases some on the spectrum, as it illustrates how problems they have encountered throughout their lives lie with 'the system' rather than themselves. Innovative approaches are required to address wicked problems and in New Zealand the ASD guideline is our first major step (see Chapter Nine). It can be seen as an attempt to tame the problem by addressing fragmentation and collecting and assessing the evidence. 
There are other examples of work to address wicked aspects. A special issue of the RTLB's journal Kairaranga (Ministry of Education, 2008) was devoted to evaluation of several ASD Participatory Action Research projects which followed the Wylie review (2000), assisted by some additional Budget funding. The Institute of Policy Studies at Victoria University (2008) commissioned a study for public sector managers and front line staff on 'joining up the horizontal and the vertical' which included examples from autism. Another approach could involve reviewing the contracting model for health and social services (Cribb, 2006; Cumming \& Stace, 2006; Tennant, 2007; World Health Organisation, 2004).

\section{Examples of ASD wicked policy}

This section considers specific examples of autism policy as wicked: the Needs Assessment and Service Coordination process and the Invalids' Benefit. One of my informants, Sam, expressed her frustration in different parts of the interview about how complicated and time-consuming it is to get support:

there are so many people ... involved they've all got a different interpretation of policy. So I interpret the NZ Disability Strategy quite differently than probably that woman from Hamilton and the Ministry of Health.

Yeah the bartering you've got to do, the bartering to get you know if I want this well what will you give up here? And will you do this and that and backwards and forwards. The amount of people you have to deal with ... the opinions ... the arguments ... apart from the paediatrician, the Child Mental Health have been the most supportive and yet they kept changing their criteria so we are forever on a 'Can Morgan [her child] access their services or not?' because they don't do dual diagnosis.

When we got individualised funding there was some money made available for a person, [the NASC] actually brought someone on an intensive ... we did a trial with The Ministry of Health and [the NASC] and we had an intensive case manager. Now that was probably the best thing out .... it was 
probably the best thing and that's probably one of the things that the system does need.

[Interviewer]: And have you still got them?

[Sam]: No no all gone, all gone.

there is a lot of in-house fighting, a lot of tall poppy stuff among the professionals who work with Morgan ... far too many opinions so it's hard to get an outcome when you have got 29 odd opinions...so they should have a strengthening professionals like the equivalent of strengthening families but you know among themselves.

\section{NASCs}

Needs Assessment and Service Coordination agencies were set up as a result of the policy work following the 1992 New Deal report by Jenny Shipley as Minister of Social Welfare and Simon Upton as Minister for Health (see Chapter Five). This revised the Third Labour Government's 1975 Disabled Persons' Community Welfare Act, which was an attempt to provide a similar level of support to disabled people that ACC provided to injured workers, with care provided on a welfare model through the Department of Social Welfare. However, this model did not fit with the neo-liberal ideology of the late 1980s and 1990s, which preferred targeted, ring-fenced and capped funding provided on a market model, with the split between funding and service provision managed through contracting.

The New Deal included a large consultative exercise undertaken by the National Advisory Committee on Core Health and Disability Support Services. An invited group of disabled people provided input for one of the reports which was called Self help and empowerment: people with disabilities challenging power, promoting change (National Advisory Committee on Core Health and Disability Support Services, 1993). This group's report asked for an inclusive person-centred human rights approach, towards empowerment of disabled people and away from the charity model. Many of these ideas were later reflected in the Disability Strategy. However, the outcome was the 1993 Health and Disability Services Act which shifted most responsibilities for disability support to four new Regional Health Authorities (RHAs). Sixteen NASCs were contracted to assess needs of disabled people and coordinate service provision, but not 
provide services. That same year guidelines were issued for the deinstutionalisation of people who had been living in the psychopaedic (although most residents were now adults) institutions, Templeton, Braemar, Mangere and Kimberley, but it was not till 2006 that the last one, Kimberley, finally closed (J. Grant, 2007; Milner, 2008). The New Deal consultation also indicated related work would happen in special education (Shipley \& Upton, 1992) which became the SE 2000 policy described earlier.

This 1990s contracting model in New Zealand has since been critiqued as an example of agency theory whereby parties are seen as independent and competitive agents who buy and sell rigidly described inputs (Cribb, 2006). Lengthy and detailed contracts are required to ensure compliance as little value is placed on trust, collaboration, or the holistic wellbeing of the disabled person. Recent years have seen some softening of the system to a more stewardship-like model of contracting, with more focus on outputs, flexibility, collaboration and improved contractual relationships (Cumming \& Stace, 2006). An example is the 2008 revision of Ministry of Health NASC service specifications to align with those of ACC and allow some 'client' or consumer choice in the services they receive. Disabled people and consumers (including myself) participated in the consultation around these changes.

So although the concept from the New Deal was that NASCs would coordinate the supports needed across a disabled person's daily life, they were limited to specific health-related disability supports. This reflected the medical model that people with disabilities were sick or had broken parts requiring mending. New Zealand is rare internationally for having disability provision under a Ministry of Health, and recent lobbying from the sector sought a Disability Commission whereby disability support would be coordinated in a standalone agency away from 'health' (Parliament. Social Services Select Committee, 2008). This has not happened but the first Disability Commissioner has recently been appointed in the Human Rights Commission. In her critique of the disability policy process, former ministerial advisor, Tessa Thompson (2007), suggests that NASCs lost their way in the 1990s as their support role became more constrained by budgets. 
My own experience of NASC in the late 1990s was a positive one. With a newly diagnosed teenage autistic son (the wait for assessment had been twelve months) I was referred to the local NASC, Capital Support, which is owned by Capital \& Coast DHB. An assessor, who was also hearing impaired (so had obvious lived experience of disability), came to visit and asked what would make our lives easier. I suggested that a 'buddy' for my son to help him participate in normal teenage activities such as going into the city, catching public transport, going to shops, museums and public events. So she referred me to the local IHC branch which subsequently employed and trained a teenage boy to support him for four hours 'respite' every second Saturday. He also participated in IHC camps and outings, and I was referred to a parent support group. However, I have since learned that that was an exceptionally positive experience with many families not getting sufficient respite hours, nor being able to access any suitable services. Once again we were 'lucky'.

The death of Casey Albury in 1997 can be seen as a result of a system that was not adequate to meet complex support needs. A problem with the competitive market model is that as only specific services are purchased, and as collaboration is not valued, gaps can arise. Casey had funding to attend a residential school, but not apparently for respite care in the holidays. So when her relationship with her mother came under stress away from school, there was nowhere to turn for help. This is why we need to see holistic person-centred support as described in 'Ordinary life report' (National Advisory Committee on Health and Disability, 2003) As a result of Casey's death, ASD came to the notice of the Ministry and NASC guidelines specifically for ASD were issued in 2000 (Health Funding Authority, 2000).

When the NASC system was set up in the early 1990s, Asperger's Syndrome was only just becoming known and autism was seen as a rare condition. Many autistic adults were still in institutionalised care. Autism wasn't mentioned as a specific condition eligible for NASC, and most people with autism entered the system because of another diagnosis such as intellectual impairment which was an assumed co-morbidity. But in 2011 people with a diagnosis of Asperger's Syndrome (thus without intellectual impairment) are still ineligible for NASC services. An internal project saw an interim guideline developed for NASCs based on the ASD guideline; however the strict 
eligibility criteria of physical, intellectual or vision/hearing impairment (which excludes Asperger's and High Functioning Autism) have not been changed (NASCA, 2009).

In 2000 the new Labour-Alliance government passed the NZ Public Health and Disability Act and 21 DHBs (later 20) were created based around the main hospitals, and once again had partially elected boards, and funding directly from the Ministry. NASC services for under $65 \mathrm{~s}$ became the responsibility of the Ministry of Health Disability Services Directorate - which would also manage the contracts for NASCs as well as the service providers, and NASC support for the over $65 \mathrm{~s}$ were devolved to the DHBs (as well as all mental health services). Over the next few years the contracting model was loosened from one of contracting for inputs to one of outputs (Cumming \& Stace, 2006) and relationships improved through the establishment of an independent NGO-MoH forum financially supported by the Ministry.

However, when the ASD guideline work was published in 2008 it was obvious that things still weren't working well with NASCs and ASD. For a start, people with ASD (children and some adults) were becoming a major client group. Many of these had the new (since 1994) diagnosis of Asperger's syndrome without intellectual disability or one of the other approved co-morbidities. Consumers reported regional inequities and inconsistencies. One of the problems was that NASCs assessed respite days for time out for parents, but this was not intended for the parent to go to work (so couldn't be used for holiday programmes for working parents but could for non-employed parents), but in many areas there were few if any respite services available.

At the twice yearly Ministry of Health's Consumer Consortium meetings (of which I was a member from 2006-2009), and occasional regional consumer forums, complaints about NASCs were frequent, and included inconsistency, inequity, untrained and disrespectful staff, limited and strict criteria, parents feeling judged as unworthy and under surveillance. When a Ministry staff member came to talk about 'Socrates' - the new NASC database to standardise and centralise information - several members who were also mothers of disabled children voiced their concern that it would have a section for 'bad and difficult mothers', as it was a common experience for parents there (including me) to feel that in asking for help for your disabled child that you were 
selfishly demanding a scarce resource. The man from the Ministry appeared surprised and said this was the first time such negative implications of a new database had been suggested to $\operatorname{him}^{14}$.

As a result of the $A S D$ guideline work, reviews of NASCs were undertaken, from reviewing the 1994 standards to looking at alternative models. The NASC system came under scrutiny at the Parliamentary Select Committee inquiry into the quality of care in service provision (Parliament. Social Services Select Committee, 2008). CCSDisabilityAction preferred the Local Area Coordination system, pioneered in Western Australia, as a simpler more person-centred, less ring-fenced system. They brought an advocate for the model, Dr Eddie Bartnik, from Perth to brief the select committee; subsequently the committee's report recommended this model. Ministry of Health officials visited Australia to find out more about that and other models.

NASC policy is wicked in that eligibility varies between regions and over time, the local NASC's name or personnel may change after contract changes and without warning, they may be hard for autistic and other disabled people to find or access, and have complicated review and renewal process. They are part of a complex disability support network from another era. NASC was set up to address a political and funding environment of the 1990s and did not anticipate that increasing numbers of people would be diagnosed with autism but without the eligibility criteria of intellectual impairment. A ministry official recently told me there was 'high level' work being done reviewing eligibility criteria, but as it has cost implications, there is no indication when or if any change will happen.

NASCs are a fragmented system funded by a competitive tendering system and usually without any links (such as stakeholder reference groups) to their local communities. Their budgets are ring-fenced and they are dependent on local services (such as respite) being available. Following approval by Cabinet for a new model of disability support in July 2010 an alternative disability support system is currently being piloted in the Bay

\footnotetext{
${ }^{14}$ Despite suggestions that this database would increase efficiency and transparency by gathering information previously held on various paper-based systems, the public can only access it by going through a lengthy Official Information Act application process (which I chose not to do for this research).
} 
of Plenty (Ministry of Health, 2010). However, without an understanding of the pitfalls of 'wicked' policy, they may face unintended negative consequences, such as adding another level of gatekeeping to the system rather than simplifying it.

\section{The Invalids' Benefit}

Examples of how 'the system' doesn't work for people with autism are numerous. Our social welfare system provides basic financial support for many categories of people who have no paid work, through Work and Income. For this agency, autism is currently defined as a permanent disability, which is helpful in that annual reviews are not required, and disabled people with autism are eligible (but not entitled) from sixteen years old to an Invalids' Benefit (IB), which is increased at eighteen. When a young person goes on the benefit their parents no longer get the small weekly Disabled Child's Allowance that a diagnosis of autism usually provides for parents. Most autistic adults are on the Invalids' Benefit (pronounced by many as something demeaning that 'invalidates' them), as they are unable to find suitable or full time employment, even in times of low unemployment. As mentioned earlier, many autistic people, like disabled people generally, are at the bottom of the socio-economic pile (Ministry of Health, 2004a).

My 25-year-old son is very lucky statistically (that 'luck' factor again) in that he has a small part-time job which he has held since 2004, after he finished a year's tertiary diploma course in vocational and lifeskills for people with intellectual impairment at a local public tertiary provider (and one of only about two such courses in New Zealand). My son was lucky to get on the course and lucky to access financial assistance for training that has since been withdrawn, and then lucky to get a job, although it is still for only a few hours each day. The job was created as part of an employment programme for disabled people in government agencies (which includes schools) called Mainstream, administered for over twenty years by the State Services Commission, although transferred to the Department of Internal Affairs in 2009. We were lucky to hear about the job through a small local supported employment organisation called Emerge, which held the Mainstream contract.

His small weekly earnings are supplemented by the IB. Each year, at Christmas, he has to provide proof from his workplace and bank about his earnings for the previous 
calendar year and projected earnings for the next. The trouble is that banks and the Ministry of Education provide information based on an April to March financial year. As he works at a school, the relevant staff are on holiday at the time the information is required. The depth of information and time constraint is very difficult for an autistic person with intellectual impairment to deal with unaided and without an advocate, and stories of benefits cut off or other problems are common. If all this information is not provided to the right person at the right time in the right way the IB is stopped and starting it again requires another round of paperwork with an advocate. Several autistic adults I know are experts on the Work and Income process as they have been visiting the offices frequently for several years; they recommend always visiting in person and getting paperwork signed and date stamped as the next staff member they see will likely give different information or have no record of decisions previously made.

My son is lucky to have me to sort all this out, lobby and advocate for his rights and entitlements; many others do not and get into endless difficulties, with benefits cut off or worse, never accessed in the first place because nobody ever showed them how to access the system. However, after considerable advocacy there has been one recent improvement to the system. Until about five years ago IB renewal required a doctor's certificate (for us the renewal came in Christmas week with documentation required by the first week of January). At least for several (approved) conditions such as autism officials now realise the individual does not grow out of them, and an initial certification, even an earlier diagnosis by an educational psychologist, is all that is required. Many of those on the IB would much rather have full-time work (Welfare Justice - the Alternative Welfare Working Group, 2010a, 2010b). However, that requires a commitment from government and employers for widespread improvements to employment support and attitudes to employing autistic people. The government has now signalled tightening up of welfare policy so new restrictions are likely.

Unemployment of people with autism, most of who are able and would like to work, the cost to the state of the Invalids' Benefit, and the complex system to maintain it, indicate this is a classic example of wicked policy. There is little agreement on what the actual problem is, although chronic policy failure has characterised the last few decades, and emotive and contested descriptions such as 'welfare dependency' by politicians and 
policy makers signal little willingness to change behaviour or engage with stakeholders (Welfare Working Group, 2011). Various policy and service responsibilities lie across numerous agencies. I suggest that a working party of disabled adults, including those with autism and other beneficiaries, supported by a secretariat, would cut through the wickedness and would find some workable solutions. This approach to complex issues has been undertaken by UK researchers with intellectual impairment (Townson, et al., 2007). Unfortunately, governments seem unlikely to try this.

\section{Conclusion}

The above examples illustrate how difficult it is to balance the "rights and service provision aspects of policy' signalled by Baker (2006a) at the beginning of this chapter. If people with autism comprise $1 \%$ of the population, as is currently indicated, and therefore most schools and communities will have autistic people and their families, it is vital that ASD is considered when developing new policies, particularly in health, education, employment, and welfare. We also need to be aware of the risks of succumbing to the wicked aspects, which the Australian Public Service Commission and Conklin (2006) have highlighted.

There are some innovative models that by respecting and utilising lived experience, are indirectly addressing these policy challenges, but they tend to be rare and local. One example of a public policy that does seem to address some wicked issues is the Strengthening Families model, mentioned earlier. It was developed in response to chronic policy failure of child abuse, neglect, and juvenile offending and involved agencies involved with children at risk getting together in one room to support the family or individual involved. I have seen how useful this model can also be for supporting families with autistic children. My friend had numerous agencies in her life trying to provide services and support for her high-needs autistic daughter, resulting in a highly stressful environment of poor planning, coordination and communication. In one room, with good facilitation, this could be sorted out and agency responsibilities shared. The new Whānau Ora programme based on the tool the Ministry of Health published in June 2008 (Ministry of Health, June 2008) seems to be based on similar principles. The holistic focus and collaborative commitments, capacity building, the linked pathways and threads towards one overall aim of 'he korowai oranga' family health and 
wellbeing, , seems appropriate for complex issues such as ASD as well (Taskforce on Whanau-Centred Initiatives, 2010; Te Puni Kokiri, 2010).

The ASD guideline is going through an implementation process which is covered in Chapter Nine. New Zealand's smallness has made it relatively easy to get a group together of educational and health professionals, policy people, service providers, parents and people with autism to advise on aspects of this. However, from the above examples autism can be justifiably described as a wicked policy and in order to tackle wicked issues around ASD there needs to be:

- Up to date, accessible, evidence based, reviewable information available to all;

- People need to speak freely across agency, departmental and political boundaries in order to share resources and information while respecting confidentiality;

- There must be good faith and intention to build relationships;

- Expertises respected.

Analysing a problem is an easier aspect of wicked policy than actually confronting it. Solutions, as with all wicked problems, are not clear but aspects of the complexity and fragmentation could be tackled by the creative process of building right relationships with those with lived experience. By incorporating all the relevant expertises we could try to move policy beyond the current wicked situation whereby autistic people need love and luck to get services and supports. In Chapter Ten I provide a new model for developing policy which respects and incorporates the lived experience of those for whom the policy is intended, such as those with autism and their families. If this process could be done in a way that builds right relationships, shared understandings and is done ethically and transparently, it might be a way to start addressing the wickedness of autism policy.

A major focus of the ASD guideline was education. There are several wicked aspects of education policy which hinder the full participation of autistic children and young people and which warrant further focus. These are examined in the following chapter. 


\title{
Chapter Eight: Education policy and ASD
}

\author{
PRINCIPAL'S OFFICE - DAY
}

PRINCIPAL: Your boy's ... different, Mrs. Gump. Now, his I.Q. is seventyfive.

MRS. GUMP: Well, we're all different, Mr. Hancock.

The principal sighs, then stands up.

Forrest sits outside the principal's office and waits.

FORREST (Voice Over.): She wanted me to have the finest education, so she took me to the Greenbow County Central School. I met the principal and all.

The principal stands in front of Mrs. Gump. Forrest, sitting left, listens.

PRINCIPAL: I want to show you something, Mrs. Gump. Now, this is normal.

The principal holds up a chart with designations according to I.Q. and points to the center of the graph, labeled "Normal." A red line below the normal area is labeled "State Acceptance." The principal points to the section below the acceptance line labeled "Below."

PRINCIPAL: Forrest is right here. The state requires a minimum I.Q. of eighty to attend public school, Mrs. Gump. He's gonna have to go to a special school. Now, he'll be just fine.

MRS. GUMP: What does normal mean, anyway? He might be a bit on the slow side, but my boy Forrest is going to get the same opportunities as everyone else. He's not going to some special school to learn to how to re-tread tires. We're talking about five little points here. There must be something can be done.

PRINCIPAL: We're a progressive school system. We don't want to see anybody left behind. ${ }^{15}$

\footnotetext{
15 This extract from 1994 movie 'Forrest Gump' was posted on the 'Red Alert' political blog by opposition New Zealand Labour Party Member of Parliament and education spokesperson, Kelvin Davis, as part of a discussion opposing the government policy of national educational standards (K. Davis, 2009)
} 


\section{Introduction: Special education in New Zealand, and implications for autism}

Educational access and quality is a big issue for most children and young people with autism and their families, as any discussion with parents or students will quickly reveal, and is the reason for the workstream ${ }^{16}$ on educational best practice in the ASD guideline. The New Zealand school leaving age is sixteen and most will also attend some form of pre-school, so a diagnosis of autism in childhood will also impact on the educational life of the student. As mentioned in the previous chapter, much of the policy around education and ASD can be considered wicked, so a fuller examination of the issues is warranted.

Unlike the situation for 1994 movie character Forrest Gump in the United States, Section Eight of the New Zealand 1989 Education Act guarantees the right of every child to attend their local school from five to nineteen years, with a legal requirement to attend from six to sixteen years (although it can be provided by distance, 'correspondence', education or approved home schooling). However, Section Nine provides an exemption so that a child may attend a 'special' school, class or unit, if their parents choose, and if there is one available. With an estimated $1 \%$ of the population on the autistic spectrum (Ministries of Health and Education, 2008, p. 29), autism is likely to be a problem, a challenge or opportunity for most New Zealand schools, as well as for families with an autistic child. A chapter entirely on education for autistic students as a policy issue therefore seemed warranted. There are also many aspects of education policy that could be considered 'wicked' in the terms of the previous chapter.

This chapter looks at the evolution of special education policies from the 1877 Education Act to the 2010 Special Education review, including debates around segregated versus mainstream/inclusive education for students with autism, targeted funding and teacher aides/education support workers. In following the theme of respecting lived experience the chapter finishes with voices of autistic students

\footnotetext{
${ }^{16}$ Workstream 1 was led by the Paediatric Society, Workstream 2 by the Ministry of Education, and Workstream 3 was funded by the Ministry of Health (Ministries of Health and Education, 2008, p. 13).
} 
themselves and what they recommend for appropriate educational support for autistic students.

Ministry of Education Special Education has responsibility for the education of autistic students if and when it is deemed that they require more attention or support than their normally developing peers. Special education is the term used for educational access for children who are presumed not to fit into some intellectual, physical or social norm, so need extra help and resources with their teaching and learning. There is an assumption made by many parents and educationalists locally and internationally, that autistic children are different, and thus require special education. However, as special is a contested term disliked by many who see it as a synonym for segregation, some parents, educationalists and disabled people prefer the terminology of an inclusive education system which caters for all children's learning needs including those with autism or other impairments (MacArthur, 2009). Inclusive means different things to different people, but for proponents such as the Inclusive Education Action Group (www.ieag.org.nz) it is about social justice and values, and promoting an inclusive society as well as supporting teachers to meet a diverse range of abilities in their classroom. Opponents are more likely to see it as forced and unsupported mainstreaming of special individual children in a normal classroom without adequate provision and support for their particular impairment-specific needs. So they prefer their individual special child to attend school with other special students (although they may not have impairments, needs or abilities in common). It is an emotional area where the language itself is contested, but for me inclusion reflects the social model of disability and removal of barriers, whereas special education focuses on individual deficit.

As autism is a relatively recent diagnostic label, historically autistic children were probably given some other exclusionary label in the special education context. Some may have struggled or coped with the school they found themselves in. Others may have left school early, or were excluded altogether. The Government reviewed special education in 2010 and the report, while recognising the division between special and inclusive schools, directed schools to become more inclusive (using the term more in a educational sense than in a social justice sense) by 2014 (Office of the Minister of Education, 2010). 
As mentioned earlier, disability theorist Michael Oliver (2009) believes we are currently in a paradigm shift. Building on Thomas Kuhn's (1970) ideas of 'knowledge paradigms' whereby anomalies in old paradigms 'eventually become so great that they force a shift to an entirely new paradigm ... in Kuhn's terms we are moving from a special to an inclusive education paradigm'. (He is using special and inclusive in the medical and social model senses referred to above.) Oliver illustrates this with a personal experience of the education of autistic children in the 1980s:

Within this school many of the children were labelled as autistic ... they could draw with architectural precision, they could memorise music after one hearing, and not just songs, whole symphonies, concertos and the like. Dustin Hoffman portrayed one such person as an adult in his film Rainman [sic]' ... special education could not bring out the best in these children...It could keep them safe and secure but was singly unable to build upon these prodigious talents to their full educational and social potential... these talents were labelled as special needs...[which] kept the paradigm safe and secure... .(Oliver, 2009, pp. 74-75)

Dan Goodley (2011), disability academic and activist, has also tackled special education, blaming neoliberalism for framing it in the language of the market place, of choice and commodity, rather than centred on children and their needs.

\section{Special educational policies: 1877 to 2010 Special Education Review}

Ideas about education tend to reflect the prevailing political and social climate. Before 1877 access to education in New Zealand largely depended on the local availability of educational options and parents' ability to pay (MacMorran, 1900). However, in 1877 the Education Act legislated for free secular and compulsory education for all 7-13 year olds including disabled children (Beatson, 2004). Compulsory and free education was seen as a good thing as it would enable state surveillance of children, as well as educate them for the future economic benefit of the country. However, school committees had discretionary powers to exclude children on grounds of 'temporary or permanent infirmity' (Mitchell, 1985, p. 7). 'Backward' children were often kept from progressing through classes with their age peers. Classes tended to be large and often under the authority of untrained teachers. Truancy and non attendance were common. Autistic 
children were of course not identified as such at that time so their plight can only be conjecture.

From the beginning of the $20^{\text {th }}$ century, there were growing fears of hereditary mental illness and disability, as mentioned in Chapter Five. A growing desire to classify and label, depending on which children were deemed worthy of education and eventual employment, was implemented and regulated by the 1911 Mental Deficiency Act. A complex classification system for these children was aided by the development of the new science of IQ testing (Stace, 1998b).

Special was already becoming a synonym for other, illustrated by the language of legislation. The Education Act of 1914 included many references to special schools, and required departmental notification of any 'mentally defective children' (Mitchell, 1985, p. 19). The first special class opened in Auckland in 1917 as a model for teacher training, followed by the first hospital class in 1920, also in Auckland, and the first special class in its own right in Whanganui in 1921, while the first speech class started at Thorndon Normal School in Wellington in 1920 (Mitchell, 1985). The 1925 Committee of Inquiry on Mental Defectives and Sexual Offenders, which linked impairment and moral failing, also had an influence on education as it promoted residential special schools as a means of surveillance of defective children (Fleming, 1981; Triggs, et al., 1925). In 1929 Templeton Farm residential school near Christchurch was opened by the Education Department. Another Education Amendment Act of 1932-3 compelled parents to enrol their 'defective' children in special schools, and the Wilson Home for physically disabled children (which is still in existence as a rehabilitation centre and recently rebuilt and expanded special school) opened on Auckland's North Shore in 1937 (Mitchell, 1985). However, apart from such residential solutions, many disabled children were unofficially excluded from schools.

The election of the first Labour Government in 1935 saw a change in philosophy to education as a basic human right. Minister of Education, Peter Fraser and his DirectorGeneral Clarence Beeby are remembered for their promotion of educational rights for everyone (notwithstanding the sexist language of the time) in this often quoted extract: 
The Government's objective, broadly expressed, is that every person, whatever his level of academic ability, whether he be rich or poor, whether he live in town or country, has a right, as a citizen, to a free education of the kind for which his is best fitted and to the fullest extent of his powers. (Mitchell, 1985, p. 29)

However, many disabled children were still denied an education until the 1989 Education Act provided for the legal right for all children to attend their local school. Soon after its passing it became apparent that this was not happening for many disabled students, and the 1996 policy of SE 2000 was the National Government's attempt to address the problem. As a school board member in that era I also noticed the lack of centralised planning for the numbers of disabled children coming into the system (for example, more disabled or premature babies were surviving due to advances in medicine and technology). Insufficient classroom support was provided for many mainstreamed children. Some parents, angered at the closing of their children's educational placement for what many saw as an inferior replacement and lack of consultation, took the Government to court (Wylie, 2002). The case dragged on until 2004 when it was settled with the Ministry of Education required to conduct an extensive parental consultation in the whole area of Special Education. This process was called 'Let’s Talk Special Education' (Ministry of Education, 2006).

One reason for the problems may have been that the policy assumed that only $1 \%$ of children would require the targeted funding known as the Ongoing Resourcing Scheme (ORS) - 'renewable' was soon added (ORRS). I tried for many years to find out where that $1 \%$ figure came from as it is far lower than the number of children requiring specialist support. It appears this number was plucked out of the air by a Treasury official. It was soon obvious that this estimate was far too low and over the next few years the scheme was extended, criteria adapted, and other funding streams provided until support of some kind is now available to $6 \%$ of children in a variety of programmes, including short-term assistance from a specialist Resource Teacher of Learning and Behaviour (RTLB). But the 2001 census indicated at least $10 \%$ of children require educational support (Ministry of Health, 2004), and some school principals have told me informally that an estimated $20 \%$ of students will require some 
sort of specialist support to succeed in the school system, at some time in their school life. One in five students 'failing' is the current government's reasoning for bringing in the policy of National Standards in primary schools (Tonkin, 2010).

A survey of the prevalence of Asperger's Syndrome in schools in the Wellington region was carried out in 2005 by Vicki Steele (2005) for the Asperger's advocacy group the Cloud Nine Children's Foundation. She found an estimated ratio of one autistic student to 166 students, with many undiagnosed (but schools made the call that they were on the autistic spectrum). Less than a third of autistic children qualified for ORRS funding.

Extra funds have been put into the system for more ORRS/ORS funding (by both the previous Labour and current National governments), and all schools get government money through their Special Education Grant (allocated by decile, not on numbers of students with special education needs; another wicked aspect) but many children and teachers are still missing out on support (Ministry of Education, 2010b). Meanwhile there are problems with this targeted funding as it is usually used to employ a casual, low paid, unskilled teacher aide, who may not be able to help the autistic student access the curriculum. Professional development opportunities for staff working with autistic students are limited. In the compulsory school sector teacher aides are employed by each school, but in the early childhood sector, they are employed centrally by the Ministry of Education's special education district. This shifts the administration and bureaucratic cost on to the Ministry but helps ensures quality and consistency across the sector (Ministry of Education, 2010a).

SE 2000 had become such a minefield by 1999 that a promised review featured in the election promises of the Labour Party which won the election in December that year (Dalziel, 2000; Wylie, 2002). The review involved several well-attended public meetings and I was present when tearful and distressed parents told heartrending stories of their child's lack of educational support. This resulted in a report by NZCER researcher Cathy Wylie appropriately called Picking up the pieces (Wylie, 2000). This policy that had intended to be more equitable, transparent and fair across the country had gone badly wrong. The new Labour-led government also addressed their manifesto promise of reincorporating Special Education Services into the Ministry of Education to 
reduce fragmentation and purchase costs for schools, more than doubling the size of the Ministry.

There remains a complicated and lengthy application process for individual funding for an autistic or disabled child. The process requires the applicant to present a worse-case scenario, whereas the dominant schooling ethos is about achievement and progress. An independent verifier, who does not see the child, decides whether they qualify (and what level of need they have). However, the money provided by government for verified children (point one of a teacher and some teacher aide hours) is insufficient for full day school support so the resource is rationed. Until January 2011, the better the child did in the classroom the more likely the assistance was to be removed so it could be allocated to a child with a more urgent need. Parents found this very hard to understand. In January 2011, ORS became non-reviewable again so that when a child was verified as requiring this help, they would keep this individualised support through their school life, although the number of hours allocated might change (www.minedu.govt.nz). Anecdotally, to make their precious funding stretch further, many schools have a teacher aide work with more than one child at a time.

The year 2010 saw another Special Education review ('Success for All') under the auspices of the Associate Minister for Education with responsibility for Special Education, Heather Roy, an MP from the small neoliberal Government coalition party, ACT (Ministry of Education, 2010a). She promised choice for parents (although not for students). However, the Minister's advisory group did include a disabled activist advisor, and about 1500 submissions from individuals and groups were received. To complicate matters, in the middle of the review process Heather Roy and a few likeminded MPs from ACT, the Māori Party and the National Party released a policy document advocating voucher schools for the top 5\% and bottom $20 \%$ academic students -which I have heard was a surprise to those Special Education officials working on the official review, as many of those with special needs are also in the bottom 20\% (Inter-Party Working Group, 2010). Before the final report in the form of a cabinet paper was released (Office of the Minister of Education, 2010) Minister Roy was replaced as Associate Minister of Education by party leader Rodney Hide, following internal party ructions. 
As mentioned earlier, there is a battle going on not just over education placements, but also terminology, between parents and organisations such as the special schools advocates who want to keep and extend their segregated environments for disabled children - although they use words such as choice - and those such as the advocacy group for intellectual disability, the IHC, who want children to attend school with their non-disabled age peers. Mainstreaming is the technical term for this latter process, but one which carries a lot of baggage from SE 2000. It is used negatively as in 'maindumping' by its opponents and positively as a synonym for supported inclusion by its proponents (illustrating the wicked problem of contested definitions).

Many autistic students, particularly in New Zealand's biggest region Auckland (which did not go as far with the mainstreaming aspects of SE 2000 as other regions), access their education in special or segregated school environments - with other disabled students, but away from their neurotypical age peers. These environments can be: dedicated day or residential schools; satellite classes or units of mainstream schools; out-of-school as home-schoolers or correspondence students (although the reasons for home schooling are more complex and can be due to unofficial exclusion from local mainstream schools or school phobias); and alternative education centres. Some students have a mixture of mainstream and special education. Many students around the country may be enrolled in a mainstream school but are segregated from their peers because of exclusionary school cultures, which do not, for example, allow students with special needs on school camps, in school productions or other activities. Or the student's teacher aide may be asked to separate the student from regular classroom activities.

The Ministry of Education itself developed and promotes the desirability of teaching to a diverse range of abilities in its BES (Iterative Best Evidence Synthesis) programme which has its own website (www.educationcounts.govt.nz). There are also other ways schools can critique their own behaviours such as an audit process called Index for inclusion which was developed by British educationalists (Booth \& Ainscow, 2002). Examples of inclusive cultures based on respect and peer support are included in the 2007 report by the Children's Commissioner and Victoria University's Institute of Policy Studies, Respectful schools (Buckley \& Maxwell, 2007). 
The concept and practice of special education is another aspect of autism as a multicausal and multi-faceted wicked problem that greatly affects autistic children and their families. I would suggest most adults in a theoretically egalitarian country like New Zealand do not want to be singled out as special (which implies problematic or requiring extra resources), so why should children?

\section{Teacher aides/educational support workers}

Schools employ their own teacher aides (the commonly used name for educational support workers in New Zealand) for which they get money in their bulk-funded operations grant, and their Special Education Grant (given to all schools on their decile rating ${ }^{17}$ but regardless of numbers of special needs students) and/or targeted money such as ORS. A teacher aide may be a kind and helpful person, but they may also be an unqualified person usually on a minimal hourly rate. They are officially part of the school's support staff rather than the professional staff. An educational psychologist from the one of the Ministry's Special Education offices told me he offered ASD training courses for teacher aides but they were poorly attended because many schools don't allow teacher aides professional development release time, and many teacher aides cannot afford to train in their own time. However, some teacher aides are utilised well by the classroom teacher as a real aid to teaching and learning by adapting curriculum materials and assisting with groups of children, not just focused on the special child.

Although each school employs its own teacher aides from ORS or Special Education Grant ${ }^{18}$ funding, teacher aides in the state early childhood sector are employed directly by each SE district. Although this is more expensive for the Ministry of Education as they carry the administrative costs such as employment and professional development, it means they can also ensure quality, training and the correct pay scale for the aide. The teacher aide works with the child until they go to school and may then be allocated to

\footnotetext{
${ }^{17}$ As stated previously, decile rating is a rating 1-10 indicating socio-economic status of households in the school area, with $1 \mathrm{~A}$ the most deprived and 10 the least. Schools with lower ratings get additional funding.

${ }^{18}$ Special Education Grants are given to all state schools based on the decile rating for any students with 'moderate' support needs. They do not need to have any students to get the grant, and schools with many of these students do not get extra for their bigger numbers.
} 
another centre (although it is the norm for New Zealand children to start school on their fifth birthday, they are not legally required to start until they are six). In contrast, schools tend to employ their teacher aides on short term contracts while the particular ORS-funded child attends that school. Some schools like to train their teacher aides and ensure continuity of employment while others do not see training as a priority. Teachers are part of the predominantly female school support staff and at the time of the 2008 change of government there was a pay equity review underway on support staff salaries, which the new Minister of Labour cancelled. I have also heard that recent cuts in government educational funding have meant some Ministry of Education districts have reduced their early childhood teacher aide coordination roles. The New Zealand situation is further complicated by the lack of centralised data - either for the numbers of children in the education system with autism, or the number of teacher aides as they are employed by each school usually on short term contracts.

Getting educational provision right for autistic children is vital and is linked with building right relationships and respecting lived experience. The following example is a real example of the complexity and wickedness of education and ASD.

\section{Everyday education provision for students with autism}

The information below was provided by parents and professionals in a public meeting that was advertised in the local paper, so is not confidential.

It began when the mother of a child claimed her primary school-aged mildly autistic son was being bullied at his local school by both staff and children. She had friends with similar stories. According to the mother 'no one' was prepared to help: the school, or local agencies. She sought a meeting with a Member of Parliament, the Green Party spokesperson for special education and disability issues, who asked for advice from agencies such as the IHC and the Children's Commissioner and organised a public meeting, inviting local MPs from Government and opposition parties. At the meeting several parents told stories of their children's needs being misunderstood by schools, of victimisation by staff, of concerns being dismissed by principals and board members. Several of the mothers were single parents. Some accused the helping agencies of sharing negative information about them behind their back and without their permission; of intimidating visits by the Government agency, Child, Youth and Family 
(CYF) such as social workers and employees coming uninvited into their homes. One even mentioned her fear of having her child assessed by the local DHB child development team as she feared it could lead to CYF taking her child from her. This was soon after the Minister of Social Development Minister had publicly revealed private information about welfare beneficiaries (Trevett, 2009), and from the comments at the meeting that example reinforced the assumption that access to and sharing their personal details was common practice by agencies.

It transpired that the local Special Education District Manager was familiar with the schools and was even working with one mentioned by the parents on a school-wide anti-bullying programme, but was unaware of these local issues around autism, and the schools had not asked for his agency's intervention. His office had an ASD specialist who could have helped and there is also a local RTLB service in the region which could have supported the children and schools involved. One of the problems under the selfmanaging school model set up by the 1989 Education Act is that school management must invite these services in to work with the school as they cannot intervene uninvited.

A further complication was that the District Manager was not allowed to talk to the Member of Parliament directly about the issues, as public servants cannot talk to MPs from opposition parties, apart from official occasions such as select committee hearings, as all issues and communications are required go through their own Minister. In this case there was a Minister of Education, and an Associate Minister with responsibility for Special Education from different political parties. This issue seemed to be about getting some local expertise into a local situation quickly and communication barriers seemed unnecessarily difficult. However, the District Manager and a staff member attended the meeting.

After listening to distressing personal stories at the meeting for a couple of hours, the District Manager took his turn to speak. He undertook to get his staff to increase focus on the school causing most concern through the anti-bullying programme they were already implementing there (some parents at the meeting were aware of the programme, but not that it was also for staff as well as students). He also announced two new programmes for schools on behaviour support. He also provided contact details of his 
local special education facilitator whose job it is to intervene in relationship breakdowns between schools and families and the existence of the role appeared to surprise most people at the meeting (unfortunately, due to budget cuts since, this role no longer exists).

He also told the meeting about ongoing community/parent organised meetings in other regions in which information about education, ASD and other useful topics, are provided, and could start in this region if anyone was interested in facilitating it. He also mentioned a training programme that he had developed in another town with local parents of children with special needs, including ASD, whereby parents' expertise is valued. Professional development days are run for special education staff where the speakers are parents of children with autism and other conditions. He handed out his card and offered to stay after the meeting to talk to anyone who currently had an unresolved problem with a specific school (many of the stories happened in the past and parents had since changed schools, with one parent saying they were on to their fourth school), or for people to contact him directly.

Most of the parents who raised concerns at the meeting identified themselves as parents of children with autism, but seemed unaware of the specific autism support programmes such as 'Tips for autism' (run by the Ministry of Education) and 'Spell' and 'Help' (run by Autism NZ). A local Autism NZ-linked support group was mentioned favourably by some of the parents, but although the coordinator was respected, there were comments that the 'agencies' have 'infiltrated' it so it was not a safe place for parents. After three gruelling hours the MP closed the meeting. But hopefully, some ways forward had been signalled.

I later met one of the parents from the meeting and asked her if anything had changed. She said that the school had, for the first time ever, invited her along to ask her about the learning needs of her son. Consequently, the school year was going much better. All it required was a bit of relationship building, and a chance to share expertise, and consequently behaviours and attitudes improved. 
This story shows the wickedness of education as it relates to autism, for example, unforeseen consequences when attempting to solve one problem. The same 1989 Education Act that ensured the right in law of every child to attend their local school, also set up a very fragmented system of self-managing schools, whereby each school is governed by an elected parent board (with staff representation, and student representation for secondary). Special Education does not have open access to schools; they have to be invited, and while every child is legally entitled to attend their local school, the school can easily make the child and their family feel very unwelcome. Parents at the meeting above had different understandings of educational access, and the purpose of schools, to those of the Ministry officials. Fragmentation (of politics, public agencies and education regions) and social complexity in the local community, also works against collaboration.

\section{Lived expertise in education}

Who is education for? Surely, the focus should be the children themselves. My thesis values the voices, knowledge and first hand expertise of people with autism as experts on their own lives. An underlying principle of my research is that those who have lived experience need to have their expertise listened to, acknowledged, and respected. Parents, educators, politicians and other experts dominate the public policy discussion: what adults can do for or to autistic children, not what expertise or agency - the ability to make decisions and take action to determine their own needs - the children themselves have. In this section I give some examples of what autistic children and adults have said about their education, and of research that shows that children do exercise agency and have strong views about their educational inclusion, rather than being passive recipients.

Little research has concentrated on the wishes, opinions or agency of autistic children, particularly those who are non-verbal. However, there are an increasing number of autobiographies written by autistic adults who vividly recall their education, and the occasional research project has attempted to give voice to the children themselves. Autistic voices on education are rare in the literature. The following are some of the few I have found from autobiographies, blogs and research papers. 


\section{Examples from lived experience}

A video on YouTube shows 14-year-old Carly, a non-verbal autistic girl, who communicates words by typing, not speech. She is shown writing a simple plea 'I want to go to school with normal kids, but not have them getting upset when I hit a table or scream' (Goldberg \& Putrino, 2009). It is a simple but profound plea.

An autistic woman recalled her own school days in a collection of essays and reflections by autistic women (J. K. Miller, 2003). At this point in her life, American woman Susan Golubock (2003, p. 74) was working in education and this experience helped her selfdiagnose:

At age 48, I was working with a pre-school class when the teacher commented that she was having one of her young students evaluated because she suspected she might be a high-functioning autistic. I had been observing this child with particular interest as I worked with the class, because she was the first child I had seen who seemed to be a carbon copy of myself as a child. The frustrated and perplexed look on her face when others said or did something out of the ordinary, the following other children around mimicking their actions with no purposeful interaction of her own, even sensory sensitivities and swallowing difficulties, were all me as a child. I had never heard of high-functioning autism. I was excited that I might possibly have found something that would explain me to me.

Wendy Lawson (2000) described her school days in 1960s England:

It is with sadness that I remember my childhood school days. I know that I lived with constant fear and confusion but it never occurred to me to ask for help or understanding. Apparently it never occurred to anyone else either! (2000, p.58)

She finds it: 
quite amazing today that a child like me could be exposed to 10 years of formal education without any teacher realising or recommending special help or assistance. (2000, p. 59)

Temple Grandin (2008) had a more enlightened experience in 1950s Texas:

At aged five I started attending a small school with typical children. In today's language, that would be called mainstreaming. It is important to note that this worked for me because the structure and composition was well matched to my needs. The school had highly structured old-fashioned classes with only twelve students. Children were expected to behave and there were strict rules. The environment was relatively quiet and controlled, without a high degree of sensory stimulation. In this environment I did not need an aide. (2008, p.26)

Today Grandin is sought out for her expertise and down-to-earth advice. Here is her advice to a modern-day father of an autistic child:

The family was ready to sell their house to have the funds to send their fouryear-old child with autism to a special school in another state. I asked him if the child was learning and making progress at the local public school. The dad told me he was. Yet, the special school was making great claims about the progress their child would make with them. I talked with the dad about the negative impact disrupting the child's life like this might have, taking him away from his family and familiar surroundings, and sending him to a school in another state. The very real possibility existed that the child could get worse, rather than better. (2008, p. 29)

Autistic savant and author Daniel Tammet is another person generous with his autistic expertise. He grew up in London as the oldest of a large working-class family. A number synaesthete (numbers for him have colour and form), he is also famed for learning Icelandic in a week. He talks about his schooling in the first volume of his autobiography Born on a blue day (2006) touching on common aspects of autism: 
sensory issues, handwriting, and bullying. Class learning he found difficult mainly because of extraneous noise and he frequently put his fingers in his ears. He suggests that earplugs for autistic children could help. As with many autistic children he found writing difficult as he could not remember how the letters were supposed to look. Joined up writing was even harder.

Whenever I wrote, I pored over every letter and word and full stop. If I noticed a smudge or error I would rub everything out and start over. This streak of perfectionism meant that I sometimes worked at a snail's pace finishing a lesson in a state of near exhaustion, yet with little to show for it. Even so, I worried that the teacher would consider me lazy or incapable and I never thought to care what any of the other children might think. I didn't then understand the concept of learning from your mistakes. (2006, p. 54)

He describes strategies he used to deal with bullying:

Some of the boys in the playground would come up to me and tease me by mimicking my hand flapping and calling me names. I did not like it when they came up very close to me and I could feel their breath on my skin. Then I would sit down on the hard, concrete ground and put my hands on my ears and wait for them to go away. When I felt very stressed I counted the powers of two, like this: $2,4,8,16,32 \ldots 1024,2048,4096,8192 \ldots$ $131072,262144 \ldots 1048576$. The numbers formed visual patterns in my head that reassured me. Since I was so different, the boys weren't entirely sure how to tease me and soon tired of it when I did not react as they wanted me to, by crying or running away. (2006, p. 86)

Tammet eventually found a friend from a refugee family who acted as an ally and social interpreter. This friend had the lead in the school play but was ill on the opening night. Tammet, who had memorised all the lines while watching him rehearse, stood in and saved the day. He reflects the experience of many autistic students in that he found some subjects very easy and some impossible, but when a teacher took the time to understand his particular learning needs, and gave encouragement it made all the 
difference to his school experience, illustrating the significance of relationship building in learning.

Lucy Blackman is an Australian non-verbal autistic woman whose autobiography, Lucy's story (2001), provides fascinating insight into classical autism. It was assumed that Lucy was intellectually impaired and she attended a special school where there was little academic achievement expected of her until she was exposed to typing in the late 1980s (through facilitated communication). She plotted to go to a regular secondary school, where she eventually had a teacher aide who could not keep up with her maths ability. Here is what the then 16-year-old wrote about her beloved maths class in 1988 :

Lousy dumb classes really seem to give me so much pleasure that it even interests me that the students wreak chaos giving the poor teacher dreadful trouble the ungrateful, lousy pigs. Such soul destroying real boorishness makes me sick when I think how I had to fight to get to school but petty irritations are not important in the overall big too marvellous wonderful lovely picture. (2001, p. 127)

She also gives insight into the fear she frequently experienced but what we might think more as panic or anxiety, and which led to some challenging behaviours: 'For me it was an overwhelming sensory chaos which was painful in some undefined way ... a lot of the sounds and movements that I found 'frightening' ... were soothing or imperceptible to other people' (2001, p. 164). She realises others find her behaviour difficult: 'The sight of someone biting her hand and screaming in a Year 11 class is a bit disconcerting for the other people!' (2001, p. 162). However, because she was so determined to attend mainstream secondary school she learned how to cope and eventually went on to university. She wrote to her special school teacher: 'Unlikely though it may seem I learnt a lot from Special School especially how to keep my temper (2001, p. 133).

A grimmer picture of education is presented by Jessica Peers (2003) who was sent to an English residential school for autistic teenagers in the 1990s where she experienced bullying from some staff who used humiliation and sadistic punishments. Expelled from her regular school for fighting back against her tormentors, she was unusual in having a 
diagnosis of Asperger's Syndrome, before it became an official diagnosis in the DSM IV in 1994 (American Psychiatric Association, 2000). Not that she knew what it meant:

It was at the clinic that I was diagnosed with Asparagus syndrome. That probably just meant that I was a bit rebellious and prone to mood-swings and making my animal noises. It was probably just another invented "mental" problem, like the ones people at school had told me I possessed.

I had been the stranger at school. Others had said I was taken over by demons and had thrown chewing-gum in my hair. They had called me a psycho because I said and did strange things. Me, being me, I had thought they were the strange ones. $(2003$, p. 13)

Three recent American books are written from the perspective of autistic adults. British civil servant Kamran Nazeer (2006) was educated in a pioneering private school for autistic children in New York. Twenty years later he tracked down some of his fellow students and teachers and described their achievements in Send in the idiots (the title was a repetitive refrain from a classmate). Dawn Prince-Hughes is an autistic anthropologist who learnt social skills from watching gorillas in the Seattle zoo. Her often harrowing experience of American education is graphically described in her autobiography Songs of the gorilla nation (2004). Bullies dominated and she felt alienated from all apart from the occasional teacher who took the time to understand her. She now supports autistic students in tertiary education and gathered some of their stories in her compilation Aquamarine blue 5: personal stories of college students with autism (2002). The title comes from a synaesthetic student. Other insights include sensory sensitivities and its effects on dealing with school food.

\section{New Zealand voices}

In her autobiography, New Zealander Jen Birch (2003) recalls her education from the 1960s and her absolute inability with some subjects (in her case maths) while excelling in German. She also describes other themes which seem common, anecdotally, with autistic people, of being a loner in the playground, 'walking round and round the school's perimeter, and digging repetitively in the ground with a stick' (2003, p. 69), and attracting, 'bullying and manipulative types [who] could easily identify me as 
someone they could dominate, and so I appeared to involuntarily attract such persons' (2003, p. 74). Many years later she attended university and completed a degree, although frustrated that her A+ course work was dragged down by poor exam marks. Her fear, and the stressful examination situation, froze her thought processes and she could not produce the knowledge she had in the required way or timeframe.

Matt Frost has described his own education in provincial 1980s and 1990s New Zealand (Frost, 2007a). After a negative assessment from an educational psychologist as a preschooler, he was placed in an assessment class when he started school. He was very fortunate to have an advocate who insisted he be allowed to develop in his own way and be taught to type to overcome his coordination difficulty with writing. It is salutary to note that his primary education took place at a time when rights to a public education were not guaranteed for disabled children.

Twenty years after Matt Frost started school, Vicki Steele (2006) interviewed four New Zealand teenage boys with Asperger's about their school experiences; two currently at school and two who had recently left. One of the boys still at school was quite positive about the experience but the two who had left appeared traumatised by some of their experiences. The boys provided insight into how the academic and social curriculum worked, or more commonly, did not work for them. For example, one boy expressed similar frustration to that mentioned above, that the written tests were not the way to find out about the considerable knowledge he had: 'I'm hopeless at tests. I can't be timed. If I'm timed at all I just get panicky... Instead of giving me written tests they should question me and talk to me' (2006, p. 49). He left school without any qualifications. One boy, to cope with bullying, joined with his tormentors: 'Often they got me into trouble, I was the one left behind ... I always seemed to take the blame' (2006, p. 66).

The physical environment affected their heightened sensory awareness. One who was particularly sensitive to noise commented that ' $I$ was usually in the special learning classes and they are always much louder than the normal classes' (2006, p. 61). 
Team school sports were also a major source of stress for these boys as well as for many autistic students as they require physical coordination, social skills and auditory processing of instructions at speed. They preferred and often enjoyed more solitary sports such as the gym or swimming, although there were also sensory aspects to overcome there, for example, the cold water temperature or the noise and crowds of the gym. But self motivation encouraged them to overcome these barriers. One boy summed up what he would like in a teacher: 'A good teacher is friendly, helps a lot, and doesn't get grumpy at you. It's one that understands me and can actually teach me ... If they explain things really well it makes a difference' (2006, p. 42).

In some innovative research a team from the Donald Beasley Institute and the Children's Issues Centre at the University of Otago reported on how disabled children aged from 11-14 negotiate school life (MacArthur, Sharp, Gaffney, \& Kelly, 2007; MacArthur, Sharp, Kelly, et al., 2007). They found that the children exercise considerable agency, and do not quietly and passively accept the bullying, discrimination or poor teaching practices they encounter.

One boy they call Luke is on the autistic spectrum. He had strong views about how he would like to be treated, and the teaching he would like, and already had negative experiences of school from an earlier exclusion. He was well aware that teachers' expectations of him influenced his behaviour and attitude in that teacher's class. Researchers asked Luke how each of his different teachers would describe him and he answered very perceptively that they would all describe him differently, from lazy to hardworking, and that largely depended on how he perceived their expectations of him. When asked to describe himself to a new teacher he reflected what he had heard others say about him in answering 'obnoxious' (MacArthur, Sharp, Kelly, et al., 2007, p. 103). Unfortunately for Luke lack of resources for professional development meant his teachers had to guess what strategies worked well, and often got it wrong. For example, he told researchers he preferred to work by himself rather than with a team which he found socially challenging. However, a teacher rewarded a class for working hard by themselves (which Luke liked and had done well) with team games (which he refused to join) so in his notebook the teacher aide recorded his negative behavioural reaction to the team activity (MacArthur, Sharp, Gaffney, et al., 2007, p. 28). Luke also had an 
ambivalent attitude to his teacher aide: 'While they could be good at helping him to do his work, they could also "get on my nerves", because they sat right next to him all the time' (MacArthur, Sharp, Kelly, et al., 2007, p. 109).

He had similar ambivalence to the learning support unit saying he felt safe there but that he would rather be outside with the rest of the school (MacArthur, Sharp, Gaffney, et al., 2007, p. 29). His favourite place, as it is for many autistic students, was the school library even though he knew it was not a 'cool' place (2007, p. 27). Luke found that he was not always believed when he reported bullying so he wrote a letter describing an incident to the staff member responsible for school discipline (MacArthur, Sharp, Kelly, et al., 2007, p. 107). The research team also found disturbing 'homogenising of difference' practices in some schools where some disabled children without behaviour issues were put in the same class as boys with behaviour issues, merely because the classes were smaller.

Berni Kelly (2005) one of the researchers in the above project, in a paper incorporating aspects of her $\mathrm{PhD}$ research called 'Chocolate ... makes you autism', concluded that disabled children are learned social actors, more aware of what is going on that adults realise. The quote of the article's title came from an autistic boy's misinterpretation of adult conversation in his presence (2005, p. 267). Children understood their difference in two ways: as a result of 'disabling barriers'; and the experience of the impairment itself (2005, p. 268). The first caused them to be excluded or bullied and made them angry or sad, whereas the second made particular activities harder for them to do. Kelly emphasises that these children are active 'experiencers' whose agency and abilities should not be underestimated (2005, p. 272).

\section{Studies with disabled children}

A 2001 Scottish study of disabled children in a mainstream school (J. Davis \& Watson, 2001) found structural discrimination against the children including '[a]cademic streaming, professional values, issues of safety, fear of litigation, concepts of normality, social class values, and ideas concerning a variety of criteria relating to physical and social skills can be employed by professionals to label children' (2001, p. 684). The researchers concluded that 'it is our belief that full inclusion is only likely to be achieved when policy decisions are built on disabled children's own lived experiences 
as articulated directly to policy makers or as collected within empirical studies' (2001, p. 685), and that: 'Children should be enabled to challenge the structural, cultural and individual conditions which create disability' (2001, p. 671).

A paper proposing a social model of childhood disability (Connors \& Stalker, 2007) reported that most disabled children in their study, "presented themselves as much the same as others, young people with fairly ordinary lives. They focused on sameness' (2007, p. 29). But children experienced disability in four ways: impairment, difference, other peoples' reactions, and material barriers (2007, p. 24). Boredom was commonly reported because they had no friends locally, possibly because of attending school out of their community. But when offered a magic wand wish only three of the 26 children aged seven to fifteeen wished to 'fix' their impairment.

In her report for the IHC Learning Better Together Jude MacArthur (2009) summarises her extensive research into disabled children's voices:

Students dislike any arrangements at school that make them feel different in negative ways such as large, noisy and outdated computer equipment; withdrawal from class for specialist support; and teacher aides who sit too close and don't provide them with the space needed to be part of the class. (2009, p. 41)

School life also includes play. An Australian study of disabled children's use of a playground (Burke, 2009) utilised photographs, visual cues and a scrapbook approach to elicit the children's opinions about aspects of the physical layout and the places they liked and avoided. It revealed how an autistic boy experienced the dignity of risk and got a sense of achievement by challenging himself on the play equipment. An autistic girl who appeared to adults to be lonely and aimless was actually playing out a rich imaginary world alone, apparently by her own choosing. They were exercising agency over their play, although not playing in the social ways that some adults expect play to be. 
The examples quoted above are among a scarce but growing collection of voices of autistic students (and other disabled children) about their educational experiences, outlining what works and does not work for them. Educators should also heed the advice of Tony Attwood, who has been studying autism for over three decades, that school can be stressful and tiring for autistic students because they have to utilise their intellect to process both the academic curriculum and also (unlike their neurotypical peers) the social curriculum (Attwood, 2009).

\section{Autistic children at school in New Zealand: two local examples}

I would like to finish with the educational experiences of two mothers I interviewed for this research. They both have teenage children with severe autism who are non-verbal or barely verbal, and with 'challenging' behaviours. Educational access for their children has required an immense amount of time, emotions and energy by the mothers. But their stories illustrate the significant role played by 'luck' in finding supportive people, and building relationships. My informant in a provincial town has had considerable support and advocacy from the local head of Special Education, in spite of an often stormy relationship, but now her child's support package includes a teacher and a teacher aide and a dedicated home room. She is mainstreamed with support for some subjects and school events, and has a right to remain at that school until she is 21 . The school principal, although initially reluctant, is apparently happy with and champions this arrangement, so long as resourcing remains. A key to the success has been the dedication of the teacher, who first worked with the girl at primary school and is now employed as the full time teacher. A few years ago some high and complex needs across-ministry funding was established, which initially helped this arrangement, but this for a maximum of two years, not long enough for those with severe autism. Luck in finding the right people in the education sector has been a factor for this family (although the road has frequently been rocky).

In early 2010 the sixteen-year-old son of my other informant was asked to leave the specialist education unit he attends. He had hardly attended the previous year as he was bored, his teacher aides changed frequently, and did not appear to know how to engage him or communicate with him (apparently a recent one was not prepared to learn the Picture Exchange Communication System he uses), and also appeared to fear his 
behaviour. A recent IEP (Individual Educational Plan), instead of curriculum goals, mentioned working on toileting (which is not an issue at home). Yet the specialist school was getting several thousand dollars a year through ORRS funding. Over many years his mother had given a great deal of voluntary time to supporting his education, and ASD educational settings generally, and she found that good staff are the key to success with many environments changing direction when good staff move on. She now despairs of finding a suitable place in the education system that engages him and his educational abilities and is seeking a day programme for him with the money he is entitled to until he is 21 (a 2008 review led to a change making its use more flexible - it did not have to be used in a standard educational setting). He has never attended his local school and his mother has had minimal interaction with the local Ministry of Education as the special schools she used were fundholders for special education resourcing and bought in their own support.

Similar stories can be found throughout New Zealand. Luck in finding champions and allies, and people prepared to build relationships, can make significant difference to the educational opportunities and achievements of autistic children.

\section{Discussion}

Instead of seeing autistic students as educational problems, we need to respect their educational strengths, wisdom and agency, and rise to the challenge of making an inclusive educational system that works for them as well as all disabled students. The examples above indicate that the lived experience of those with autism (and other impairments) and their families provide a wealth of valuable information. If we can get it right for students with autism we would be helping to create an inclusive society whereby diversity is welcomed and celebrated, as advocated by our Disability Strategy (Ministry of Health, 2001).

Research is also needed into how autistic children might contribute positively to inclusive school cultures, and how schools might develop and value their expertise. For example, autistic people are known to be very loyal friends and supporters. Many autistic children have extensive knowledge of particular topics or expertise in particular fields such as computers or music, that they would be willing to share; a strong sense of 
justice, that may be employed in roles as sports umpires, peer mediators or prefects; or a particular ability to cut off from the world in an almost meditative state, that others might learn and benefit from. Reframing autistic traits as positive could also have positive effects on students' views of their own autistic identity.

All children, including those with autism, deserve an education that encourages and supports them to reach their potential. The achievements of some autistic adults such as Grandin and Tammet show what is possible. We can learn a great deal about how to improve education for our autistic children, we only need to ask them. We must therefore be innovative and creative in supporting their educational achievement, and develop mechanisms to incorporate this lived experience into policy.

Examples of education policy initiatives include the SCERTS early intervention programme (www.asdev.org.nz), whereby a team of professionals in partnership with families, work around an autistic child in an early childhood setting and at home, and which was trialled throughout New Zealand. Another example is the Quality Learning Circle one South Island school uses rather than the school-led Individual Education Plan to encourage the achievement and inclusion of an autistic student, mentioned previously (Guerin, 2008), and the capability building local Ministry innovation mentioned above, whereby parents of autistic children become the educators of staff. A new post-graduate Diploma in Specialist Teaching began in 2011, taught jointly by Massey and Canterbury Universities, with an endorsement in autism (with guest lectures from some autistic people mentioned in this research). With the new Go To ASD specialists in the Ministry of Education (see Chapter Nine), structural improvements are happening, but the lived expertise of autistic students remains a largely untapped source.

\section{Conclusion}

This chapter has provided several examples of the wicked aspects of education and autism policy. Autistic children in New Zealand are required to attend school, and are entitled to attend their local school. The reality for many families is quite different from this expectation. Battle lines remain over educational environments for autistic students and whether resources should be put into special schools or mainstream schools. However, none of these approaches recognises the wealth of expertise that children with 
autism, and adults with autism can provide about education, if we had some mechanism to incorporate it. In the meantime education access largely depends on luck in finding supporters and champions. As Oliver (2009) says, we need a new educational paradigm that has more than just a special place for these children. It needs to accommodate all students, provide for their education and learning needs and build on their strengths, interests and abilities and diversity. To get there will require the cooperation and expertise of autistic people and their families in collaboration with innovative approaches from educationalists and policy people. In the meantime many parents face the same exclusionary attitudes that Forrest Gump's mother found.

Because the issues are so big, the ASD guideline had a workstream dedicated to educational best practice. The following chapter will examine the Guideline as a case study of an innovative approach to that and some other wicked aspects of autism policy. 


\section{Chapter Nine: Case study, the NZ ASD Guideline}

I am one of the lucky parents in the autism community. I had a supportive family. No one took my child off me and placed him in an institution and told me to forget about him. No one told me he couldn't attend their school, no one asked me to pay for a teacher aide, and neither was he asked to leave school because they didn't understand autism. No one said his behaviour was too difficult for respite care. No one said he was too disabled for a job, for independent living, to be treated as a human being with feelings, hopes and dreams. No one said it was all my fault.

Many parents have fought and continue to fight for their autistic children to be supported to live ordinary lives like other New Zealanders. Often a mother copes alone - and her whole life involves managing the complex care requirements of her child - the erratic access to education, the turnover of care workers, and the negotiations required to keep all these balls in the air.

In contrast my experience was of a friendly Plunket nurse who arranged for my son to attend a local three-year-old check one day in 1988. In that same hall was a speech language therapist, an educational psychologist and early intervention specialists. Within weeks there was a plan around my son where specialist teachers came regularly to Playcentre and home, and he also had weekly speech therapy. All free, all part of an integrated system. At school he continued daily on-site speech therapy. Note this was before the big fragmentation of the 1990s. I did not regard this at the time as 'lucky' - this integrated approach just seemed sensible. It is ironic and a commentary on the world we live in that it has taken 20 years and best practice evidence from around the world, and over 300 recommendations, to attempt to build a collaborative system that just instinctively feels right. But this time it is going to be better and more effective.

(Part of my speech at the NZ ASD guideline launch 2 April 2008) 


\section{Introduction: What is the Guideline and why was it written?}

In Chapter One I asked the research question: to what extent does the ASD guideline meet the criteria of incorporating 'right relationships' and 'lived experience', and what can be learnt from its development and implementation? This chapter is a case study of the Guideline.

Three years from its launch is it possible to do any evaluation of Guideline's development and implementation? In attempting an assessment of progress so far, this chapter outlines Guideline-related work, pre- and post- publication, assisted by information from interviews with key informants, in attempting to answer the research question. In order to untangle the threads, this chapter is divided into three overlapping chronological sections. Part One describes the process from the death of Casey Albury through the following decade of government work. Part Two outlines the publication process of the Guideline, from its draft in 2006 to the launch in 2008 and to subsequent processes towards prioritisation and implementation. Part Three attempts an evaluation, assisted by my key informants.

For this chapter implementation is used in two senses 1) attempts to improve autism service delivery generally 2) implementation as a result of the published ASD guideline.

The 2008 publication of the NZ ASD guideline was an attempt to address or tame the wicked nature of autism (although that term was not used at the time). New Zealand was the first country in the world to attempt a whole-of-government, whole-of-life, whole-of-spectrum approach to autism using international research evidence:

the first in the world to cover the whole person over their whole life, and to combine evidence, experience and practice from education, medical and community fields of practice into one single, credible source. (Curzon, 2008)

It is evidence-based, using international guideline methodology to grade its more than 300 recommendations: 55 key ones, 249 others and 32 good practice points (Curzon, 2008). An A grade indicates there is a considerable body of supportive evidence and a $\mathrm{C}$ 
grade that there is less evidence, not that $\mathrm{C}$ is necessarily less effective than $\mathrm{A}$. Because there is not enough evidence in some areas, good practice points are included based on the extensive practical knowledge of those compiling the Guideline (Ministries of Health and Education, 2008).

Its three workstreams (led by the Paediatric Society, the Ministry of Education and the Ministry of Health respectively) compiled the eight sections of the final Guideline and it:

provides a single, credible source of overseas and New Zealand experience and practice in recognising and treating ASD, supporting children and adults with ASD, teaching children and young adults with ASD, employing people with ASD, and living well with ASD. (Curzon, 2008)

The project received \$17.5 million in the 2007 Budget for its implementation through Vote: Health over the following three years (Curzon \& Hearn, 2008). Most importantly, the Guideline development process was an innovative example of collaborative processes being led by two government departments - Health and Education - which also brought in other agencies, professionals, advocacy groups, parents and most importantly people on the spectrum. This was a big project, but largely invisible outside the circle of the those immediately involved.

In his book A perfect world: a father's quest to unriddle the mysteries of autism, Wellington journalist David Cohen (2007) included an assessment of the state of international autism research and knowledge, and he interviewed Simon Baron-Cohen, Temple Grandin and others working in the field. The impression given is that little work had been done on autism support in New Zealand since the burst of activity following Casey Albury's death (and Casey's mother is one of his interviewees). However, my large collection of reports, papers and minutes, of research and projects and committees working in the area of autism, all in the public record, shows a great deal of work had gone on, but it was largely unnoticed, and its effectiveness is hard to ascertain. There appears to be little public awareness of most projects, even among those in the autism sector. It is hard to untangle the various pieces of work, research and development in 
ASD so I have provided some examples of ASD-related projects from my extensive collection of reports and minutes of meetings and other grey literature that I have collected over many years, supplemented by interviews with some key informants.

\section{Part One: sowing the seeds for the ASD Guideline: Casey Albury and government work on autism 1998-2008}

As mentioned in previous chapters, after the July 1997 death of Casey Albury there were several initiatives seeking to address the issue of autism and improve ASD support services. Two reports were commissioned and reported in 1998: child psychiatrist Professor John Werry (1998) led an inquiry into the circumstances around the death of Casey Albury; and the Ministry of Health's Curry report (1998) investigated the autism support services situation across Health and other government agencies. Both reports made significant recommendations on building capacity in the area of autism, development of services and more collaboration.

So in 1999 an interdepartmental group known as the Autism Services Interdepartmental Working Group [ASIWG] was established with representation from the Ministries of Education and Health and the then Department of Child, Youth and Family, to oversee the implementation of the recommendations (Autism Services Interdepartmental Working Group, 1999). In July 2004, this was replaced by an ASD cross-government officials group with representation from several ministries (Ministries of Health and Education, 2008, p. 12), which in 2011 survives as the Senior Officials group and which oversees and approves much government ASD guideline related work. The Senior Officials group currently has representatives from Health and Education, Social Development, Child Youth and Family and Justice ${ }^{19}$.

In September 2002, in response to the Curry Report's call for guidance in the area of ASD, the Ministries of Health and Education and the Paediatric Society of New Zealand started working towards scoping a Guideline and by the end of that year had established a Guideline steering group to incorporate a variety of perspectives including service users. Significantly there was representation, although small, from people with autism.

\footnotetext{
${ }^{19}$ In May 2011 I could not find out exactly who all the current Senior Officials were and they had apparently not met for several months.
} 
The Steering Group members include[d] representation from: adults with ASD; parents/families of people with ASD; the Paediatric Society; the Faculty of Child and Adolescent Psychiatry of the Royal Australia and New Zealand College of Psychiatrists; disability provider organisations; Needs Assessment Service Coordination (NASC) services; Child, Youth and Family; Pacific advisors; school principals; early intervention services; the Ministry of Education, Special Education (GSE); and the Disability Services, Maori Health, Clinical Services, and Mental Health directorates within the Ministry of Health. (2008, p.12).

The Guideline had three workstreams led by the Paediatric Society, the Ministry of Education and the Ministry of Health respectively, as well as Māori and Pacific advisory groups, and:

The purpose of the group was to ensure the perspectives of service users were included in the ASD guideline, promote awareness of cultural and migrant issues and help build the credibility of the project within the community. (2008, p.12).

For her Master of Public Policy thesis, Lynda Little (2003) evaluated progress on the Werry report from 1998 to 2003. She found substantial attention to some of the recommendations but progress was not as fast as hoped. The Guideline work was then underway and she expected publication shortly (in fact it took another five years).

For a decade ongoing inter-sectoral, autism-specific work continued in the Ministries of Education and Health to address the concerns expressed in the Curry (1998) and Werry (1998) reports about lack of co-ordination locally and across government, and serious gaps in services. Some firm foundations and successful projects eventuated, which are elaborated on later in this chapter. But to address the fundamental problems of appropriate support and services a Guideline was needed. Below are some of the significant pieces of work that affected autism policy in the decade leading to the Guideline. 


\section{Policy initiatives}

The Labour-led coalition government elected in December 1999 continued the work on autism started as a result of Casey's death. The 2000 Budget gave $\$ 10$ million (although not ASD specific) to the Health Funding Authority (HFA) to improve services identified in the Werry and Curry reports of insufficient residential care, respite care and home support services (A. King, 2000). As mentioned in Chapter Five, disability became a policy priority, framed under the social model of disability. Ruth Dyson became the first Minister for Disability Issues in December 1999, with an Office for Disability Issues in 2002 in the Ministry of Social Development. In 2001 the New Zealand Disability Strategy was published.

Research was commissioned to assess the extent of the problems of caring for disabled children. A Ministry of Health report Just surviving (Carpinter, et al., 2000) interviewed several parents whose children, many of whom were on the autism spectrum, had severe behaviour issues. The report revealed parents fearing for the safety of themselves, their children and the siblings of the child. They also reported property damage caused by their children. The Autistic Association, soon to become Autism New Zealand, undertook an extensive survey of its members which revealed lack of services throughout New Zealand (Autistic Association of New Zealand, 2001). New guidelines for Needs Assessment Service Coordination Agencies were developed for agency workers assisting clients with autism (Health Funding Authority, 2000). A new postgraduate course in autism started at Massey University to teach professionals working in the sector, with Tony Attwood brought over from Australia as a regular guest lecturer (A. King, 2000). Unfortunately, the course ceased within a few years as it had too few students to be sustainable (Ministry of Health, 2004b).

\section{NGO support - Autism New Zealand}

As the only dedicated national organisation, the Autistic Association was identified by government advisors after Casey's death as the group with the potential to improve the situation for families. In November 1998 \$200,000 was given to develop parent packs and bring overseas experts such as Christopher Gillberg from Sweden to upskill parents and professionals (A. King, 2000). The HFA provided personnel to help the association develop its capability as a professional organisation and as an autism training provider. 
Although it was 30 years since parents of autistic children had made the first steps to set up their own organisation, by the late 1990s it was still only a small Christchurch-based organisation run out of the chief executive's home. It had a board and a network of volunteer-run branches, but few paid staff. With government help policies were written, research advice provided and the organisation helped to develop into a nationwide NGO soon renamed Autism New Zealand. A successful national conference was held in Wellington in September 2000 and conferences have been held biennially since then in Wellington, Christchurch or Auckland.

\section{Parent courses - EarlyBird and SPELL}

One of the first ASD-specific projects to be funded by the new government was the UK's National Autism Society's EarlyBird for parents of newly diagnosed preschoolers delivered by Autism New Zealand, which first piloted in Wellington in 2000 with six families (A. King, 2000), then expanded in 2002, followed by a preliminary evaluation in 2003. A literature review prepared for the Ministry of Education by researchers at the University of Auckland's Department of Psychology estimated that New Zealand ASD prevalence was 1:150 (Birkin, Anderson, Moore, \& Seymour, 2003a). The research team also undertook an uptake study of EarlyBird in November 2003 (Birkin, Anderson, Moore, \& Seymour, 2003b) and interviewed 77 caregivers of autistic children. Although it was popular, they noted significant barriers to accessing the course in its current format particularly from those in lower income brackets who could perhaps not afford the time off work or access transport to courses, those from nonEuropean ethnic groups, and from those whose children were older at the time of ASD diagnosis. In 2006 EarlyBird was fully evaluated by the same University of Auckland team and this time the team recommended modifications making it more relevant and culturally appropriate in the New Zealand context (Anderson, Birkin, Seymour, \& Moore, 2006).

Autism New Zealand also won a contract from the Ministry of Education to run the two-day SPELL course developed by the UK's National Autism Society for families of people with autism. Regular reports were made by Autism NZ to the Ministry of Education including predominantly positive reports from participants' evaluation sheets for courses held in several centres from July to August 2003 (Autism New Zealand, 2003). However, in 2010, after evaluation, the SPELL contract finished and the 
Ministry decided not to renew it (Ministry of Health Disability Support Services, April 2010).

\section{School-based initiatives}

The Ministry of Education (2000) first published a regularly updated booklet on autism for schools in 2000. The 2004 Budget provided $\$ 1.5$ million baseline funding through Vote: Education for ASD. Among projects funded were several using participatory action research methodology (Ministry of Education, 2008). One project based around a Māori child changed direction after the child unexpectedly died and it became instead a qualitative study of nineteen Māori children with autism and their families - the first ever study of Māori and ASD (Bevan-Brown, 2004).

\section{'Lets Talk' consultation process}

The 'Let's Talk' public consultation process in 2004 was Group Special Education's response to the verdict in the Daniels case (Ministry of Education, 2005, 2006). As mentioned in the previous chapter, this case was taken in the late 1990s against the government by a group of parents of disabled children protesting education changes as a result of SE 2000, which they saw as removing educational choices and support for their disabled children. Their case also involved complex legal and educational issues about identification of special needs and mechanisms about opting out of mainstream schooling though Section Nine of the 1989 Education Act (Wylie, 2002). When the case started Special Education Services was a separate agency from the Ministry of Education, but by the time of the verdict it had come back into the Ministry of Education as its Group Special Education (it is now just Ministry of Education Special Education). After the verdict, a large consultation process was carried out by the Ministry of Education with parents and educationalists (Ministry of Education, 2005). One of a series of responses by the Ministry was a review of 'local service profiling' which revealed gaps in special education coverage and effectiveness resulting in a pilot programme for schools (schools applied for the few places available) called Enhancing Effective Practice in Special Education (EEPiSE) (Bond, 2005). Various autism specific programmes undertaken included the participatory action research projects mentioned above and local initiatives to look at why autistic students were disengaged from schools (Burgon \& Stace, 2007). 


\section{Needs Assessment and Service Coordination initiatives}

The Health-funded Needs Assessment and Service Coordination system also received attention as mentioned in Chapter Seven. New NASC guidelines for ASD had been developed in 1999 (Health Funding Authority, 2000) but NASC ASD awareness and response varied across the country in the sixteen different NASCs (the number a remnant of the four RHAs) across the now 21 (later twenty) DHB regions. ASD did not fit into the narrow impairment categories developed in 1994 for NASC service users of physical, intellectual or sensory (hearing/vision) impairment, so each NASC developed its own approach. For example, in 2004 Capital Support, the NASC in the Capital and Coast $(\mathrm{CCH})$ DHB region, which was owned by $\mathrm{CCH}$ set up an ASD consumer advisory panel (Capital Support, 2004) as part of its participation in the I-NASC project which is described below. Adult clients with ASD, and some family members, met on a regular basis with Capital Support management to discuss support issues. The advisors were paid for their time and transport. Unfortunately, it did not last past the general manager's departure a few months later.

In August 2004, Dunedin's Donald Beasley Institute applied for funding from the Health Research Council to evaluate three trials of innovative intersectoral practice by NASC agencies (A. Bray, et al., 2006). This followed a 2003 review of NASCs by the Ministry of Health which concluded that 'existing inter and intra-sectoral NASC arrangements for people with disabilities were fragmented and poorly coordinated' (2006 Appendix 1, page 3). In what became known as the I-NASC project, NASCs in centres including Wellington and Christchurch trialled a new collaborative approach with agencies in health, education, employment and supported living, mainly around the fraught area of transition of young people from school.

The projects evaluated took many forms. One case study referred to those people with Asperger's in particular and found the issues included long waiting lists and difficulty in getting a diagnosis, lack of information and expertise, and lack of understanding of issues around ASD such as sensory sensitivity, behaviours and communication needs (2006 Appendix 19). Attempts were made to build person-centred processes and supports such as mentoring support for the young people with Asperger's and subsequently found that the 'families and trial participants felt more supported and less 
isolated'. Suggestions for system improvements included employing staff with personal experience of Asperger's and listening to the participant 'rather than professionals assuming what was best for them' (A. Bray, et al., 2006, Appendix 19). This reflects the focus of this thesis on respecting lived experience building relationships.

The study reported that getting funding for those with Asperger's required NASC staff to spend time negotiating the Ministry of Health system in order to get discretionary funding, as NASCs were funded (as mentioned above) for the limited impairment categories of physical, intellectual and sensory impairment. So a person with ASD but without a co-morbidity such as an intellectual disability (ID) was not eligible for funding. This problem goes back to the setting up of NASCs in 1994 when Asperger's was largely unknown (as has been mentioned in previous chapters) and autism was rare and considered primarily an intellectual impairment. (In 2011 not all NASCs do this extra advocacy and paperwork for people with ASD but without ID, but Ministry advice is to keep doing what they have been doing until the whole system is reviewed (Gibson, 2010).) It has been hard to find out what, if anything has changed long-term as a result of this I-NASC project into which went extensive effort at collaborations, reporting and evaluation.

\section{ASD pilot projects}

By the early 2000s it was obvious that ASD-related services funded by the health sector needed major improvement. The 'Auckland ASD Project' evolved from the 2002 Ministry of Health's 'Northern Regional Sustainable Support Systems Project' which had identified a need for a comprehensive range of supports for ASD for those under 21 years (S. Robertson, 2004). The ASD project reviewed available services with a particular focus on Māori and Pacific people as well as Asian populations and refugees and included feedback from focus groups. Its final report in January 2005 (S. Robertson \& Bray, 2005) recommended attention to many areas including information, respite, transition support and social and life skills programmes, services to particular migrant groups and better coordination for assessment, diagnosis and behaviour support (these themes would be largely reflected in the later ASD guideline prioritisation for implementation). An advisory group was set up to suggest pilot programmes and develop services for families and young people with ASD in the Auckland region (2005, p. iv). 
Autism New Zealand has long advocated for funding for a network of field workers, outreach workers or navigators. 'Regional autism support officers' or RASOs was what this role was known as in the early 2000s when I joined the Autism NZ Board. Their role would be to advocate and facilitate and navigate around the autism maze for families, people on the spectrum and others. However, the most Autism NZ could provide (on the available funding) in most regions was information and phone support from another parent or, in some of the bigger branches, a part-time office worker. So, Ministry of Health funding for Autism New Zealand to run a pilot 'Outreach' (facilitator-led) project in Auckland in 2005, was warmly welcomed. The subsequent report from Autism NZ noted that 83 children and young people with a variety of ethnicities were referred (Whitworth, 2006). Among the recommendations for more information and collaborations between agencies was the main one for a person who:

would provide a constant and consistent level of support as required by a family for how ever long required. All families stated that what they wanted and needed was one person who would help support them as they negotiated their way through Health, Education, Social Services and Disability Services. (Whitworth, 2006, p. 5)

The report gives the following example of how valuable such help can be:

One family was told by three different WINZ [Work and Income NZ] officers that they were not eligible for the Child Disability Allowance, because they both worked...This was incorrect but it took several long phone calls [by the Facilitator] to various Managers in WINZ to establish the correct criteria ... the Facilitator accompanied the parents to the local WINZ office, together with all the paperwork, and a successful application was made. Without the Facilitator's assistance this family would still not have accessed the Disability Allowance to which they were entitled, and needed. (2006, p. 9) 
(After the Guideline publication and prioritisation this service was funded on an ongoing basis with contract holders Autism NZ and Ohomairangi Trust, but only for the first three months after diagnosis.)

\section{ASD Disability Information and Advisory Service (DIAS)}

In 2006 the Minister for Disability Issues (Hon Ruth Dyson) attended the Autism NZ national conference in Wellington (which I attended) and announced funding for a new ASD-specific Disability Information and Advisory Service (DIAS). The general assumption was that Autism NZ would win the contract as it was the only nationwide autism-specific NGO, but after a lengthy contestable contractual tendering process another group won the contract in 2007. The successful tenderer was a new collaboration between two NGOs, Parent to Parent and the NASC provider Life Unlimited, who then formed a new group called Altogether Autism to provide regional and national ASD information. As a consequence, the relationship between Altogether Autism and Autism NZ became fraught in many regions. But by the time this contract came up for renewal two years later, the new regional advisory jobs had already been disestablished as they proved financially unsustainable, the relationship with Autism NZ was largely healed with an official Memorandum of Understanding, and Altogether Autism was instead playing a major role in developing and disseminating Guidelinerelated information from their Hamilton base. Altogether Autism had also established their own expert advisory group of clinicians. However, this example shows that the contestable contractual arrangements for government funded services, that we have had in New Zealand for the last two decades (Stace \& Cumming, 2006), can be harmful to relationship-building in the sector.

\section{Māori and Pasifika}

Meanwhile the lack of information about ASD and Māori and Pasifika populations led to a series of hui and a fono on ASD in late 2005 (Ministries of Health and Education, 2008, p. 29), and appropriate expertise was also sought for the Guideline workstreams. The eventual Guideline had separate chapters for Māori and Pacific perspectives.

\section{Intellectual Disability (Compulsory Care and Rehabilitation) Act 2003}

After some high-profile media cases, the problem of how to deal with people with intellectual impairment who commit crimes led to the passage of the Intellectual 
Disability (Compulsory Care and Rehabilitation) Act 2003 with forensic residential provision and specialist support (Bonardi, 2009). It is probable that some of these people are on the autism spectrum (although possibly undiagnosed) and the criminal behaviour related to their ASD, for example, stalking or other inappropriate behaviour could be as a result of a special interest. It is likely that there are also many people with undiagnosed and unsupported ASD in our youth justice and other services, with one estimate of $13 \%$ of prisoners having undiagnosed ASD (Taylor, 2011b) which is one reason why a representative from the Ministry for Justice has been on the government's Senior Officials group.

\section{Part Two: ASD Guideline publication and progress}

The examples above are just some of ASD-related government work which took place from 1998-2008. It had been a busy time but largely unnoticed except to those directly involved. The sector looked forward to the guidance of an official Guideline to ensure future work was prioritised and effective.

\section{Draft Guideline}

After the draft Guideline was completed in late 2006, public submissions were called for, and an Adelaide-based organisation, Health Outcomes International (HOI), won the contract for an impact analysis on the draft. This was completed in January 2008 (Health Outcomes International, 2008). Their report noted the problems caused by the sheer number and complexity of the recommendations. About 4000 people, including the membership of Autism NZ, were surveyed by HOI on-line or by paper copy. The survey was long and detailed and the report notes (unsurprisingly for those familiar with autism) that a member of their team 'spent six hours with an individual assisting him in completing the survey and discussing a number of issues of relevance to the implementation of the draft ASD guideline' (2008, p. 3). HOI also noted that it was difficult to separate ASD out from other government policies on disability and that while they had been able to focus on legislation and government policy, operational level policy 'was not forthcoming in any valuable form or quantity' (2008, p.40).

The HOI report identified this lack of data as a major issue, as well as the complexity and interrelatedness of the recommendations, making it difficult to make specific 
suggestions for implementation. In the end they identified only one area requiring strengthening across all seven areas of the guideline which was, 'improving professional learning and development and increasing workforce capacity', and two areas common across five sections were, 'agreeing and implementing areas for ongoing research' and 'agreeing and implementing pathways to interventions, including intersectoral linkages' (2008, p. 220). These themes of workforce, research and coordination were not new.

My concerns about the HOI report were that their prevalence estimates were low (highest estimate was 60 per 1000 or 25,749 people) (2008, p. 44) and although they had reviewed many reports and legislation they had not apparently consulted the Curry or Werry reports, the drivers for the Guideline (2008, pp. 35-38). There was also some cynicism in the sector (which I noticed as a temporary member of the steering group at the time) about an Australian company evaluating a New Zealand work, especially one with significance for Māori wellbeing and cultural awareness (see Chapter Six).

\section{Publication and planning for implementation}

The ASD guideline was finally published in April 2008 and launched in Parliament's Banquet Hall by the Minister of Health, David Cunliffe, on World Autism Day 2 April (Cunliffe, 2008). Included among the speakers were two people with autism who voiced their hopes that the Guideline would make a significant difference for people with autism and their families. One was Jen Birch from Auckland, whose autobiography Congratulations! Its Asperger Syndrome (2003) discusses her life as an autistic person. Jen had been one of the few autistic people involved with the Guideline development for several years. Her hopes for the work were that, '[E]very ASD person who's born will get an early assessment, and early diagnosis so that they can get early intervention' (Curzon, 2008) . Matt Frost also spoke saying, 'there should be no limits to the positive things that people with ASD can engage in' (2008).

Health and Education jointly ran a tender process for a Technical Implementation Service (TIS), to prioritise and oversee implementation of the Guideline using ASD specific Budget funding of $\$ 17.5$ million (Curzon, 2008; New Zealand Guidelines Group, 2008). Work would be sponsored jointly by the Ministries of Health and Education and overseen and subject to approval by the ASD Senior Officials group. A 
consortium led the New Zealand Guidelines Group (NZGG), an NGO specialising in clinical guidelines won the contract. Almost 100 applications were received for the twenty positions on the Implementation Advisory Group (IAG) which eventually included representation from Altogether Autism, Autism NZ, parents, people with autism, NGOs, educationalists, health professionals, academics and Māori (several people held multiple roles), as well as ex-officio members from Health, Education and Social Welfare. The Pacific representative position was never filled. The IAG with Matt Frost as chair held its first meeting in May 2008.

I was also a participant. In November 2007 I was elected by the members to the board of the New Zealand Guidelines Group as a consumer representative. About this time the tender for the TIS was advertised. I was surprised when a former colleague who was by then research coordinator for the NZGG approached me for advice about the possibility of bidding for this work. He knew my interest in autism and his organisation knew about guidelines, although it developed and implemented clinical guidelines rather than those relating to disability. Knowing how complex autism policy is, and the short timeframe to get the proposal prepared, I initially advised against it. However, since he was determined I encouraged him to get Matt Frost involved as an expert in lived experience. He also sought help from Acqumen, a consultancy whose members had some previous involvement with autism and Autism New Zealand. NZGG put the proposal for a Technical Implementation Service together within a couple of weeks and by Christmas had won the contract. My official involvement from then, until the disestablishment of the IAG in mid-2010, was mainly as a representative of the governance board, although I had expertise as a parent and through membership of Autism New Zealand's board and local committee.

As mentioned in the introduction to this chapter the Guideline was launched at in April 2008, almost 18 months after the draft Guideline first appeared. The work behind the Guideline could be traced back a decade, and it was largely due to some dedicated public servants that the momentum had been kept going. 


\section{Prioritisation}

The first job was to prioritise the over 300 recommendations of the Guideline. Advised by the Implementation Advisory Group (representatives from the sector), the Technical Implementation Service (staff from the NZGG) prioritised work from the Guideline as:

- Supporting individuals, families, and carers

- Diagnosis, assessment and support for interventions

- Improving coordination

- Workforce - professional learning and development. (Curzon \& Hearn, 2008)

These were then to be ranked in terms of effectiveness and equity:

- How effective would the service be in improving the lives of people living with ASD?

- How equitable would the service be in improving the lives of people living with ASD?

- How does the service contribute to the achievement of whanau ora [in the sense of resilient families]?

- Are there any constraints that might limit or prevent service development? (Curzon, 2008)

Several face-to-face and electronic meetings of the IAG were held over the next two years with considerable work between times by the TIS, including drafting regular newsletters on implementation progress for the website of the Ministry of Health's Disability Support Services. The newsletter of December 2008 listed the agreed priorities as:

- Assessment and diagnosis

- Support for families

- Interventions (including early intervention and behaviour support to strengthen families, and transitions)

- Respite 
'Improving co-ordination and developing the workforce flows through all the above priorities' (Ministry of Health Disability Support Services, December 2008, p. 1), although later versions had co-ordination as a separate fifth point (June 2009).

The first phase was to scale up projects already working and fill gaps in coverage, such as parent education, behaviour support, and respite. Among the first actions was to contract the Ohomairangi Trust to run the Auckland Outreach (coordination) project mentioned above which had already been piloted and evaluated. Phase two included work on new initiatives such as improved assessment and diagnosis, extending parent education and support, interventions, respite and more coordination. Phase three saw the development of the Living Guideline process, new models for service development focusing on the district health boards and better communication. The most recent newsletter available is dated June 2010 (Ministry of Health Disability Support Services, June 2010) with progress linked to specific Guideline recommendations.

Assessment and diagnosis had five projects underway:

- Guideline website established providing diagnostic resources for 'recognisers' and 'referrers' including information 'quickcards' in five languages;

- Specialist training package for clinicians;

- Three NASC review projects: revision of operational guidelines, ASD specific Guideline and associated staff resources. (June 2010)

\section{Resources}

New reference resources for assessment and diagnosis have been developed by Auckland's Werry Centre (founded by Professor Werry), Altogether Autism and the NZGG, for face-to-face and e-learning by professionals and others. The www.asdguideline.com NZGG-hosted website features a holographic introduction by Matt Frost and accessible resources to be used by clinicians ('referrers'), or lay people ('recognisers') in the community. Simplified laminated cards are available and the ones 
for recognisers have been translated into Māori, some Pacific Island languages, with Chinese still to come. Altogether Autism has developed information material including publicity, conference and library resources. The ASD website and the quickcards particularly, seem to be appreciated by those who have seen them and can access them.

\section{NASC}

Four NASC projects were started by parent body NASCA NZ (Harrison, 2008; Ministry of Health Disability Support Services, March 2009). This work included revising standards and guidelines and incorporating the ASD guideline work, including an interim NASC ASD Guideline, 'Cross-government Autism Spectrum Disorder (ASD) Work Programme - mandate to improve services and outcomes for people with ASD, their families, carers, whanau and aiga' (NASCA, 2009b). Unfortunately, none of this work involved the power to revise the eligibility criteria to include ASD as an impairment in its own right without a co-morbidity such as intellectual impairment. Such an outcome is dependent on higher-level Ministry policy work on eligibility, (Office of the Associate Minister of Health, 2010).

\section{Family support}

Support to strengthen families also had five initiatives (Ministry of Health Disability Support Services, June 2010):

- distribute ASD Guideline information (Altogether Autism);

- parent education: EarlyBird and ASD Plus: Education for Families, fully operational around the country;

- 'tips for autism' (for parents, carers and teachers) extended in schools with 23 courses planned;

- SPELL to be discontinued and money reallocated;

- Bright Sparks Auckland recreation programme documented for replication.

As a result of the prioritisation of the Guideline recommendations, and incorporating improvements recommended by the evaluations, and to tackle waiting lists, more money flowed to parent education courses, training more trainers, and increasing the number and accessibility of courses (including in more remote regions). Autism NZ continues to hold the contract to provide EarlyBird in the North Island as far north as Auckland until 
June 2011. IDEA Services (IHC's service provider arm) has developed its own programme called 'ASD Plus: Education for families' which won the parent education contract for the South Island and north of Auckland. Two child-centred education-based autism interventions run internally by the Ministry of Education - 'Tips for autism' for primary schools and Social Communication, Emotional Regulation and Transactional Support (SCERTS) for pre-schools - have also been boosted to reach more children and families. Lou, a mother of a recently diagnosed child reported positively to me on EarlyBird:

The EarlyBird course was very valuable. It was practical and helped a lot with getting autism in perspective, breaking down issues into manageable chunks, particularly through providing explanations of very useful and immediately applicable strategies. It wasn't too long (generally welltimetabled) and was no more inconvenient than any of the other appointments we have needed to fit in to our lives. It was certainly valuable to meet other families, and enabled everyone to make comparisons of children and situations in a tactful and neutral manner. The weekly or fortnightly sessions meant that there was time to process both information and emotional reactions to what came up. Its structure meant that I felt like I could make a contribution to the group discussions if I wanted to, and also be proactive in my family's situation. This wasn't a common feeling during most of the other appointments we have had over the last 18 months or so, even though they involved us talking endlessly about our daughter. Perhaps the only negative thing I would say about the course is that there were very frequent assessment forms, but if they were required in order to ensure course funding then I have no problem with that.

The lack of cost and affirmation of the parenting role was appreciated:

I was secretly pretty impressed with the fact that it was all free - it was never talked about, and you feel that the facilitators think you deserve it, which is really lovely and has been of course quite a rare approach! 


\section{Behaviour support}

Interventions mentioned in the June 2010 ASD Newsletter focused on behaviour support (Ministry of Health Disability Support Services, June 2010), with an Auckland-ASD specific communication and behaviour support service evaluated and contracts for ASD specific behaviour support services for rest of country expected to be let by August/September.

In December 2009 contractors Bennett and Bijoux Limited (2009) reported on a feasibility study for an ASD specific behavioural service (Ministry of Health Disability Support Services, December 2009) which recommended an ASD specific behavioural support service (BSS) made up of collaborative regional teams. This would circumvent problems with providing BSS through regionally inconsistent NASCs, and which only covered people with ASD plus an intellectual impairment or other eligible condition. In May 2010 an official request was put out by the Ministry of Health for proposals for such a service throughout New Zealand, apart from Auckland, as the Auckland contract had already gone to IDEA Services after some complex negotiations.

There was some confusion about this contract. I heard complaints that the behaviour support service for Auckland, which apparently has a six-month waiting list, does not provide a service adequate to cope with the demands of autistic children with high and complex needs. However, it seems the tender was to assist ASD children with their communication and support needs, not support those whose behaviour challenges - a subtle but significant difference - as those with challenging behaviour include those who harm themselves, family members and their environment (Gibson, 2010).

Unfortunately, after many delays, on 22 September 2010, the Ministry of Health sent out an email announcing that they had cancelled the ASD behaviour tender for the rest of New Zealand and would fold the ASD aspect into more generalised behaviour support work they were doing (Marshall, 22 September 2010). It is distressing to think of the months of work, and expense that went into this failed implementation over eighteen months, for not one hour of behaviour support. Autism behaviour support is a highly specialist job, and there is a global skills and knowledge shortage. Complex cases could involve family issues or medication and require long term-multi-systemic 
wrap around approaches by specialist therapists. Professional behaviour support could make the difference between school inclusion and exclusion. One behaviour specialist organisation, Tautoko, based in Wellington, frustrated by lack of government funding, set up a private TACTICS ASD service to provide diagnosis and various evidencebased interventions and therapies.

Some of the behaviour support money for the 2010-11 year has apparently been allocated to other projects. Some organisations have been able to seek funds, for example Autism NZ was awarded funding in the 2010-11 financial year to run a new Australian programme for parents and Asperger's children called the Secret Agent Society. A Ministry source told me that discussions are continuing on ongoing BSS, but there have been no public announcements.

\section{Respite}

Respite is another complex area, as family needs vary over time. By June 2010 work was underway (Ministry of Health Disability Support Services, June 2010) and respite tenders had been let in most areas apart from Nelson. As 'out-of-family' services were apparently underused in some areas, a more flexible general disability service was to be trialled in Nelson by DSS, and a NZGG/Acqumen/IAG Paper on respite and draft service specifications would be included in a review of respite late in the year. Respite was early identified by parent representatives on the IAG as an area of need and work was done developing a tender proposal in areas where it was considered the need was greatest, including some provincial areas. The Christian-based provider Open Home Foundation and various other agencies won these contracts. Kim, a parent with a long interest in respite services reported:

I was on the subgroup for respite ... and I went on to that with great hope and energy and thinking well at last we can do some better conditions for families to have some respite ... I'm still waiting to see what came out of that actually. I think there were two homes [run by a provider in two regions]. I believe one of the homes is not being used at its full capacity. So Ministry are saying, well see why did you want a respite home because it's not actually being filled. But we don't know the reasons why it's not being filled. 
Referral for respite has to go through NASC. Again the pathway is blocked for many on the autistic spectrum, and this could be one reason why services have not been taken up. Respite also seems to be uneven in quality and accessibility. One of my informants, with a high-needs child in a provincial area, had no options for time-out residential respite in her area. A city-based parent has had to put in a lot of work with the local provider to sort out issues of lack of staff training. DSS has now begun a review of general disability residential options (Ministry of Health, August 2010). Kim referred to a 'tidal wave' of autistic teenagers coming through the system who would require residential options very soon.

\section{Coordination}

Coordination is arguably the most important area as it underpins the effectiveness of the other aspects of ASD support and services. Baseline funding was obtained from the Ministry of Health for an ASD coordinator for those under nineteen years old, and who did not qualify for NASC support, through the DHB system in response to several recommendations in the Guideline for coordination support. The age limit was apparently due to funding restraints, and as there was not enough money for a full time person in each DHB, tenderers were encouraged to provide evidence of collaboration and consultation with other DHBs, relevant agencies and community groups.

The June 2010 ASD newsletter noted that fourteen proposals covering eighteen of the twenty DHBs (Southland and Otago DHBs had recently merged) for developmental coordination had been received; the NASC ASD coordination and implementation plan was completed; and a review of equipment and therapy protocols between Ministries of Health and Education for school-aged children was under review (June 2010).

Through sector networks I have heard that there have been a steady stream of DHB coordination job advertisements and appointments, although several DHBs either did not apply or were initially unsuccessful in their tender. Through my membership of the Disability Services Advisory Committee of Capital \& Coast DHB, I heard that the Wellington region initially missed out, though funding for a twelve-hour per week job had since been negotiated, and a person appointed for the DHB region (the neighbouring DHBs of Hutt Valley and Wairarapa do not have such a role so it will remain to be seen what happens to ASD families in these regions). Those responsible 
for compiling the Capital \&Coast tender apparently did not consult the person whose role it is to provide disability information for the DHB, who was familiar with the ASD guideline work, and who could have added that dimension to the proposal which may have made it successful. As someone involved in both the Guideline implementation advisory work and on a DHB disability advisory committee, I assumed that this basic coordination happened across policy and operations. But the DHBs are apparently just as silo-ed as any other bureaucracy. It illustrates that fragmentation which Conklin (2006) cites as an indicator of wicked policy and an enemy of collaboration.

My personal view is that ASD coordination through the DHB structure is a flawed model, and I would have preferred independent coordinators. Firstly, DHB functions reinforce the medical model of disability, of focusing on individual health deficit, when support for autism needs to be holistic and multi-systemic. Secondly, in times of fiscal restraint, ASD funding could be lost to subsidise another area of DHB work. Thirdly, adults have missed out as the service is only for those under nineteen. I would have preferred funding for independent ASD field workers/facilitators, or even the Regional Support organisers for which Autism NZ once advocated. This would remove the role from the DHB structure or boundaries.

One of my informants, Kim, with a long history in the sector sees coordination as a role for Autism NZ and described her vision for it as:

a field worker, first call person ... who links [parents] up to all the local agencies or support people whatever they need to know within their own area. Leads them in the right direction ... gets them into training ... won't have to be like me who had to find out where do I go to get his benefit and where do I go to find out about OTs or speech language therapist or whatever.

It remains to be seen if the DHB coordinator fulfils this aspiration. Apparently, 15 of the 20 DHBs have so far signed contracts for these services as at February 2011 and the service will be evaluated in two years. 
The NASC coordination work mentioned above has been complicated by the release of a Cabinet paper on a 'new model for supporting disabled people' and a subsequent pilot for an alternative system to NASC (Ministry of Health, 2010; Office of the Associate Minister of Health, 2010). It is anticipated that this would be more along the lines of the Australian Local Area Coordination (LAC) system which is a geographically based, person-centred service. The key difference is that LAC asks the disabled person what is a good life for them, and then seeks out appropriate supports, whereas the NASC asks what a disabled person needs within a ring-fenced limit. Fortunately, two adults with Asperger's have advisory roles in the pilot. In the meantime, none of the four ASD NASC projects mentioned in the June 2010 newsletter appear to have tackled the core problem of eligibility criteria for people with ASD, so unless a special case can be made and the local NASC is prepared to do the extra work required, a diagnosis of autism by itself (without intellectual, sensory, or physical disability) is still not sufficient to get an assessment and support package.

\section{Ministry of Education funded work}

The June 2010 newsletter also reported progress on associated activity led by the Ministry of Education (Ministry of Health Disability Support Services, June 2010) which included a supplementary paper on Applied Behaviour Analysis (ABA) for the Living Guideline, as well as new work underway on revising the evidence about three commonly used medications.

While the Ministry of Health funded the Guideline implementation, the Ministry of Education set up the Living Guideline process (with Matt Frost as deputy chair, and the NZGG providing administrative support) in 2009 and their first task was to evaluate and update the Guideline in the controversial area of Applied Behaviour Analysis, work which was signalled at the time of its publication. The Living Guideline Group then reviewed evidence around three separate medications commonly used with ASD, and their third and final area (unless further funding eventuates), currently underway, is reviewing best practice for employment.

The Ministry developed an ASD Action plan including 'a coordinated national plan for professional learning and development, which involved establishing a network of 'Go To' people who will take a leading role in providing evidence-based support and current 
information' (Ministry of Health Disability Support Services, December 2009, p. 11). The December 2009 newsletter also reported that the SCERTS programme had thirteen teams across the country working with individual children and families. There has also been work done on innovative ways to assess educational progress for ASD children, utilising the collective expertise of teachers and families. The Go To people have large regions to cover, for example one person covers the whole of the South Island from Wellington, and another covers the lower half of the North Island from their base in Palmerston North. But the people employed are highly skilled ASD educationalists and so this is a definite gain, in spite of general cutbacks in government spending. Recent cuts include the disestablishment of the Special Education roles of family/school liaison throughout New Zealand, which were well utilised by ASD families. The school-based 'Tips for autism', has also received additional resources to train more teams.

Since the June 2010 newsletter ASD-specific official information is scarce (as there are no resources for newsletter production). The final IAG meeting was held by videoconference in June 2010, and a new more focussed advisory group established of which five of the twenty places were reserved for people on the spectrum. This group which is intended to advise the Senior Officials, will run until 2012 and be largely Ministry of Education funded ${ }^{20}$. The final role of the NZGG's Technical Implementation Service was to set up this Ministry-run group. The NZGG retains a small role providing research and advising on the Living Guideline work.

In an innovative arrangement, an ASD-specific collaborative role working across the Ministries of Health and Education and located in Health, but independently funded, was created in late 2009 and will run until the end of 2011. This role is key for effective Guideline implementation, and it is unclear what will happen afterwards, as many of those involved in the Guideline work from the Ministry of Health have left.

The Guideline has started to appear in peer-reviewed literature such as a recent article in the New Zealand Medical Journal about an increase in trace element testing in the Auckland region, 'current guidelines for the investigation of autism spectrum disorder

\footnotetext{
${ }^{20}$ Apparently the funding and work for this group finished in June 2011.
} 
do not include the measurement of trace elements' (Song, Palmer, du Toit, \& Davidson, 2010).

\section{Part Three: evaluation}

The above is only a snapshot of activity associated with ASD since 1998, the publication of the Guideline in April 2008, and work since. The threads are complex and confusing, so is it possible to assess implementation so far?

In 2009 the Ministry of Health's Disability Support Services had another round of their regional consumer forums for disabled people and the issues raised included: lack of information, resources, respite, workforce, support, inflexible system, regional discrepancies, with particular issues for Māori and Pasifika (Ministry of Health, 2009a). These are the same concerns that have arisen through the Guideline work.

The political climate has changed since the Guideline launch in April 2008, with a conservative government elected in November 2008 with less commitment to strong public services, a prolonged recession and now the cost of the earthquakes ${ }^{21}$ in Christchurch. There have been significant funding and staff cuts throughout government including the Ministries of Health and Education and restructuring and public money has become elusive. ASD work continues but money for new programmes is unlikely. Several current pieces of work which have implications for ASD are not part of the Guideline work: the work programme following from the Special Education review; the new model for supporting disabled people (Ministry of Health, 2010; Office of the Associate Minister of Health, 2010), a review of residential support for disabled people; and a behaviour review which has incorporated Guideline implementation money.

To further complicate matters, the IHC, which is contracted and funded by government to provide residential and other programmes for people with intellectual impairment including ASD, was placed in statutory management in October 2010 for not having sufficient funds to pay overnight workers the minimum wage as required by a recent

\footnotetext{
${ }^{21}$ Major earthquakes in Christchurch in September 2010 and February 2011 caused an estimated \$8billion damage.
} 
court decision NZPA, 2010b), and which is now going through a complex appeal process $^{22}$. In another long-running legal wrangle, in December 2010 the High Court agreed with the Human Rights Commission that family members of disabled adult children should be paid for this work as non-family members are, but the government instructed Crown Law to appeal this decision (Human Rights Commission, 2010; NZPA 2010a). In yet another case, IHC Advocacy is still awaiting a decision from the Human Rights Commission on complaints from several families of school exclusion of their disabled (including autistic) children (IHC, 2009).

\section{Gaps yet to address}

From my research I have concluded that there are some major gaps in the Guideline, particularly regarding adults and mental health, and it is also light on evidence for Māori/Pasifika. Unfortunately, the Living Guideline process can only review evidence already in the Guideline, and cannot start on new work, such as services for adults.

The Paediatric Society was an important part of the process from the early days of Guideline development as many aspects such as information and diagnostic pathways were urgently needed for autistic children. However, this emphasis has meant less focus on services and supports for autistic adults and related issues such as ageing. There is no pathway for diagnosis and support for adults with ASD in the public system. Many adults with autism come into the system via a mental health pathway, and coordination with disability support can be complicated. At the inquest of a young Wellington man with Asperger's who took his life at a time of crisis, the coroner recommended better communication between agencies and his mother asked for better autism awareness (Anonymous, 2010; Newton, 2010). Ironically, the coroner recommended that DHB staff familiarise themselves with the Guideline, even though adult-specific recommendations are few.

I am not sure what progress there has been for Māori and Pacific people with ASD as a result of the Guideline work so far, and as a non-Māori/Pacific person I am not qualified to judge. The Pasifika position on the IAG was never filled. There was one fono and a few hui on marae as part of the Guideline development which helped inform its

\footnotetext{
${ }^{22}$ Finally settled in October 2011.
} 
Chapters Seven and Eight. Auckland's Ohomairangi Trust has a contract to work with all families with ASD in their local area, but only for three months after diagnosis. There were two tangata whenua representatives on the IAG, and Jill Bevan-Brown (who has Maori whakapapa) is on the Living Guideline Group. The Guideline quick cards for lay people (www.asdguideline.com) have been translated into Māori and some Pacific languages. At the September 2009 'Making Inclusive Education Happen' conference Jill Bevan-Brown gave a presentation 'Please include my child with ASD' (BevanBrown, 2009) which covered strategies for schools and parents (including Māori parents) and drew on the local Palmerston North DVD In my shoes (Pai4ASD Trust, 2008) which includes resources for Māori.

However, I suspect that Māori and Pasifika ASD support will come from within their communities as disability awareness grows and develops. The Whānau Ora concept of a navigator to support families in an holistic way sounds well-suited to ASD, and Whānau Ora contracts are now being let throughout New Zealand. There have been some significant developments in Pasifika organisation disability resourcing and supports, including the recent National Pasifika Disability Plan, Faiva Ora, and the development of Pasifika providers such as Vaka Tautua.

The minutes of the first meeting of the new expert advisory group, which includes several members on the spectrum, notes that sexuality is also a gap in the Guideline (Autism Spectrum Disorder Advisory Group, 2010). They are also contributing to work on clinical pathways using the Guideline recommendations for the Ministry of Health.

\section{Lack of information}

One thing I have found frustrating, even though I participated in several advisory projects, is how hard it is to get information about Ministry-related autism work. The NZGG's Implementation Advisory Group (IAG) could advise on material they were provided with, but much of the negotiation was in confidence and only between relevant public servants and the NZGG Technical Implementation Service (TIS) staff. This was possibly because the public service is governed by a code of conduct, is careful about conflicts of interest, and particularly careful not to leak any unauthorised information. The IAG and TIS also took care not to be seen as advocates as advocacy risks becoming politically compromising. 
But to be visible and effective the Guideline prioritising and implementation work needed public championing and discussion, particularly by Autism New Zealand as the major New Zealand autism NGO. There were two board members of the IAG on the Autism NZ board (including myself), but no one from management. But when we raised it at board meetings it was hard to generate interest as it seemed too big, too complex and had not been seen to make a difference in anyone's life yet, while other governance issues were more urgent. Yet there had been presentations by public servants at both Autism NZ and related conferences (Curzon, 2008; Curzon \& Hearn, 2008) and many opportunities for consultation and discussion. But practice, not theory is how people generally judge effectiveness, and there is little in the way of new services yet to see. However, the new advisory group which had its first meeting on 1 December 2010 had the Autism NZ CEO as a member, and the Guideline work may now become more visible in the organisation ${ }^{23}$.

I wrote posts about the IAG's work on the New Zealand autism blog, http://humans.org.nz, mentioned it at three different select committee hearings and even got a letter published in the New Scientist (Stace, 2010a). But my impression was, and still is, that there will be little interest until the Guideline can be seen to be making a difference to individual people's lives, and while people struggle to get services, it will be dismissed by the few who have heard of it, as merely aspisrational. So there was little championing of the work in the autism sector itself (apart from Altogether Autism which provided information in meetings and on its website), and a lack of information about what was happening, apart from the ASD newsletters which were quite detailed, technical and not well publicised. In retrospect the IAG only interacted with a few people from government departments and did not have, as my informant Alex noted, 'a huge involvement with the intersectoral advisory group, the Senior Officials group, and that's a little disappointing'.

As a parent and advocate I have found it hard over the years to get specific information about ongoing work. In her research on disability policy, Tessa Thompson (2007) notes that there are several barriers to the message getting up through the levels of

\footnotetext{
${ }^{23}$ The work of this advisory group was completed in June 2011 when funding ran out.
} 
bureaucracy, including fragmentation and dilution, as different groups of people sit around different tables in the hierarchy. I suspect that the problems getting the message out around and across government departments, district health boards, GPs, clinicians and schools, are as big as those getting the message to parents.

The ASD newsletters published on the Ministry of Health website were infrequent and dense, and to decipher it required the reader to have knowledge of the Guideline details. So it is not surprising that the work is not well known in the sector, or to journalists such as Cohen (2007), whose book I mentioned at the beginning of this chapter. The Guideline work needs its own public relations publicity campaign to shout about all the good things that have happened, and specific examples to applaud, as well as a process of continual improvement, gap filling, review and evaluation.

\section{Assessment of Guideline by my informants}

Is the Guideline contributing to building right relationships and respecting lived experience? I interviewed on audiotape a purposive sample of nine people about the Guideline, and their assessment of the state of ASD policy. Others asked gave me email responses. Included were perspectives from parents, people with autism and other key informants. Most had long involvement in the sector so were very well aware of the long journey towards the Guideline and had high expectations of the work, tempered by an understanding of the realities of autism and of government processes.

The interviews were semi-structured and wide ranging and I asked my informants about their personal experience with autism, their involvement with autism issues and the Guideline development, their assessment of any progress since the Guideline publication (several had been members of the IAG), and their hopes for the future. The interviews reveal some contrasting opinions on common themes such as the process, funding, managing expectations, gaps, what hopes for the future. Considering these may help decide whether the Guideline was effective at building right relationships and respecting lived experience. However, topics covered a range of issues and thematic analysis revealed the following significant topics. 


\section{Commitment to the Guideline}

Empathy for Janine Albury Thomson who started the Guideline process by killing her daughter was expressed by Kim, a parent of autistic teenager:

What it did for me was just highlight the case of services, the lack of supports. How a mother can be led to such sheer stress and frustration and absolutely lose her mind really, and I think what it highlighted for me is how you can get to that stage.

Kim's own experience of parenting led to involvement in advocacy and government committees, 'I think wherever ... I can get on to something and do something and have a say, I'm there'. Jess, who has long experience in autism policy and services, reflected the complexity of getting service provision right for people with autism, 'I always think people with autism show up the flaws in services.

Enthusiasm is tempered with realism for several of my informants:

Well I was involved right from the beginning and I guess the day it was completed was actually hard to believe that we finally got there ... Reading through the Guidelines there is some good stuff in there ... but in the real world some of it doesn't apply ... and families will do what families want to do... I think they are still going to search out what they think is best. (Kim)

I went to the launch at parliament and I've used it and distributed it widely. (Pat)

It was just the sense of privilege to be involved in something like this ... I remember the sense of immense privilege at the launch of the Guideline. (Alex)

The ASD guideline ... admits as a society we are drawing a blank in providing virtually anything from diagnostics and assessments all the way 
through to end of life services ... but how do you quantify how poorly we are doing without the help of the Guidelines? (Pat)

I am rather cynical about the bureaucratic process which spends much of the scarce money available for ASD in producing paper-plans for action rather than action itself. People are very proud of the quality of the Guideline but if that is as far as it goes then it is a waste of time and money. (Max)

\section{The implementation process}

Again there is acknowledgement of a new type of process of working together, but a questioning of the overall effectiveness:

There was a desire to do something different. (Jess)

It was a bit of a learning experience for everyone. (Alex)

It was a good team. We've had complementary skills and perspectives. ... did a very good job in bridging a very fraught set of politics....It did enable a very diverse group to come together and do some work together. I remember that day after we did the prioritisation stuff and how buzzy people were, I mean it was nice to see how proud people were about what they had achieved. (Jess)

The first few meetings when we talked about what we were going to achieve and actually knowing now was has been achieved...we haven't achieved much at all actually and that's really disappointing and as time goes on from now less and less will be achieved I guess because there's just not the money. (Kim)

The desire to engage with autistic people and families was applauded, particularly by Alex, in different parts of the interview:

I think there was a genuineness to try and engage people with autism and their families. 
I had really strong and high expectations of the process, that here was a world leading approach, here was an approach ... that also had some basis in rights so it mentioned the Disability Strategy .... there was a sense of what do we need to do to make a good life for people?

They saw people with autism as being a partner ... I still believe that approach has incredible potential ... but I'm not sure that we fully harnessed that yet.

\section{Funding}

Many people referred to the lack of money for the work, such as Alex: 'People think with eighteen million dollars over four years we are going to solve everything'. But Jess had a different view: 'I kind of admire them for not just throwing more money in because money can be a hindrance factor... it can divert away from fixing systemic issues and a lot of the issues are systemic.

\section{Managing expectations}

Several people mentioned the complexity and the huge expectations about what could be achieved:

I don't think you will ever get a full solution to these issues. (Alex)

I think it worked well but the biggest challenge was always going to be, and I don't think we did it, and we are never going to be able to deliver on people's expectations. And to some degree that was because the document was so enormous that it was never going to be possible anyway. (Jess)

The Guideline had been sold as this kind of big, big...this was the capsule that was going to solve everything and so there was a bit of a learning process... about the expectations. ...everybody thought this was going to be huge because the Guidelines Group are going to do just about everything and even politicians I think thought that. (Alex) 
Expectations ranged from the global to the specific, as illustrated by Alex's observations of wishes from various interest groups:

they said, 300 recommendations all should have been done yesterday and we can't prioritise them because they are all so important. But ' $[\mathrm{I}]$ really need a teacher aide for my five-year-old with autism and is there some funding?'

\section{Gaps identified}

Coordination and adults were the two most frequently mentioned:

A mum picking up that Guideline wanting help with their newly diagnosed child wouldn't find a pathway or where to from here or what next or who do I ring? (Chris)

The one that nobody could prioritise because they saw it went across everything and it just had to be sorted was coordination ... what happened is the ministry gave that money to NASCA to sort out. (Jess)

One of the regrets I have is that I don't think we did enough for adults. (Alex)

When you have the Paediatric Society involved at the very beginning of the process ... adults were never going to get [attention]... but I guess the potential biggest impact was to improve the lives of children and some people will fall through that gap ... but you know who do you try and help? (Chris)

[Where are the services for] the 25-year-olds who are feeling suicidal because they can't get services, for the 50-year-old with autism who hasn't got a diagnosis and is still waiting? (Alex)

However, some of my informants understood that there was work underway at the Ministry of Health around eligibility for services which may help adults: 
There is a policy paper being written which will hopefully clear up who is responsible for the funding of people on the spectrum without another disability or without a disability actually...I guess adults will be captured by this eligibility [and] the decision around who is eligible for funding - they will be captured but there isn't anything specific. (Chris)

The Ministry of Health ages and stages of severity study... finished recently looking at how to redefine where the cut off is between autism and Asperger's, like there is a cut off point between the two for who should be provided with services and who should not be .... They shouldn't define severity according to co-morbidities because the co-morbidities often arrive after a failure to accommodate the Asperger's syndrome difference itself .... they are a bit of a self-fulfilling prophecy. (Pat)

\section{Achievements}

Reflection on the work brought out comments on the process and specific achievements:

I am proud of a lot of the stuff we did. I really want to make that clear. (Alex)

Another step got taken, a good step, but just another step. (Jess)

[A]bout autism policy we do have to be open to sensible pragmatic solutions to issues... it's about the end goal. (Alex)

The first thing that was on the list to have the handbook for diagnosing ... is about to come out now. (Kim)

[S]pecialist training packages for professionals around paediatrics and I think some of that stuff was fantastic. (Alex)

One informant who has been involved in further work mentioned: 
It's such an eye-opener of a process about how little capacity there is out there to do anything well for people with autism and that people are bending and flexing services for other people to try to meet that need in order to meet the spec ... in order to get the money when in many cases autism isn't even their cup of tea. (Pat)

But overall the Guideline work could have been improved:

The Paediatric Society and the Ministry of Health and the Ministry of Education which isn't broad enough... probably mental health should have been in more at the beginning... it should have looked more like the senior cross-government official group... like the national drug policy...when there is Police and Justice and ALAC and service providers and Policy in the same room... The Guideline ended up trying to be too many things for all people... it should have been tighter... Fewer recommendations .... And... if you have recommendations they need to be funded and there was never going to be enough money. So I think the money available and the recommendations should have been tighter. (Chris)

\section{The Future}

Many of my informants had hopes for future improvements, although tempered by the knowledge that there were many young people with autism and high needs coming through the system:

I'd have good evidence-based policy that worked in conjunction with operations and the development of programmes that were then evaluated to make sure that they were doing what they needed to do and actually improve the lives of New Zealanders with ASD. (Chris)

I guess that's where the guidelines are good - you have this evidence-base benchmark for training ... Training for all the people that come into your life if you've got a child with ASD, for all the education people, for the health people, for carers, everybody that you need cause you can't do it 
alone ... I guess diagnosing is first, then training for all those people you need in your life. (Kim)

When parents suspected their child had ASD they would have someone to contact who would put them into a system which saw the needs of the child and their family catered for without then having to spend huge amounts of time and effort to make things happen. (Max)

We will have outreach workers... in every area not just Auckland....A field worker, first call person... who links [families] up to all the local agencies or support people, whatever they need to know within their own area. Leads them in the right direction really ... will all be there as a package. (Kim)

Obviously my ideal world would be that Morgan [her child] should just be budgeted within the Government's Budget each year. (Sam).

But there was also the realisation that they would have to do it themselves through their own organisations:

And saying this is what we dreamt about when we sat in that room with the Ministry. And now we're going to do it. Because I think we've learnt you can't just sit and wait for it to happen, if we're going to do it we've got to get up and do it. (Kim)

\section{A story of current processes}

A local parent wrote a blog post in which he beautifully expresses the complicated process of diagnosis and assessment. Unfortunately, building relationships and respecting their parental lived experience, are not greatly in evidence in his story:

The pattern of all our subsequent dealings with the public service in this area establishes itself right from the beginning: a prompt initial contact followed by a seemingly endless wait for actual support and intervention. The Ministry of Education assigns us a speech therapist who comes to our home in a matter of days for an initial assessment of the situation. She 
seems courteous and capable. She asks us lots of questions, and we welcome them: it feels good to talk to someone about our concerns, to get some things off our chest and receive some basic advice. But as for the response that will follow, things get more complicated. To turn the suspicion of autism into a diagnosis and access the services offered by the health authorities, we need to see the Child Development Team at our local hospital, in six to twelve months (it turns out to be twelve); while the Ministry of Education will deploy their optimistically named Early Intervention Team in approximately six months (it turns out to be nine). There is no interim provision, no half measure: so long as our daughter can tolerate being at kindergarten - and she does, at this point - it has to suffice....we have to meet with the Child Development Team at Wellington Hospital, so they can tell us what we already know. It is a long meeting, and whilst we are used by now to discussing our daughter as if she wasn't in the room, this time we are probed much more deeply, and expertly. There is nothing especially tactless about the interrogation, other than the unwelcoming room itself, other than the strain of having her there, for over two hours, wondering how she feels, what she does and doesn't understand, what she will and won't remember.

The alternative, to have determinations made without talking to us, or without seeing her, would be worse. But it's especially difficult at times like this not to feel that your child is a problem, and that you may be at fault: for not having done enough, for having passed on the wrong genes. None of these thoughts have to be rational, let alone justified, to affect you. So while we answer the questions, many of which are unavoidably of an intimate nature, we feel that we are all being examined, the three of us, and we figure, Justine and I, that we are the fortunate ones, for we are intelligent and knowledgeable and resourceful, for we found ways and had the means to intervene. ... One week later, when we are summoned again to the same room - this time without our daughter - they tell us out right: you're doing all the right things, we have no recommendations for you. (They are pleased with us!) Oh, and yes, your daughter has autism. That phrase in the report is 
actually in block letters, and you could read a lot into that typographical choice if you were so inclined, about the need to label, its usefulness, and the fear of the label. (Tiso, 2010)

\section{Conclusion}

This chapter has been the most complex to research and write. The Guideline story started with a death and included much enthusiasm, expertise, cynicism and sadness, and finished on a tone of resignation from a parent of a newly diagnosed child. So what can we learn from the development and implementation of the ASD guideline and to what extent does it meet the criteria of incorporating right relationships and lived experience?

There has been considerable government funding, directly and indirectly, and the input of a great deal of time and effort by large number of people into the issues around autism over several years. Only fragments have been mentioned here. There have been numerous reports and committees, research, programmes, initiatives and evaluations, and enormous paid and voluntary effort by an army of people. Over several years three working parties assessed the evidence and wrote eight chapters, 305 pages and over 300 recommendations to compile the Guideline. But it is a very complex policy area and all this work and preparation does not guarantee success. So at the launch on 2 April 2008, Richard Belton, the acting Chief Executive of Autism New Zealand and with the wisdom of decades of autism sector experience, challenged the audience to make it work and not let it all be for nothing.

The development and implementation of the Guideline has been all about building relationships. In preparation for the publication of the Guideline, The New Zealand Guidelines Group led a group that won the tender from the government for a Technical Implementation Service for the Guideline in December 2007. The TIS established an Implementation Advisory Group (IAG) of representatives from the sector, as well as a Living Guideline Group (LGG). All of these groups worked within guidance and parameters provided by the Ministries of Health and Education who were the sponsors 
of this work. Now the IAG, and the second advisory group have finished their work, while the LGG has funding for another one or two topics.

The Guideline can be seen as an attempt by officials to tame the complexity of issues around autism by defining, collating and providing in one volume international best practice evidence (Conklin, 2006). It had to be done, to get all that information together, to understand the issues better. The intentions were excellent. But it is a one-off solution, good enough for now but not the whole answer. It is too unwieldy and there hasn't been enough communication with, and buy-in from the sector. Implementation has not gone as planned, such as with coordination which underpinned all the priorities. We still have a maze to negotiate and parents need a pathway and trusted navigators, and some autistic people need life-long person-centred support systems; over three years we have only made small advances in putting it in place.

As regards lived experience and right relationships, from the beginning of the process back in the late 1990s, parents and people with autism were consulted and represented and there were sincere attempts by the public servants involved to build relationships and respect their lived experience by bringing them into the process. Many of my informants appreciated and frequently mentioned the efforts of those behind the Guideline development and implementation processes to involve and engage people with autism and their families. But it was never more than a few individuals, and how much power they were given and have in an ongoing sense is less clear. Getting information about the Guideline out to the sector, and its ownership by parents, professionals and people on the spectrum appears to have only been partially successful so far.

The jigsaw motif is often used by parent autism groups and the risk is that many people will have a little piece of the picture but few will have the bigger picture. This reflects back to the wicked fragmented nature of autism, that an improvement in one place might lead to negative consequences elsewhere. But to understand a wicked problem you need to attempt solutions and there is now much to learn from the Guideline attempt. It is commendable that people with autism and family members are acting as advisors in ongoing work. Improving autism policy, support and services from now on 
are for new people to take on and build on, particularly the next generation of people with autism and the emerging autism entrepreneurs. My conclusion is therefore one of hope that things will continue to improve for people with autism and their families, recognising that the work of the last decade has provided a firm foundation to build on, and the NZ ASD guideline provides a unique benchmark. 


\section{Section Four: Summary and conclusions}

This final chapter draw the threads together in a summary of the argument. A visual representation of the problem, a diagrammatic plan for incorporating lived experience into the policy process, and a glimpse of what the future might look like are suggested.

The concluding section answers the research questions, considers the contribution to knowledge from this thesis, remaining gaps, and areas for future research and action. 


\section{Chapter Ten: Summary and conclusions}

\section{Summary of the argument and scholarly framework}

While Casey Albury's 1997 death set the scene for policy concern about the condition of autism, the experience of Arie Smith-Voorkamp after the second Christchurch earthquake in February 2011 justifies the assumptions behind this thesis. The 25-yearold with Asperger's and an interest in electrical fittings, and his partner Michael Davis, were arrested for allegedly looting after Arie had entered an unsafe and badly damaged building to 'rescue' two light fittings which he could see from the road, with Michael reluctantly following. Arie's badly-beaten face (allegedly inflicted by the police) appeared in the paper under the heading 'the face of looting' (Wade, 2011). His foster sister, who had been looking for him, soon found out what had happened and over the following five months his situation became a popular topic for the media, blogs and talkback radio, and one particular commentator used his radio programme and newspaper column to attack him and his family in the hate-filled language of eugenics. ${ }^{24}$ Ironically, he used the language of luck claiming Arie was 'bloody lucky that he received only a black eye' (Satherley, 2011). An Auckland lawyer, also with Asperger's (and financially supported by the Asperger's community), got Arie out on bail two weeks later, and eventually a senior barrister succeeded in having all charges dropped against both of them.

Arie Smith-Voorkamp was unlucky on several counts:

- he was on the autism spectrum so has an increased risk of being apprehended by the police (Debbault 2002);

- he was in the wrong place at the wrong time and under stress could probably not explain why in the terms that the authorities could understand;

- a crisis (major earthquake) meant theoretical best practice was overlooked;

\footnotetext{
${ }^{24}$ Details of the saga can be found on the Public Address blog site http://publicaddress.net/hardnews/about-arie/; http://publicaddress.net/hardnews/angry-and-thrilled-aboutarie/
} 
- he could not find a job to utilise his special interest;

- his natural family were unable to advocate for him when a crisis happened.

The title of this thesis suggests that good outcomes for autism are currently dependent on a person having family to advocate for them and luck that they will find services and supportive people. This thesis has deconstructed and examined this hypothesis using a wide variety of literature, from peer reviewed reports from clinicians and other professionals to autistic autobiographies and websites, as well as interviews with several key informants with firsthand knowledge of autism policy and its implications. I suggest that autism policy could be improved, and be made more equitable and consistent, if the expertise of several groups of experts could be brought together. It is also important to recognise and harness the expertise of those with insider knowledge - people with autism. These sources of expertise are outlined in Chapter Three. For my purposes people with autism, and family members rank highly. At the end of this concluding chapter, I offer some recommendations and a vision for the future, where love and luck are no longer necessary for good outcomes.

My interest in this topic arose from having an autistic son who now has a job and a full social life, but he is still autistic as it is a permanent condition, and part of who he is.

\section{Autism: contested meanings}

Chapter Four outlined the history and conditions for the diagnosis and cultural creation of autism, internationally and in New Zealand. Autism as a separate condition was named in 1943 by Austrian-born Kanner (1943), working in the new field of child psychiatry in Baltimore. This diagnosis built on contemporary developments in psychology, psychiatry and the understanding of childhood and psychology (Nadesan, 2005). In Austria Hans Asperger was studying a similar group of children but his work would not become well-known until the 1990s (Frith, 1991). The most recent descriptions (see Appendix One) in the Diagnostic and Statistical Manual IV Text Revision (American Psychiatric Association, 2000) consider it to be a triad of impairments: in communication (none or inappropriate use of language), in understanding others (mind-blindness or lack of empathy) and imagination (replaced by obsessive special interests). It is now considered a wide spectrum from the non verbal, 
intellectually impaired person apparently cut off from the world, to the highly articulate and intelligent person.

Some autistic self-advocates describe the condition differently. They often use the term neurotypical for non autistic people and neurodiverse to encompass neurological alternatives such as autism, and terms such as Aspie for themselves (Baker, 2006b, 2011; Boundy, 2008; S. M. Robertson, 2010; S. M. Robertson \& Ne'eman, 2008). Autistic people usually describe problems with understanding and predicting neurotypical peoples' actions and behaviour, particularly their non-verbal cues, and often report sensory sensitivities to such things as sound, light, touch, taste. Many autistic people think very visually and literally. An instruction to 'hop upstairs and get your coat' could see an autistic child hopping upstairs on one leg and getting their coat but not coming down the stairs again as that was not part of the instruction. In her video-link address to the 2010 Autism New Zealand conference, Temple Grandin, explained that when someone says church steeple she sees in her mind specific church steeples that she is familiar with, not a generic one, and her thought processes are like replaying a video.

Autism is further complicated by cultural battles between those who see autism as a neurological difference, requiring understanding, services and support, and those who see it as a tragedy requiring cure, fixing or eliminating (Baker, 2006b, 2011; Nadesan, 2005; Osteen, 2008; S. M. Robertson, 2010). Others joust over aetiology, and contest the evidence for cause and interventions (Deer, 2011a, 2011b; Mnookin, 2011; Offit, 2008; Wakefield, 1998). The battles often play out through powerful parent-led nonprofit organisations and their allies in the media and politics, in the fight for policy attention and resourcing.

ASD is itself a contested label, with widespread preference evident from the sources within the autistic community for autism spectrum 'difference' or 'condition'. A new edition of the DSM is due out in 2013, and the official description of the spectrum is likely to be simplified, removing subtypes such as Asperger's (Grinker, 2010), which will then shape future diagnoses and understanding. Additionally, many autism researchers suggest that autistic characteristics are more widely spread through the 
population than previously thought (Attwood, 2009; Constantino \& Todd, 2003; Grinker, 2010), but prevalence data may depend on local diagnostic expertise (Lord \& Bishop, 2010; Maenner \& Durkin, 2010).

\section{New Zealand and personal context}

In New Zealand autism came to public focus in July 1997 after a mother killed her autistic teenage daughter when she could not find support and services when she needed them (Cohen, 2007). Two reports (Curry, 1998; Werry, 1998) were commissioned. Both made significant and largely similar recommendations including for improved services and collaboration, and led to a decade of work led by the Ministries of Health and Education but also including other government agencies, professionals, autism groups, family members and people on the spectrum that culminated in the publication of the ASD guideline in April 2008 (Ministries of Health and Education, 2008). Implementation of various recommendations of the Guideline has been ongoing since then (covered in Chapter Nine).

Soon after Casey Albury's death, my son, then twelve years old, was diagnosed with autism after a year's wait for assessment in the public health system. We had been lucky to have a primary school which included him as any other student and provided him with appropriate support, without requiring a diagnostic label of autism. Since the Education Act of 1989 any New Zealand child is legally allowed to attend their local school and my son's school had been particularly welcoming (which I later found was unusual, but lucky for us). They had developed their own programme and strategies for those with learning difficulties around speech, language and communication, which is how his learning need had mainly manifested. But the new policy of Special Education 2000 seemed to ignore what was already working for us and imposed another model that would have removed that support. Access to education and appropriate educational support is of great significance for people with autism and their families (Chapter Eight). I joined Autism New Zealand, and served on its board and local committee, found that services and supports were not equitable and accessible across New Zealand and observed the progress towards what became the Guideline. 


\section{Love and luck, right relationships, lived experience}

Matt Frost, a young autistic colleague, identified and speaks about the two vital ingredients that had meant good outcomes for him, such as in his education: he called it love and luck. Unfortunately, that is not the case for everyone with autism.

In anything to do with policy or human interaction, relationships are very important. Almost any problem can be solved if the parties involved put some effort into building relationships. But there was a particular ethical concept of right relationship which is advocated by Michael Kendrick (2000, 2008b), an American theorising a better way to do the human services of disability support, which encompasses values of respect, equality and of treating disabled service users as fully human rather than as other, that describes the particular nature of the relationship I hoped to advocate. Largely missing in the policy process were those with lived experience. There was a hierarchy of expertise that needed challenging as the valuable insider perspective of people with autism and their families is usually overlooked. So I sought a model that would privilege the lived experience of people with autism, but also respect the expertises that everyone else brought. In Chapter Six I unpicked the concepts of love and luck, right relationships, and lived experience and argued why considering them in the policy context is important.

\section{Policy issues: wicked policy, autism as public policy}

A condition which depends on love and luck indicates a policy problem so socially and politically complicated that it could be called 'wicked' policy, meaning a way forward is not obvious, it is socially complex, and that improving one aspect risks negative unintended consequences elsewhere (Australian Public Service Commission, 2007; Conklin, 2006). Conklin (2006) suggests that 'collective intelligence is a natural property of socially shared cognition, a natural enabler of collaboration,' but is threatened by 'the forces of fragmentation' (p. 2). How to deal with the wickedness of autism policy became one aspect of my research thesis. I suggest that complexity and fragmentation can be tackled by the creative process of building right relationships with those with lived experience, and by incorporating all the expertises we could move policy beyond the current wicked situation whereby autistic people need love and luck to get services and supports. Chapter Seven looks at various aspects of wicked policy, 
asserts that autism policy fits the criteria, and suggests how and why these aspects need to be addressed. Innovative approaches would encourage autism policy entrepreneurs to develop from within the sector. Policy entrepreneurship is one of many ideas developed by policy theorist John Kingdon (1995). He suggests there are times when windows of policy opportunity open. Dana Lee Baker (Baker, 2006a, 2011; Baker \& Steuernagel, 2009), has utilised such concepts in the autism public policy context. The New Zealand death of Casey Albury in 1997 can be seen as the policy crisis which opened a window. There are also many potential autism policy entrepreneurs in New Zealand who could be identified and nurtured by the sector.

\section{Methodology: disability studies and the transformative paradigm}

Chapter Five examined the wider historical and political disability context for autism, including the British critical disability theorists. Disability studies came out of the general activism of the 1960s and 70s which saw the rise of feminist, ethnic and gay rights methodologies bringing the marginalised into the mainstream and gave us the slogan 'nothing about us without us' (Charlton, 1998). Disability rights activists critiqued the dominant medical or individual model of disability which saw disabled people as broken individuals and body parts requiring fixing, and replaced it with the social model of disability which challenges the oppression and the barriers non disabled people create for disabled people in laws, policies and attitudes. Michael Oliver (2009) promotes the social model as a political tool, an implementation action, not just a theory, and the discipline of disability studies theorises how disabled people and their non-disabled allies can work together for emancipation from that marginalisation.

In New Zealand we have confusion between the constructivist and essentialist understandings of disability (Baker, 2006a), which causes conflict between policy objectives and operational reality. For example, we have a Disability Strategy which seeks to remove barriers to disabled peoples' participation, but service delivery, particularly in Health-funded services, depends on narrow range of impairment labels.

To understand and address all the above my methodology needed to consider: my values, my situated perspective, and practical suggestions for improvement. The methodology discussion in Chapter Two explains why Donna Mertens' (2009) transformative paradigm fitted my approach. She provides a framework that is cross- 
disciplinary and encompasses the rights critiques of those from the marginalised groups who had earlier challenged both the dominant research narratives (which assumed the white able-bodied, heterosexual male was the norm), and the positivist research paradigm which sought to find some quantifiable truth without considering the researchers' bias, background or any shortcomings of the quantitative data itself to reveal this truth. Instead Mertens starts with questions about values, social justice and human rights, tries to work in an ethical and inclusive way, and encourages a mixed methods approach with an emphasis on the qualitative (Mertens, 2007, 2009; Mertens, et al., 2010). The researcher has a valid place in such an approach which is why I have used the first person voice. My research data mainly comprised a large variety of texts which I have collected over many years, and key informant interviews. The transformative paradigm allowed for the grey literature required in order to capture the authentic voices of autistic people and families, and I utilised various techniques such as historical and social constructivism and narrative and thematic inquiry to help understand the contexts, interpret and try to make sense of the data from my writers and informants.

The basic beliefs of the transformative paradigm as outlined by Mertens (2009) include the following aspects, which I have used as a guide:

- axiology or ethics - respect for culture, human rights and social justice;

- ontology or assumptions about what exists - recognises researchers' privilege and that realities are shaped by such things as values, culture, gender, disability and economic status;

- epistemology or assumptions about knowledge - accurate knowledge depends on developing a trusting relationship between researcher and participants or stakeholders, and addresses issues of power and recognises that knowledge is socially and historically situated;

- methodology or what methods are appropriate - mixed methods can be used but need to include qualitative, and research questions must acknowledge and accommodate cultural contextual and historical factors (2009, p. 49). 


\section{NZ ASD Guideline}

The major piece of autism policy in New Zealand, and with a coverage and scope which is rare internationally, is the 2008 ASD guideline (Ministries of Health and Education, 2008) and it became a case study for my research. Work on it can be traced back to Casey Albury's death, and it is a mammoth policy document with over 300 recommendations. Chapter Nine covers my interpretation and evaluation of the path towards the Guideline and the story of the process of implementation since 2008. I was helped by key informants, who have all been personally involved in various aspects of autism policy development and implementation, most of them for many years.

\section{Main conclusion from Guideline: more coordination required}

My main conclusion from all the material, reports and interviews is that if independent, knowledgeable and holistic coordination was available to all people and families someone to act as guide, counsellor, service coordinator, facilitator - throughout life from the time of suspected diagnosis, that some of the confusion, duplication and poor outcomes would be avoided and there would be less need for the sometimes elusive variables of love and luck. (Lessening stress on autistic people and families and improving well-being may actually nurture love and luck.) Secondly, there needs to be appropriate equitable and accessible services, but even if services did not exist a guide or facilitator could be effective in helping the autistic person and their family to build community networks and find and train support people. This enabling role has been asked for by families for many years, particularly for those with Asperger's who are locked out of NASC support because they lack a dual diagnosis. But a sad commentary on the limitations of the Guideline implementation was that the vital and prioritised new role of coordination, was first limited to DHB services (so to health only, not education or other areas), then to people under nineteen (so not adults), and some DHB regions have missed out altogether. So the ability of the person in this role to help the autistic person and their family build and maintain relationships with all the people involved in an autistic person's life across New Zealand, 24 hours a day, seven days a week, over a lifetime, will be severely curtailed.

This need for coordination is also highlighted in the IHC's submission on New Zealand's first report to United Nations on the UNCRPWD. 
New Zealand's report would benefit from a greater recognition of the interdependency of individuals and the overlap of support systems, both funded and natural. A whole-of-life-approach that overcomes the barriers imposed by funding silos needs to underpin a whole-of-government framework, developed in partnership with disabled people and their families/whanau and the disability sector. (T. Grant, 2010)

Additionally, the wicked aspects of ASD need to be understood and recognised by those involved in policy so they are empowered to fight against fragmentation and for the collaboration which is vital to challenging such problems.

\section{Conceptualised research model}

My research model can be conceptualised as a garden representing society and autistic people are slightly different flowers mixed in with all the rest of the diversity of the garden. Watering and nurturing represent the love and luck that some receive and they grow well, even though they still look a little different to the others, while others struggle on the harsh ground. Individual plants may be sprayed, trimmed or even espaliered, in an attempt to improve them, which reflect the medical model aim of fixing individuals. But what we need is actually a big compost fertiliser of right relationships that will benefit the whole garden. However, it will sit on the surface and be underutilised without some hard work with the shovel of the social model to dig it in and make it effective. In fact a collaborative team of gardeners (representing all our experts) would be even better.

Research can also be judged on outcomes, and I have developed a model (Figure 11, below) which incorporates autistic and other disability expertise into any policy question. If this model was incorporated into the policy process it could improve policy and people's lives. As UK disability activist Geof Mercer says:

Disability research should be judged in terms of its capacity to facilitate the empowerment of disabled people. (Mercer, 2002, p. 245) 


\section{Policy model}

The diagram below outlines a potential new policy process. When a policy problem is identified (as in the balloon at the top) those asking the question could reflect on whether it affects the lives of real people. If it does, the next question is to consider who will benefit from attention to the problem. It could be that someone wants to do the research for their own academic benefit, or a politician for favourable media response (such as the MMR vaccine scare which was manufactured for the academic and financial benefit of the doctor leading it). If the main beneficiary of the policy is not intended to be the target population, that raises an ethical issue about the overall value of the research.

If it is an autism related problem to be addressed, such as something to do with service gaps, where are the autistic people and families who can provide the lived experience perspective in the process? The diagram outlines four alternative ways to include the target community, ranging from telling them after the process (note that consultation and engagement here reflect my observations of similar processes rather than any interrogation of the academic literature), to more degrees of engagement or power sharing. However, the most transformative process would be to give the target community the leadership of the policy process and provide secretariat or other support as required. Aspects of the Guideline process have involved the first three processes, (and the Ministry of Health's Consumer Consortium, mentioned earlier, has aspects of the third) while my recommendation would be for a policy approach that trials the fourth. That would be the best way to incorporate right relationships and lived experience in New Zealand's autism policy, and would also be a way to generate new ideas and find innovative, and as yet untried, solutions. They might just come up with solutions to conquer the current problems. There is the capacity in the NZ autistic community and it would be exciting to have the opportunity to trial it, perhaps for the neglected area of support for autistic adults. 
Figure 10: Transformative paradigm relationship building model

\section{Transformative paradigm relationship building model}

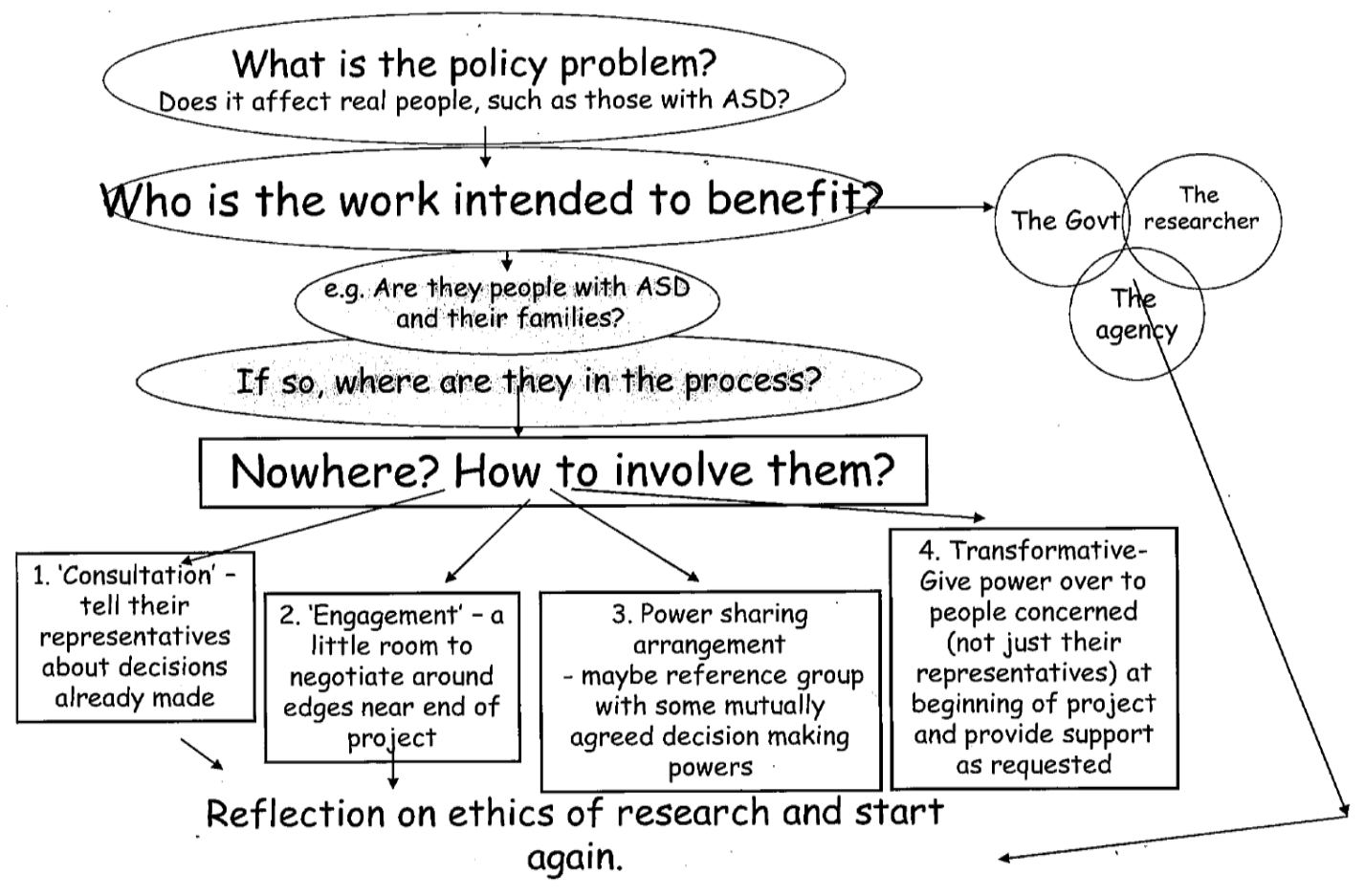

\section{Vision: Aspie cafe and enterprise centre}

This café and enterprise centre is located in the central city near a busy public transport hub as few of the staff drive. It is open from six am to midnight and is staffed by a roster of people, most of whom are on the autistic spectrum. Most previously survived on the Invalids' Benefit and some of the part timers still receive a partial benefit, as full time work in the neurotypical world can be very stressful for the neurodiverse. The café is low sensory with carpets, a mixture of dim and natural lighting, soft chairs and sofas and quiet alcoves. The staff are rostered for shifts that suit them. Some work a couple of hours a week, some everyday. They work in the areas they feel comfortable with such as cooking, cleaning, clearing tables, serving, washing-up, dealing with money, computer orders, barista, delivery and website maintenance. The rosters are done weeks in advance and the simple and clear rules are displayed on the walls. Variations, such as closure for holidays, are negotiated and agreed to well in advance. The secrets to this successful business are good support for the staff, rosters and jobs to suit interests and abilities, and time out spaces. There are agreed procedures to follow if any problems arise, such as staff incompatibility or sensory overload. People initially come to support 
the café as a good cause and keep coming back as both the environment and the food are congenial.

Autistic artists, craftspeople and techies occupy adjoining rooms and their work is on display and for sale (a computer game developed by one of the members has proved particularly profitable). A health clinic operates from the premises with staff who understand the clinical and mental health issues around autism, and are also qualified to sign documentation for benefits and other official documents. An advocacy service is provided for those needing help with student loans or benefit processes. The centre also employs neurotypical staff as required, mainly for their organisational skills, or to act as social interpreters for appointments with various agencies. As this centre is known for its autistic expertise, there are frequent requests from educationalists or clinicians wanting professional development around autism, or government agencies wanting autism representation on advisory groups. There are also job opportunities such as IT companies looking for technology testers, schools looking for teacher aides or families looking for mentors for their autistic children. Centre staff act as agents for these jobs.

In order to develop the business the staff have partnered with the local university for ongoing evaluation. Each month those involved with the centre have a two hour meeting facilitated by staff on a rostered basis to discuss their group work, suggest improvements and new workplans. Those who do not use words to communicate use their usual communication devices. Suggestions could include such things as expansion of facilities or skills development.

Business was set up in partnership with central government's Work and Income, supported employment agencies, local tertiary educational providers and business mentors. A business plan was initially developed in partnership with adults on the spectrum and NGOs, and some parents and friends also lent capital and time such. Now representatives of the café and enterprise's staff sit on government taskforces, write submissions, speak at select committees and at conferences to inspire and inform others about their successful model. A newly elected MP found his first job at the centre. Staff and volunteers can train for NZQA qualifications from the local tertiary provider for the work they do. The government is very supportive, with politicians as regular visitors, 
particularly pleased because this successful venture has saved the government a large amount of money in welfare payments and provides a world-leading model of employment support. The staff of this enterprise are in demand for their technical, business, creative, IT and cooking skills, and the centre has become a bit of an incubator.

This model is a theoretical and practical model about how autism policy could develop and blossom into something that is transformative for autistic people. There is already a successful model in the DAL café, Geelong, Victoria, Australia which has been going for about fifteen years. Initially set up by a parent of a young adult with intellectual impairment from an old catering company (Dial a Lunch) it is now a successful café and training establishment (www.dal.org.au). The staff participate in ongoing action research and evaluation, and the young people involved, many who have gone into mainstream food businesses, have addressed conferences and workshops around Australia and overseas about their enterprise. The craft and technological aspect I have mentioned is an adaptation of Thorkil Sonne's Specialisterne (the Specialists), a Danish-based but now international franchise whereby people with autism are employed in IT and electronics development and testing (http://specialisterne.com).

The whole enterprise idea is based on right relationships and respecting lived experience, and nurturing autism skills and entrepreneurship. We have huge untapped potential in New Zealand for the autistic community to fully participate in such a venture, with the appropriate ongoing support.

\section{Conclusions}

This thesis has suggested that autism is a wicked policy problem, characterised by aspects such as differing definitions, problems changing over time, and solutions to one aspect leading to unforeseen consequences elsewhere. Weaving through the maze, or finding good - or any services - depends on the uncontrollable variables of love and luck, phrases that many of my sources and key informants have used. Wicked policy is socially complex, with fragmentation a major problem. How then to tackle this from a policy perspective? The transformative paradigm suggests evaluation of a complex issue 
should start by looking at the issues of human rights, social justice and ethics and this involves partnership with, respect for, and involvement with, those who are the subjects of the research or policies. Michael Kendrick takes this personal ethical approach what he calls right relationship -into a human services context which includes services for people with autism. Synthesising these approaches leads to my thesis that autism policy could be improved and therefore the importance of love and luck becoming less significant, by building right relationships with, and respecting the lived experience of those who live daily with autism. These conditions will hopefully allow both autistic policy entrepreneurs and collective enterprises to emerge and flourish. With appropriate structural support - legislative, policy, economic, social, family and associated allies people with autism will develop their own solutions.

\section{Consideration of research questions}

\section{How can right relationships and lived experience be better incorporated into New Zealand ASD policy?}

This is the main challenge for the thesis and has been answered through examination of the following questions. But first we need to be clear what is meant by right relationships and lived experience in autism policy and that is clarified in Chapter Six. Autism policy has been discussed and clarified throughout this thesis, particularly in Chapter Nine.

I have also developed a model of how a transformative research/relationship building model for autism policy or service development might look (Figure 10) which could be used as evaluation by those involved in policy development or implementation to help them ensure those for whom the policy is for, are fully involved.

\section{What do the concepts of love and luck, right relationships and lived experience mean in the context of the ASD policy process?}

Chapter Six examined what is meant by these terms. Right relationships are to do with ethics, respect, partnership, and treating other people as fully and equally human. Lived experience refers to those on the spectrum who live daily with autism. Other people such as family members and those who live close to people with autism have another 
kind of lived experience - the experience of what it is like to live with or support a person with autism.

\section{Why is ASD a wicked policy problem?}

Chapter Seven summarised characteristics of wicked policies and why autism policy could be considered wicked. Indicators of both wicked and autism policy include social complexity, lack of agreement about the problem, fragmentation and unintended consequences. An aspect of wicked problems is that they lack either clear definition or an end point (Conklin, 2006), which describes many of the projects mainly funded and led through the Ministries of Health and Education in Chapter Nine. The Guideline itself can be seen as an attempt to tame the wicked aspects of autism policy and although it did not provide the solution, the attempt added to knowledge and fuller understanding of the problems.

\section{How might policy ensure that people with ASD and the families move beyond the uncertainties of love and luck to reliable and appropriate supports which give individuals and families more choice and control over their lives?}

This challenge is at the core of my thesis and there are several approaches. Figure 10 illustrates how people with insider or lived experience of the issues may be involved in their resolution. The vision for the future in Chapter Ten signals another approach. The significance of love and luck for supports and services is covered in Chapter Six, and both currently need to be present for good outcomes. My parent informants have unconditional love for their children, but luck often evades them. The death of Casey Albury was an example of a lack of luck, not a lack of love. Luck is sometimes dependent on where one lives or finding those particular people who make a difference. Although many had examples of resilience, several of my informants gave sad examples of parents who struggle to cope without support (like Janine Albury Thompson) and of autistic people who had neither love nor luck. This is an unacceptable and morally unethical situation for a modern democracy such as New Zealand.

In Chapter Nine I provided examples over the last several years of research, pilots or other projects, particularly in the health and education sectors. There have been many attempts to address policy and service issues relating to autism with several pilots 
successfully evaluated. However, for some reason the impetus generally then stalls, the people leave, and the report forgotten. Communication of good work, and sector buy in or ownership has been largely overlooked. Among the tasks required to change this are to involve the autism sector in planning, research, evaluation and monitoring, communicating good work with the community, with other agencies, and even with people in the next office. As mentioned above, we need all the various experts to dig in the social model compost to have the best chance at good outcomes.

Several chapters have given examples where services exist but with little choice and control for those who use them. Therefore there are major systemic issues to address. The government's new model for supporting disabled people (Office of the Associate Minister of Health, 2010) shows an awareness from the top of a need to change. However, this covers Health spending only, and autism consumer pathways indicate that people's lives have extensive networks covering several government agencies. Provision of holistic person-centred coordination around the person with autism and their family (without ring-fencing) is now urgently required.

\section{To what extent does the NZ ASD Guideline meet the criteria of incorporating 'right relationships' and 'lived experience' and what can we learn from the development and implementation of the Guideline?}

Chapter Nine examined the Guideline development and implementation so far. Since the policy opportunity created for ASD by the death of Casey Albury in 1997 there have been significant attempts by government to include family members and the occasional person with autism in the various responses, from providing support to build the capacity of parent-led Autism New Zealand, and including representatives in the various advisory groups that have emerged from the process over the last decade, including in the guideline workstreams. The Implementation Advisory Group set up in 2008 after the publication of the Guideline had as chair a person on the spectrum, who also became the deputy chair of the Living Guideline Group. The Expert Advisory Group which followed had five representatives (out of twenty) on the spectrum, although they were appointed on behalf of the Senior Officials group rather than elected as representatives of the autism community (which should be the process in the future). So far representation has not included those who are non-verbal, or with higher support needs. But as a result of some specific policy champions in the system over the last several 
years, there has been much innovation in attempting to address right relationships and lived experience even if these terms are not specifically used, and sometimes the process has been messy, or not worked as intended. My main criticism is that the work has often been poorly communicated to other parts government (including within Health and Education) and to the larger autism sector, so there is little knowledge or ownership of it so far. However, the stage is now set for policy entrepreneurs from within the sector to now take leadership. The sector also needs to know who the Senior Officials are and have access to their meeting notes and workplans to build confidence in the sector that collaboration and knowledge is being shared at a high level (which does not appear to be happening at the moment).The Guideline also needs to be seen in the context of wicked policy, as mentioned in earlier chapters.

\section{Recommendations for improving autism policy}

As befits the wicked problem that autism is, the future is hard to foretell.

The size, treatment and experiences of the current population of children with autism manifestly differ from those of previous generations. This makes long-term prognoses for individuals with autism virtually impossible (Fombonne, 2003), thereby complicating the development and implementation of related policies and programs. (Baker, 2008, p. 574)

The likelihood is that there will continue to be public funding constraints. Funding for Guideline implementation has almost run out, although there is some new baseline funding, for example for ASD coordination in some DHBs. My recommendations are more systemic than costly.

1. Have a single broad definition of autism and agreed eligibility criteria across government departments, including when children become adults, and collect prevalence data.

Definitions of autism need to be updated and agreed across government departments and prevalence data collected. The DSM $V$ will soon be published and indications are that there will be one simplified autism spectrum. The Ministry of Health needs to 
urgently update eligibility for services through its Disability Support Services. Currently, a diagnosis of intellectual, physical or sensory (hearing or vision) impairment is required and thus a relevant co-morbidity is required for a person with ASD necessitating a further expensive diagnostic process, for example, a cognitive assessment. This criteria goes back to the days when autism was rare and the assumption was that autism also meant intellectual impairment, which is no longer the case. Standardised diagnostic tests for autism are available and improving. Statistics New Zealand does not include a category for autism. Little effective information about autism is available through official Statistics data. Education and MSD have their own eligibility criteria. There is also considerable variation across government agencies about when a child becomes an adult for funding and service purposes, and this needs to be standardised.

2. Set up holistic lifelong person-centred coordination processes and overcome the fragmentation of the current system.

Once an autism diagnosis is suspected there could be a mechanism for an independent coordinator to support the family and the individual, to organise the services and supports they need through the diagnostic, assessment, educational systems (as well as parental support such as grief counselling and parent education). The premise would be 'what constitutes a good life for me as I grow up and grow older', not 'what is available' or 'what do you need?' This coordination could develop into a facilitated circle of support and could at different times include teachers, those involved in supported employment or independent living, and family members. At times of transition or crisis the coordinator could increase the people and agencies represented much like the Strengthening Families or Whānau Ora model. Te Ohomairangi Trust has a contract for such coordination, but only in Auckland, and only for three months post diagnosis. The model I am describing would attack the current fragmentation, and be lifelong, as even high functioning adults with autism need coordinated support at certain times in their life. Moreover, it would likely mean cost savings as potential expensive crises (such as those involving mental health, police or justice) could be averted. 


\section{Address the gaps in the current system}

This is more than addressing the eligibility criteria and the fragmentation of policy development and services. A full stocktake of all research and services, and a gap analysis is required based on an autistic lifetime in New Zealand in all its diversity. Gaps also include lack of autism-specific data such as numbers of children and adults with autism and numbers of teacher aides employed to work with children with autism.

\section{Nurture autism policy entrepreneurs}

Autistic people themselves are the key to improved services and supports for autistic people and training of policy people and service providers, just as Māori, given the opportunity, have developed their own policy responses and models such as te whare tapa whā (the four sides of a house) (Durie, 1998) and whānau ora (Ministry of Health, 2008; Te Puni Kokiri, 2010). Non-autistic allies may emerge, such as those people who promote autism research or training in their workplaces, and they may also require support. It is up to the rest of us (the neurotypical community) to help ensure the conditions and opportunities are right to nuture and encourage policy entrepreneurs and enterprises from within the autism community. In the case of Arie Smith-Voorkamp the autism community itself funded a lawyer with Asperger's to help him. A few autistic people are also involved in training of police, social workers, teachers and others, and such initiatives need to be extended and funded.

\section{Create a clearing house/depository for all autism research and reports and} evaluations of autism programmes and services across government. Continue to encourage, resource, pilot and evaluate new initiatives.

This would be a knowledge bank of autism and would ensure that good work is not lost when the relevant people move on. Chapter Nine mentioned several examples of successful initiatives that were forgotten; this oversight in collecting earlier research and building on successful initiatives is a gap that also needs to be addressed. Reports of successful pilot programmes and evaluations can then be utilised and adapted by new leaders as they address gaps in services. 


\section{Recommendations for future research}

Research needs to be commissioned on how best to address the issues above in theory and practice to ensure consistent and sustainable outcomes. Addressing the wicked aspects is urgent as continued fragmentation will doom any long term success of new initiatives. Future research could contribute to knowledge and understanding of autism in other ways, such as oral history projects by and for autistic people, longitudinal studies following autistic people as they age, or the provision of autism specific research funds through funding agencies such as the Health Research Council.

\section{Contribution to knowledge}

This thesis has made several contributions to knowledge. It has:

- offered a non-medicalised account of autism in New Zealand, one that is based on a social construction approach;

- developed a new conceptual framework for autism policy that takes into account the specific and significant New Zealand contexts of the New Zealand Disability Strategy, and the Treaty of Waitangi;

- provided an analysis of how autism policy is currently developed and implemented in the context of rapidly increasing knowledge and diagnoses;

- traced the development of the policy challenge of autism in New Zealand - up until the first steps in implementation of the NZ autism spectrum disorder guideline - through its local and international and historical contexts, and against the background of international disability activism and disability studies;

- examined autism as a 'wicked' policy and looked at how this could be addressed;

- thought through ways of using such concepts as lived experience and right relationships in the development and implementation of policy, and proposed a new self-reflective, inclusive, policy model (building on what has already been achieved in the NZ ASD guideline);

- validated the use of grey literature for significant academic research;

- utilised social media including Facebook and Twitter as primary sources for authentic autism research, as well as commentary on autism blogs and websites; 
- $\quad$ suggested that the Whānau Ora tool could be adapted for ASD policy development, implementation and evaluation

- $\quad$ suggested that developing and nurturing autism policy entrepreneurs from within the autism community should be actively encouraged.

\section{Final comment: autism policy leadership}

I would like to finish with a major landmark in New Zealand ASD policy. It is the employment by Autism New Zealand of a researcher and advisor who himself has autism. This development would not have been envisaged by the parents who made the tentative steps towards their own autism parents' committee 40 years ago. Significantly, for this project the new employee is Matt Frost whose analysis of autism support being dependent on 'love and luck' provided the name for my thesis. Matt represents a new generation of people with autism who have expectations of independent lives, employment and of making a contribution to their communities. They are the children of an environment providing compulsory schooling in their own communities, and decreasing tolerance for bullying. They will not be incarcerated in institutions nor forced to work in sheltered workshops because of who they are, not what they have done. They are the children of the Disability Strategy and the UN Convention; the embodiment of 'nothing about us without us'. A new project is underway to train autistic teenagers in leadership skills. Matt and his peers are the authentic autism advocates, mentors and policy entrepreneurs, and the transformative policy future is theirs. 


\section{References}

Abrahamson, S. J., Enticott, P. G., \& Tonge, B. J. (2010). High-functioning pervasive developmental disorders in adults. Medical Journal of Australia, 192(1), 44-48.

Allen, A. (2009). Treating autism as if vaccines caused it: the treatment may be dead but the theory lives on, 1 April 2009. Retrieved 3/04/09, from www.slate.com

American Psychiatric Association. (2000). Diagnostic and statistical manual of mental disorders (DSM IV) Text revision. Washington DC: American Psychiatric Assocation Press.

Anderson, A., Birkin, C., Seymour, F., \& Moore, D. (2006). EarlyBird evaluation: final report. Auckland: Auckland UniServices Ltd.

Anonymous. (2007). Community in fear of violent autistic boy. Dominion Post, 24 December 2007.

Anonymous. (2009). Autism and schizophrenia could be polar opposites. New Scientist, 5 December 2009, 18.

Anonymous. (2010). Mum calls for more autism awareness. Dominion Post, 15 October 2010.

Anonymous. (2011). Autism Bill defeated at stage 1. Law Society of Scotland: the journal on line, 13 January 2011, from http://www.journalonline.co.uk/News/1009190.aspx

APAC09. (2009). Asia Pacfic Autism Conference. Connecting today-inspiring tomorrow. Sydney.

Ariel, C., \& Naseef, R. (Eds.). (2006). Voices from the spectrum: parents, grandparents, siblings, people with autism and professionals share their wisdom. London: Jessica Kingsley Publishers.

Armstrong, H., \& Laurs, R. (2008). Blood on the coal: the origins and future of New Zealand's Accident Compensation scheme (2nd ed.). Wellington: Trade Union History Project.

Arnold, L. (2009). The week that was in autism. New Republic blogspot, 28 November 2009.

Association of Non-Governmental Organisations of Aotearoa. (2009). Good intentions: an assessment of the Statement of Government Intentions for an Improved Community-Government Relationship. Wellington.

Attwood, T. (1998). Asperger's syndrome : a guide for parents and professionals. London ; Philadelphia: Jessica Kingsley Publishers. 
Attwood, T. (2007). The complete guide to Asperger's syndrome. London: Jessica Kingsley Publishers.

Attwood, T. (2009). Wellington seminar. 21 September 2009.Wellington, Autism New Zealand.

Australian Government Department of Health and Aging. (2008). A review of the research to identify the most effective models of practice in early intervention for children with autism spectrum disorders. Canberra.

Australian Public Service Commission. (2007). Tackling wicked problems: a public policy perspective. Canberra: Australian Public Service Commission.

Autism New Zealand. (2003). SPELL framework for intervention: course evaluation report. Christchurch.

Autism New Zealand. (2005). Draft strategic plan. Christchurch: Autism NZ Inc.

Autism New Zealand. (2011a). Are we back in the 18th century, ministers? Scoop Independent News, 9 March 2011.

Autism New Zealand. (2011b). Respite care: the results of our survey. Thinking differently: the quarterly newsletter of Autism New Zealand, March 2011.

Autism Services Interdepartmental Working Group. (1999). Implementation plan. Wellington: Ministry of Health.

Autism Spectrum Disorder Advisory Group. (2010). Minutes of meeting 1 December 2010. Wellington: Ministries of Health and Education.

Autistic Association of New Zealand. (2001). The needs and gaps in services for families and individuals with an autistic disorder. Christchurch: Autistic Association of NZ, Inc.

Autistic Childrens' Association of South Australia Inc. (1967). Autism: cure tomorrow, care today: proceedings of a conference on the autistic child held at Adelaide, South Australia, 16-18 August 1967, Adelaide.

Autistic Self Advocacy Network. (2009). Sign our petition: tell Dr Tony Attwoood to end the hate: autistic people deserve equality in family law and relationships. (19 April 2009),

Autistic Self Advocacy Network. (2011). About autism. Retrieved 22 January 2011, from

http://www.autisticadvocacy.org/modules/smartsection/category.php?categoryid $=19 \% 20 \% 20$ Online

Baird, G., Siminoff, E., Pickles, A., \& Chandler, S. (2006). Prevalence of disorders of the Autism Spectrum in a population cohort of children in South Thames: the Special Needs and Autism Project (SNAP). The Lancet, 368(9531). 
Baker, D. L. (2004). Public policy and the shaping of disability: incidence growth in educational autism. Education Policy Analysis Archives, 12(11).

Baker, D. L. (2006a). Autism as public policy. In D. Pothier \& R. Devlin (Eds.), Critical disability theory (pp. 177-194). Vancouver: University of British Colombia Press.

Baker, D. L. (2006b). Neurodiversity, neurological disability and the public sector: notes on the autism spectrum. Disability \& Society, 21(1), 15-29.

Baker, D. L. (2007). Defining autism in Canada: unfolding the public aspects of neurological disability. The Social Science Journal, 44(4), 687-697.

Baker, D. L. (2008). Issue definition in rights-based policy focused on the experiences of individuals with disabilities: an examination of Canadian parliamentary discourse. Disability \& Society, 23(6), 571-583.

Baker, D. L. (2009). Cause and cure: tension between disability policy agendas in Canada and the United States. Paper presented at the Western Political Science Association Conference.

Baker, D. L. (2011). The politics of neurodiversity: why public policy matters. New York: Lynne Rienner Publishers.

Baker, D. L., \& Steuernagel, T. (2009). Comparative policy entrepreneurship: the case of autism-related policy in North America. Journal of Comparative Policy Analysis: Research and Practice, 11(2), 233-248.

Ballard, K. (Ed.). (1994). Disability, family, whanau and society. Palmerston North: Dunmore.

Baron-Cohen, S. (1997). Mindblindness: an essay on autism and theory of mind (Rev ed ed.). Boston: MIT Press.

Baron-Cohen, S. (2004). The essential difference. London: Penguin.

Baron-Cohen, S. (2009). The distorting lens. New Scientist, 26-27.

Baron-Cohen, S., Leslie, A. M., \& Frith, U. (1985). Does the autistic child have a "theory of mind"? Cognition, 21, 37-46.

Beatson, P. (2004). The disability revolution in New Zealand : a social model (2nd ed.). Palmerston North, N.Z.: Massey University.

Belich, J. (1996). Making peoples: a history of the New Zealanders from Polynesian settlement to the end of the nineteenth century. Auckland: Allen Lane Penguin.

Belich, J. (2001). Paradise reforged: a history of the New Zealanders from the beginning of the twentieth century Auckland: Allen Lane Penguin.

Bell, J. (2009). Doing your research project. Maidenhead, England: Open University Press. 
Bennett and Bijoux Limited. (2009). ASD-specific behavioural support services: feasibility study, executive summary. Auckland.

Bettelheim, B. (1967). The empty fortress: infantile autism and the birth of the self. New York: Free Press.

Bevan-Brown, J. (2004). Maori perspectives of Autism Spectrum Disorders. Wellington: Ministry of Education.

Bevan-Brown, J. (2009). Please include my child with ASD. Paper presented at the Making Inclusive Education Happen Conference. Wellington.

Bierens, F. (2009). A spectrum of light: inspirational interviews with families affected by autism. London: Jessica Kingsley Publishers.

Biever, C. (2009). Savant skills may be widespread in people with autism. New Scientist, 12(15).

Biklen, D. (2005). Autism and the myth of the person alone. New York: New York University Press.

Birch, J. (2003). Congratulations! It's Asperger syndrome. London: Jessica Kingsley.

Birkin, C., Anderson, A., Moore, D., \& Seymour, F. (2003a). Literature review: EarlyBird project. Auckland: UniServices.

Birkin, C., Anderson, A., Moore, D., \& Seymour, F. (2003b). NAS EarlyBird programme: uptake study. Auckland: UniServices.

Blackman, L. (2001). Lucy's story: autism and other adventures. London: Jessica Kingsley.

Bonardi, A. (2009). The balance between choice and control: risk management in New Zealand intellectual disability services. Wellington: Fulbright New Zealand.

Bond, J. (2005). Special education strategic directions. Wellington: Ministry of Education Special Education.

Booth, T., \& Ainscow, M. (2002). Index for Inclusion: developing learning and participation in schools (2nd ed.). Bristol: Centre for Studies on Inclusive Education.

Boston, J., Callister, P., \& Wolf, A. (2006). The policy implications of diversity. Wellington: Institute of Policy Studies, Victoria University of Wellington.

Boulton, A. (2005). Provision at the interface: the Mãori mental health contracting experience. Unpublished doctoral thesis. Massey University, Palmerston North.

Boundy, K. (2008). 'Are you sure, sweetheart, that you want to be well?': an exploration of the neurodiversity movement. Radical Psychology, 17. 
Braun, V., \& Clarke, V. (2006). Using thematic analysis in psychology. Qualitative Research in Psychology 2006;3, 77-101.

Bray, A., \& Mirfin-Veitch, B. (2003). Disabled people and research: putting families first. In R. Munford \& J. Sanders (Eds.), Making a difference in families (pp. 7492). Sydney: Allen \& Unwin.

Bray, A., Mirfin-Veitch, B., Sharp, S., Stewart, C., Kelly, B., Cleland, G., et al. (2006). Evaluation of intersectoral disability Needs Assessment and Service Coordination trials. Dunedin: Donald Beasley Institute, Creative Solutions, University of Canterbury, Grace Systems.

Brookes, B. (1993). Frederic Truby King 1858 - 1938 Dictionary of New Zealand biography (Vol. 2). Wellington: Department of Internal Affairs.

Brown, G., \& Vance, A. (2011). Man wrongly jailed for rape gets Govt payout. www.stuff.co.nz, 14 April 2011.

Brown, R. (2010). Hard News: still crazy after all these years. Public Address, 29 March 2010.

Bruce, M. (1960s-2010). Collection of archival material relating to the development of the Autistic Association (later Autism New Zealand). Raumati.

Bruce, M. (2010). Interview about the NZ ASD guideline by Hilary Stace. Wellington.

Buckley, S., \& Maxwell, G. (2007). Respectful schools:restorative practices in education, a summary report. Wellington: Office of the Children's Commissioner/ Institute of Policy Studies, Victoria University of Wellington.

Burgon, J., \& Stace, H. (2007). Working with ASD students in secondary schools: a research project. Greater Wellington Special Education Reference Group, 30 May 2007: Lower Hutt.

Burke, J. (2009). Children's perception of accessible playgrounds. Ballarat: School of Education, University of Ballarat.

Burns, C. (1959). The mental deficiency services: an analysis of existing policy and the community's requirements: a report. Wellington: British Medical Association. New Zealand Branch. Mental Deficiency Sub-committee,.

Burroughs, A. (2006). Running with scissors: a memoir. New York: St Martins Press.

Busch, G., \& Johnsen, H. (2008). The man with no arms and other stories. Christchurch: University of Canterbury Press.

Byrnes, G. (Ed.). (2009). The new Oxford History of New Zealand. Melbourne: Oxford University Press.

Capital Support. (2004). Minutes from the meet and greet ASD advisory panel meeting Tuesday 25 May. Porirua: Capital Support. 
Carpinter, A., Irwin, C., \& Rogers, G. (2000). Just surviving: talking with parents of children with very high disability support needs. Wellington: Ministry of Health.

CCS. (2007). Submission to the Ministries of Education and Health on the Draft Evidence-Based Guideline for Autism Spectrum Disorder. Wellington: CCS.

Chapple, W. A. (1903). The fertility of the unfit. Melbourne, Christchurch: Whitcombe and Tombs.

Charlton, J. I. (1998). Nothing about us without us: disability oppression and empowerment. Berkeley and Los Angeles: University of California Press.

Clarkson, D. (2011). Police drop charges against 'looter' with autism. . Christchurch Court News, 22 August 2011.

Cohen, D. (2007). A perfect world: a father's quest to unriddle the mysteries of autism. Auckland: Random House.

Committee of Inquiry into Allegations Concerning the Treatment of Cervical Cancer at National Women's Hospital and into Other Related Matters. (1988). Report. Auckland: The Committee.

Cone, D. H. (2010). Share and shares alike: how having Asperger's can help you make a stock-market killing. New Zealand Listener, 20-26 March 2010, 10.

Confidential Listening and Assistance Service. (2009). Confidential Listening and Assistance Service: an opportunity to be heard. from http://www.listening.govt.nz/web/RCCMS cla.nsf/weblivehome/\$first?open

Conklin, J. (2006). Dialogue mapping: building shared understanding of wicked problems. New York: Wiley.

Connors, C., \& Stalker, K. (2007). Children's experiences of disability: pointers to a social model of childhood disability. Disability \& Society, 22(1), 19-33.

Constantino, J. N., \& Todd, R. D. (2003). Autistic traits in the general population: a twin study. Arch Gen Psychiatry, 60(5), 524-530.

Consultative Committee on Intellectually Handicapped Children. (1953). Report of the Consultative Committee set up by the Hon. the Minister of Education in August 1951. Wellington: Department of Education.

Convention Coalition. (2010). Disability rights in Aotearoa New Zealand: a report on the human rights of disabled people in Aotearoa New Zealand. Wellington: Convention Coalition for Disability Rights Promotion International.

Corker, M., \& French, S. (Eds.). (1999). Disability discourse. Buckingham: Open University Press.

Costley, C., Elliott, G., \& Gibbs, P. (2010). Doing work based research: Approaches to enquiry for insider-researchers. London: Sage. 
Creswell, J. W. (2003). Research design : qualitative, quantitative, and mixed methods approaches (2nd ed.). Thousand Oaks: Sage Publications.

Cribb, J. (2006). Agents or stewards? Contracting with voluntary organisations. Policy Quarterly, 2(2), 11-17.

Cullen, M. (2007). Correspondence between Hon Dr Michael Cullen, Attorney General and Hilary Stace about official apology for institutionalisation. Wellington.

Cumming, J., \& Stace, H. (2006). Contracting between government and the voluntary sector: where to from here? Policy Quarterly, 2(4), 13-20.

Cunliffe, D. (2008). Autism Spectrum Disorder Guideline launch: speech to launch Autism Specrum Disorder Guideline, Parliament Buildings, Wellington, 2 April 2008. Retrieved from www.beehive.govt.nz/speech/autism+spectrum+disorder+guideline+launch

Curry, D. (1998). Autism services in New Zealand: a report by the interdepartmental 'Autism Services project' team. Wellington: Ministry of Health.

Curzon, J. (2008). The New Zealand Autism Spectrum Disorder Guideline. Paper presented at the Autism New Zealand conference. Christchurch.

Curzon, J., \& Hearn, A. (2008). New Zealand Autism Spectrum Disorder Guideline. Paper presented at the New Zealand Association for the Study of Intellectual Disability conference. Wellington.

Dalziel, L. (2000). First steps to implement special education review. (11 October 2000). Retrieved from www.beehive.govt.nz/release/first+steps+implement+special+education+review

Darwin, C. (1859). On the origin of species by means of natural selection; or the preservation of favoured races in the struggle for life. London: John Murray.

Davis, J., \& Watson, N. (2001). Where are the children's experiences? Analaysing social and cultural exclusion in 'special' and 'mainstream' schools. Disability \& Society, 16(5), 671-687.

Davis, K. (2009). Forrest Gump's principal could be NZ's Minister of Education, Red Alert. Wellington: New Zealand Labour Party.

Debbault, D. (2002). Autism, advocates and law enforcement professionals. London: Jessica Kingsley Publishers.

Deer, B. (2009). MMR doctor Andrew Wakefield fixed data on autism. The Sunday Times/Timesonline. Retrieved from http://www.timesonline.co.uk/tol/life_and_style/health/article5683671.ece

Deer, B. (2011a). How the case against the MMR vaccine was fixed. BMJ, 342(5 January 2011). 
Deer, B. (2011b). How the vaccine crisis was meant to make money. BMJ, 342(11 January 2011).

Deer, B. (2011c). The Lancet's two days to bury bad news. BMJ, 342(18 January 2011).

Delahunty, C. (2010). Establishing a Disability Commissioner. Retrieved 4 November 2010, 28 October 2010, from http://blog.greens.org.nz/2010/10/28/establishinga-disability-commissioner/

Denzin, N., \& Lincoln, Y. (Eds.). (2005). Handbook of qualitative research (3rd ed.). Thousand Oak: Sage.

Department of Internal Affairs. (2007). Te Aiotanga: Report of the Confidential Forum for former in-patients of psychiatric hospitals. Wellington: Department of Internal Affairs.

Department of Statistics. (1980). New Zealand official yearbook. Wellington: Department of Statistics.

Duncan, G. (2004). Society and politics: New Zealand social policy. Auckland: Pearson Education New Zealand.

Durie, M. (1998). Whaiora : Maori health development (2nd ed.). Auckland, N.Z.: Oxford University Press.

Dyson, R. (2007). NZ wins Roosevelt International Disability Award 3 December 2007. Wellington: Minister of Disability Issues/ Beehive Press Release.

Education Review Office. (2004). Evaluation of the Resource Teacher: Learning and Behaviour Service. Wellington: ERO.

Education Review Office. (2009). Resource Teachers: Learning and Behaviour: an evaluation of cluster management. Wellington: ERO.

English, B. (2007). Personal communication with author on experience as Minister of Health after the death of Casey Albury. Wellington.

Evans, S. E. (2004). Forgotten crimes: the holocaust and people with disabilities. Chicago: Ivan R Dee.

Fairburn, M. (1990). The ideal society and its enemies: foundations of modern New Zealand society, 1850-1900. Auckland: Auckland University Press.

Feinberg, E., \& Vacca, J. (2000). The drama and trauma of creating policies on autism: critical issues to consider in the new millenium. Focus on Autism and Other Developmental Disabilities, 15(3), 130-138.

Field, M. (2009). TelstraClear employs NZ hacker. stuff.co.nz, 25 March 2009.

Fisher, J. T. (2008). No search, no subject? Autism and the American conversion narrative. In M. Osteen (Ed.), Autism and Representation. New York: Routledge. 
Fitzgerald, M. (2005). The genius of artistic creativity: Asperger's syndrome and the arts. London Jessica Kingsley Press.

Fitzgerald, M. (2010). Young, violent, and dangerous to know: Nova Science Publishers.

Fitzgerald, M., \& O'Brien, B. (2007). Genius genes: how Asperger talents changed the world. Shawnee Mission, Kansas: Autism Asperger Publishing Company.

Fleming, P. (1981). Eugenics in New Zealand, 1900-1940. . Unpublished MA, Massey University, Palmerston North.

Fombonne, E. (2003). Modern views of autism. Canadian Journal of Psychiatry, 48(8), 503-505.

Foucault, M. (1977). Discipline and punish: the birth of the prison (A. Sheridan, Trans.). London: Allen Lane.

Foucault, M. (1980). Two lectures In C. Gordon (Ed.), Power/knowledge, selected interviews and other writings 1972-1977. New York: Pantheon.

Frame, J. (1989). An autobiography. Auckland: Century Hutchinson.

Frawley, P. (2007). 'My knowledge is not as good as other people's'. People with an intellectual disability having an equal and meaningful voice in government advisory forums. Unpublished $\mathrm{PhD}$, LaTrobe University, Bundoora, Victoria.

Frawley, P., \& Bigby, C. (2011). Inclusion in political and public life: the experiences of people with intellectual disability on government advisory bodies in Australia. Journal of Intellectual and Developmental Disability, 36(1), 27-38.

Freire, P. (1972). Pedagogy of the oppressed. New York: Penguin.

Frith, U. (2003). Autism: explaining the enigma (2nd ed.). Malden, USA: Blackwell.

Frith, U. (Ed.). (1991). Autism and Asperger syndrome. Cambridge: Cambridge University Press.

Frost, M. (2007a). New Zealand disability history: a personal and political journey. Paper presented at the New Zealand Historical Association Conference.

Frost, M. (2007b). The United Nations Convention on the Rights of Persons with Disabilities: a cause for celebration? Human Rights Research/Centre for Public Law/Victoria University of Wellington, 5th ed.

Frost, M., \& Gourley, M. (2010). One in five. Wellington: Radio New Zealand, 12 September.

Frozen Funds Charitable Trust. (2009). from http://www.publictrust.co.nz/grants-andscholarships/how-do-i-find-one/grants/frozen-funds-charitable-trust.html 
Ganz, M. L. (2007). The lifetime distribution of the incremental societal costs of autism. Archives of Pediatrics and Adolescent Medicine, 161(4).

Gates, S. (2008). The impact of deinstitutionalisation on the staff of the Kimberley Centre. Dunedin: Donald Beasley Institute.

General Medical Council. Fitness to Practise Panel. (2010). Fitness to practise panel hearing 28 January 2010. London: General Medical Council.

Gibson, P. (2010). Updates on actions, parking letter, autism services for children, equipment changes. Wellington: Disability Support Advisory Committee, Capital \& Coast District Health Board.

Ginsberg, P., \& Mertens, D. M. (Eds.). (2008). The handbook of social research ethics. Thousand Oaks: Sage.

Goggin, G., \& Newell, C. (2005). Disability in Australia: exposing a social apartheid. Sydney: University od New South Wales Press Ltd.

Goldberg, A. B., \& Putrino, L. (2009). Teen locked in autistic body finds inner voice. $A B C$ News. Retrieved from http://abcnews.go.com/print?id=8258204

Goodley, D. (2011). Disability studies: an interdisciplinary introduction. London: Sage.

Graham, P. (1993). Obituary: Dr Mildred Creak. The Independent, 6 November 1993.

Grandin, T. (2006). Thinking in pictures: my life with autism (2nd ed.). New York: Vintage.

Grandin, T. (2008). The way I see it. Texas: Future Horizons.

Grandin, T., \& Johnson, C. (2009). Animals make us human: creating the best life for animals. Orlando: Houghton Mifflin Harcourt Publishing Company.

Grant, J. (2007). Community participation and quality of life for ex-Templeton Centre residents: policy, theory and practice. An opportunity for NGO collaboration. Social Policy Journal of New Zealand (30), 79-93.

Grant, T. (2010). IHC submission. Implementing the United Nations Convention on the Rights of Persons with Disabilities: draft government report and focus areas. Wellington: IHC.

Gray, D. E. (1994). Coping with autism: stresses and strategies. Sociology of Health \& Illness, 16(3), 275-300.

Gray, D. E. (2001). Accommodation, resistance and transcendence: three narratives of autism. Social Science and Medicine, 53, 1247-1257.

Gray, D. E. (2002). Ten years on: a longitudinal study of families of chidren with autism. Journal of Intellectual and Development Disability, 27(3), 215-222. 
Green, V. A., Pituch, K. A., Itchon, J., Choi, A., O'Reilly, M., \& Sigafoos, J. (2006). Internet survey of treatments used by parents of children with autism. Research in Developmental Disabilities, 27(1), 70-84.

Grinker, R. R. (2007). Unstrange minds: remapping the world of autism. New York: Basic Books.

Grinker, R. R. (2010). Disorder out of chaos. New York Times, 10 February 2010.

Guba, E. G., \& Lincoln, Y. S. (1994). Competing paradigms in qualitative research. In N. K. a. L. Denzin, Y.S. (Ed.), The handbook of qualitative research (pp. 105117). Thousand Oaks: Sage Publications.

Guerin, A. P. (2008). It's the small things that count: making sense of working in a partnership to support the inclusion of a child with autism spectrum disorder. Unpublished Master of Teaching and Learning thesis, University of Canterbury, Christchurch.

Haddon, M. (2003). The curious incident of the dog in the night-time. Oxford: David Fickling Books.

Hall, L. (2004). Confidentially speaking - an ethical dilemma for interviewers. In M. Hutching \& A. Green (Eds.), Oral history in New Zealand. Auckland: Oxford University Press.

Happe, F. (2003). Theory of mind and the self. Annals of the New York Academy of Sciences, 1001, 134-144.

Happe, F., \& Frith, U. (2009). The beautiful otherness of the autistic mind.

Philosophical Transactions of the Royal Society.B: Biolological Sciences, 364, 1345-1350.

Harrison, H. (2008). NASC Document Review Report - DRAFT. Wellington: Ministry of Health.

Health Funding Authority. (2000). Guidelines for needs assessment and service coordination agencies working with people with autism and their families/whanau. Wellington.

Health Outcomes International. (2008). The evidence based guideline for Autism Spectrum Disorder: impact analysis/technical report. Adelaide: NZ Ministries of Health and Education.

Hill, M. (2005). Madness in the early twentieth-century New Zealand: the patient case records of Porirua hospital, 1909-15. Unpublished Masters, Victoria University of Wellington, Wellington.

Hornby, N. (1998). About a boy. London: Gollancz.

Howlin, P. (2005). The effectiveness of interventions for children with autism. Journal of Neural Transmission, Supplement 69(101-119). 
Human Rights Commission. (2010). Resounding victory for caregiver parents in landmark case. Auckland: Human Rights Commission.

Hunt, P. (1981). Settling accounts with parasite people. Disability Challenge:UPIAS, 1.

Hunt, R. (1988). People with disabilities. Report of the Royal Commission on Social Policy; April Report (Vol. IV Social Perspectives, pp. 767-804). Wellington: New Zealand Government.

Huws, J. C., \& Jones, R. S. P. (2010). 'They just seem to live their lives in their own little world': lay perceptions of autism. Disability \& Society, 25(3), 331-344.

IHC. (2009). Update on IHC's education complaint to Human Rights Commission.

Ihimaera, W. (2009). The Trowenna Sea. Auckland: Penguin.

Institute of Policy Studies. (2008). Better connected services for Kiwis: a discussion document for managers and front-line staff on better joining up the horizontal and the vertical. Wellington: Victoria University of Wellington.

Inter-Party Working Group. (2010). Step change: success the only option.Report of the Inter-Party Working Group for School Choice. Wellington: Parliament.

Interagency Autism Coordinating Committee. (2007). Department of Health and Human Services National Institutes of Health Interagency Autism Coordinating Committee minutes November 30, 2007 Washington.

Internet Movie Database. (1971). Harold and Maude. Retrieved 14 November 2010, from http://www.imdb.com/title/tt0067185/

Internet Movie Database. (1979). Being there. Retrieved 14 November 2010, from http://www.imdb.com/title/tt0078841/

Internet Movie Database. (1988). Rain man. from http://www.imdb.com/title/tt0095953/

Internet Movie Database. (1993). What's eating Gilbert Grape? Retrieved 14 November 2010, from http://www.imdb.com/title/tt0108550/

Internet Movie Database. (1994). Forrest Gump. from http://www.imdb.com/title/tt0109830/

Internet Movie Database. (1996). Shine. Retrieved 15 November 2010, from http://www.imdb.com/title/tt0117631/

Internet Movie Database. (2001). I am Sam. Retrieved 15 November 2010, from http://www.imdb.com/title/tt0277027/

Internet Movie Database. (2002). About a boy. Retrieved 15 November 2010, from http://www.imdb.com/title/tt0276751/

Internet Movie Database. (2005). Mozart and the whale. Retrieved 15 November 2010, from http://www.imdb.com/title/tt0392465/ 
Internet Movie Database. (2006). Snow Cake. Retrieved 14 November 2010, from http://www.imdb.com/title/tt0448124/

Internet Movie Database. (2007a). Eagle vs shark. Retrieved 15 November 2010, from http://www.imdb.com/title/tt0494222/

Internet Movie Database. (2007b). Lars and the real girl. Retrieved 14 November 2010, from http://www.imdb.com/title/tt0805564/

Internet Movie Database. (2007-). The big bang theory. Retrieved 15 November 2010, from http://www.imdb.com/title/tt0898266/

Internet Movie Database. (2008). The black balloon. Retrieved 14 November 2010, from http://www.imdb.com/title/tt0865297/

Internet Movie Database. (2009). Adam. Retrieved 15 November 2010, from http://www.imdb.com/title/tt1185836/

Internet Movie Database. (2010). Temple Grandin. Retrieved 15 November 2010, from http://www.imdb.com/title/tt1278469/

Jarbrink, K., Fombonne, E., \& Knapp, M. (2003). Measuring the parental, service and cost impacts of children with Autistic Spectrum Disorder: a pilot study Journal of Autism and Developmental Disorders, 33(4), 395-402.

Jarbrink, K., \& Knapp, M. (2001). The economic impact of autism in Britain. Autism, 5, 7-22.

Kalb, C. (2009). Erasing autism. Newsweek, 18 May 2009.

Kanner, L. (1943). Autistic disturbances of affective contact. Nervous Child, 2, $217-$ 250.

Kelly, B. (2005). 'Chocolate ... makes you autism': impairment, disability and childhood identities. Disability \& Society, 20(3), 261-275.

Kendrick, M. (2000). Right relationship. Queensland Advocacy Incorporated Newsletter, Part A and B, March and July 2000.

Kendrick, M. (2003). The role of personal integrity in upholding 'right relationship' in organisations. CRUcial Times(28), 4-5.

Kendrick, M. (2008a). The key ingredients of optimal partnerships between service users and families and their possible human service system partners. Interaction, $3(1)$.

Kendrick, M. (2008b). The principle of 'right relationship' as a a guide for ethical partnership. Paper presented at the Trusting Partnerships Conference. Rotorua.

Kendrick, M. (2009). Letting in the light: reflections on leadership, ethics and human services. Brisbane: CRU Publications. 
Kerr, A., \& Shakespeare, T. (2002). Genetic politics: from eugenics to genome. Cheltenham: New Clarion Press.

King, A. (2000). King gives cheque to university for autism [press release from the Minister for Health]. 20 December 2000.

King, M. (2003). The Penguin history of New Zealand. Auckland: Penguin.

Kingdon, J. W. (1995). Agendas, alternatives and public policies (2nd ed.). New York: Longman.

Kirby, D. (2011). The autism-vaccine debate: why it won't go away. The Huffington Post, 11 February 2011.

Kochmeister, S. J. (2009). The Voices and Choices of Autism: Learning to exist with hope and joy in a world that's not always your 'friend', 1(1 and 2).

Kudlick, C. (2006). A history profession for every body. Journal of Women's History, 18(1), 163-167.

Kuhn, R., \& Cahn, C. H. (2004). Eugen Bleuler's concepts of psychopathology. History of Psychiatry, 15, 361.

Kuhn, T. (1970). The structure of scientific revolutions (2nd ed.). Chicago: University of Chicago Press.

Lane, H., Hoffmeister, R., \& Bahan, B. (1996). A journey into the Deaf-world. San Deigo: DawnSign Press.

Lawson, W. (2000). Life behind glass: a personal account of Autism Spectrum Disorder. London: Jessica Kingsley Publishers.

Lawson, W. (2008). Concepts of normality: the autistic and typical spectrum. London: Jessica Kingsley Press.

Lincoln, Y., \& Guba, E. (2000). Paradigmatic controversies, contradictions, and emerging confluences. In N. Denzin \& Y. Lincoln (Eds.), Handbook of qualitative research (2nd ed., pp. 163-189). Thousand Oaks, CA: Sage.

Lister, R. (1997). Citizenship: feminist perspectives. New York: New York University Press.

Little, L. (2003). Implementation of Autism Services in New Zealand. Unpublished MAPP580 Reseach project, Victoria University, Wellington.

Liu, K.-Y., King, M., \& Bearman, P. S. (2010). Social influence and the autism epidemic. American Journal of Sociology, 115(5), 1387-1434.

Lord, C., \& Bishop, S.L. (2010) Autism spectrum disorders: diagnosis, prevalence, and services for children and families. Social Policy Report, 24(2),1-27 
Lovaas, O. I. (1987). Behavioral treatment and normal educational and intellectual functioning in young autistic children. Journal of Consulting and Clinical Psychology, 55(1), 3-9.

Lyons, V., \& Fitzgerald, M. (2005). Asperger Syndrome: a gift or a curse? New York: Nova Science Publishers.

MacArthur, J. (2009). Learning better together: working towards inclusive education in New Zealand schools Wellington: IHC.

MacArthur, J., Sharp, S., Gaffney, M., \& Kelly, B. (2007). Does it matter that my body is different? Disabled children, impairment, disability and identity. Childrenz Issues, 11(2).

MacArthur, J., Sharp, S., Kelly, B., \& Gaffney, M. (2007). Disabled children negotiating school life: agency, difference and teaching practice. International Journal of Children's Rights, 15, 99-120.

McDermott, S., Williams, K., Ridley, G., Glasson, E., \& Wray, J. (2007). The prevalence of autism in Australia: can it be established from existing data? Canberra: Australian Advisory Board of Autism Spectrum Disorders.

MacMorran, G. (1900). Some schools and schoolmasters of early Wellington: with an account of the provision made for education in later times. Wellington: $\mathrm{S} \& \mathrm{~W}$ MacKay.

McNeil, D. G. (2009). Autism rates are higher for U.S.-born Somali children in Minneapolis. New York Times, 1 April 2009.

McNeil, D. G. (2011). Autism in Somali children will be investigated. New York Times, 25 January 2011.

Maenner, M. J., \& Durkin, M. S. (2010). Trends in the prevalence of autism on the basis of special education data. Paediatrics, 126(5), e1018-e1025.

Managh, C. (2005). A special sort of ordinary life. Dominion Post, 20 June 2005, A10

Mandell, D. S., Wiggins, L. D., Carpenter, L. A., Daniels, J., DiGuiseppi, C., Durkin, M. S., et al. (2009). Racial/ethnic disparities in the identification of children with Autism Spectrum Disorders. American Journal of Public Health, 99(3), 493498.

Marshall, M. (22 September 2010). Ministry of Health National Services Purchasing.

Meekosha, H., \& Shuttleworth, R. (2009). What's so critical about critical disability studies?'. Australian Journal of Human Rights, 15(1), 47-75.

Mercer, G. (2002). Emancipatory disability research. In C. Barnes, M. Oliver \& C. Barton (Eds.), Disability studies today. Cambridge: Polity.

Mertens, D. M. (2007). Transformative paradigm: mixed methods and social justice. Journal of Mixed Methods Research, 1(3), 212-225. 
Mertens, D. M. (2009). Transformative research and evaluation. New York: The Guilford Press.

Mertens, D. M., Bledsloe, K., Sullivan, M., \& Wilson, A. (2010). Utilization of mixed methods for transformative purposes. In A. Tashakkori \& C. Teddlie (Eds.), Sage handbook of mixed methods in social \& behavioral research (2nd ed ed.). Thousand Oaks: Sage.

Mertens, D. M., Sullivan, M., \& Stace, H. (2011). Disability communities: transformative research for social justice. In N. K. Denzin \& Y. S. Lincoln (Eds.), The Sage handbook of qualitative research (4th ed.). Thousand Oaks: Sage.

Millen, J. (1999). Breaking barriers : IHC's first 50 years. Wellington, N.Z.: IHC New Zealand.

Miller, E. J., \& Gwynne, G. V. (1972). A life apart. London: Tavistock.

Miller, J. K. (2003). Women from another planet? Our lives in the universe of autism. Bloomington: Authorhouse.

Milner, P. (2008). An examination of the outcome of the resettlement of residents from the Kimberley Centre. Dunedin: Donald Beasley Institute.

Ministerial Review Group. (2009). Meeting the challenge: enhancing sustainability and the patient and consumer experience within the current legislative framework for health and disability services in New Zealand. Wellington: Minster of Health.

Ministries of Health and Education. (2006). Draft evidence-based guideline for Autism Spectrum Disorder. Wellington: Ministry of Health.

Ministries of Health and Education. (2008). New Zealand Autism Spectrum Disorder Guideline. Wellington: Ministry of Health.

Ministry of Education. (2000). Autism Spectrum Disorders: a resource for teachers. Wellington: Ministry of Education.

Ministry of Education. (2005). Special education action plan. Wellington: Ministry of Education.

Ministry of Education. (2006). Let's Talk Special Education Newletter, July. Wellington: Ministry of Education.

Ministry of Education. (2008). Kairaranga. 9(Special edition).

Ministry of Education. (2010a). Review of special education 2010: discussion document. Wellington.

Ministry of Education. (2010b). Review of special education: public response summary. Wellington. 
Ministry of Health. (2001). The New Zealand Disability Strategy: making a world of difference/whakanui oranga Wellington.

Ministry of Health. (2004a). Living with disability in New Zealand. Wellington.

Ministry of Health. (2004b). Postgraduate Diploma in Arts (Autism). Evaluation report. Wellington.

Ministry of Health. (2006). Operational standard for ethics committees. Wellington.

Ministry of Health. (2008). The Whanau Ora Tool. June 2008, from http://www.publichealthworkforce.org.nz/data/media/documents/Maori\%20PH WD/Final\%20Whanau\%200ra\%20A4-4.pdf

Ministry of Health. (2009a). Disability in New Zealand: consumer forums 2006,2007,2009. Retrieved 14/05/2009, from ttp://www.moh.govt.nz/moh.nsf/indexmh/disability-keyprojects-consumerforum

Ministry of Health. (2009b). Needs Assessment and Service Coordination (NASC) national information system. Retrieved 11 May 2009, 2009, from http://www.moh.govt.nz/moh.nsf/indexmh/disability-keyprojectsnascinfosystem-faq

Ministry of Health. (2010). Request for proposal: the Ministry of Health's new model for supporting disabled people: implementation support services for a demonstration project 28 July 2010. Wellington.

Ministry of Health. Disability Support Services. (August 2010). Information update for Disability Support Service providers; review of residential services work programme. Wellington..

Ministry of Health. Disability Support Services. (April 2010). Autism Spectrum Disorder Newsletter. Wellington.

Ministry of Health. Disability Support Services. (December 2008). Autism Spectrum Disorder Newsletter. Wellington.

Ministry of Health. Disability Support Services. (December 2009). Autism Spectrum Disorder Newsletter. Wellington.

Ministry of Health. Disability Support Services. (June 2009). Autism Spectrum Disorder Newsletter. Wellington.

Ministry of Health. Disability Support Services. (June 2010). Autism Spectrum Disorder Newsletter. Wellington.

Ministry of Health. Disability Support Services. (March 2009). Autism Spectrum Disorder Newsletter. Wellington.

Ministry of Social Development. (2008). The New Zealand Carers' Strategy and fiveyear action plan. Wellington. 
Mitchell, D. R. (1985). Out of the shadows : a chronology of significant events in the development of services for exceptional children and young persons in New Zealand, 1850-1983. Hamilton, Wellington: University of Waikato ; Dept. of Education.

Mnookin, S. (2011). The panic virus: a true story of medicine, science, and fear. New York: Simon \& Schuster.

Moloney, P. (2010). 'How can a chord be wierd if it expresses your soul?' Some critical reflections on the diagnosis of Aspergers syndrome. Disability \& Society, 24(2), 135-148.

Moriarty, L. (2009). New Zealand and the UN Convention on the Rights of Persons with Disability. Paper presented at the Disability Studies Research Conference, Sydney.

Moriarty, L., \& Dew, K. (2011). The United Nations Convention on the Rights of Persons with Disabilities and participation in Aotearoa New Zealand. Disability \& Society 26(6), 683-697.

Munro, J. (1996). The Story of Suzanne Aubert. Auckland: Auckland University Press.

Murray, B. (2006). James' gift : the story of an Asperger family. Wellington, N.Z.: First Edition.

Murray, S. (2008a). Hollywood and the fascination of autism. In M. Osteen (Ed.), Autism and Representation. New York: Routledge.

Murray, S. (2008b). Representing autism: culture, narrative and fascination. Liverpool: Liverpool University Press.

Myers, S. M., \& Plauche Johnson, C. (2007). Management of children With Autism Spectrum Disorders. Pediatrics, 120(5), 1162-1182.

Nadesan, M. H. (2005). Constructing autism: unravelling the 'truth' and and understanding the social. New York: Routledge.

Nadesan, M. H. (2008a). The biopolitics and bioeconomics of autism: conference paper. Arizona State University.

Nadesan, M. H. (2008b). Constructing autism: a brief genealogy. In M. Osteen (Ed.), Autism and representation. New York: Routledge.

Nadesan, M. H. (2008c). Governmentality, biopower and everyday life. New York: Routledge.

Nadesan, M. H. (2010). Governing childhood into the 21st century: biopolitical technologies of childhood management and education. New York: Palgrave Macmillan.

NASCA. (2009a). NASC standards and guideline workshop. Wellington. 
NASCA. (2009b). Working with people with Autism Spectrum Disorder: an interim guideline for Ministry of Health Needs Assessment and Service Co-ordination organisations. Wellington: Ministry of Health, NZ NASCA Inc.

National Advisory Committee on Core Health and Disability Support Services. (1993). Self help and empowerment: people with disabilities challenging power, promoting change. Wellington.

National Advisory Committee on Health and Disability. (2003). To have an 'ordinary' life: kia whai oranga 'noa'. Wellington.

National Autistic Society (UK). (2009). Government reaches first milestone towards a national adult autism strategy: press release. London: National Autistic Society.

National Equal Opportunities Network. (2007). Disabled people's employment bill repealed. 16 April 2007, from http://www.neon.org.nz/newsarchive/dpep/

National Health Committee. (2010). How should we care for the carers, now and into the future? Manaaki tangata. Wellington.

Nazeer, K. (2006). Send in the idiots: stories from the other side of autism. New York: Bloomsbury.

New Zealand Government. (2001). Statement of Government Intentions for an Improved Community - Government Relationship. Wellington.

New Zealand Guidelines Group. (2008). Report to the Ministry of Health from the New Zealand Guidelines Group for the month of November 2008: Autism Spectrum Disorder Guideline - Technical Implementation Service. Wellington.

New Zealand Guidelines Group. Living Guideline Group. (2009). Living Guideline research report: synthesis of recently published secondary literature on Applied Behaviour Analysis for the New Zealand Autism Spectrum Disorder Living Guideline Group (September 2009). Wellington.

Newell, C. (2005). Moving disability from other to us. In P. O'Brien \& M. Sullivan (Eds.), Allies in emancipation: shifting from providing service to being of support. Melbourne: Thomson/Dunmore.

Newell, C. (2006). Representation or abuse? Rhetorical dimensions of genetics and disability. Interaction, 20(1), 28-33.

Newell, C. (2007a). From other to us. Interaction, 20(4), 2-9.

Newell, C. (2007b). 'What's wrong with you?' Disability and genes as ethics. In J. Swinton \& B. Brock (Eds.), Theology, disability and the new genetics: why science needs the church (pp. 44-56). London: T\&T Clark.

Newport, J., Newport, M., \& Dodd, J. (2007). Mozart and the whale: an Asperger's love story. New York: Simon \& Schuster. 
Newton, K. (2010). Inquiry into way mentally ill are dealt with. Dominion Post, 15 October 2010.

NZPA. (2003). Tragic end to life of beauty and misery. New Zealand Herald,22 February 2003. Retrieved from http://www.nzherald.co.nz/nz/news/article.cfm?c id=1\&objectid=3197236

NZPA. (2009). Autistic girl locked in police cells. www. stuff.co.nz, 23 March 2009.

NZPA. (2010a). Govt to mull over court ruling on family carers. Yahoo! Xtra News, 19 December 2010.

NZPA. (2010b). IHC firms in statutory management. www.stuff.co.nz, 5 October 2010.

O'Brien, P., \& Sullivan, M. (Eds.). (2005). Allies in emancipation : shifting from providing service to being of support. Melbourne: Thomson Dunmore Press.

O'Connell, H. O., \& Fitzgerald, M. (2003). Did Alan Turing have Asperger's Syndrome? Irish Journal of Psychiatric Medicine, 20(1), 28-31.

Office for Disability Issues. (2010). History of the New Zealand Sign Language Act. Retrieved 4 November 2010, 2010, from http://www.odi.govt.nz/what-wedo/nzsl/nzsl-history.html

Office of the Associate Minister of Health. (2010). Ministry of Health's new model for supporting disabled people [cabinet paper]. Wellington.

Office of the Minister for Social Development and Employment. (2010). Welfare Working Group [cabinet paper]. Wellington.

Office of the Minister of Education. (2010). Review of special education recommendations for change [cabinet paper]. Wellington: New Zealand Government.

Offit, P. A. (2008). Autism's false prophets: bad science, risky medicine and the search for a cure. New York: Columbia University Press.

Ogren, K., Sjöström S., \& O, B. N. (2000). [The unknown history of lobotomy: women, children and idiots were lobotomized]. Lakartidningen, 97(July 26), 3395-3398.

Oliver, M. (1990). The politics of disablement. London: Palgrave Macmillan.

Oliver, M. (1997). Emancipatory research: realistic goal or impossible dream? In C. Barnes \& G. Mercer (Eds.), Doing disability research. Leeds: The Disability Press.

Oliver, M. (2002). Emancipatory research: a vehicle for social transformation or policy development. Paper presented at the 1st Annual Disability Research Seminar: Using Emancipatory Methodologies in Disability Research.

Oliver, M. (2009). Understanding disability: from theory to practice (2nd ed.). London: Palgrave Macmillan. 
Olssen, E. (1981). Truby King and the Plunket Society: an analysis of a prescriptive ideology. New Zealand Journal of History, 15(1), 3-23.

Orange, C. (1996). The Treaty of Waitangi (Rev. ed.). Wellington: Bridget Williams Books.

Osteen, M. (Ed.). (2008). Autism and representation. New York: Routledge.

Pai4ASD Trust. (2008). In my shoes. Palmerston North.

Palermo, M. T. (2003). Preventing filicide in families with autistic children. International Journal of Offender Therapy and Comparative Criminology, $47(1), 47$.

Park, C. C. (1982). The siege: a family's journey into the world of an autistic child (2nd ed.). Boston: Back Bay Books.

Park, C. C. (2001). Exiting nirvana: a daughter's life with autism. Boston: Little, Brown and Company.

Park, J. (2000). Loved to death. Guardian, 23 August 2000.

Parliament. Social Services Select Committee. (2008). Inquiry into the quality of care and service provision for people with disabilites. Wellington: House of Representatives.

Peek, F. (1996). The real Rain man (2nd ed.). Salt Lake City: Harkness Publishing Consultants.

Peers, J. (2003). Asparagus dreams. London: Jessica Kingsley Publishers.

People First New Zealand Inc. (2010). A place of our own: living with the legacy of institutionalisation. Wellington: People First New Zealand.

Perry, A., \& Condillac, R. (2003). Evidence-based practices for children and adolescents wth Autism Spectrum Disorders: review of the literature and practice guide. Toronto: Children's Mental Health, Ontario.

Phend, C. (2010). California autism clusters tied to parents' education, not environment. ABC news, 9 January 2010,

Portway, S. M., \& Johnson, B. (2005). Do you know I have Asperger's Syndrome? Risks of a non-obvious disability. Health, Risk and Society, 7(1), 73-83.

Prince-Hughes, D. (2002). Aquamarine blue 5: personal stories of college students with autism. Athens, Ohio: Swallow Press.

Prince-Hughes, D. (2004). Songs of the gorilla nation: my journey through autism. New York: Random House.

Rioux, M. H., \& Valentine, F. (2006). Does theory matter? Exploring the nexus between disability, human rights, and public policy. In D. Pothier \& R. Devlin 
(Eds.), Critical disability theory (pp. 47-69). Vancouver: University of British Colombia Press.

Roberts, J. M. A., \& Prior, M. (2006). A review of the research to identify the most effective models of practice in early intervention for children with Autism Spectrum Disorders. Canberra: Australian Government Department of Health and Aging.

Robertson, A., Frawley, P., \& Bigby, C. (2008). Making life good in the community: when is a house a homellooking at how homely community houses are for people with an intellectual disability who have moved out of an institution. Melbourne: La Trobe University/ State Government of Victoria.

Robertson, S. (1989). Production not reproduction: the problem of mental defect in New Zealand, 1900-1939. Unpublished BA Hons, University of Otago, Dunedin.

Robertson, S. (2004). Auckland ASD project: focus group report. Wellington: Ministry of Health.

Robertson, S., \& Bray, A. (2005). Auckland ASD Project. Wellington: Ministry of Health.

Robertson, S. M. (2010). Neurodiversity, quality of lfe, and autistic adults: shifting research and professional focuses onto real-life challenges. Disability Studies Quarterly, 30(1).

Robertson, S. M., \& Ne'eman, A. D. (2008). Autistic acceptance, the college campus, and technology: growth of neurodiversity in society and academia. Disability Studies Quarterly, 28 Fall 2008(4).

Robison, J. E. (9 April 2010). Some new research is funded. from http://jerobison.blogspot.com/2010/04/some-new-autism-research-isfunded.html

Robison, J. E. (2007). Look me in the eye: my life with Asperger's. New York, Crown.

Rocque, B. (2010). Mediating self-hood: exploring the construction and maintenance of identity by mothers of children labeled with autism spectrum disorder. Disability \& Society, 25(4), 485-497.

Royal Commission to Inquire into and Report Upon Workers' Compensation. (1967). Compensation for personal injury in New Zealand; report of the Royal Commission of Inquiry. Wellington: Govt Print.

Roylance, F. D. (2011). O'Malley ousts David Geier from autism commission. Baltimore Sun, 20 May 2011

Ryan, G., \& Barnard, H. (2003). Techniques to identify themes. Field Methods, 15(1), 85-109.

Sacks, O. (1995). An anthropologist on Mars. Sydney: Picador. 
Samuel, R. (1994). Theatres of memory: Vol 1 Past and present in contemporary culture. London: Verso.

Sanchez-Valle, E., Posada, M., Villaverde-Hueso, A., Tourino, E., Ferrari-Arroyo, M. J., Boada, L., et al. (2008). Estimating the burden of disease for Autism Spectrum Disorders in Spain in 2003. Journal of Autism and Development Disorders, 38, 288-296.

Sanders, J. L. (2009). Qualitative or quantitative differences between Asperger's Disorder and Autism? Historical considerations. Journal of Autism and Developmental Disorders, 39, 1560-1567.

Satherley, D. (2011). Michael Laws defends 'outrageous' Asperger's comments. www.3news.co.nz, 17 March 2011.

Schechter, R., \& Grether, J. K. (2008). Continuing increases in Autism reported to California's Developmental Services System: mercury in retrograde. Archives of General Psychiatry, 65(1), 19-24.

Severson, K. D., Aune, J. A., \& Jodlowski, D. (2008). Bruno Bettelheim, autism, and the rhetoric of scientific authority. In M. Osteen (Ed.), Autism and representation. New York: Routledge.

Shakespeare, T. (2006). Disability rights and wrongs. London: Routledge.

Sheldon, A., Traustadottir, R., Beresford, P., Boxall, K., \& Oliver, M. (2006). Disability rights and wrongs? Disability and Society, 22(2), 209-234.

Shipley, J., \& Upton, S. (1992). Support for independence for people with disabilities: a new deal. Wellington: Ministries of Health and Social Welfare

Shore, S. (2008). Club 299 mentioned at the Autism NZ conference. Christchurch.

Shute, N. (2010). Desperation drives parents to dubious autism treatments. Scientific American, 6 October 2010, 11.

Silberman, S. (2010). Exclusive: first autistic presidential appointee speaks out. Wired Science (6 October 2010).

Silverman, C., \& Brosco, J. P. (2007). Understanding autism: parents and pediatricians in historical perspective. Archives of Pediatrics and Adolescent Medicine, 161, 392-398.

Singer, J. (1999). 'Why can't you be normal for once in your life?' From a 'problem with no name' to the emergence of a new category of difference. In M. Corker \& S. French (Eds.), Disability discourse. Buckingham: Open University Press.

Smith, L. (1993). Necessary knowledge: Piagetian perspectives on constructivism. Hove [England]: Lawrence Erlbaum Associates.

Smith, L. (2007). Kairaranga (Special Issue). 
Smith, L. (2009). Paper presented at the Post Graduate Students' conference. Wellington, Victoria University.

Song, D., Palmer, B., du Toit, S., \& Davidson, J. S. (2010). Inappropriate trace element testing in the Auckland region. New Zealand Medical Journal, 123(1327).

Spectrum Care Trust Board. (2010). Extraordinary journeys: twelve extraordinary people retrace their journeys from institutional care to supported community living. Auckland: Spectrum Care Trust Board.

Spiegel, A. (2010). What's a mental disorder? Even experts can't agree. 29 December 2009 Retrieved 7 January 2011, 2011, from http://www.npr.org/2010/12/29/132407384/

Stace, H. (1998a). Gene dreaming: New Zealanders and eugenics. Phanzine. Retrieved from http://www.phanza.org.nz/content/gene-dreaming-new-zealanders-andeugenics

Stace, H. (1998b). Valentine, Wnifred Annie, 1886-1968 Dictionary of New Zealand Biography (Vol. 4). Wellington: Department of Internal Affairs.

Stace, H. (2007). The long unfinished journey towards human rights for disabled people in Aotearoa New Zealand. Human Rights Research/Centre for Public Law/Victoria University of Wellington 5.

Stace, H. (2008). Why weren't there people with autism 100 years ago? Paper presented at the Autism New Zealand Conference. Christchurch.

Stace, H. (2010a). Autism and guilt. New Scientist (2773).

Stace, H. (2010b). Student research report: mother blaming; or autism, gender and science. Women's Studies Journal, 24(2), 66-70.

Stace, H., \& Cumming, J. (2006). Contracting between government and the voluntary sector: where to from here? Policy Quarterly, 2(4), 13-20.

Stace, H., \& Sullivan, M. (2011). Can policy be ethical without consumer input? In J. Boston, A. Bradstock \& D. Eng (Eds.), Ethics and public policy: contemporary issues. Wellington: Victoria University Press.

Stanley, L. (1992). The auto/biographical I: the theory and practice of feminist auto/biography. Manchester: Manchester University Press.

Statistics New Zealand. (2007). 2006 Disability Survey. Wellington.

Statistics New Zealand. (2009). 2011 disability survey: discussion paper on proposed content. Wellington.

Steele, V. (2005). Survey of Wellington region schools to provide a resource for parents choosing a school for their child with Asperger Syndrome (AS). Wellington: Cloud 9 Children's Association. 
Steele, V. (2006). Life histories of four teenage boys with Asperger Syndrome, with an emphasis on their experiences at school. Unpublished MA Applied Social Science Research, Victoria University of Wellington, Wellngton.

Sullivan (blogger). (2011). The autism-vaccine debate: why it won't go away. www.leftbrainrightbrain.co.uk, 11 February 2011.

Sullivan, M. (1991). From personal tragedy to social oppression: the medical model and social theories of disability. New Zealand Journal of Industrial Relations, 16, 255-272.

Sullivan, M. (1995). Regulating the anomalous body in Aotearoa/New Zealand. New Zealand Journal of Disability Studies, 1, 9-28.

Sullivan, M. (2000). Does it say what we mean, do we mean what it says, do we know what we are saying? Problematising the way disability is conceptualised, written and spoken about. New Zealand Journal of Disability Studies, 8, 36-46.

Sullivan, M. (2005). Systematic abuse: institutionalised disablism or professionals behaving badly? Paper presented at the Many Faces of Abuse Conference, Auckland.

Sullivan, M. (2007). 'The silent holocaust: 1939-45.' Manuscript prepared for Holocaust Survivors Living in New Zealand Memorial, Auckland War Memorial Museum.

Sullivan, M. (2008). Philosophy, ethics and the disability community. In D. M. Mertens \& P. Ginsberg (Eds.), The handbook of social research ethics (pp. 6984).Thousand Oaks, Ca.: Sage.

Sullivan, M. (2009). Thinking disability studies in Aotearoa in the $21^{\text {st }}$ Century; keynote address. Paper presented at the Australian and New Zealand Disability Studies Conference, University of New South Wales, Sydney.

Sullivan, M., \& Munford, R. (1998). The articulation of theory and practice: critique and resistance in Aotearoa New Zealand. Disability \& Society, 13(2), 183-198.

Sutch, W. B. (1966). The quest for security in New Zealand, 1840-1966 (2nd ed.). Wellington: Oxford University Press.

Svoboda, E. (2009). 'I am not a puzzle, I am a person'. www.salon.com, (27 April 2009).

Swedo, S. (2008). Report of the DSM-V Neurodevelopmdental Disorders Work Group, November 2008. Arlington: American Psychiatric Association.

Tammet, D. (2006). Born on a blue day: the gift of an extraordinary mind. London: Hodder \& Stoughton.

Tammet, D. (2009). Embracing the wide sky: a tour across the horizons of the mind. London: Hodder \&Stoughton. 
Taskforce on Whānau-Centred Initiatives. (2010). Whānau Ora: report of the Taskforce on Whanau-Centred Initiatives to Hon Tariana Turia Minister for the Community and Voluntary Sector. Wellington: NZ Government.

Taylor, P. G. (2011a). A beginner's guide to Autism Spectrum Disorders. London: Jessica Kingsley

Taylor, P. G. (2011b). ADHD, ASD and the NZ justice system. Paper presented at the ADD and Family Support Centre seminar 4 September 2011.

Te Puni Kokiri. (2010). Whānau Ora Fact Sheet. Wellington.

Tennant, M. (1996). Disability in New Zealand: an historical survey. New Zealand Journal of Disability Studies, 2, 3-33.

Tennant, M. (2007). The fabric of welfare: voluntary organisations, government and welfare in New Zealand, 1840-2005. Wellington: Bridget Williams Books.

Thomas, C. (1999). Female forms: experiencing and understanding disability Buckingham: Open University Press.

Thompson, T. (2007). Midstream musing on policy craft: efforts to improve support for disabled people in New Zealand. Unpublished MAPP575, Victoria University of Wellington, Wellington.

Tiso, G. (2010). Questions asked. Bat, Bean, Beam: a weblog on memory and technology 13 September. http://bat-bean-beam.blogspot.com.

Tolich, M., \& Flanagan, P. (2009). New Zealanders can learn about themselves when comparing the 'Unfortunate Experiment' with both the Tuskagee Syphilis Trial and Nuremberg Code. Ethics Notes: Health Research Council of New Zealand(November 2009), 6-7.

Tonkin, C. (2010). National Standards are here to stay, says Tolley 10 July 2010. www.3news.co.nz.

Townson, L., Macauley, S., Harkness, E., Docherty, A., Dias, J., Eardley, M., et al. (2007). Research project on advocacy and autism. Disability \& Society, 22(5), 523-536.

Traolach, S., et al.(2011) Epidemiology of Autism Spectrum Disorders in adults in the community in England. Arch. Gen. Psychiatry, 68(5),459-466.

Tremain, S. (Ed.). (2005). Foucault and the government of disability. Ann Arbor: University of Michigan Press.

Trevedi, B. (2005). Autistic and proud. New Scientist, 18 June 2005, 36-40.

Trevett, C. (2009). Bennett: I consulted website before releasing mums' benefits. New Zealand Herald, 28 July 2009. 
Triggs, W., McGavin, D., King, F. T., Elliot, J. S., Patterson, A. G., Matthews, C., et al. (1925). Mental defectives and sexual offenders: report of the Committee of Inquiry appointed by the Hon Maui Pomare, Minister of Health. Wellington: NZ Parliament.

US Congress. Combating Autism Act of 2006: To Amend the Public Service Act to combat autism through research, screening, intervention and education, Public Law 109-416 Dec.19 2006 C.F.R. (2006).

US Department of Health \& Human Services. Interagency Autism Coordinating Committee. (2009). Advisory panel releases first federal strategic plan for autism research. Washington.

US Department of Health \& Human Services. Interagency Autism Coordinating Committee. (2010a). Member roster Interagency Autism Coordinating Committee. Washington.

US Department of Health \& Human Services. Interagency Autism Coordinating Committee. (2010b). The 2010 Interagency Autism Coordinating Committee strategic plan for Autism Spectrum Disorder research January 19, 2010. Washington.

US Department of Health \& Human Services. Interagency Autism Coordinating Committee. (2011). IACC full committee meeting (18 January 2011).Washington.

US Food and Drug Administration. Center for Drug Evaluation and Research. (2009). [Review of drug utilization patterns for six atypical antipsychotics in the pediatric population]. Washington.

US Food and Drug Administration. (2010). FDA warns marketers of unapproved 'chelation' drugs. FDA Consumer Health Information, October 2010. Washington.

US National Library of Medicine. (2006). Health services research and health policy grey literature project: summary report. Washington.

United Nations. (2006). Convention on the Rights of Persons with Disabilities. New York: United Nations.

UPIAS. (1976). Fundamental principles of disability. London: London Union of the Physically Impaired Against Segregation/The Disability Alliance.

Victoria Australia Department of Human Services. (2009). Autism State Plan. Melbourne: State Government of Victoria.

Wade, A. (2011). Christchurch looting case: cops accused of bashing. New Zealand Herald, 9 March 2011.

Wakefield, A. J., et al. (1998). Ileal-lymphoid-nodular hyperplasia, non-specific colitis, and pervasive developmental disorder in children. The Lancet, 351, 637-641. 
Wallis, C. (2009). 'I am autism': An advocacy video sparks protest. Time (6 November 2009). Retrieved from http://www.time.com/time/health/article/0,8599,1935959,00.html

Weber, B. (2009). Kim Peek, inspiration for 'Rain Man,' dies at 58. New York Times, 26 December 2009.

Welfare Justice - the Alternative Welfare Working Group. (2010a). Welfare justice for all: reflections and recommendations. A contribution to the welfare reform debate. Wellington: Caritas Aotearoa.

Welfare Justice - the Alternative Welfare Working Group. (2010b). Welfare justice in New Zealand: what we heard. A summary of submissions made to the Welfare Justice Alternative Welfare Working Group. Wellngton: Caritas Aotearoa New Zealand.

Welfare Working Group. (2010). Reducing long-term benefit dependency: the options. Wellington: Welfare Working Group.

Welfare Working Group. (2011). Reducing long-term benefit dependency: recommendations. Wellington: Welfare Working Group.

Werry, J. (1998). Extracts from the report to the Director-General of Health under 547 of the Health \& Disability Services Act 1993 on Casey Albury. Wellington, NZ Government.

White, N. (2007). Saying sorry effectively: Government apologies for historical wrongs. In G. Maxwell \& J. H. Liu (Eds.), Restorative justice and practices in New Zealand: Towards an inclusive society (pp. 235-259). Wellington: Institute of Policy Studies, Victoria University of Wellington.

Whitworth, M. (2006). Auckland outreach project: report of pilot programme run in Auckland 2005-2006. Christchurch: Autism New Zealand.

Willey, L.H. (1999). Pretending to be normal: living with Asperger's syndrome. London: Jessica Kingsley Publishers.

Williams, D. (1992). Nobody nowhere: the extraordinary autobiography of an autistic. NewYork: Avon.

Williams, D. (1994). Somebody somewhere: breaking free from the world of autism. New York: Three Rivers Press.

Wing, L. (1997). The autistic spectrum. The Lancet, 350(9093), 1761-1766.

Wolman, D. (2008). The truth about autism: scientists reconsider what they think they know. Wired Magazine, (16 03),

Woodcock, F., \& Robertshaw, K. (2008). Survey of unmet need in families affected by autistic spectrum disorders in Hawke's Bay 2008. Hastings: Autism Hawkes Bay. 
World Health Organisation. (2004). Contracting for health services: lessons from New Zealand. Geneva.

World Health Organisation. (2007). The ICD-10 classification of mental and behavioural disorders: diagnostic criteria for research. Geneva.

Wylie, C. (2000). Picking up the pieces: a review of Special Education 2000. Wellington: New Zealand Council for Educational Research.

Wylie, C. (2002). Meeting individual educational needs: legal identification, or systemic support? (No. 2002/1). Wellington: New Zealand Council for Educational Research.

Zarb, G. (1992). On the road to Damascus: first steps towards changing the relations of disability research production. Disability, Handicap \& Society, 7(2), 125-138.

Zaroff, C. M., \& Uhm, S. Y. (2011). Prevalence of autism spectrum disorders and influence of county of measurement and ethnicity. Social Pyschiatry and Psychiatric Epidemiology, Published online 4 February 2011. Retrieved from http://www.springerlink.com/content/1083424q520562k5/fulltext.pdf 


\section{Appendix One: Diagnostic criteria for ASD (DSM-IV-TR and ICD-10)}

(Appendix 4 of: Ministries of Health and Education. 2008. New Zealand Autism

Spectrum Disorder Guideline Wellington: Ministry of Health)

\section{DSM-IV-TR (American Psychiatric Association, 2000)}

\subsection{Autistic Disorder}

A. A total of six (or more) items from (1), (2) and (3), with at least two from (1), and one each from (2) and (3):

(1) qualitative impairment in social interaction, as manifested by at least two of the following:

(a) marked impairment in the use of multiple nonverbal behaviours such as eye-to-eye gaze, facial expression, body postures, and gestures to regulate social interaction

(b) failure to develop peer relationships appropriate to developmental level

(c) a lack of spontaneous seeking to share enjoyment, interests, or achievements with other people (eg, by a lack of showing, bringing, or pointing out objects of interest)

(d) lack of social or emotional reciprocity

(2) qualitative impairments in communication as manifested by at least one of the following:

(a) delay in, or total lack of, the development of spoken language (not accompanied by an attempt to compensate through alternative modes of communication such as gestures or mime)

(b) in individuals with adequate speech, marked impairment in the ability to initiate or sustain a conversation with others

(c) stereotyped and repetitive use of language or idiosyncratic language

(d) lack of varied, spontaneous make-believe play or social imitative play 
appropriate to developmental level

(3) restricted repetitive and stereotyped patterns of behaviour, interests and activities, as manifested by at least one of the following:

(a) encompassing preoccupation with one or more stereotyped and restricted patterns of interest that is abnormal either in intensity or focus

(b) apparently inflexible adherence to specific, non-functional routines or rituals

(c) stereotyped and repetitive motor mannerisms (eg, hand or finger flapping or twisting, or complex whole body movements)

(d) persistent preoccupation with parts of objects

B. Delays or abnormal functioning in at least one of the following areas, with onset prior to age 3 years: (1) social interaction, (2) language as used in social communication or (3) symbolic or imaginative play

C. The disturbance is not better accounted for by Rett's Disorder or Childhood Disintegrative Disorder

\subsection{Asperger's Disorder}

A. Qualitative impairment in social interaction, as manifested by at least two of the following:

(1) marked impairment in the use of multiple nonverbal behaviours such as eye-toeye gaze, facial expression, body postures, and gestures to regulate social interaction

(2) failure to develop peer relationships appropriate to developmental level

(3) a lack of spontaneous seeking to share enjoyment, interests, or achievements with other people (eg, by a lack of showing, bringing or pointing out objects of interest to other people)

(4) lack of social or emotional reciprocity 
B. Restricted repetitive and stereotyped patterns of behaviour, interests, and activities, as manifested by at least one of the following:

(1) encompassing preoccupation with one or more stereotyped and restricted patterns of interest that is abnormal either in intensity or focus

(2) apparently inflexible adherence to specific, non functional routines or rituals

(3) stereotyped and repetitive motor mannerisms (eg, hand or finger flapping or twisting, or complex whole-body movements)

(4) persistent preoccupation with parts of objects

C. The disturbance causes clinically significant impairment in social, occupational, or other important areas of functioning.

D. There is no clinically significant general delay in language (eg, single words used by age 2 years, communicative phrases used by age 3 years).

E. There is no clinically significant delay in cognitive development or in the development of age-appropriate self-help skills, adaptive behaviour (other than in social interaction), and curiosity about the environment in childhood.

F. Criteria are not met for another specific Pervasive Developmental Disorder or Schizophrenia.

\subsection{Pervasive Developmental Disorder Not Otherwise Specified (Including Atypical Autism)}

This category should be used when there is a severe and pervasive impairment in the development of reciprocal social interaction associated with impairment in either verbal or nonverbal communication skills or with the presence of stereotyped behaviour, interest, and activities, but the criteria are not met for a specific Pervasive Developmental Disorder, Schizophrenia, Schizotypal Personality Disorder, or Avoidant Personality Disorder. For example, this category includes 'atypical autism' presentations that do not meet the criteria for Autistic Disorder because of late age at onset, atypical symptomatology, or subthreshold symptomatology, or all of these. 


\section{ICD-10 (World Health Organisation, 2007)}

\section{F84 Pervasive developmental disorders}

A group of disorders characterized by qualitative abnormalities in reciprocal social interactions and in patterns of communication, and by a restricted, stereotyped, repetitive repertoire of interests and activities. These qualitative abnormalities are a pervasive feature of the individual's functioning in all situations.

Use additional code, if desired, to identify any associated medical condition and mental retardation.

A type of pervasive developmental disorder that is defined by: (a) the presence of abnormal or impaired development that is manifest before the age of three years, and (b) the characteristic type of abnormal functioning in all the three areas of psychopathology: reciprocal social interaction, communication, and restricted, stereotyped, repetitive behaviour. In addition to these specific diagnostic features, a range of other nonspecific problems are common, such as phobias, sleeping and eating disturbances, temper tantrums, and (self-directed) aggression.

Autistic disorder Infantile:

- $\quad$ autism

- $\quad$ psychosis

Kanner's syndrome

Excludes: autistic psychopathy (F84.5)

\section{F84.1 Atypical autism}

A type of pervasive developmental disorder that differs from childhood autism either in age of onset or in failing to fulfil all three sets of diagnostic criteria. This subcategory should be used when there is abnormal and impaired development that is present only after age three years, and a lack of sufficient demonstrable abnormalities in one or two of the three areas of psychopathology required for the diagnosis of autism (namely, reciprocal social interactions, communication, and restricted, stereotyped, repetitive 
behaviour) in spite of characteristic abnormalities in the other area(s). Atypical autism arises most often in profoundly retarded individuals and in individuals with a severe specific developmental disorder of receptive language.

Atypical childhood psychosis

Mental retardation with autistic features

Use additional code (F70-F79), if desired, to identify mental retardation.

\section{F84.5 Asperger's syndrome}

A disorder of uncertain nosological validity, characterized by the same type of qualitative abnormalities of reciprocal social interaction that typify autism, together with a restricted, stereotyped, repetitive repertoire of interests and activities. It differs from autism primarily in the fact that there is no general delay or retardation in language or in cognitive development. This disorder is often associated with marked clumsiness. There is a strong tendency for the abnormalities to persist into adolescence and adult life. Psychotic episodes occasionally occur in early adult life.

Autistic psychopathy

Schizoid disorder of childhood

F84.8 Other pervasive developmental disorders

F84.9 Pervasive developmental disorder, unspecified 


\section{Appendix Two: Key Informants}

\begin{tabular}{|c|c|c|}
\hline Kim & $\begin{array}{l}\text { Parent of high needs autistic } \\
\text { teenager, long-time ASD } \\
\text { activist }\end{array}$ & Interview recorded March 2010 \\
\hline Pat & $\begin{array}{l}\text { Asperger adult and parent of } \\
\text { autistic child }\end{array}$ & Interview recorded April 2010 \\
\hline Alex & Asperger adult & Interview recorded May 2010 \\
\hline Jess & $\begin{array}{l}\text { ASD policy and services } \\
\text { specialist }\end{array}$ & Interview recorded May 2010 \\
\hline Sam & $\begin{array}{l}\text { Parent of high needs autistic } \\
\text { teenager, Morgan }\end{array}$ & Interview recorded May 2010 \\
\hline Chris & Public servant & Interview recorded June 2010 \\
\hline $\operatorname{Max}$ & $\begin{array}{l}\text { Parent of autistic adult, long- } \\
\text { time ASD activist }\end{array}$ & July 2010 (email) \\
\hline Fran & $\begin{array}{l}\text { Parent of young autistic child, } \\
\text { partner of Lou }\end{array}$ & Interview recorded August 2010 \\
\hline Lou & $\begin{array}{l}\text { Parent of young autistic child, } \\
\text { partner of Fran }\end{array}$ & $\begin{array}{l}\text { Interview recorded August 2010, } \\
\text { plus follow up emails } 31 \text { August, } \\
1 \text { September } 2010\end{array}$ \\
\hline Marion & $\begin{array}{l}\text { Mother of middle aged autistic } \\
\text { son. Long history of ASD } \\
\text { activism }\end{array}$ & $\begin{array}{l}\text { Interview recorded December } \\
2010\end{array}$ \\
\hline
\end{tabular}




\section{Appendix Three: Ethics Approval}

\author{
- Health \\ and \\ Disability \\ Ethics \\ Committees
}

\author{
Multi-region Ethics Committee \\ Ministry of Health \\ 133 Molesworth Street \\ PO Box 5013 \\ Wellington 6145 \\ Phone (04) 4700655 \\ (04) 4700646 \\ Fax (04) 4962340 \\ Email: multiregion_ethicscommittee@moh.govt.nz
}

31 July 2010

Ms Hilary Stace

c/- HSRC, School of Government

Rutherford House, Pipitea Campus

Victoria University of Wellington

PO Box 600 , Wellington

Dear Hilary

Re: Ethics ref: MEC/09/10/107 (please quote in all correspondence)

Study title: Moving beyond love and luck: building right relationships and valuing lived experience in New Zealand autism policy

Investigators: Ms Hilary Stace

This study was given ethical approval by the Multi-region Ethics Committee in December 2009.

\section{Approved Documents}

- Protocol number dated December 2009

- Information sheet version dated December 2009

- Consent form version dated December 2009etc

This approval is valid until $31^{\text {st }}$ of December 2014, provided that Annual Progress Reports are submitted (see below).

Amendments and Protocol Deviations

All significant amendments to this proposal must receive prior approval from the Committee. Significant amendments include (but are not limited to) changes to:

- the researcher responsible for the conduct of the study at a study site

- the addition of an extra study site

- the design or duration of the study

- the method of recruitment

- information sheets and informed consent procedures.

Significant deviations from the approved protocol must be reported to the Committee as soon as possible. 


\section{Annual Progress Reports and Final Reports}

The first Annual Progress Report for this study is due to the Committee by. The Annual Report Form that should be used is available at www.ethicscommittees.health.govt.nz. Please note that if you do not provide a progress report by this date, ethical approval may be withdrawn.

A Final Report is also required at the conclusion of the study. The Final Report Form is also available at www.ethicscommittees.health.govt.nz.

\section{Requirements for the Reporting of Serious Adverse Events (SAEs)}

For the purposes of the individual reporting of SAEs occurring in this study, the Committee is satisfied that the study's monitoring arrangements are appropriate.

SAEs occurring in this study must be individually reported to the Committee within $7-15$ days only where they:

- are unexpected because they are not outlined in the investigator's brochure, and

- are not defined study end-points (e.g. death or hospitalisation), and

- occur in patients located in New Zealand, and

- if the study involves blinding, result in a decision to break the study code.

There is no requirement for the individual reporting to ethics committees of SAEs that do not meet all of these criteria. However, if your study is overseen by a data monitoring committee, copies of its letters of recommendation to the Principal Investigator should be forwarded to the Committee as soon as possible.

Please see www.ethicscommittees.health.govt.nz for more information on the reporting of SAEs, and to download the SAE Report Form.

We wish you all the best with your study.

Yours sincerely

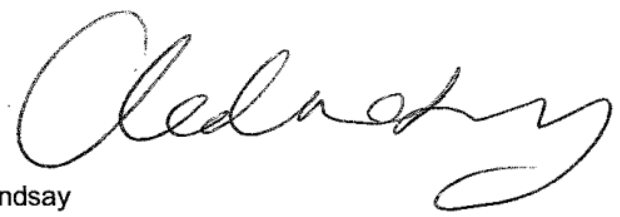

Claire Lindsay

Administrator

Multi-region Ethics Committee

Email: claire_lindsay@moh.govt.nz 


\section{INFORMATION SHEET: Interviews}

\section{The development and implementation of the New Zealand Autism Spectrum Disorder Guideline as a case study of NZ ASD policy}

I am a PhD student researching New Zealand autism policy, including the $2008 \mathrm{New}$ Zealand Autism Disorder Guideline. I would like to talk to you about your views on the Guideline and any role you have had in its development or implementation. I am also interested in hearing about your lived experiences of autism and what ideas you have for improving autism policy in New Zealand. The interview will take about an hour and take place at a time and venue suitable for you. I hope to complete these interviews by the end of January 2010.

As you will be aware, Autism Spectrum Disorder (ASD) diagnoses have been rising rapidly in recent years and New Zealand is just one country grappling with the policy challenge this presents. Currently, love - such as a supportive family, and luck - that appropriate services are available, are required by people with autism and their families for good outcomes. To move beyond this situation requires innovative and collaborative approaches. One New Zealand response has been the development of the New Zealand Autism Spectrum Disorder Guideline which is the first whole-of-spectrum, whole-oflife, whole-of-government best practice approach in the world to addressing the complexity of issues surrounding ASD.

Interviews with people involved in the Guideline and/or with lived experience of autism will provide valuable personal insight for this study, and I hope to do about 20 interviews. You have been selected as I know you have significant expertise in this area. There is no personal benefit to you, but your expertise may help build understanding of autism.

Your participation is entirely voluntary (your choice). You do not have to answer all the questions, and you may stop the interview at any time. You are also free to withdraw from the study at any time, without having to give a reason and without any repercussions. 
Usually in such research the tapes are transcribed and the tapes and transcriptions destroyed after five years or so, and any extracts used have any identifying material removed. I am seeking your consent to follow a different protocol. If you are not happy with any of these conditions but still consent to be interviewed I will revert to standard protocol of destruction of tapes and any transcripts after five years.

The information you provide is likely to be historically significant in the development of understanding of New Zealand autism policy, so I am seeking your permission to deposit the tapes in the Alexander Turnbull Library's Oral History Centre where they will be available for future researchers (on your access terms). I can also provide you with a copy of the tape if you choose.

I also intend to use the tapes themselves as the primary research material and only transcribe sections as necessary for my research report.

In previous research I have found that many people prefer to have their own names used for quotes. So for any transcribed sections of your interviews that I use in my written research I will ask you first whether you would like to have your own name or a pseudonym.

I can send you a summary or full copy of my completed research when eventually available if you are interested.

If you have any queries or concerns regarding your rights as a participant in this study,you may wish to contact an independent health and disability advocate: Free phone: 0800555 050, Free fax: 08002 SUPPORT (0800 2787 7678), Email: advocacy@hdc.org.nz

This study has received ethical approval from the Multi-region Ethics Committee, which reviews national and multi regional studies, ethics reference number MEC/09/10/107.

For more information about the study contact: 
Hilary Stace, PhD student, Health Services Research Centre, Victoria University of Wellington, hilary.stace@vuw.ac.nz

ph 044636569 , or

Assoc Prof Jackie Cumming, Director, Health Services Research Centre, Victoria University of Wellington, jackie.cumming@vuw.ac.nz ph 044636567

Please feel free to contact the researcher if you have any questions about this study. Thank you. 


\section{CONSENT FORM: Interviews}

The development and implementation of the NZ ASD guideline as a case study of NZ $\underline{\text { ASD policy. }}$

I have read and I understand the information sheet dated

12 November 2009 for volunteers taking part in the study

to evaluate the NZ Autism Spectrum Disorder Guideline, and the New Zealand autism policy process. Yes/No

I have had the opportunity to discuss this study. Yes/No

I am satisfied with the answers I have been given. Yes/No

I understand that taking part in this study is voluntary (my choice),

and that I may withdraw from the study at any time, without any repercussions. Yes/No

I understand that my participation in this study is confidential

and that no material that could identify me will be used in any

reports on this study, without my written consent. Yes/No

I consent to my interview being audiotaped. Yes/No

If yes:

I would like a copy of the tape. Yes/No

I consent to depositing the original interview tape in the Alexander Turnbull Library's

Oral History Centre. Yes/No

If yes:

I agree that the tapes of my interview will be:

-freely available to users Yes/No

-available for use only with my written/verbal consent

Yes/No 
I wish to receive a summary/full copy of the research Yes/No
I........ (full name)
c/- (optional contact details) hereby consent to take part in this study.

Date:

Signature:

Full names of researcher:
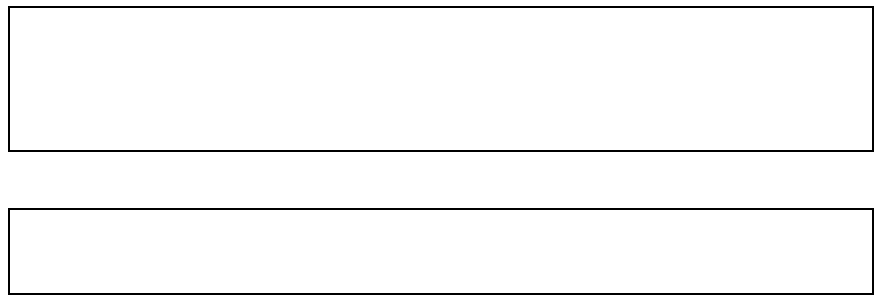

Full names of researcher:

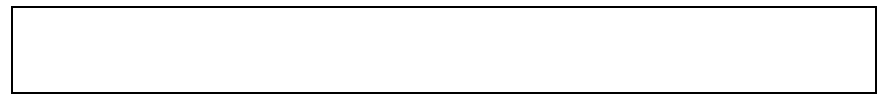

Contact phone number for researcher:

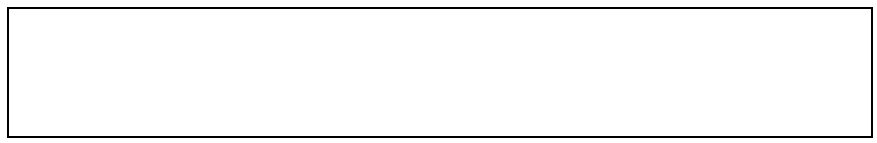

Project explained by:

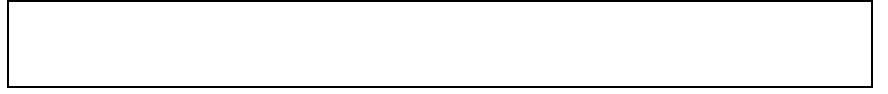

Project role:

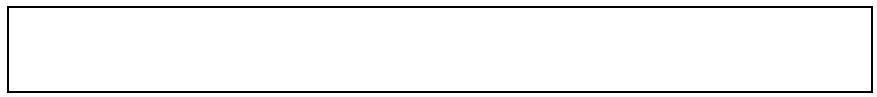

Signature:

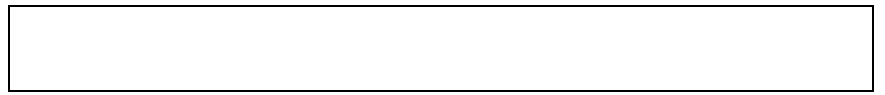

Date: 